\title{
Cape Romain Partnership for Coastal Protection
}

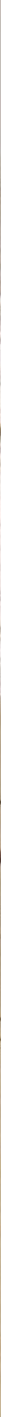

Open-File Report 2021-1021

U.S. Department of the Interior

U.S. Geological Survey 
Background: Barrier island at Cape Romain National Wildlife Refuge, South Carolina, experiencing dune erosion and loss of maritime forest. Refuge beaches are important nesting areas for several threatened and endangered shorebirds and are among the most critical sites for nesting populations of loggerhead sea turtles north of Cape Canaveral, Florida. Persistent erosion and repeated overwash of dune and beaches alter habitat and destroy hundreds of turtle nests each season. Photograph by Mitchell Eaton, U.S. Geological Survey.

Inset photographs: (clockwise from top left) Sea turtle nest exposed by dune erosion (photograph by U.S. Fish and Wildlife Service; in the public domain), North Charleston Port (Photograph by Ryan Bowley, licensed under the Creative Commons Attribution-NonCommercial-NoDerivs 2.0 Generic), shrimp boats (Photograph by dutchbaby, licensed under Creative Commons AttributionNonCommercial-NoDerivs 2.0 Generic), red knot shorebird (Photograph by Dick Daniels, licensed under the Creative Commons Attribution-Share Alike 3.0 Unported), regeneration of longleaf pine (Photograph by William Boyer, U.S. Department of Agriculture Forest Service, Bugwood.org; in the public domain), recreating in the saltwater marsh (Photograph by Stephen Morton, licensed under Creative Commons Attribution-NonCommercial 2.0 Generic), traditional coastal sweetgrass baskets made by Gullah-Geechee artisans (Photograph licensed under Creative Commons Attribution 2.0 Generic), sandbag barricades protecting coastal homes on Isle of Palms, South Carolina, from sealevel rise (Photograph by Mitchell Eaton, U.S. Geological Survey). 


\section{Cape Romain Partnership for Coastal Protection}

By Mitchell J. Eaton, Fred A. Johnson, Jessica Mikels-Carrasco, David J. Case, Julien Martin, Bradley Stith, Simeon Yurek, Bradley Udell, Laura Villegas, Laura Taylor, Zulquarnain Haider, Hadi Charkhgard, and Changhyun Kwon

Open-File Report 2021-1021 


\section{U.S. Geological Survey, Reston, Virginia: 2021}

For more information on the USGS - the Federal source for science about the Earth, its natural and living resources, natural hazards, and the environment—visit https://www.usgs.gov or call 1-888-ASK-USGS.

For an overview of USGS information products, including maps, imagery, and publications, visit https://store.usgs.gov/.

Any use of trade, firm, or product names is for descriptive purposes only and does not imply endorsement by the U.S. Government.

Although this information product, for the most part, is in the public domain, it also may contain copyrighted materials as noted in the text. Permission to reproduce copyrighted items must be secured from the copyright owner.

Suggested citation:

Eaton, M.J., Johnson, F.A., Mikels-Carrasco, J., Case, D.J., Martin, J., Stith, B., Yurek, S., Udell, B., Villegas, L., Taylor, L., Haider, Z., Charkhgard, H., and Kwon, C., 2021, Cape Romain Partnership for Coastal Protection: U.S. Geological Survey Open-File Report 2021-1021, 158 p., https://doi.org/10.3133/ofr20211021.

ISSN 2331-1258 (online) 


\section{Acknowledgments}

The authors especially thank Sarah Dawsey and the Cape Romain staff for their dedication and patience with this process. We also thank the organizations and individuals representing the Cape Romain Partnership: Francis Marion National Forest, National Oceanic and Atmospheric Administration, South Carolina Department of Natural Resources, South Carolina Aquarium, Southern Environmental Law Center, Lowcountry Land Trust, Center for Heirs Property, South Carolina SeaGrant, and The Nature Conservancy. G. McMahon, Scott Lanier, Nathan Walker, Johnny Boggs, Emrys Treasure, and Amy Nathanson provided constructive comments on earlier drafts of this report.

We gratefully acknowledge Gerard McMahon and Nathan Wood of the U.S. Geological Survey for their earlier involvement and valuable intellectual contributions. 



\section{Contents}

Acknowledgments ……...................................................................................................................

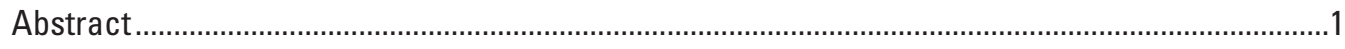

Chapter A. Introduction

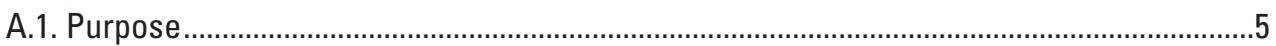

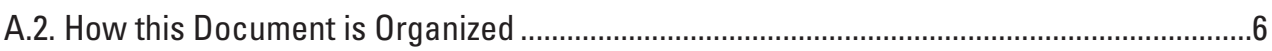

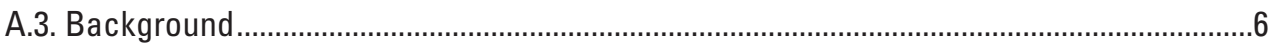

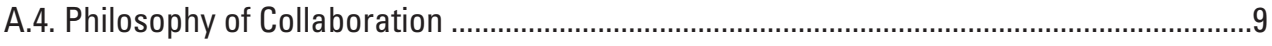

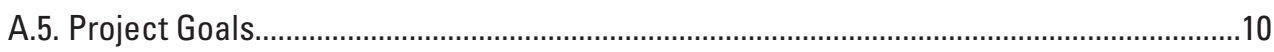

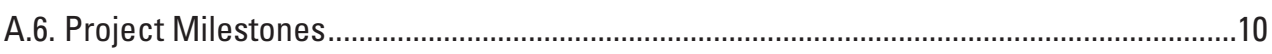

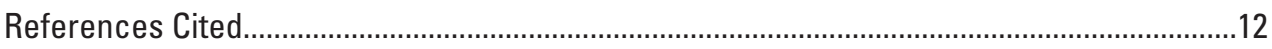

Chapter B. Drivers of Change in South Carolina's Lowcountry.......................................................15

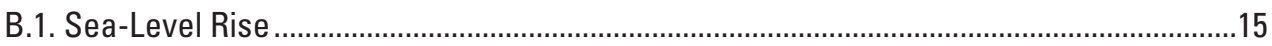

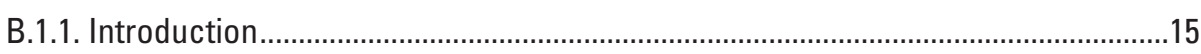

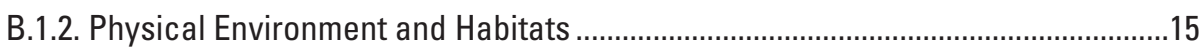

B.1.3. Sea-Level Rise_-Trends and Forecasts..........................................................16

B.1.3.1. Climate Change and Sea-Level Rise .......................................................16

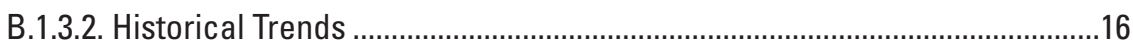

B.1.3.3. Future Predictions and Scenarios............................................................16

B.1.3.4. Application of Sea-Level Rise Projections to Project Components and Output .........................................................................................

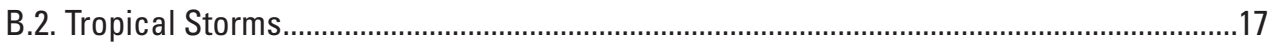

B.2.1. Background and Trends in Storm Records and Storm Surge..............................17

B.2.2. Modeling Storm Surge and Interactions with Sea-Level Rise .............................19

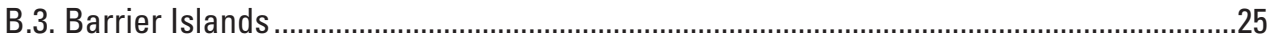

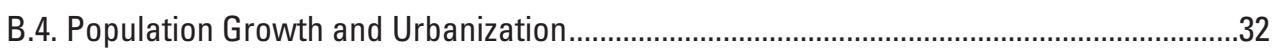

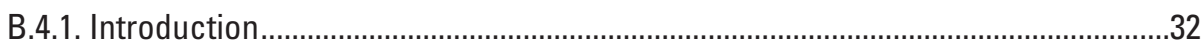

B.4.2. Past Trends in Population Growth and Land-Use Land Change ...........................32

B.4.2.1. Past Spatial Growth Patterns and Drivers .................................................33

B.4.3. Predictions of Future Urban Growth and Development ..........................................34

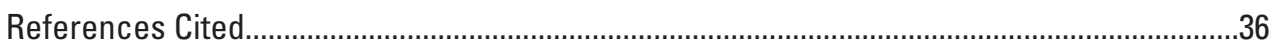

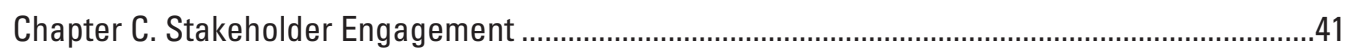

C.1. Introduction

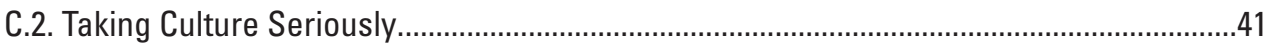

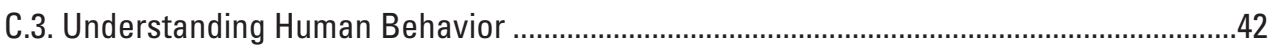

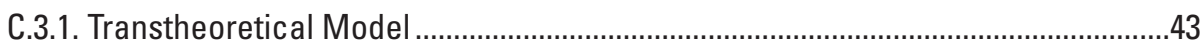

C.3.2. Internal Components of the Transtheoretical Model ...............................................44

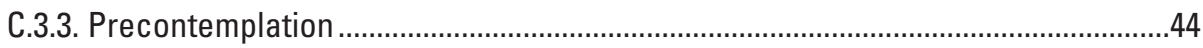

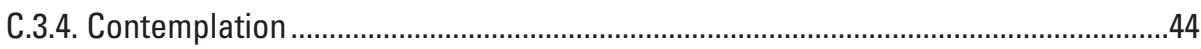

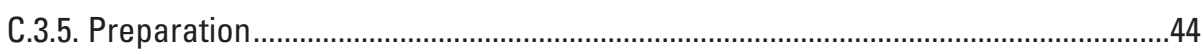

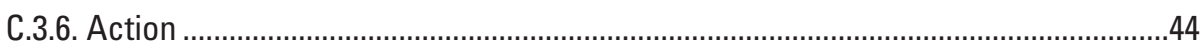

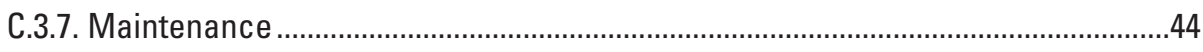

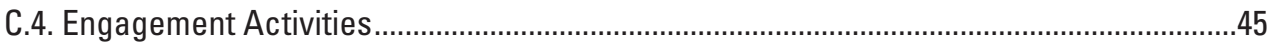

C.4.1. Face-to-Face Meetings ..................................................................................46

C.4.2. Creative Engagement Opportunities—Seizing Opportunities to Learn..................48 
C.4.3. Workshops

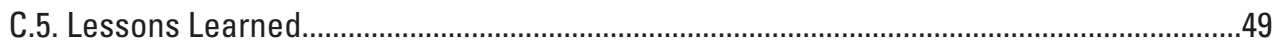

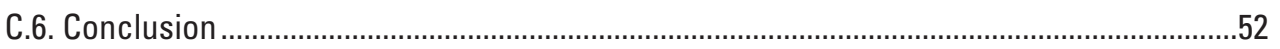

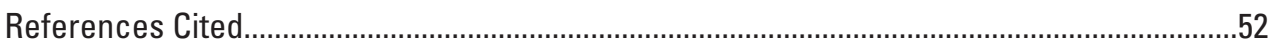

Chapter D. Scenario Planning —Possible Futures in the South Carolina Lowcountry ....................55

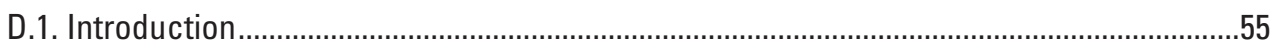

D.2. Methods

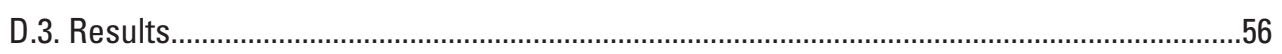

D.3.1. Scenario 1-The Three Horsemen ..............................................................59

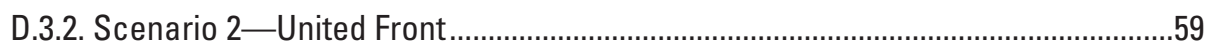

D.3.3. Scenario 3-Real Life ...................................................................................60

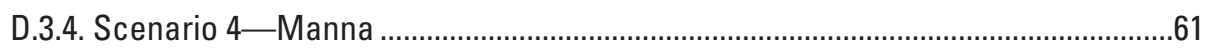

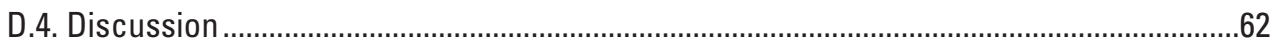

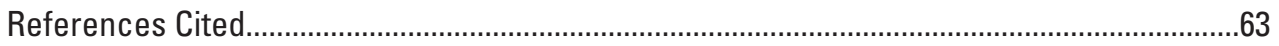

Chapter E. Strategic Planning Using a Strengths, Weaknesses, Opportunities, and

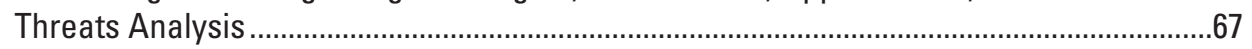

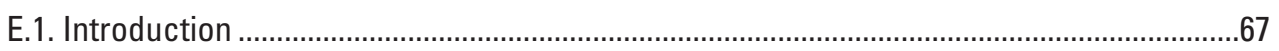

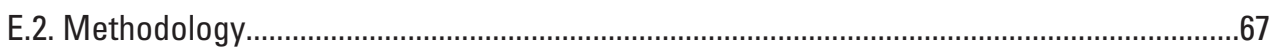

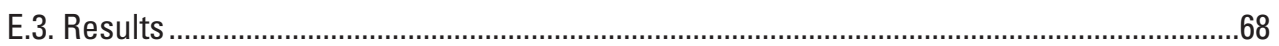

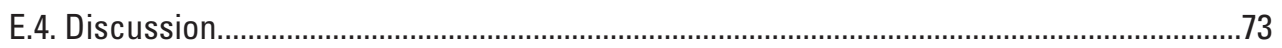

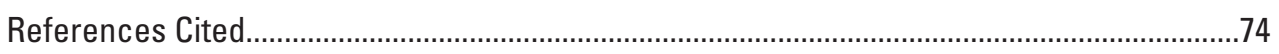

Chapter F. Decision Support Tools to Assist with Adaptation to Sea-Level Rise and

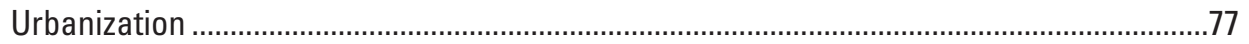

F.1. Reserve Design Using Marxan ......................................................................................

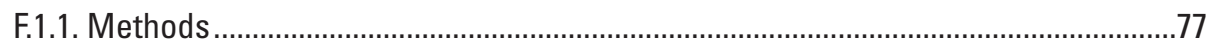

F.1.1.1. Objective Function for Optimal Reserve Design .........................................77

F.1.1.2. Index of Habitat in Cape Romain National Wildlife Refuge and the Surrounding Region .........................................................................................

F.1.1.3. Target Setting and Geospatial Processing ...............................................78

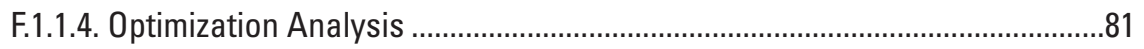

F.1.2. Results Using Only the Highway Parcels North of Cape Romain National

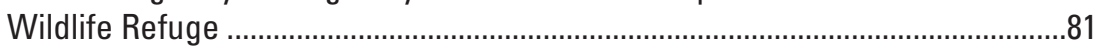

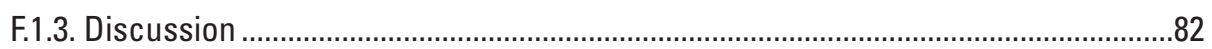

F.2. Portfolio Decision Analysis—Reserve Design Using Modern Portfolio Analysis .............84

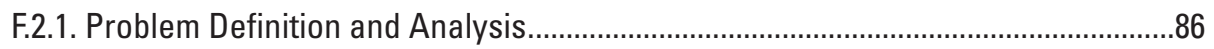

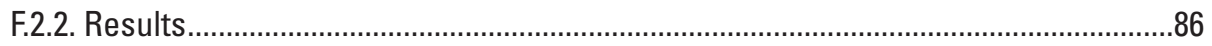

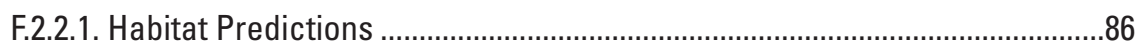

F.2.2.2. Pareto-Optimal Reserve Design—Unconstrained Budget ..........................88

F.2.2.3. Budget-Constrained Optimization .............................................................93

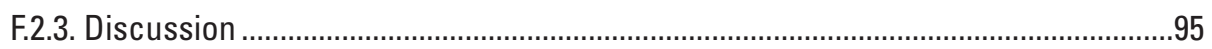

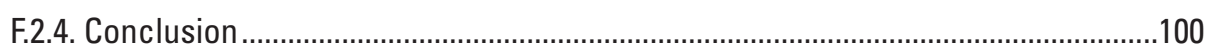

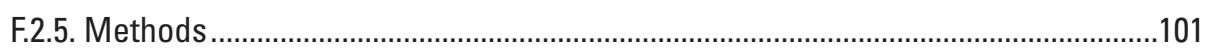

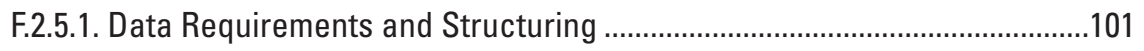

F.2.5.2. Portfolio Optimization—Acquiring Parcels for Reserve Design ................102

F.2.5.3. Extending the Portfolio Optimization to Consider Acquisition and Divestment. 
F.2.5.4. Optimization Algorithm for Computing the Pareto-Optimal Frontier.104 F.2.5.5. Selecting Among Pareto-Efficient Portfolios-Possible Global

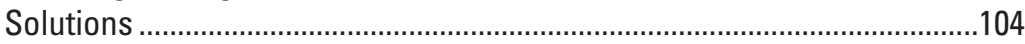

F.2.5.6. Budget-Constrained Optimization Scenarios ............................................105

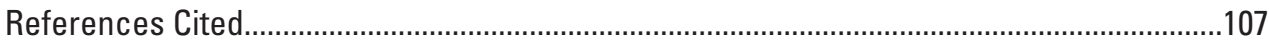

Chapter G. Cape Romain Partnership for Coastal Protection—Parting Thoughts .........................111

G.1. Proposition 1-Effective Adaptation May Rely More on Bottom-Up Governance than Centralized Governments...................................................................................111

G.2. Proposition 2-Recognize that Conservation is Integral to a Broader Set of Governance Issues, Which Include Social, Economic, and Cultural Values............111

G.3. Proposition 3-Approach Land Protection in a Way that is Consistent with the Preservation of the Lowcountry's Cultural Heritage and the Long-Standing Deference to Private Property Rights ....................................................................112

G.4. Proposition 4-Engage Stakeholders with the Understanding that Variation in Behavior Reflects Diverse Social-Cultural Perceptions............................................113

G.5. Proposition 5-Decision Makers, Scientists, and Stakehoders Work Together to Coproduce Knowledge and Meaning.......................................................................113

G.6. Proposition 6 —Build Adaptive Capacity ........................................................................114

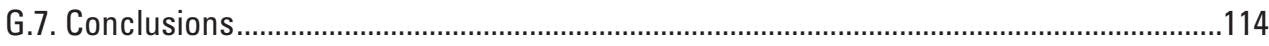

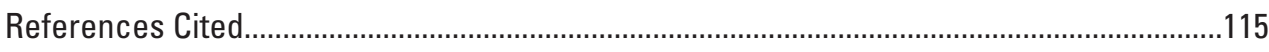

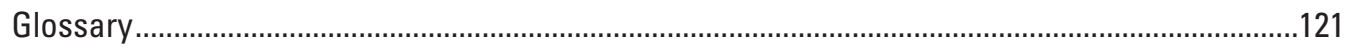

Appendix 1. Tracks of Tropical Storms Affecting the Lowcountry, 1910-2009...........................123

Appendix 2. Coastal Salinity and Water Temperature Model ....................................................134

Appendix 3. Predicting Long-Term Performance and Risk of Oyster Reef Restorations Under Deep Uncertainty in Climate and Management Policy..........................................139

Appendix 4. Integrating Econometric Land-Use Models with Ecological Modeling of Ecosystem Services to Guide Coastal Management and Planning-Methods and Provisional Results.

\section{Figures}

A1. Map showing protected landscapes in the South Carolina Lowcountry..........................5

A2. Diagram showing global-change impacts on coastal national wildlife refuges ...............7

A3. Map showing Cape Romain National Wildlife Refuge, coastal geomorphology,

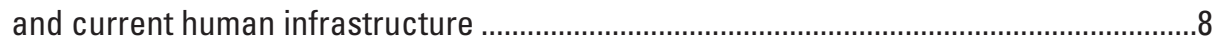

A4. Photograph showing a refuge biologist surveying the effect of sea-level rise at the "boneyard" on Cape Romain National Wildlife Refuge................................................

B1. Graph showing a histogram of tropical cyclone history that made landfall on southeast South Carolina and northern parts of southeast Georgia, 1850s-2010s.........18

B2. Map showing inundation depths of land subject to category 1 hurricanes as modeled by the Sea, Lake, and Overland Surges from Hurricanes model ...

B3. Map showing inundation depths of land subject to category 3 hurricanes as modeled by the Sea, Lake, and Overland Surges from Hurricanes model ......................21

B4. Map showing inundation depths of land subject to category 5 hurricanes as modeled by the Sea, Lake, and Overland Surges from Hurricanes model...

B5. Cross section showing maximum observed height of storm surge and forecast storm surge height the South Carolina coast for hurricane Hugo ... 
B6. Maps showing the additional Sea, Lake, and Overland Surges from Hurricanes model cells that would be inundated by 1 and 4 feet of sea-level rise for category 1 hurricane storm surge.

B7. Map showing four major islands that were analyzed for coastal erosion based on aerial photography and historical charts. 26

B8. Map showing losses and gains in island acreage between 1875 and 2011 for four barrier islands in Cape Romain National Wildlife Refuge. Inset graph shows overall trend for all acreage combined.....

B9. Map showing losses and gains in island acreage between 1949 and 2011 for Bulls Island. Inset graph shows overall trend for island acreage. .28

B10. Map showing losses and gains in island acreage between 1949 and 2011 for Raccoon Key. Inset graph shows overall trend for island acreage.

B11. Map showing losses and gains in island acreage between 1949 and 2011 for Cape Island. Inset graph shows overall trend for island acreage

B12. Map showing losses and gains in island acreage between 1949 and 2011 for Lighthouse Island. Inset graph shows overall trend for island acreage beginning in 1875

B13. Map showing sediment transport directions, rates of erosion, and areas prone to breaches and washovers at Cape Romain National Wildlife Refuge and the Santee River.

B14. Graphs showing population growth and net migration during 1950-2010 for three South Carolina coastal counties.

B15. Map showing North Charleston as an example of rapid urban growth, 1972-2007........34

B16. Map showing predictions of urban growth in 2080 based on the Slope, Land use, Excluded, Urban, Transportation and Hillshade cellular automata model for the Santee River region in the South Carolina Lowcountry ..

B17. Graph showing predicted urban footprint by 2080 based on the Slope, Land use, Excluded, Urban, Transportation and Hillshade model .....................................................36

C1. Diagram showing the Transtheoretical Model of human behavior.

C2. Map showing a geographical representation for application of the Transtheoretical Model to Cape Romain National Wildlife Refuge ..

C3. Map showing the density of spaces marked as favorite places by participants in the mapping activity at the Bulls Bay Nature Festival

C4. Density of spaces marked as areas of concerns by participants in the mapping activity at the Bulls Bay Nature Festival

D1. Diagram showing a depiction of future scenario entitled "The Three Horsemen," in which three principle driving forces of climate change, changing world order, and local values and power structure are all anticipated to be severe through 2050 .

D2. Diagram showing a depiction of future scenario entitled "United Front," in which two principle driving forces of climate change and changing world order are anticipated to be severe, while the third force (local values and power structure) is expected to be a moderate driver of change through 2050 .

D3. Diagram showing a depiction of future scenario entitled "Real Life," in which climate change is predicted to be a severe driving force, while changing world order and local values and power structure are foreseen to be moderate drivers of change through 2050

D4. Diagram showing a depiction of future scenario entitled "Manna," in which all three primary driving forces of climate, changing world order and local values and power structure are predicted to be moderate factors through 2050 
E1. Photograph showing an example of brainstorming partner strengths by organizational affiliation for strengths, weaknesses, opportunities, and threats analysis.

F1. Maps showing habitat distribution in the region of Cape Romain National Wildlife Refuge based on local sea-level rise projections and Sea Level Affecting Marshes Model output scenario B1 (2040)

F2. Map showing selected parcels north of Cape Romain National Wildlife Refuge obtained from the optimization analysis

F3. Map showing selected parcels north of Cape Romain National Wildlife Refuge and along the Santee River obtained from the optimization analysis.

F4. Graph showing an evaluation of hypothetical portfolio alternatives with objectives of maximizing return and minimizing risk.

F5. Diagram showing conceptual spatial planning model using multicriteria decision analysis and modern portfolio theory

F6. Map showing spatial orientation of study area division into 14 subgroups of less than or equal to 100 parcels each for reserve design analysis

F7. Graphs showing predicted changes in the distribution of wetland habitat types protected to 2050 under the current reserve network for three sea-level rise scenarios

F8. Maps showing potential reserve designs optimized using a modern portfolio theory analysis when the decision maker is looking at risk and reward options

F9. Map showing reserve design solutions that are robust to uncertainty related to risk attitude of the decision maker.

F10. Graph showing predicted differences (year 2050) under low, medium, and high sea-level rise scenarios of protected wetland habitat types under an optimal reserve design relative to the current protected area network

F11. Maps showing the effect of budget constraints on optimal modern portfolio theory reserve design portfolios

F12. Graph showing tradeoff comparisons among the primary metrics of the modern portfolio theory analysis: portfolio reward, risk, and cost.

F13. Graph showing properties of the Nash Bargaining Solution ........................................105

F14. Graphs showing Pareto-optimal frontiers computed for 14 parcel subgroups .............106

\section{Tables}

A1. Organizations composing the Cape Romain Partnership for Coastal Conservation.......12

B1. Projected sea-level rise for the Cape Romain region of South Carolina .........................17

B2. Conversion of year 2050 sea-level rise estimates for the Cape Romain region, South Carolina, to closely matched emission scenarios used in the Sea Level Affecting Marshes Model for land-cover change effects.

C1. Behavior models commonly used in environmental social sciences and their ability to address our model criteria

C2. Linking stakeholders and actions

D1. Internet resources provided to participants before the scenario planning workshop, January 26-27, 2017.

D2. Summary of ecological goods and services of value identified by participants of the scenario planning workshop, January 26-27, 2017. 
D3. Characterizations of "moderate" and "severe" climate change used to develop alternative future scenarios

E1. Mean and standard deviation of importance scores assigned to the principal strengths, weaknesses, opportunities, and threats analysis factors by workshop participants.

E2. Primary strengths, weaknesses, opportunities, and threats analysis factors and potential strategies for the Cape Romain conservation partnership...

E3. Importance scores for strategies developed by the Cape Romain conservation partnership

E4. Threats and opportunities produced by workshop facilitators for further exploration for scenarios 1-4

F1. Habitat category targets for the Marxan analysis ..........................................................

F2. Partial Marxan habitat outcomes for highway parcels .................................................83

F3. Partial Marxan habitat outcomes for Santee River parcels..............................................83

F4. Current habitat distribution and future predictions under current and optimal protected area designs.

F5. Budget scenarios hypothesizing a range of fiscal constraints on protected area design

F6. Expected habitat extent in protected status using modern portfolio theory optimization

F7. Notation of parameters and variables used in the portfolio analysis and optimization

\section{Conversion Factors}

U.S. customary units to International System of Units

\begin{tabular}{lll}
\hline \multicolumn{1}{c}{ Multiply } & By & \multicolumn{1}{c}{ To obtain } \\
\hline foot (ft) & \multicolumn{1}{c}{ Length } \\
mile (mi) & 0.3048 & meter $(\mathrm{m})$ \\
\multicolumn{3}{c}{ Area } \\
\hline acre & 1.609 & kilometer $(\mathrm{km})$ \\
acre & 4,047 & square meter $\left(\mathrm{m}^{2}\right)$ \\
acre & 0.4047 & hectare $($ ha) \\
acre & 0.4047 & square hectometer $\left(\mathrm{hm}^{2}\right)$ \\
square mile $\left(\mathrm{mi}^{2}\right)$ & 0.004047 & square kilometer $\left(\mathrm{km}^{2}\right)$ \\
square mile $\left(\mathrm{mi}^{2}\right)$ & 259.0 & hectare (ha) \\
\hline \multicolumn{2}{c}{ Flow rate } & \\
\hline mile per hour $(\mathrm{mi} / \mathrm{h})$ & 1.609 & kilometer per hour $(\mathrm{km} / \mathrm{h})$ \\
\hline
\end{tabular}

International System of Units to U.S. customary units

\begin{tabular}{|c|c|c|}
\hline Multiply & By & To obtain \\
\hline \multicolumn{3}{|c|}{ Length } \\
\hline centimeter (cm) & 0.3937 & inch (in.) \\
\hline millimeter (mm) & 0.03937 & inch (in.) \\
\hline
\end{tabular}




\begin{tabular}{|c|c|c|}
\hline Multiply & By & To obtain \\
\hline meter (m) & 3.281 & foot $(\mathrm{ft})$ \\
\hline kilometer (km) & 0.6214 & mile (mi) \\
\hline kilometer (km) & 0.5400 & mile, nautical (nmi) \\
\hline meter (m) & 1.094 & yard (yd) \\
\hline \multicolumn{3}{|c|}{ Area } \\
\hline hectare (ha) & 2.471 & acre \\
\hline hectare (ha) & 0.003861 & square mile $\left(\mathrm{mi}^{2}\right)$ \\
\hline square kilometer $\left(\mathrm{km}^{2}\right)$ & 0.3861 & square mile $\left(\mathrm{mi}^{2}\right)$ \\
\hline \multicolumn{3}{|c|}{ Flow rate } \\
\hline meter per year (m/yr) & 3.281 & foot per year ft/yr) \\
\hline millimeter per year $(\mathrm{mm} / \mathrm{yr})$ & 0.03937 & inch per year (in/yr) \\
\hline
\end{tabular}

\section{Datum}

Vertical coordinate information is referenced to the North American Vertical Datum of 1988 (NAVD 88).

Horizontal coordinate information is referenced to the North American Datum of 1983 (NAD 83). 


\section{Abbreviations}

$\begin{array}{ll}\text { CSI } & \text { Coastal Salinity Index } \\ \text { DEB } & \text { Dynamic Energy Budget } \\ \text { DOD } & \text { U.S. Department of Defense } \\ \text { EPA } & \text { U.S. Environmental Protection Agency } \\ \text { GIS } & \text { geographic information system } \\ \text { GMSL } & \text { global mean sea level } \\ \text { IPCC } & \text { Intergovernmental Panel on Climate Change } \\ \text { MCDA } & \text { multicriteria decision analysis } \\ \text { MPT } & \text { modern portfolio theory } \\ \text { NOAA } & \text { National Oceanic and Atmospheric Administration } \\ \text { NWR } & \text { national wildlife refuge } \\ \text { NWS } & \text { National Weather Service } \\ \text { SECASC } & \text { Southeast Climate Adaptation Science Center } \\ \text { SLR } & \text { sea-level rise } \\ \text { SLAMM } & \text { Sea Level Affecting Marshes Model } \\ \text { SLOSH } & \text { Sea, Lake, and Overland Surges from Hurricanes } \\ \text { SPI } & \text { Standard Precipitation Index } \\ \text { SWOT } & \text { strengths, weaknesses, opportunities, and threats } \\ \text { TTM } & \text { Transtheoretical Model } \\ \text { USGS } & \text { U.S. Geological Survey }\end{array}$




\title{
Cape Romain Partnership for Coastal Protection
}

\author{
By Mitchell J. Eaton, ${ }^{1}$ Fred A. Johnson, ${ }^{1,2}$ Jessica Mikels-Carrasco, ${ }^{3}$ David J. Case, ${ }^{3}$ Julien Martin, ${ }^{1}$ Bradley \\ Stith, ${ }^{4}$ Simeon Yurek, ${ }^{1}$ Bradley Udell, ${ }^{5}$ Laura Villegas, ${ }^{6}$ Laura Taylor, ${ }^{6}$ Zulquarnain Haider, ${ }^{7}$ Hadi Charkhgard, \\ and Changhyun Kwon ${ }^{7}$
}

\section{Abstract}

This final report summarizes activities, outcomes, and lessons learned from a 3-year project titled "Climate Change Adaptation for Coastal National Wildlife Refuges" with the Cape Romain National Wildlife Refuge (NWR) and local partners in the surrounding South Carolina Lowcountry. The Lowcountry is classified as the 10-county area encompassing the coastal plain of South Carolina (this report specifically focuses on Berkeley, Charleston, and Georgetown Counties). The goals of this work, sponsored by the U.S. Geological Survey's Southeast Climate Adaptation Science Center (SECASC), were to foster active engagement with stakeholders; to develop a comprehensive definition of adaptation problems faced by agencies, organizations, and individuals near the Cape Romain NWR that accounts for global change, local values, knowledge and perceptions; and to encourage social learning and building of effective networks and trust across South Carolina Lowcountry organizations and individuals. Although project scoping began at the scale of the Atlantic seaboard, by engaging with NWRs from Massachusetts to Florida, participating refuge personnel eventually selected the Cape Romain NWR to serve as a case study for testing our goals. The Cape Romain Partnership for Coastal Conservation was established to address global change impacts at a regional level and includes representation from Federal and State resource agencies, local conservation nongovernmental organizations, and organizations representing underserved community interests. Research topics, originating from discussions with Cape Romain Partnership for Coastal Conservation members, focused on quantifying key drivers of change including localized sea-level rise (SLR) predictions, estimates of coastal hurricane inundation as amplified by SLR, and

\footnotetext{
${ }^{1}$ U.S. Geological Survey.

${ }^{2}$ Aarhus University.

${ }^{3}$ DJ Case and Associates.

${ }^{4}$ Cherokee Nations Technology.

${ }^{5}$ University of Florida.

${ }^{6}$ North Carolina State University.

${ }^{7}$ University of South Florida.
}

urban growth trends and forecasts. These key drivers provided a foundation to engage stakeholders in planning exercises to begin a process of collective understanding and collaborative decision making. The goal of this process was to develop collective strategies of adaptation to enhance community and ecosystem resilience in the South Carolina Lowcountry.

South Carolina's Lowcountry is experiencing rapid environmental and social transformation because of SLR rates approaching twice the global average, chronic tidal flooding and catastrophic storm surges, erosion and loss of habitats that provide essential services to wildlife and humans, and increasing social polarization fueled by aggressive low-density urban growth and other forms of land conversion. To support characterizations of plausible future scenarios, we used available or, in some cases, developed new models to project future conditions of key environmental and social-economic drivers. Because of the imprecision of mean global SLR projections, the SECASC commissioned a climatological study to account for local conditions and multiple representative concentration pathways to project a tailored distribution of future sea levels. These projections were matched to SLR scenarios provided by existing models to anticipate the range of future coastal habitat changes in the South Carolina Lowcountry. SLR scenarios were also incorporated into existing stormsurge models, which do not account for alternate baseline sea levels, to project the local effects of future hurricanes. To evaluate the extent and effects of population growth and urban expansion, we relied on an existing urban-growth model to map the spatial distribution of land-conversion probabilities, the total area of which is predicted to increase twofold to threefold over the next 60 years. In addition to this simplified model, an econometric model is in development to account for nonlinear feedback dynamics in land value, land use, and ecosystem service production. Although not yet completed, the goals of this model are to produce more-detailed projections of growth dynamics and to allow predictions of development patterns resulting from alternate land-use planning policies and incentives.

Collaborative planning for an uncertain future requires more than providing decision makers with information on future physical and ecological conditions; developing effective and consensual strategies must also integrate sociological values, multiple cultural perspectives, and an understanding of 
human behavior. To support broad stakeholder engagement in integrative approaches to adaptation planning, emphasis was placed on the importance of considering differences in how individuals perceive their environment and create meaning. Because cultural frameworks form the basis for perceptions and, ultimately, the behaviors of individuals and institutions, we describe a model of human behavior and how it can be used to understand the effect of cultural complexity and variation in perception on choices, behavioral change, and long-term maintenance of behaviors. We consider a model commonly used in the field of behavioral health that accommodates variation in human perception when describing stages of behavior and the dynamics of behavioral change. Tailoring communication and engagement activities to targeted stakeholders is likely to benefit from increased understanding of behavioral change processes.

The complex nature of this problem limited the usefulness of a traditional decision-analytic approach, we explored alternative methods for engagement, collaborative learning and decision making. Recognizing that project partners and Lowcountry stakeholders may be at different stages of preparedness and interest level for modifying behavior as a function of global change, we facilitated a scenario-planning exercise to familiarize partners with this well-established approach for communicating the opportunities and threats arising under alternative, plausible futures. We developed narratives for four alternative South Carolina Lowcountry scenarios to be used in later strategic planning that focus on quantitative trends for three primary drivers with high impact and high uncertainty: manifestations of climate change, social-political shifts at a global level, and forces of local value and power structures. This scenario-planning exercise underscored the complex relation between the temporospatial scale of the production of ecological goods and services and the institutional scale at which they are managed. We then guided the partners through an assessment of the relevant strengths and weaknesses of the Cape Romain Partnership for Coastal Protection, using the threats and opportunities characterized by each scenario to understand how the partnership might respond when attempting to meet conservation and societal objectives. The partnership identified key strengths including partnership experience, outreach and technical capacities, a substantial conservation land base, and high social cohesion in the South Carolina Lowcountry. Limited communication expertise, institutional inertia, and insufficient staffing and funding were recognized as important weaknesses across the partnership. By examining and scoring combinations of internal strengths and weaknesses and external threats and opportunities, the partnership developed sets of prioritized strategies to consider in the context of a given scenario. Although we had insufficient time to examine all scenarios in detail, the intent was to identify a portfolio of strategic actions to address threats and opportunities represented in multiple plausible futures. Top-ranking strategies encompassed a range of actions that focused on strengthening the conservation community and communicating the benefits of nature (that is, ecosystem services) to leveraging partnerships to expand land protection.

This report also details the methods and preliminary results of several models developed or applied in support of this project. Two parcel-selection algorithms were used to evaluate anticipated habitat changes and patterns of urban growth to guide decisions on optimal conservation reserve design to protect habitat communities. One approach used a widely available planning software (MARXAN) to maximize conservation benefits near the Cape Romain NWR, whereas the other approach was a novel application of economic theory to account for uncertainty in future conditions and for the risks of unanticipated habitat loss. This latter model applies modern portfolio theory to estimate the risk of investing in any portfolio of land parcels (that is, candidate "reserves") under climate-change uncertainty by quantifying the variation and spatial correlation of conservation benefits derived from each portfolio. We expanded the range of actions beyond simply whether or not to invest in a set of land parcels, an approach commonly used in spatial conservation planning, to also include consideration of divestment from currently protected lands. Such refinements allow for better accounting of system dynamics and can evaluate the benefits of flexible conservation tools such as rolling easements. Model results were conditional on a decision maker's risk tolerance but highlighted general strategies of land conservation to increase future habitat representation beyond what is expected under the current protected land base. We built models that may help inform coastal planning by estimating salinity dynamics and the performance of oyster reef restoration efforts to predict the combined effects of global change and management of freshwater flows on coastal habitats and the processes that contribute to their resilience. These models can support restoration decisions by evaluating the expected benefits of site locations for shoreline protection and fisheries production. Lastly, we developed a spatially explicit economic model that predicts feedback dynamics among land value, land-use change, and effects on ecosystem service provision to explore zoning policies and incentives on urban growth and ecosystem services.

We summarize these efforts with insights and considerations for the Cape Romain Partnership for Coastal Protection to continue to engage stakeholders in effective adaptation planning. First, notions of place attachment (referred to as sense of place), and the role of culture in social discourse are increasingly being used to understand the complex interactions between society and the environment and how societies respond and adapt to climate change. Sense of place was a unifying theme whenever the future of the South Carolina Lowcountry was discussed. The contribution of the South Carolina Lowcountry's environmental wealth, rich cultural heritage, and quality of life to sense of place has important implications for how adaptation planning might best be pursued. More community-based governance of the commons (in other words, natural and cultural resources held in common), in which broad stakeholder participation and power sharing 
are key elements, is considered important. This devolution of governance is characterized by polycentric institutions and self-organizing social networks that promote a local culture of knowledge sharing, problem solving, and learning. These so-called bridging organizations (or individuals) often provide the leadership necessary to bring together potentially disparate Government agencies and institutions, private organizations, and individuals in a collective process of problem solving. Our observations also suggest that the conservation community in the South Carolina Lowcountry views its activities as integral to the broader governance of social-ecological systems, in which responses to the forces of global change are mediated through culture, economics, and politics. Rather than directly competing with other interests, the South Carolina Lowcountry conservation community seems to embrace an interpretation of conservation in which the fundamental objective is the quality of human life rather than environmental protection.
Fundamental to the types of governance reforms described above is the notion of coproduction, in which experts and users collaborate to develop a shared body of knowledge. In this approach, scientists work with stakeholders to help frame questions, design research, and collect and analyze data. Such sustained collaborations are increasingly believed to be an effective way to produce useable (or actionable) science. The emphasis on social learning, leveraging strong social networks, coordinating and deliberating among diverse stakeholders, and applying principles of adaptive management is an essential contribution to adaptive capacity. The diverse and robust set of scientific approaches, methods to help stakeholders collaborate in effective and goal-driven planning processes, and decision tools resulting from this project hopefully will assist Cape Romain NWR and its partners prepare for climatic, ecological, and social changes over the coming decades. 



\section{Chapter A. Introduction}

\section{A.1. Purpose}

This document is a final report for "Climate Change Adaptation for Coastal National Wildlife Refuges," a 3-year project sponsored by the U.S. Geological Survey Southeast Climate Adaptation Science Center. This document is primarily intended as an adaptation guide for Cape Romain National
Wildlife Refuge (NWR), but it is also for all those in South Carolina's Lowcountry (fig. A1) who are interested in conserving the region's environmental, aesthetic, and cultural values in the face of global change. The approaches and insights from this project may also benefit other coastal NWRs and conservation partners in their efforts to confront sea-level rise, climate change, and population growth.

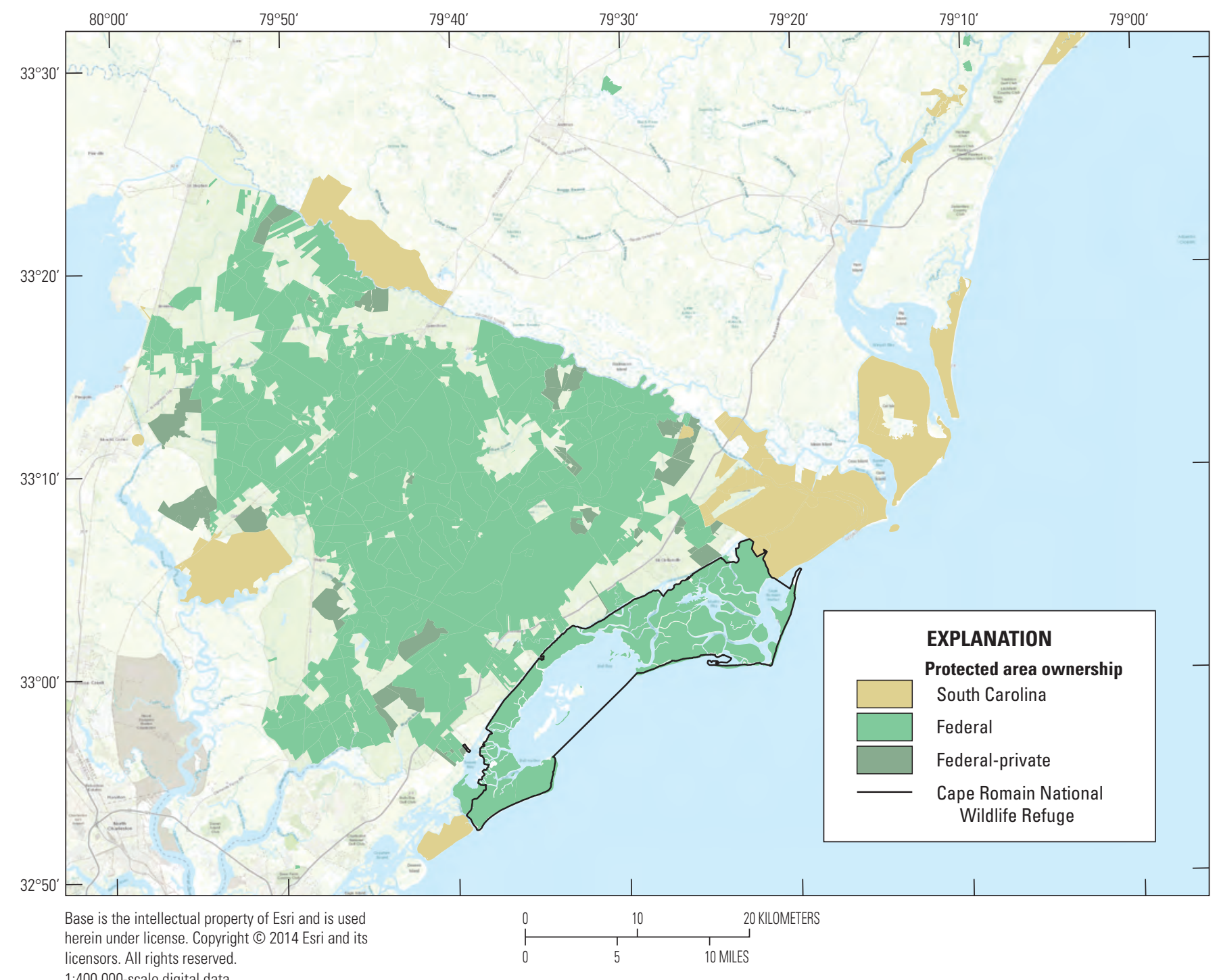

Figure A1. Protected landscapes in the South Carolina Lowcountry. 


\section{A.2. How this Document is Organized}

How this document is organized, and a brief overview of each chapter are provided herein. Each chapter can be read independently, and thus in any order, but an ordered reading of chapters $\mathrm{B}-\mathrm{G}$ will provide the most coherent understanding of the project as it evolved over time.

The rest of chapter A provides background concerning the project, including its philosophy of collaboration, goals, and project milestones.

Chapter B provides motivation for this project by examining the forces of global change in the South Carolina Lowcountry, including sea-level rise, frequency and intensity of tropical storms, erosion of barrier islands, and population growth and urbanization.

Chapter $\mathrm{C}$ focuses on engagement of stakeholders interested in the social-ecological future of the South Carolina Lowcountry. It describes the choice of a human-behavior model, which attempts to explain how people modify their behavior in response to emerging environmental and social issues. This chapter also describes the importance of a cultural context in adaptation planning. Responses to global change in the South Carolina Lowcountry involve a diversity of stakeholders and decision makers, who bring with them not only competing priorities but also various ways of understanding the world.

Chapter D describes a scenario planning exercise. Four scenarios are described, which posit alternative futures for the South Carolina Lowcountry in 2050. The scenarios help partners communicate how climate change, a changing geopolitical order, and local values and power structures might threaten, or provide opportunities for, conservation efforts.

Chapter E details how the scenarios from Chapter D were used in a strengths, weaknesses, opportunities, and threats (SWOT) analysis to propose and prioritize stakeholder engagement strategies that will foster a more coherent and coordinated approach to global-change adaptation.

Chapter F provides two approaches for prioritizing the protection of lands to conserve the ecological goods and services of the South Carolina Lowcountry in the face of global change. One approach considers the change in habitats under expected sea levels in 2050, and the other considers a broader planning region, as well as uncertainty in the extent of sealevel rise and urbanization.

Chapter $\mathrm{G}$ focuses on insights, lessons learned, and partnership considerations for an ongoing and effective stakeholder communication and engagement effort. This chapter describes, through a series of propositions, how the authors believe project partners may be able to strengthen the effectiveness of interactions with a diverse array of stakeholders.

Appendixes provide tracks of tropical storms affecting the South Carolina Lowcountry (app. 1), a coastal salinity model (app. 2), a model of oyster dynamics (app. 3), and econometric land-use models (app. 4).

\section{A.3. Background}

\author{
"We must act now, as if the future of fish and wildlife \\ and people hangs in the balance- - for indeed, all \\ indications are that it does."
}

\section{U.S. Fish and Wildlife Service (2010a).}

Coastal ecosystems in the eastern United States have been severely altered by human development, including drainage of coastal wetlands, changes in hydrology that alter sediment and freshwater delivery to the coast, land clearing, agricultural and forestry activity, and the construction of seawalls and other structures that harden the coast (Stedman and Dahl, 2008). Sea-level rise and the changing frequency of extreme storm events associated with climate change are now further degrading the capacity of those ecological and social systems to remain resilient in the face of disturbance (Arkema and others, 2013).

Coastal NWRs have an especially important role to play in sustaining valued natural resources and in helping socialecological systems respond and adapt to the global-change processes of sea-level rise, climate change, and changing land use. Coastal NWRs protect critical habitat and ecosystems for a host of wildlife species but also contribute to essential goods and services that benefit coastal communities, businesses, and individuals. Some of the many benefits to society contributed by coastal NWRs include storm-surge protection, improved water quality, nurseries for commercially important fin and shellfish, and recreational opportunities. However, faced with global-change drivers, including climate, economic, demographic, and land-use change, the role of coastal NWRs in protecting the Nation's natural resources and providing ecosystem services is in jeopardy (Griffith and others, 2009). See figure A2 for a conceptual model of drivers, landscape changes, and impacts to NWRs.

In 2013, the U.S. Geological Survey's Southeast Climate Adaptation Science Center began an effort to help NWRs along the eastern seaboard address adaptation strategies in response to climate change and other global-change processes. In an uncertain world, good decisions do not guarantee good outcomes, but a systematic process, in which decision makers (managers) and scientists are engaged in the development of potential solutions to complex problems, should enhance the likelihood of favorable outcomes (Keeney, 2004; Meadow and others, 2015). In pursuing this management-research collaboration, several of the authors worked with NWR staff along the Atlantic coast to understand the problems they face and to provide decision support. Our initial focus was on (a) exploring how the managers' ability to meet their objectives is affected by the larger social-ecological system in which the NWRs are embedded; (b) understanding how to account for stakeholders' values and perceptions of tradeoffs; and (c) developing decision-support tools appropriate for problems with deep uncertainty, conflicting values, and multiple decision makers. 


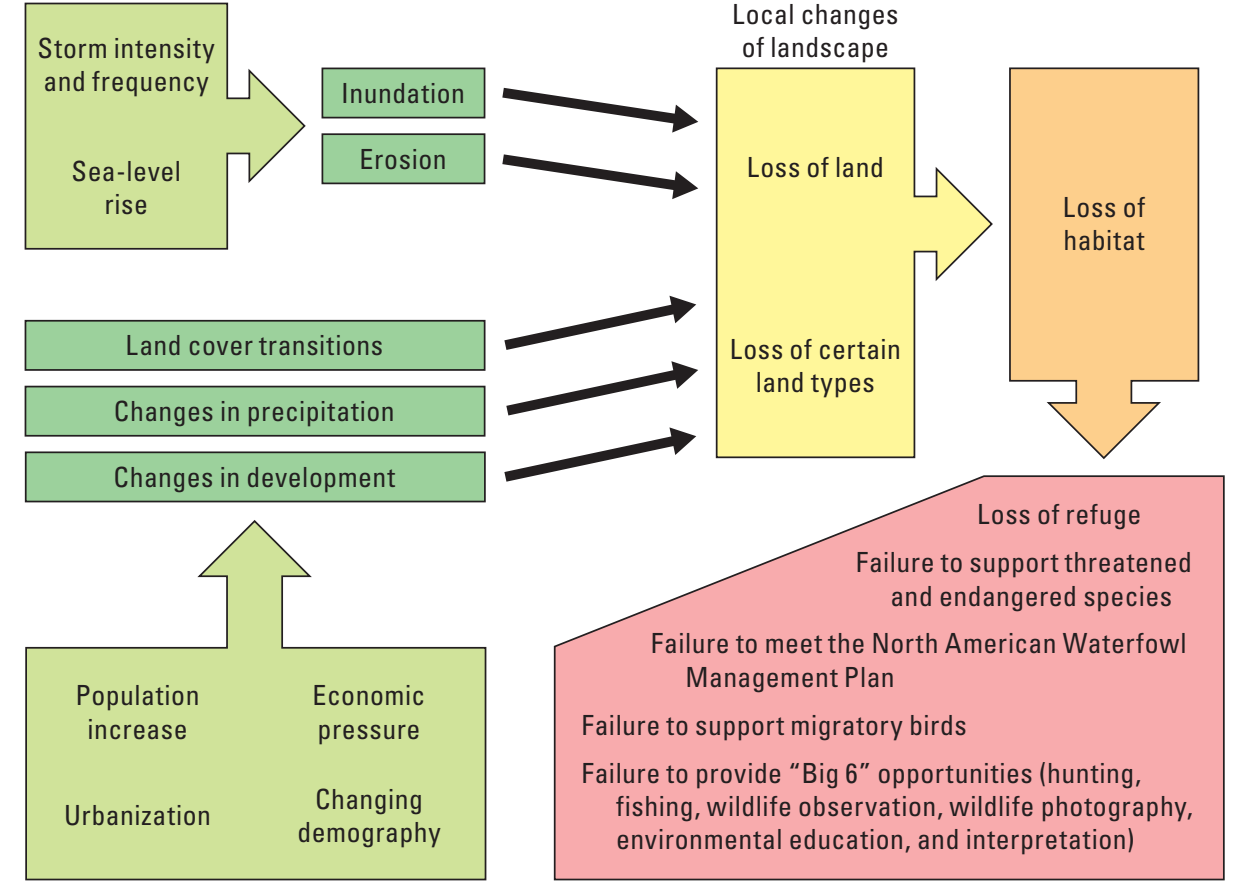

Figure A2. Global-change impacts on coastal national wildlife refuges. Modified from Nilius and others (2014); used with permission.
The project initially involved listening sessions with coastal NWRs on the Atlantic and Gulf of Mexico coasts. Our team visited Alligator River, Cape Romain, Savannah, Lower Suwannee, and St. Marks NWRs during fall 2013. After these visits, we conducted a 2-day workshop involving staff from four coastal NWRs or NWR complexes: Coastal North Carolina NWR Complex, Cape Romain NWR, Chesapeake Marshlands NWR Complex, and Parker River NWR. In 2014, at the recommendation of these NWRs, focus was shifted to Cape Romain NWR and the surrounding human-ecological systems in South Carolina's Lowcountry (see study area, fig. A1).

Established in 1932 as a migratory bird refuge, Cape Romain NWR encompasses a 35-kilometer segment of the Atlantic coast north of Charleston, South Carolina (fig. A1). The refuge consists of 26,825 hectares, composed of barrier islands, salt marshes, coastal waterways, sandy beaches, fresh and brackish water impoundments, and maritime forest (fig. A3; U.S. Fish and Wildlife Service, 2010b). The refuge's original objectives were to conserve in public ownership habitat for waterfowl, shorebirds, and resident species. In recent years, objectives have expanded to include managing endangered species, protecting the only Class 1 Wilderness in South Carolina (11,735 hectares), and conserving the Bulls Island and Cape Island forests (fig. A3) and associated diverse plant communities. Currently, the refuge is actively working to aid the recovery of the threatened Caretta caretta (Linnaeus, 1758) (loggerhead sea turtle).

Cape Romain NWR has become an example of globalchange problems faced by coastal NWRs. In 2013, then Department of the Interior Secretary Sally Jewell visited Cape Romain NWR to view the ongoing impacts of sea-level rise and to encourage conservation of uplands so that less development would occur in the path of rising seas (Fretwell, 2013). Accelerated beach erosion, submergence of salt marsh habitats, conversion of salt marsh to tidal flats and open water, and saltwater intrusion are apparent at the refuge and are largely attributable to sea-level rise (Ellis and Nilius, 2012; Faustini and others, 2013) (fig. A4). Yet landward migration of these coastal habitats is limited by development, hardened shorelines, and dredged boat channels. Moreover, Charleston is one of the most rapidly growing metropolitan areas in the country (Allen and Lu, 2003), which puts the area's natural environment under additional stress. In addition to sea-level rise and urbanization, the Cape Romain region can expect more rainfall extremes, more heat waves, and stronger tropical storms (see chap. C; South Carolina Sea Grant Consortium, 2017). 


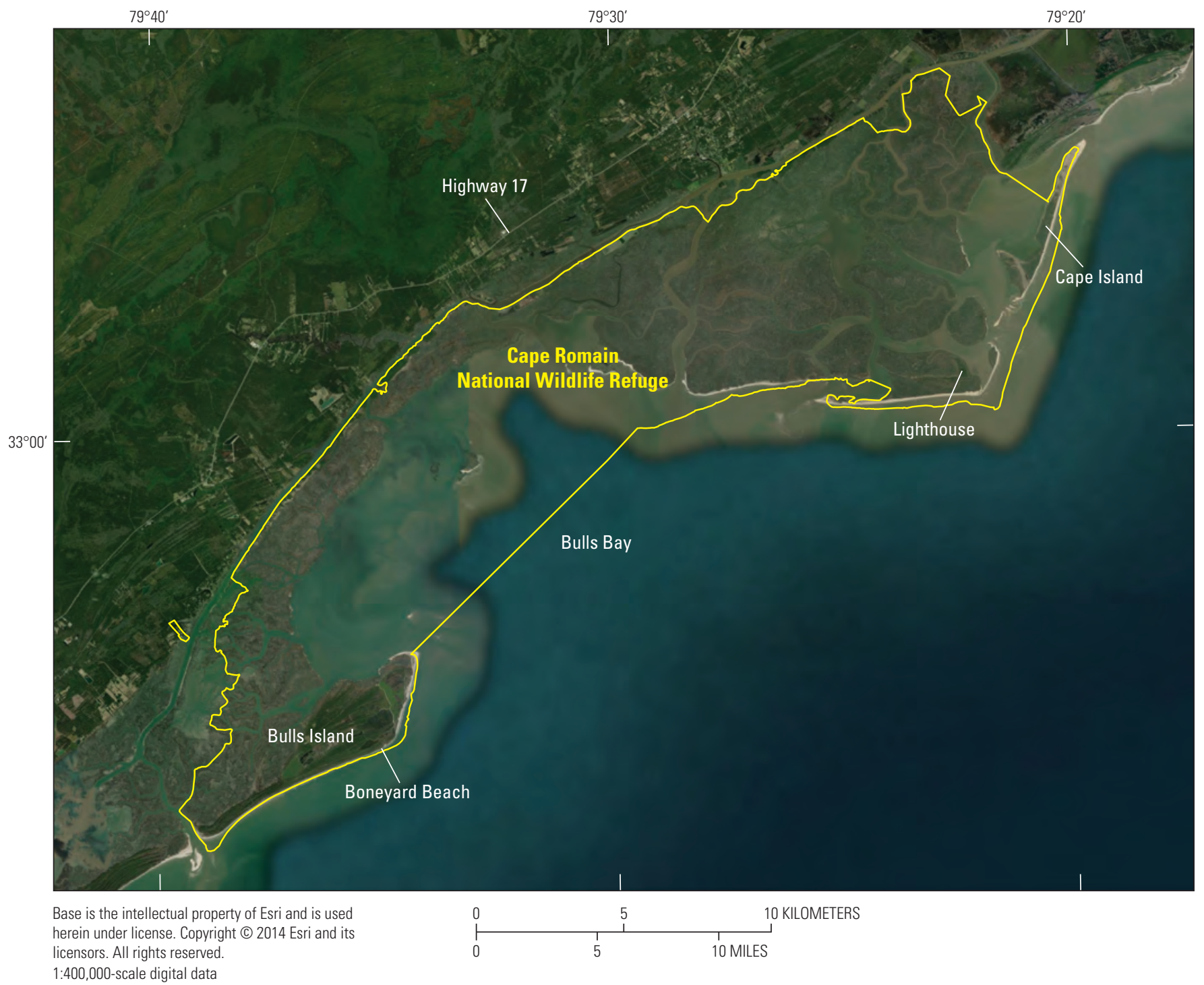

Figure A3. Cape Romain National Wildlife Refuge, coastal geomorphology, and current human infrastructure. All of Cape Romain National Wildlife Refuge is designated as wilderness, with the exception of Bulls Island, Garris Landing, and a band of marsh along the Intracoastal Waterway. 


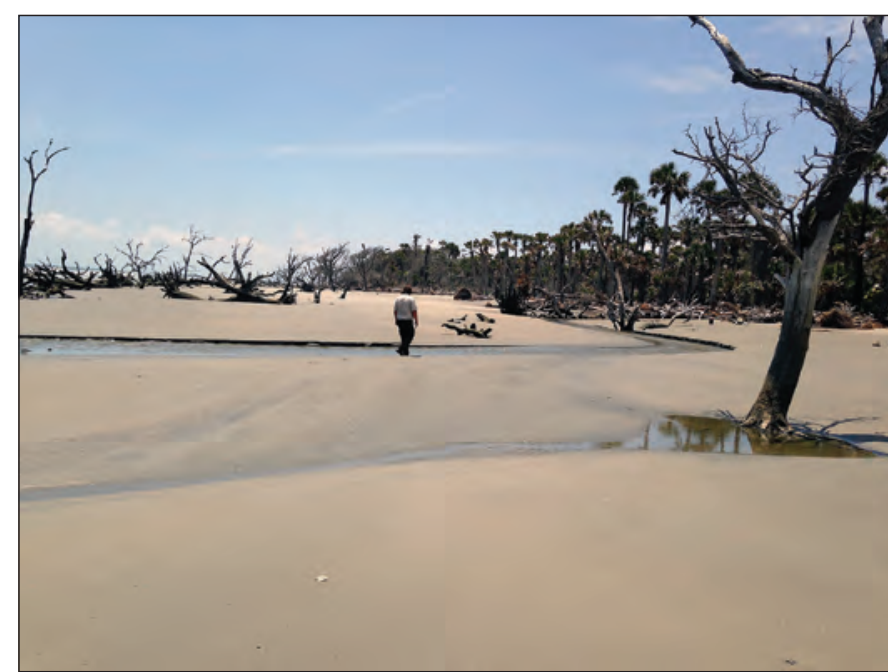

Figure A4. A refuge biologist surveys the effect of sea-level rise at the "boneyard" on Cape Romain National Wildlife Refuge, including beach erosion and saltwater intrusion into freshwater forests, resulting in the decline of rare Atlantic maritime forest habitat. Photograph by F. Johnson, U.S. Geological Survey.

\section{A.4. Philosophy of Collaboration}

Mitigating and adapting to the effects of climate change presents unprecedented challenges for resource managers. Planning processes can quickly be overwhelmed by the difficulty of accounting for multiple decision makers; diverse, often competing, values; complex interactions of social and ecological systems; and profound uncertainties regarding the future and society's ability to affect it. Rittel and Webber (1973) introduced the notion of "wicked" planning problems, which in addition to the features above, are characterized by (a) the lack of a definitive problem formulation; (b) no finite set of decision alternatives; (c) a never-ending search for solutions; and (d) interdependencies with other wicked problems. Solutions to wicked problems do not arise from a systematic, linear process of planning but from a social planning process involving multiple stakeholders, effective communication, visioning of alternative futures, and acceptance of diverse opinions (Camillus, 2008).

Perspectives about conservation and resource management are also changing (Berkes, 2010). To many, the term "management" has come to imply domination of nature, efficiency, simplification, and expert-knows-best, command-andcontrol approaches (Ludwig, 2001). In contrast, the emerging philosophy emphasizes stewardship, pluralism, collaboration, partnerships, and adaptive governance (Mace, 2014). This emerging perspective of resource governance is less utilitarian and more cognizant of the two-way, dynamic relations between people and nature. It emphasizes the importance of variability in cultural perspectives that produce differing interpretations of the landscape and the complexity of developing sustainable and resilient interactions between human societies and the natural environment. The advantage of the "people and nature" perspective is that it has traction with other societal needs from the environment and connects better to policy because of its broad focus (that is, its ability to appeal to a wider set of constituents). A key challenge, however, is that it largely lacks the analytical foundations that make traditional natural-resource management deliverable and measurable.

Armitage and others (2012) described five key concepts in the search for improved resource governance:

1. The scale of the environmental or resource problem must be matched by the scale at which agents of change can act. Governance arrangements to address problems of fit require strong horizontal and vertical linkages among scientists, managers, stakeholders, and civil society. Authority is distributed rather than residing at a single level. Adger and others (2005) describe horizontal linkages as local actors (resource users, civil society groups, scientific organizations, and so on) sharing common interests with other local communities in the same situation and at the same level in which common lessons are learned and best practices spread. Horizontal linkages can also refer to Government agencies with horizontally structured departments. Vertical linkages refer to exchange among entities at different scales (for example, a local nongovernmental organization initiative engaging with university researchers or Government agencies).

2. A conventional desire for stable and predictable institutions (in other words, entrenchment) conflicts with the need for governance and decision-making processes that are flexible and adaptive in the face of uncertainty and change. Yet there is a growing demand for the design of institutions and governance with adaptive capacity, defined as the ability of the conservation enterprise to learn from experience, be robust to external disturbances, and be capable of responding to change (PahlWostl, 2009).

3. Empirical studies show that drawing from multiple sources of knowledge, including knowledge from scientists, policy makers, and stakeholders, can lead to better social and ecological outcomes (Meadow and others, 2015). The emphasis in contemporary environmental governance is thus of the coproduction of knowledge, highlighting the value of managers and scientists engaging with diverse actors to build more holistic understandings. For conservation practitioners, this means supporting decision-making processes that involve meaningful participation and that do not privilege western science over other ways of knowing. Drawing understanding from scientists, resource users, and others with local forms of knowledge can only increase the ability to meet the needs in complex and changing systems.

4. Hybrid forms of governance involve the participation of diverse sets of non-State actors, as well as new perspectives on actor roles and responsibilities. For example, the 
State may transition from a role of provider of expertise and decision maker to facilitator of knowledge and decision broker. The rationale for participation of an array of non-State actors include increased legitimacy; more effective and equitable allocation of resources, costs, and benefits; and improved access to diversity of knowledge and expertise. Bridging organizations have emerged as a key way to build links between communities and the State, and science and policy (Berkes, 2009). Bridging organizations have specialized roles, but they also function outside defined roles and therefore provide the context for different actors to make sense of information, learn about conservation challenges, and work together to build knowledge in a collaborative manner.

5. Accountability and legitimacy traditionally have been determined by legislation and supporting regulations and through formal agency mandates associated with those regulations. However, in networked models of governance with dispersed power and incentives among a collection of State and non-State actors, the sources of accountability and legitimacy are less clear. Accountability and legitimacy can be enhanced by reasonable clarity about roles and responsibilities, consequences for performance, responsiveness to other actors, checks and balances, transparency, and the free flow of information.

In light of the emerging philosophies concerning wicked problems and resource governance, the Cape Romain NWR partnership emphasized collaborative stakeholder engagement to (a) identify and work with those already affected by, and working on, global-change issues in the South Carolina Lowcountry; (b) look beyond traditional conservation objectives to address a broad spectrum of concerns, values, and desired ecological goods and services associated with the coastal region; (c) identify possible collaborations and sources of conflict; and (d) use the best-available science to understand and guide decisions to achieve societal goals for the future of the coast.

\section{A.5. Project Goals}

To assist the Cape Romain Partnership for Coastal Conservation cope with global change, we came to believe there would be greater long-term benefit in providing a robust process for productive engagement and collaborative learning relative to the potentially shorter-term benefits of offering specific scientific products. The Cape Romain NWR and its partners would likely be better positioned to confront change well into the future by developing an adaptive and resilient process of collective governance and decision making than could short-lived models and quickly outdated data. We fostered early and active engagement with stakeholders and allowed for pluralistic problem definitions that value local knowledge and perceptions. We encouraged social learning and the building of social networks and trust across disciplines and organizations. Notably, research questions were sourced from conservation practitioners. Overall, project goals evolved to the following:

- Collaboratively envision and describe a variety of possible futures to serve as a basis for collaboration with people, communities, and organizations that benefit from and enjoy South Carolina's Lowcountry.

- Work together to foster greater understanding and more collaborative decision making among those that benefit from and value Cape Romain NWR and the surrounding area.

- Produce decision-support tools that are useful for those working to protect the coasts in South Carolina.

\section{A.6. Project Milestones}

In June 2014, a structured decision-making workshop was convened at the U.S. Fish and Wildlife Service's National Conservation Training Center in West Virginia. NWR managers and project leaders from four NWR complexes on the Atlantic coast participated in developing decision prototypes for sea-level rise planning and adaptation of Cape Romain NWR (Nilius and others, 2014; Johnson and others, 2015). Results and insights gained from the workshop served as a starting point for developing a more complete understanding of stakeholder values, local impacts of sea-level rise on barrier islands, coastal marshes and upland habitat, and analytical methods for evaluating the complex set of tradeoffs faced by decision makers.

A second workshop was held in February 2015 at Bulls Island on Cape Romain NWR. This workshop brought together the authors and Cape Romain NWR staff to discuss models of human behavioral change and to develop preliminary stakeholder engagement and communication strategies.

A key insight from these two workshops was that partnerships with, and public support from, other decision makers and stakeholders are critical for effective global-change adaptation. Examples of the kinds of stakeholders whose interests and decisions may directly or indirectly affect the outcomes for natural-resource objectives include the following: commercial anglers; large private and public landowners; nongovernmental organizations; public agencies that enforce State or Federal laws and regulations that affect habitat; NWR volunteers; State and Federal agencies (for example, departments of transportation); local and county governments; and small businesses such as lodging and restaurant owners who benefit from ecotourism. Engendering political support will likely be most effective if the objectives of this broad array of stakeholders are considered when quantifying the value of the NWR. Doing so presents an opportunity to reframe the metrics used for appraising the value of the NWR; that is, scaling the evaluation of benefits to match the decision context of a 
broader set of stakeholders whose interests are focused on the NWR's production of ecological goods and services for human well-being.

These workshops also served to help focus scientific efforts, which were initially designed to help understand the social-ecological forces of change in the South Carolina Lowcountry. We ultimately were able to provide up-to-date assessments of sea-level rise, tropical storms, and urbanization. From the project beginning, the NWR was also interested in a strategy for landward migration of the refuge to replace habitats lost to rising seas. We explored ways to prioritize lands for conservation and developed a portfolio approach that seeks to quantify the level of risk for any given investment in properties. This portfolio analysis ultimately can be used as a basis for collaboration among the many conservation practitioners in the South Carolina Lowcountry.

In April 2016, our team (including staff from Cape Romain NWR) traveled to the Charleston area to interview potential partners in the collaboration. Our goal was to listen to others, to introduce our efforts, to hear what others are doing, to find areas where work such as this is already happening, and to recognize areas of potential conflict. We believed it important to uncover issues that are most important on the landscape to different stakeholders. We ultimately had conversations with local, State, and national organizations working in the South Carolina Lowcountry, including the following:

- South Carolina Department of Natural Resources,

- The Nature Conservancy of South Carolina,

- National Oceanic and Atmospheric Administration Office for Coastal Management,

- the Center for Heirs Property,

- the Lowcountry Land Trust,

- Francis Marion National Forest, and

- the South Carolina Sea Grant Consortium.
From these conversations, we discovered an active network of scientists and conservation practitioners engaged in global-change issues in the South Carolina Lowcountry. All the aforementioned organizations continued to participate in efforts to develop strategies intended to help conserve the natural and cultural resources of the region. With the U.S. Geological Survey, the Cape Romain NWR, and a few additional members, we formed the Cape Romain Partnership for Coastal Conservation (table A1).

In January 2017, we held a scenario planning workshop in Awendaw, South Carolina, with members of the partnership. Scenario planning involves development of alternative, but plausible, descriptions of the future. It is used to help explore uncertain futures, as a method of collective learning, and as a communication tool for working with a diversity of stakeholders.

In November 2017, a second workshop was held in Awendaw to use the scenarios in development of strategic actions that might help mitigate the effects of global change on the South Carolina Lowcountry. Attributes from a SWOT analysis were assessed from an internal (within an organization) and external (among organizations) perspective when developing strategies. After these workshops, project leaders focused on summarizing the outcomes from scenario planning and SWOT exercises, developing decision-support tools for land conservation prioritization, building models to increase understanding of coastal biological systems and economic drivers and ecosystem impacts of land-use change, and synthesizing lessons learned to identify some tangible recommendations for the Cape Romain Partnership for Coastal Conservation. Some of these outcomes represent ongoing work, whereas most are detailed in this report.

Finally, it is ironic that in the course of this project, two workshops in the Cape Romain region had to be cancelled due to tropical storms: one because of Hurricane Matthew in 2016 and one because of Hurricane Irma in 2017. The next chapter describes drivers of change in the South Carolina Lowcountry, including the frequency and intensity of tropical storms. 
Table A1. Organizations composing the Cape Romain Partnership for Coastal Conservation.

\begin{tabular}{l} 
Organization \\
\hline Cape Romain National Wildlife Refuge \\
South Carolina Department of Natural Resources \\
The Nature Conservancy of South Carolina \\
National Oceanic and Atmospheric Administration \\
Office for Coastal Management
\end{tabular}

Center for Heirs Property

Lowcountry Land Trust

Francis Marion National Forest

South Carolina Sea Grant Consortium

South Carolina Aquarium

U.S. Geological Survey

\section{Description}

Operating under the U.S. Fish and Wildlife Service's National Wildlife Refuge System, Cape Romain National Wildlife Refuge is managed as part of the South Carolina Lowcountry Refuges Complex which includes four coastal wildlife refuges protecting 46,540 hectares of South Carolina's Lowcountry habitat, fish, and wildlife.

State agency charged with regulating hunting, fishing, boating, and the conservation efforts of the South Carolina government.

A national nongovernmental conservation organization dedicated to protecting biodiversity and conserving the lands and waters on which all life depends.

The Federal agency, within the U.S. Department of Commerce, tasked with implementation of the Coastal Zone Management Act, legislation designed to keep the natural environment, built environment, quality of life, and economic prosperity of our coastal areas in balance.

A South Carolina nonprofit that protects heirs' property (land jointly owned by descendants of a deceased person whose estate was never handled in probate) and promotes its sustainable use to provide increased economic benefit to historically underserved families.

A South Carolina Lowcountry nonprofit land conservation organization focused on protecting ecologically, agriculturally, and historically significant lands and the way of life they make possible.

The U.S. Forest Service operates this national forest to sustain its health, diversity, and productivity to meet the needs of present and future generations for economic, ecological, and social vitality.

An independent State agency operated by a program within the National Oceanic and Atmospheric Administration that supports integrated research, education, and engagement to generate and apply science-based information to enhance sustainable use and conservation of coastal and marine resources.

A nonprofit organization whose mission is to inspire conservation of the natural world by exhibiting and caring for animals, through research, and by providing education and visitor experience.

An agency in the U.S. Department of the Interior, which provides science on natural hazards, water, energy, minerals, and other natural resources; the health of our ecosystems and environment; and the effects of climate and land-use change.

\section{References Cited}

Adger, W.N., Brown, K., and Tompkins, E.L., 2005, The political economy of cross-scale networks in resource comanagement: Ecology and Society, v. 10, no. 2, art. 9. [Also available at https://doi.org/10.5751/ES-01465-100209.]

Allen, J., and Lu, K., 2003, Modeling and prediction of future urban growth in the Charleston region of South Carolina-A GIS-based integrated approach: Ecology and Society, v. 8, no. 2, art. 2, accessed April 2018 at https://www.ecologyandsociety.org/vol8/iss2/art2/.

Arkema, K.K., Guannel, G., Verutes, G., Wood, S.A., Guerry, A., Ruckelshaus, M., Kareiva, P., Lacayo, M., and Silver, J.M., 2013, Coastal habitats shield people and property from sea-level rise and storms: Nature Climate Change, v. 3, no. 10, p. 913-918. [Also available at https://doi.org/10.1038/nclimate1944.]
Armitage, D., de Loë, R., and Plummer, R., 2012, Environmental governance and its implications for conservation practice: Conservation Letters, v. 5, no. 4, p. 245-255. [Also available at https://doi.org/10.1111/ j.1755-263X.2012.00238.x.]

Berkes, F., 2009, Evolution of co-management-Role of knowledge generation, bridging organizations and social learning: Journal of Environmental Management, v. 90, no. 5, p. 1692-1702. [Also available at https://doi.org/10.1016/j.jenvman.2008.12.001.]

Berkes, F., 2010, Shifting perspectives on resource management-Resilience and reconceptualization of "natural resources" and "management": Maritime Studies, v. 9, p. 13-40. [Also available at http://www.marecentre.nl/mast/ documents/Mastvo19no1_Berkes.pdf.] 
Camillus, J.C., 2008, Strategy as a wicked problem: Harvard Business Review Magazine, p. 99-106. [Also available at https://hbr.org/2008/05/strategy-as-a-wicked-problem.]

Ellis, C., and Nilius, R., 2012, Climate change and coastal refuge dynamics - The case of Cape Romain National Wildlife Refuge, in Weber, S., ed., Rethinking protected areas in a changing world-Proceedings of the 2011 George Wright Society Biennial Conference on Parks, Protected Areas, and Cultural Sites: Hancock, Mich., The Geroge Wright Society, p. 90-92. [Also available at http://www.georgewright.org/1118ellis.pdf.]

Faustini, J., Thom, T.A., Hunt, K.J., Nilius, R., and Burns, R.E., 2013, Water resource inventory and assessmentCape Romain National Wildlife Refuge, Charleston County, South Carolina: Atlanta, Ga., U.S. Fish and Wildlife Service, Southeast Region, 84 p. [Also available at https://ecos.fws.gov/ServCat/DownloadFile/22595?Refere nce $=24097$.]

Fretwell, S., 2013, U.S. Interior chief stunned by eroding S.C. island: The State, accessed July 17, 2020, at https://www.thestate.com/news/politics-government/ article13829591.html.

Griffith, B., Scott, J.M., Adamcik, R., Ashe, D., Czech, B., Fischman, R., Gonzalez, P., Lawler, J., McGuire, A.D., and Pidgorna, A., 2009, Climate change adaptation for the US National Wildlife Refuge System: Environmental Management, v. 44, no. 6, p. 1043-1052. [Also available at https://doi.org/10.1007/s00267-009-9323-7.]

Johnson, F.A., Eaton, M.J., McMahon, G., Nilius, R., Bryant, M.R., Case, D.J., Martin, J., Wood, N., and Taylor, L., 2015, Global change and conservation triage on national wildlife refuges: Ecology and Society, v. 20, no. 4, art. 14. [Also available at https://doi.org/10.5751/ES-07986-200414.]

Keeney, R.L., 2004, Making better decision makers: Decision Analysis, v. 1, no. 4, p. 191-249. [Also available at https://doi.org/10.1287/deca.1040.0009.]

Ludwig, D., 2001, The era of management is over: Ecosystems, v. 4, no. 8 , p. $758-764$. [Also available at https://doi.org/10.1007/s10021-001-0044-x.]

Mace, G.M., 2014, Whose conservation?: Science, v. 345 , no. 6204 , p. $1558-1560$. [Also available at https://doi.org/10.1126/science.1254704.]

Meadow, A.M., Ferguson, D.B., Guido, Z., Horangic, A., Owen, G., and Wall, T., 2015, Moving toward the deliberate coproduction of climate science knowledge: Weather, Climate, and Society, v. 7, no. 2, p. 179-191. [Also available at https://doi.org/10.1175/WCAS-D-14-00050.1.]
Nilius, R., Dawsey, S., Eaton, M., Martin, J., Romanach, S., Baird, S., Bryant, M., Case, D., Johnson, F., McMahon, G., Pau, N., Pienaar, E., Ratnaswamy, M., Seibert, S., Wingrove, P., and Wood, N., 2014, Maximizing the social and ecological value of Cape Romain National Wildlife Refuge, South Carolina as the effects of global change processes increase: National Conservation Training Center Structured Decision Making Workshop, Shepherdstown, W.V., June 2-6, 2014, workshop report, 20 p., accessed April 2018 at https://training.fws.gov/courses/ALC/ ALC3159/reports/final-reports/2014FR/CRNWR_workshop_report_FINAL.pdf.

Pahl-Wostl, C., 2009, A conceptual framework for analysing adaptive capacity and multi-level learning processes in resource governance regimes: Global Environmental Change, v. 19, no. 3, p. 354-365. [Also available at https://doi.org/10.1016/j.gloenvcha.2009.06.001.]

Rittel, H.W.J., and Webber, M.M., 1973, Dilemmas in a general theory of planning: Policy Sciences, v. 4, no. 2, p. 155-169. [Also available at https://doi.org/10.1007/ BF01405730.]

South Carolina Sea Grant Consortium, 2017, Our Coastal Future Forum-Ocean mineral and energy resources in a changing climate: South Carolina Sea Grant Consortium, SCSGC-H-18-04, 20 p., accessed April 2018 at https://www.scseagrant.org/wp-content/uploads/ OCFF-Ocean-Mineral-and-Energy-Resources.pdf.

Stedman, S., and Dahl, T.E., 2008, Status and trends of wetlands in the coastal watersheds of the Eastern United States 1998 to 2004: National Oceanic and Atmospheric Administration, National Marine Fisheries Service, and U.S. Fish and Wildlife Service, 32 p. [Also available at https://www.fws.gov/wetlands/documents/Status-andTrends-of-Wetlands-in-the-Coastal-Watersheds-of-the-Eastern-United-States-1998-to-2004.pdf.]

U.S. Fish and Wildlife Service, 2010a, Rising to the urgent challenge-Strategic plan for responding to accelerating climate change: U.S. Fish and Wildlife Service, 36 p. [Also available at https://www.fws.gov/home/climatechange/pdf/ CCStrategicPlan.pdf.]

U.S. Fish and Wildlife Service, 2010b. Draft comprehensive conservation plan and environmental assessment - Cape Romain National Wildlife Refuge Charleston County, South Carolina: Atlanta, Ga., U.S. Fish and Wildlife Service, Southeast Region, 220 p., accessed April 2018 at https://www.fws.gov/southeast/planning/PDFdocuments/ CapeRomainDRAFT/Cape\%20Romain\%20Draft\%20CCP. pdf. 



\section{Chapter B. Drivers of Change in South Carolina's Lowcountry}

\section{B.1. Sea-Level Rise}

Concern about long-term sea level rise (SLR) has been a primary focus in discussions about global climate change. Although coastal systems are naturally dynamic, and changes are inevitable, increasing rates of SLR present a highly visible and consequential threat worldwide. Rising seas and more powerful storms are rapidly altering coastal habitats, affecting human infrastructure, contaminating fresh and groundwater systems, and risking human lives and safety.

\section{B.1.1. Introduction}

Because of SLR, 2016 saw a record number of tidal flood days $(n=50)$ in Charleston, South Carolina (fig. A2), compared to less than 10 per year up to 1980 . The city predicts as many as 180 of these nuisance flood days per year by 2045 (City of Charleston, 2015). In 2010, 39 percent (123 million people) of the U.S. population lived in coastal areas (Crossett and others, 2013). This represents a 40-percent increase from 1970 but is slightly lower than the overall U.S. growth rate during this period. The U.S. coastal population was expected to add an additional 8 percent by the 2020 census. In addition to presenting an existential threat to human wellbeing (safety, transportation and energy infrastructure, and military installations), increases in global mean sea level (GMSL) are substantially affecting coastal ecosystems and the supporting goods and services they provide for humans and wildlife, including provisioning services (habitat for waterfowl and endangered species, timber and sweetgrass, and water), regulating services (flood control, water and air quality regulating, and carbon storage), and cultural services (recreation, heritage values, and subsistence livelihoods). Coastal fresh and saltwater wetlands contribute substantially to these services but are at risk of converting to open water if unable to accrete sediment fast enough to keep pace with SLR. Upland habitat may be able to transition into wetlands as sea levels rise, but wetland and upland habitats may be lost if either are blocked from migrating to higher elevations (Shellenbarger Jones and others, 2009).

Identifying adaptation decision strategies in response to current and future SLR was a primary motivation for forming a partnership between the U.S. Geological Survey and the South Carolina Lowcountry Refuges Complex. SLR at Cape Romain NWR has already resulted in loss of infrastructure (for example, impoundments) to support migratory waterfowl; a reduction of nesting habitat for endangered shorebirds and Caretta caretta (Linnaeus, 1758) (loggerhead sea turtle) populations through erosion of barrier islands and beach loss (see chap. C.3); and degradation or loss of other critical habitats such as tidal and freshwater marsh, maritime forest, and Carolina Bays. Such visible changes are largely structural in nature and may belie underlying functional changes to important processes such as altered hydrological dynamics or nutrient cycling (Shellenbarger Jones and others, 2009). Above global average SLR on the south Atlantic coast, which is of similar concern to other partners engaged with the Cape Romain Partnership for Coastal Protection, local residents, and visitors to the complex, is threatening traditional managed wetlands (for example, rice fields), local transportation infrastructure, private property, and recreational access and opportunities. Here, we provide a brief overview of the physical conditions and habitats at risk in the South Carolina Lowcountry followed by a summary of the latest SLR trends and forecasts tailored to the Cape Romain region. We have used these forecasts, projected to 2050, to support other activities under this project including scenario-planning engagement (chap. D), assessment of the magnified effects of coastal storm surge (chap. B.2), conservation reserve design based on uncertainty about future habitat composition (chap. F), and modeling of specific ecosystem goods and services (for example, oyster reef structure and distribution; app. 3).

\section{B.1.2. Physical Environment and Habitats}

The low-lying South Carolina coast is characterized by dynamic landforms and habitats that are subject to natural processes of flooding, erosion, habitat succession, and barrier island modification. The ecosystem has evolved to adapt under these naturally occurring dynamic conditions, a process characterized by the term "living shorelines." A proliferation of human infrastructure (built environment, transportation networks, and hydrologic modifications) along the southeast coastline alters or impedes many of these dynamic processes. This infrastructure, which in most cases was not designed to cope with a dynamic coastline, is also highly vulnerable to SLR, hurricanes, and extreme fluctuations in water availability. About 1.2 million inhabitants live in 8 Counties that compose South Carolina's 305 linear kilometers of coastline (fig. A2). The coastal shoreline, when including bays, island, coastal creeks, and other features, represents more than 4,500 kilometers of unique and important habitats and ecosystem which, in turn, support vast numbers of ecologically and economically important species of birds, fishes, and other wildlife. These habitats include low-lying freshwater hammocks, salt and brackish wetlands and marsh, beach dunes and barrier islands, maritime forest, estuarine flats, as well as managed habitats such as rice fields and wetland impoundments. Tidal salt marshes, for example, are considered the most productive habitats in the world (Teal, 1986).

South Carolina's habitats and the natural resources they produce are the foundation of the State's history and economy, including major manufacturing (forestry and 
fisheries) and nonmanufacturing (tourism and recreation) sectors of the economy. Tropical storms, hurricanes, and SLR threaten human infrastructure and coastal habitats on which humans and wildlife depend. An area of 2,100 square kilometers of coastal land near the city of Charleston is less than 1.2 meters above the mean high-water mark (Runkle and others, 2017), which illustrates the direct threat to human infrastructure and safety. Critical wildlife habitat is similarly at risk. An estimated 2,333 square meters of South Carolina's coast is vulnerable to a SLR of 1.5 meters (von Lehe, 2008). Hammocks that provide freshwater to birds, amphibians, and sensitive life stages of some fishes are typically low lying (less than 0.3 meter) and exposed to saltwater intrusion from storm overwash and SLR. Slow-growing maritime forests may be limited in their ability to retreat at the rate of SLR and are being lost to drowning at an alarming speed. Barrier islands and beach dunes are eroding faster than they can retreat or be replenished, resulting in loss of nesting sites for loggerhead sea turtles and shorebirds. Salt marsh, estuarine flats, and other nearshore habitat may not have sufficient space or time to migrate landward, or sufficient sediment input to maintain appropriate elevation, risking conversion to open water and threatening critical nursing and foraging habitat for major fisheries including shrimp, crab, and numerous inshore fish species (South Carolina Department of Natural Resources, 2013).

\section{B.1.3. Sea-Level Rise-Trends and Forecasts}

\section{B.1.3.1. Climate Change and Sea-Level Rise}

Increasing atmospheric concentrations of greenhouse gases, whether human contributed or not, are warming the atmosphere and the oceans. In the southeastern United States, warming trends are contributing to increases in extreme rainfall events, as well as longer and more frequent summer heat waves (Carter and others, 2018). Changes in GMSL are largely driven by these changing global temperatures, which affect thermal expansion of ocean water and increase ocean volume through loss from glaciers, ice caps, and ice sheets. Relative sea levels can also be strongly affected by subsidence from groundwater and hydrocarbon extraction (Kirwan and Megonigal, 2013) and, to a lesser degree, by continental movement (isostatic adjustments) and accretionary processes. Local sea level dynamics can differ significantly from global means, suggesting that adaptation planning for future changes at a local level cannot reliably assume that local conditions will precisely follow global projections. This spatial variation in local SLR is because of heterogeneity in ocean dynamics, heat and salinity distribution, differences in earth gravitational field, isostatic adjustment, and vertical land movement caused by tectonic activity, groundwater depletion, and sediment transport (Kopp and others, 2014). Variation in local geomorphology can also produce fine-scale differences in SLR, necessitating localized impact assessments.

\section{B.1.3.2. Historical Trends}

The most recent U.S. and international assessments of climate change indicate that GMSL has risen an average of 1.4 millimeters per year during the 20th century, a rate faster than any time in the past three millennia (Sweet and others, 2017). This translates to about 0.3 meter of relative SLR, on average, over the past 100 years. In comparison, changes in local sea levels at Charleston, South Carolina, have occurred at a rate of 3.28 millimeters per year (plus or minus 0.14 millimeter) over this same period, or nearly double the global average. The mean annual rate of SLR in the southeastern United States for 2004-50 is projected to more than double the past observed rate at 7.2 millimeters per year (plus or minus 2.3 millimeters) (Horton and Bader, 2014). This difference in the rate of relative SLR in the mid-Atlantic and Gulf of Mexico is believed to be caused by localized land subsidence from tectonic dynamics and high rates of water and hydrocarbon withdrawal (Williams and others, 2009).

\section{B.1.3.3. Future Predictions and Scenarios}

Given the uncertainties about future global emissions and ice melt, GMSL is projected to rise an additional 0.3 to 2.5 meters by 2100 (Sweet and others, 2017). Projections of mean global SLR, however, are not likely of sufficient precision at the local level to make well-informed adaptation planning decisions. The U.S. Geological Survey Southeast Climate Adaptation Science Center commissioned a study by climatologists at Columbia University to develop SLR projections for Cape Romain, S.C., in support of this project (Horton and Bader, 2014). Projections are based on calculations derived for four primary input variables driving ocean height relative to coastal elevation (Kopp and others, 2014). These elements include the following:

1. Thermal expansion of oceans as a function of heat absorption and global atmospheric temperatures (Coupled Model Intercomparison Project Phase 5, called "CMIP5”). Global thermal expansion is translated to a local change in ocean height at the scale of 1 degree latitude.

2. Water addition to oceans estimated as ice melt from the Greenland Ice Sheet, East and West Antarctic Ice Sheets, glaciers, and Arctic ice caps as a function of global atmospheric temperatures. Local effects of global ice loss were calculated considering gravitational, isostatic, and earth rotational effects.

3. Reduction in sea level as a function of global terrestrial water storage (impoundments) and contributions to SLR from unsustainable groundwater extraction.

4. Vertical land movement (geostatic rebound) estimated for Charleston, S.C. 
Table B1. Projected sea-level rise for the Cape Romain region of South Carolina.

\begin{tabular}{lccc}
\hline \multirow{2}{*}{ Decade } & \multicolumn{3}{c}{ Projected sea-level rise, in millimeters } \\
\cline { 2 - 4 } & $\begin{array}{c}\text { Low-estimate } \\
\text { (10th } \\
\text { percentile) }\end{array}$ & $\begin{array}{c}\text { Middle range } \\
\text { (25th to 75th } \\
\text { percentile) }\end{array}$ & $\begin{array}{c}\text { High- } \\
\text { estimate (90th } \\
\text { percentile) }\end{array}$ \\
\hline 2020s & 51 & 76 to 152 & 203 \\
2050s & 152 & 229 to 432 & 635 \\
2080s & 254 & 381 to 838 & 1,245 \\
\hline
\end{tabular}

Models projections were derived using these components from 24 global circulation models and multiple representative concentration pathways (greenhouse gas concentration scenarios). Projections are relative to the 2000-4 baseline sea level and generated over 10-year intervals. Estimates of local SLR for decades 2020, 2050, and 2080 are expressed as the 10th, the middle 50th (25th to 75th), and the 90th percentiles of the aggregate probability distributions of model components (table B1; Horton and Bader, 2014).

\section{B.1.3.4. Application of Sea-Level Rise Projections to Project Components and Output}

For many of the modeling applications undertaken for this project, including spatial conservation planning, scenario planning, and the combined effects of SLR and storm surge, we selected a planning horizon of 2050 for which to evaluate the effects of SLR on sustainability of values in the South Carolina Lowcountry. To develop scenarios of SLR and their associated probabilities from the estimates produced by the Horton-Bader model (Horton and Bader, 2014), we had to convert the relevant confidence intervals from a continuous distribution model into values and probabilities associated with discrete points. To do so, we used numerical integration (quadrature) to find approximations of the area under the distribution curve to represent discrete SLR values and their associated probabilities of occurrence. Once we calculated these values, we then had to match these to published SLR estimates incorporated into available modeling tools used in other applications of the project. For developing scenarioplanning exercises and quantifying habitat changes under different possible futures, we matched the discretized 10th, 50th, and 90th percentiles of vertical sea level to the closest emissions scenario and year combination documented in the Sea Level Affecting Marshes Model (called "SLAMM," Warren Pinnacle Consulting, Inc., Waitsfield, Vermont). Emission scenarios, relative SLR, and their probabilities from this exercise are provided in table B2.
Table B2. Conversion of year 2050 sea-level rise estimates for the Cape Romain region, South Carolina, to closely matched emission scenarios used in the Sea Level Affecting Marshes Model for land-cover change effects.

[SLAMM, Sea Level Affecting Marshes Model]

\begin{tabular}{lcccc}
\hline \multirow{2}{*}{$\begin{array}{c}\text { SLAMM } \\
\text { emission } \\
\text { scenario }\end{array}$} & Year & \multicolumn{2}{c}{$\begin{array}{c}\text { Sea-level rise, in } \\
\text { centimeters }\end{array}$} & \\
\cline { 3 - 4 } Probability & Quadrature & SLAMM & \\
\hline A2 & 2020 & 12.88 & 18.31 & 0.167 \\
B1 & 2040 & 31.37 & 31.42 & 0.667 \\
B1 & 2100 & 78.33 & 77.37 & 0.167 \\
\hline
\end{tabular}

\section{B.2. Tropical Storms}

Storms and storm-related wave action and flooding have had substantial effects on the natural resources of Cape Romain National Wildlife Refuge (NWR) and on humans within the region (U.S. Fish and Wildlife Service, 2010). Negative impacts to natural resources include severe erosion of beaches and dunes, loss of nests of sea turtles and shorebirds, loss of coastal habitat, loss of maritime forests, overwashing of coastal dunes, and burial of salt marsh. Negative effects on humans include loss of life, loss of homes and infrastructure, wind damage, flood damage caused by storm surge, rainfall, river overflows, excessive runoff, and disruptions caused by evacuation of thousands of residents. Severe losses to forestry and agricultural resources also have occurred. In this section, storm surge and coastal flooding associated with hurricanes are discussed, along with potential interactions with SLR. The section that follows discusses how storms may affect coastal erosion and the barrier islands.

\section{B.2.1. Background and Trends in Storm Records and Storm Surge}

Substantial effects to Cape Romain NWR are caused by storms that lead to coastal flooding from storm surge, which can be defined as the increase in observed water depths beyond what is expected from predicted tidal levels. Storm surge and hurricanes have been the subject of extensive research because of their importance to human safety and economic costs. The frequency, strength, and tracks of hurricanes and tropical storms have been officially recorded since 1851 for southeast South Carolina and northern coastal Georgia, with unofficial records extending back to 1686 (National Weather Service [NWS], 2020). NWS (2020) provides a narrative description for each recorded storm in the study area. A series of maps showing tropical storms affecting the Cape Romain region for each decade (1910 through 2009) are provided in appendix 1. NWS generated a simple histogram showing frequencies of tropical cyclones from different storm categories affecting the study area (fig. B1). The maps and 


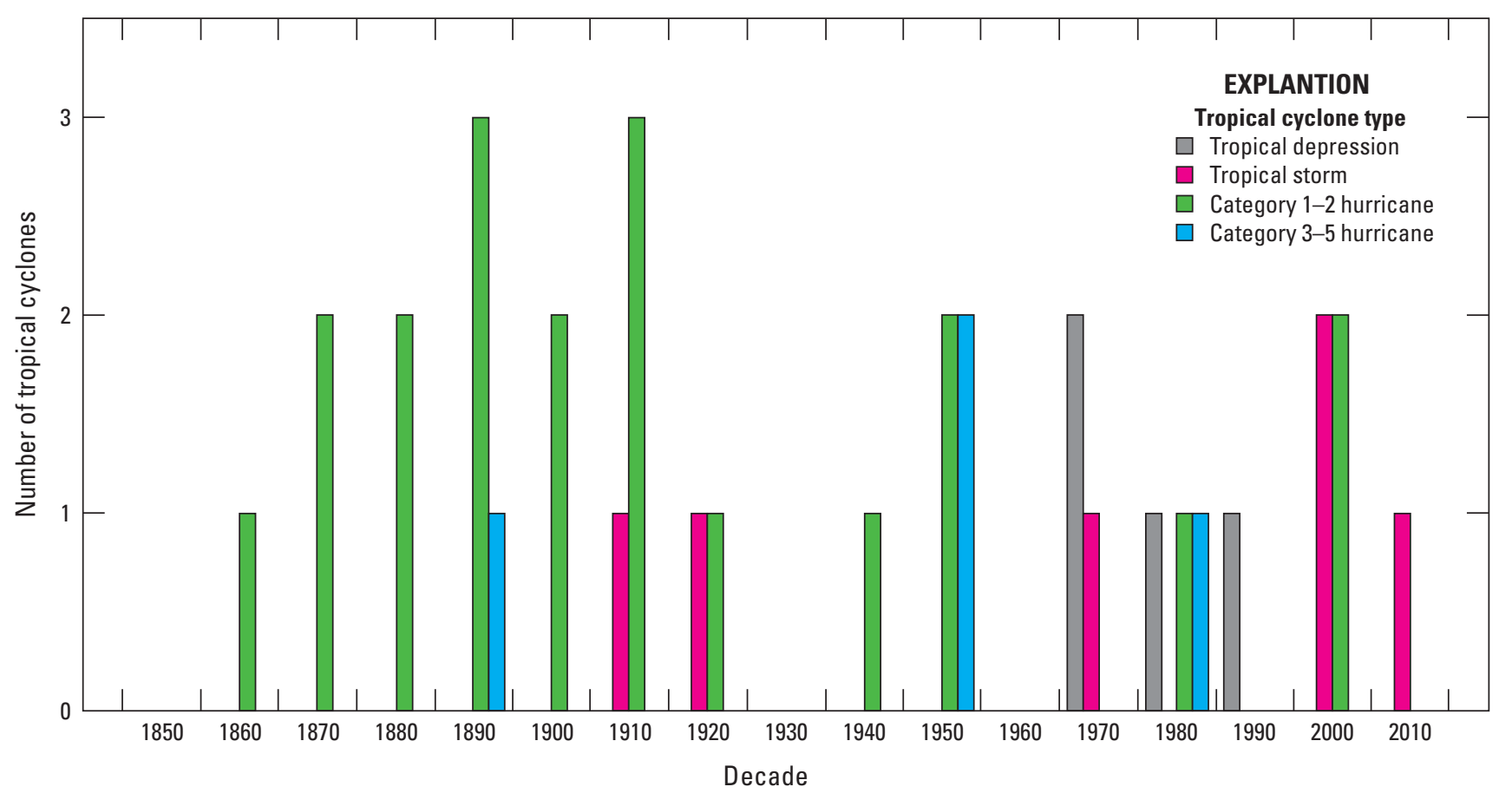

Figure B1. Histogram of tropical cyclone history that made landfall on southeast South Carolina and northern parts of southeast Georgia, showing the number of tropical cyclones in each category: tropical depressions, tropical storms, category 1-2 hurricanes, and major hurricanes (categories 3-5), 1850s-2010s. Modified from National Weather Service (2020).

histogram suggest that multiple tropical force storms can be expected for any given decade, generally including at least one major hurricane. Myers (1975) estimated that hurricanes cross the South Carolina coast on average of once every 7 years.

The storm dataset for the Cape Romain NWR region is likely insufficient to analyze for trends in storm frequency or strength. Analyses of larger datasets that encompass the entire Atlantic Basin seem more promising, but climate researchers at the National Oceanic and Atmospheric Administration's (NOAA's) Geophysical Fluid Dynamics Laboratory have concluded (see also Knutson and others, 2010) that the Atlantic Basin hurricane data indicate strong multidecadal periods of high and low storm activity that are consistent with changing phases of the Atlantic Multi-decadal Oscillation, rather than being correlated with well-documented increasing trends in sea surface temperatures. They suggest that the existing data have too much variability to allow for statistical detection of an increasing trend in number or intensity of hurricanes. They advocate greater reliance on model projections; the Geophysical Fluid Dynamics Laboratory model suggests an increase in the frequency of the strongest hurricanes in the Atlantic, roughly by a factor of two by the end of the century, despite a decrease in overall number of hurricanes (Bender and others, 2010).

Considerable information exists for individual storms and their impacts on humans and natural resources in the area. Hurricane Hugo, which made landfall just southwest of Cape Romain NWR with sustained wind speeds in excess of 135 miles per hour, is particularly noteworthy for its direct track through the study area. Hugo's effects on human infrastructure were deadly (50 deaths in the Carolinas) and extremely costly, estimated at $\$ 6$ billion ( $\$ 500$ million for flooding; $\$ 1.2$ billion for forestry and agriculture; $\$ 4$ billion for property; Sparks, 1991), and resulted in the evacuation of 256,000 people in South Carolina (Post, Buckley, Shuh and Jernigan, Inc., 1990) and 129,687 homes destroyed or damaged (Brennan, 1991). Hugo's effects on coastal and inland natural resources were massive, resulting for example in extensive forest damage of 4.5 million acres in South Carolina (Sheffield and Thompson, 1992) and the destruction of important maritime forests (Helm and others, 1991). Even though Hugo was a fast-moving storm, the effects on the barrier islands of Cape Romain NWR were large, resulting in erosion of already regressive beaches (for example, Raccoon Key) by 20-25 meters, the dissection of islands and formation of new tidal inlets, extensive dune flattening and erosion by 90-180 meters, and broadening of washover terraces (Sexton and Hayes, 1991).

Lesser storms, such as hurricane Matthew in 2016, which passed offshore of Cape Romain NWR as a category 2 hurricane, had substantial impacts on the barrier islands, resulting in the destruction of nests of federally listed species of sea turtles and shorebirds at Cape Romain NWR (S. Dawsey, USFWS, oral commun.).

Although hurricanes may be a major source of storm surge and flooding, severe winter storms known as northeasters can have comparable impacts on the South Carolina coast (Hirsch and others, 2001). Sweet and Zervas (2011) 
determined that the highest number of storm surges (greater than 0.3 meter) at Charleston, S.C. (and other Atlantic stations) occurred because of cool season storms (October-April) compared to warm season storms. During 1960-2010, Sweet and Zervas (2011) determined an average of three cool season storm surges per year for Charleston. Some researchers (for example, Hirsch and others, 2001) have found evidence that these extratropical winter storms are increasing in frequency over time.

\section{B.2.2. Modeling Storm Surge and Interactions with Sea-Level Rise}

A useful tool for visualizing how tropical storms may affect the South Carolina coast is the Sea, Lake, and Overland Surges from Hurricanes (SLOSH) model (NOAA, 2008). The SLOSH model provides the capability to view maps showing how storm surge could inundate coastal areas when subjected to any of the five major categories of hurricanes (based on the Saffir-Simpson hurricane wind scale). The SLOSH model has been run for a series of subbasins along the U.S. coast; the Charlotte, S.C., subbasin model covers a large subregion that includes Cape Romain NWR and the study area. The SLOSH model results provide a maximum stormwater height at each grid cell location from a composite of thousands of different simulated hurricanes with varying storm radii, forward speed, landfall location, angle of approach to the shoreline, and other factors.

A series of three SLOSH maps for hurricane categories 1,3 , and 5 are presented for the study area in figures B2, B3, and B4, respectively. To properly interpret the SLOSH maps, it is important to consider that the modeled inundation depths do not depict the expected storm surge from a single storm of a given category. Rather, the depth values represent the maximum inundation depth at each location based on thousands of simulated storms with different hypothetical trajectories and landfall locations within the Charleston subbasin, providing an upper threshold or worst-case scenario estimate of inundation throughout the entire basin. The SLOSH maps show what could be expected for a particular area experiencing the full brunt of a specific category of hurricane. For example, figure B2 indicates that the barrier islands and salt marshes of Cape Romain NWR would likely be completely inundated if the area was subjected to the full impacts of a category 1 storm.

Note that the SLOSH model does not include effects associated with storm-related wave action, or flooding due to heavy rainfall or river flooding, which would likely increase the inundation depths. Additionally, the SLOSH model assumes, as an initial condition, that sea levels are at mean high water tides; inundation would be worse under higher tide conditions (for example, mean higher high water or "King" tides). In addition to the composite maps generated from hundreds of simulated hurricanes, the SLOSH model can be run for a single hurricane track. An evaluation of the SLOSH model predictions at Bulls Bay in Cape Romain NWR, near where the eye of hurricane Hugo made landfall (Post, Buckley, Shuh and Jernigan, Inc., 1990), indicated that the observed high-water marks from field reports were extremely close to those predicted by the SLOSH model (fig. B5). The storm tide peaked at about 20 feet above sea level near McClellanville, S.C., with high-water elevations of 12 feet or more occurring as far as 80 miles away (Schuck-Kolben, 1990).

SLOSH model results are not currently available that account for different SLR scenarios. To investigate how SLR might interact with storm surge, we added SLR to the SLOSH model results and laterally extended the resulting area of inundation based on an underlying digital elevation model. The method used a simplistic extension of the so-called bathtub geographic information system approach, similar to methods used by previous researchers (Tate and Frazier, 2013; Frazier and others, 2010). In general, the results indicate a relatively small effect of SLR when added to the inundation associated with storm surge. This is likely due to the much larger depths associated with storm surge even for a category 1 hurricane, compared to SLR depths. For example, figure B6 shows inundation of the low elevation, low gradient coastal areas by storm surge, and inundation associated with SLR rise at 1 or 4 feet (highlighted for emphasis). The results from this simplistic approach might differ substantially from future simulations of the SLOSH model that use different SLR scenarios as an initial condition. 


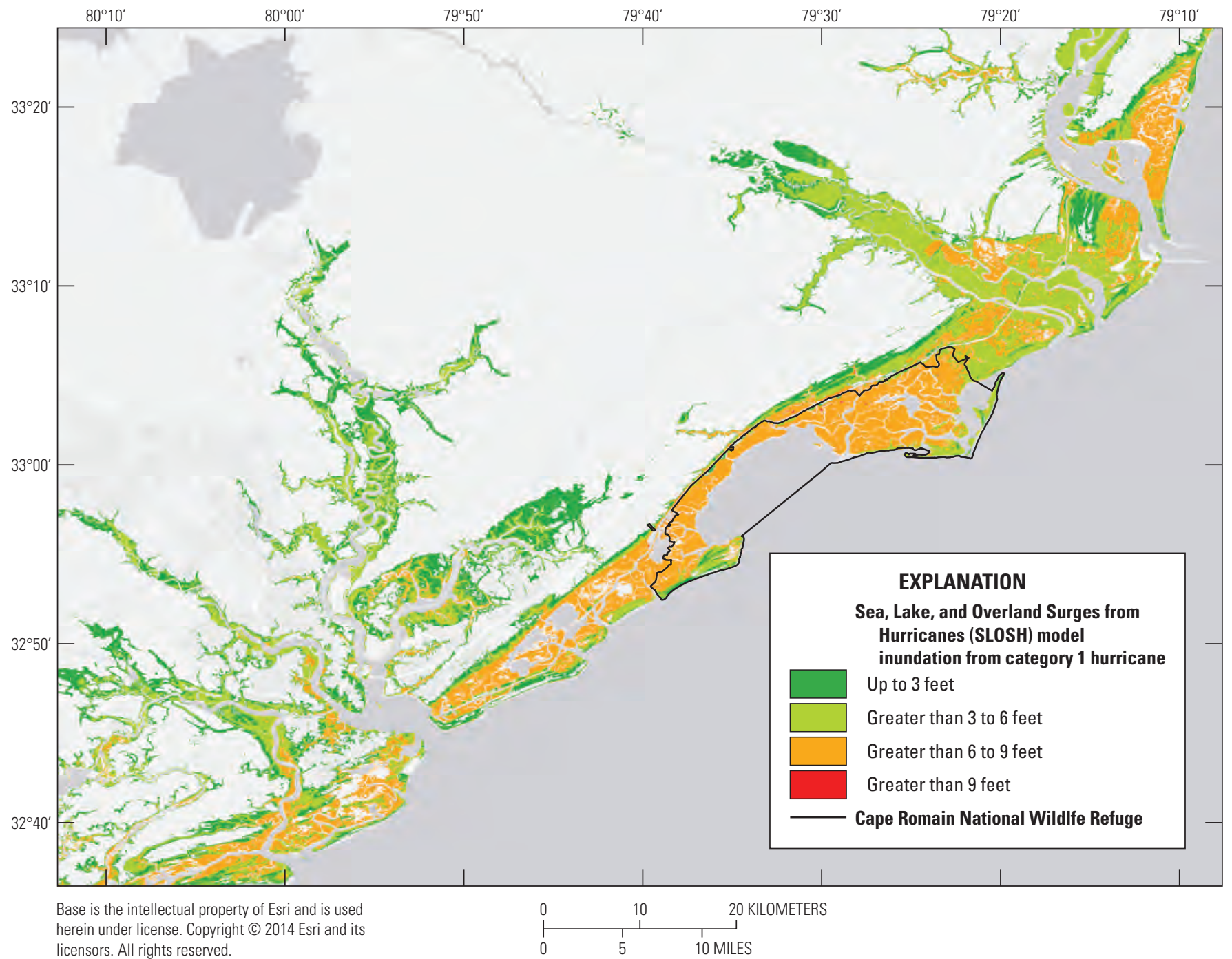

Figure B2. Inundation depths of land subject to category 1 hurricanes as modeled by the Sea, Lake, and Overland Surges from Hurricanes model. 


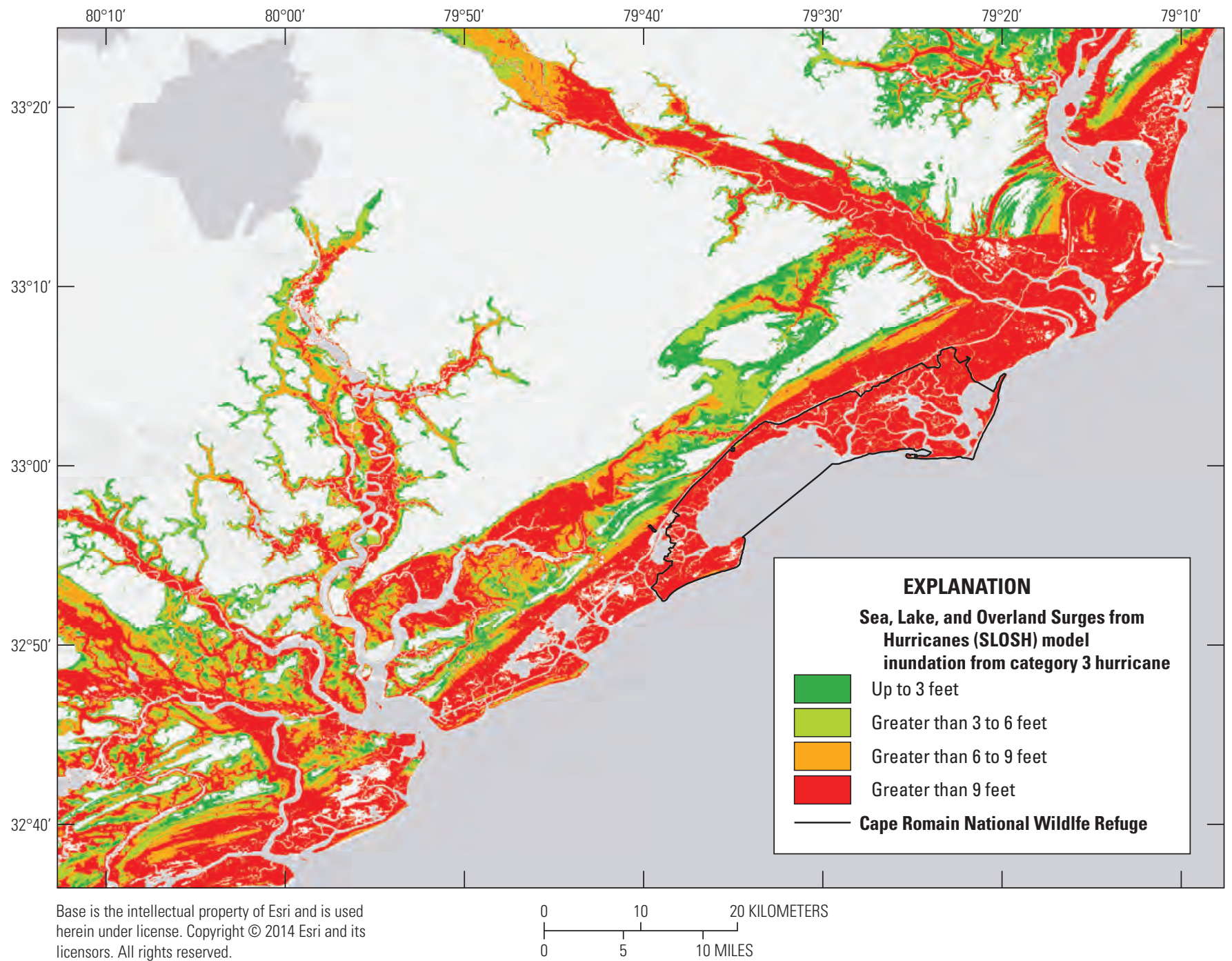

Figure B3. Inundation depths of land subject to category 3 hurricanes as modeled by the Sea, Lake, and Overland Surges from Hurricanes model. 


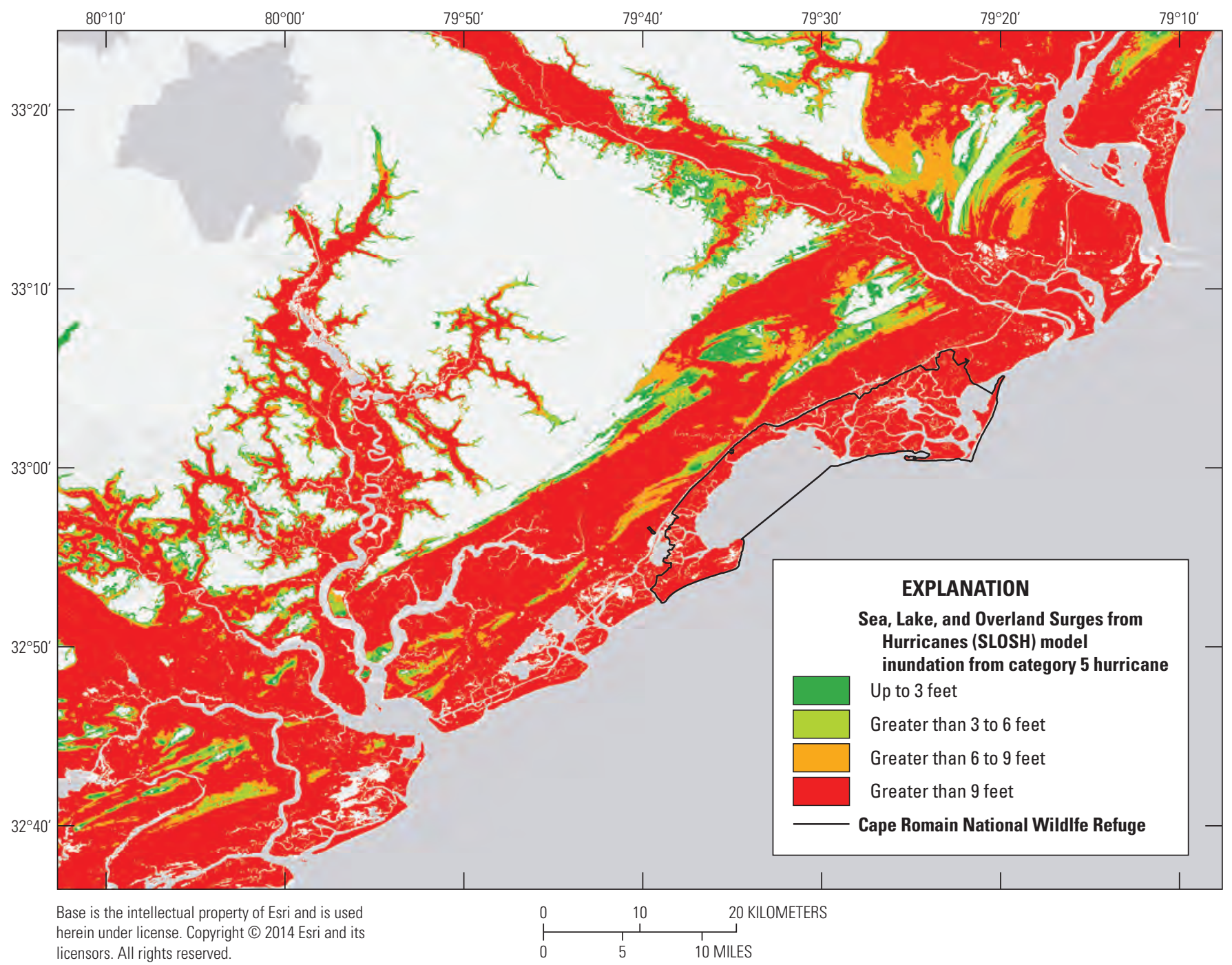

Figure B4. Inundation depths of land subject to category 5 hurricanes as modeled by the Sea, Lake, and Overland Surges from Hurricanes model. 


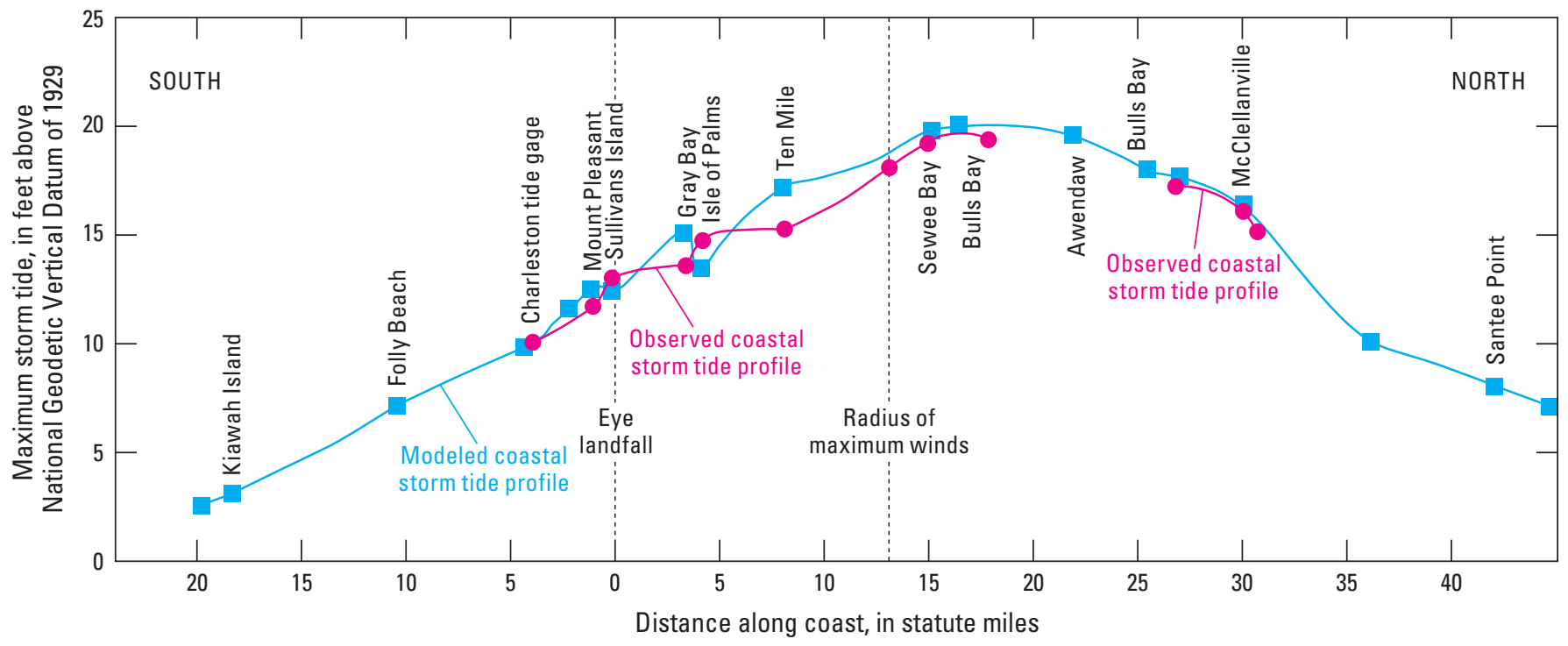

Figure B5. Maximum observed height of storm surge and forecast storm surge height (from the Sea, Lake, and Overland Surges from Hurricanes model) along the South Carolina coast for hurricane Hugo. Modified from Post, Buckley, Shuh and Jernigan, Inc. (1990); in the public domain. 


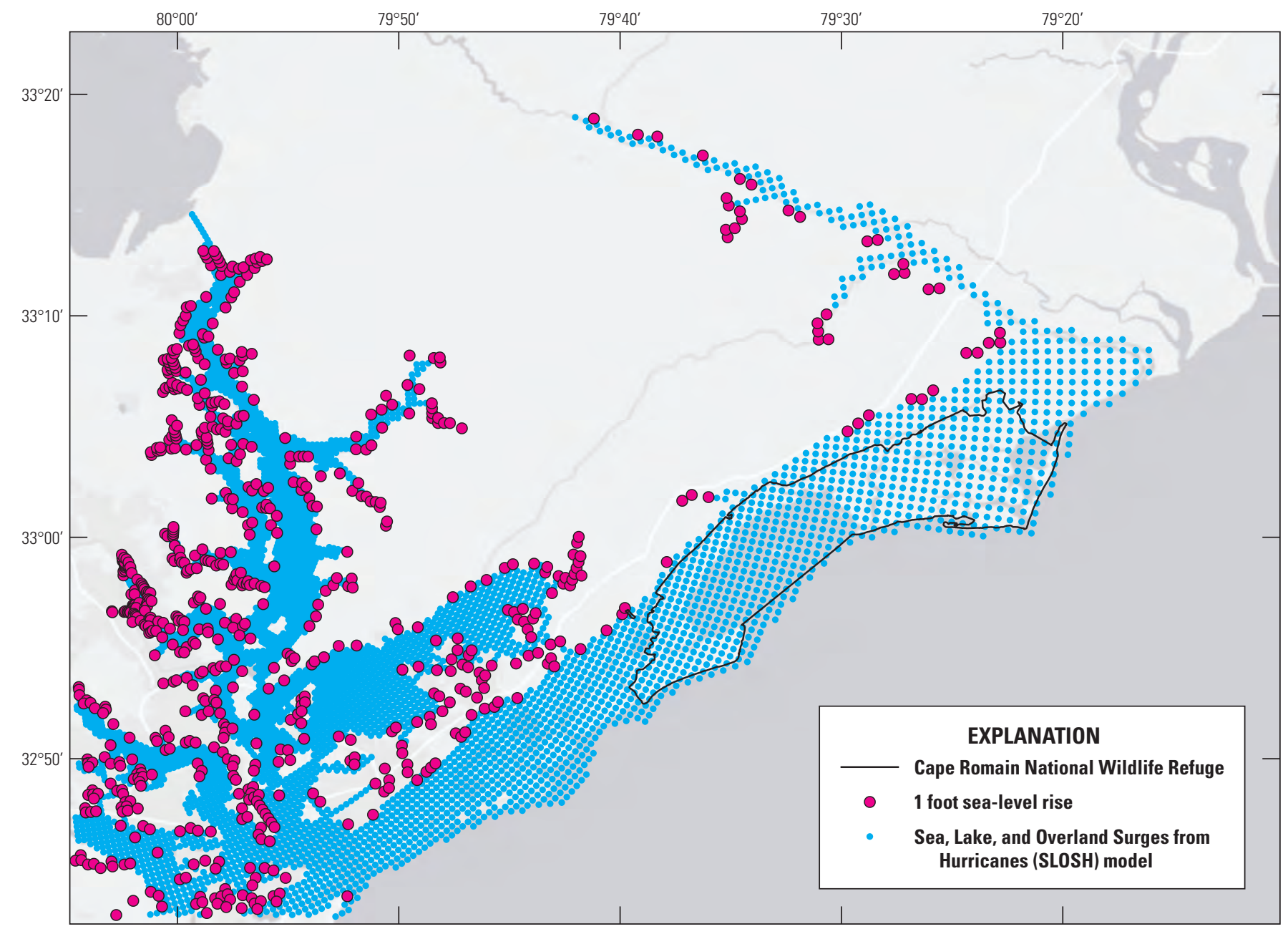

Base is the intellectual property of Esri and is used herein under license. Copyright (C) 2014 Esri and its licensors. All rights reserved.

1:400,000-scale digital data

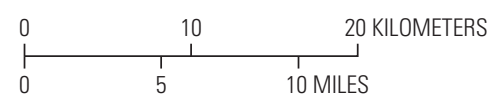

Figure B6. Additional Sea, Lake, and Overland Surges from Hurricanes model cells that would be inundated by 1 and 4 feet of sea-level rise for category 1 hurricane storm surge. 


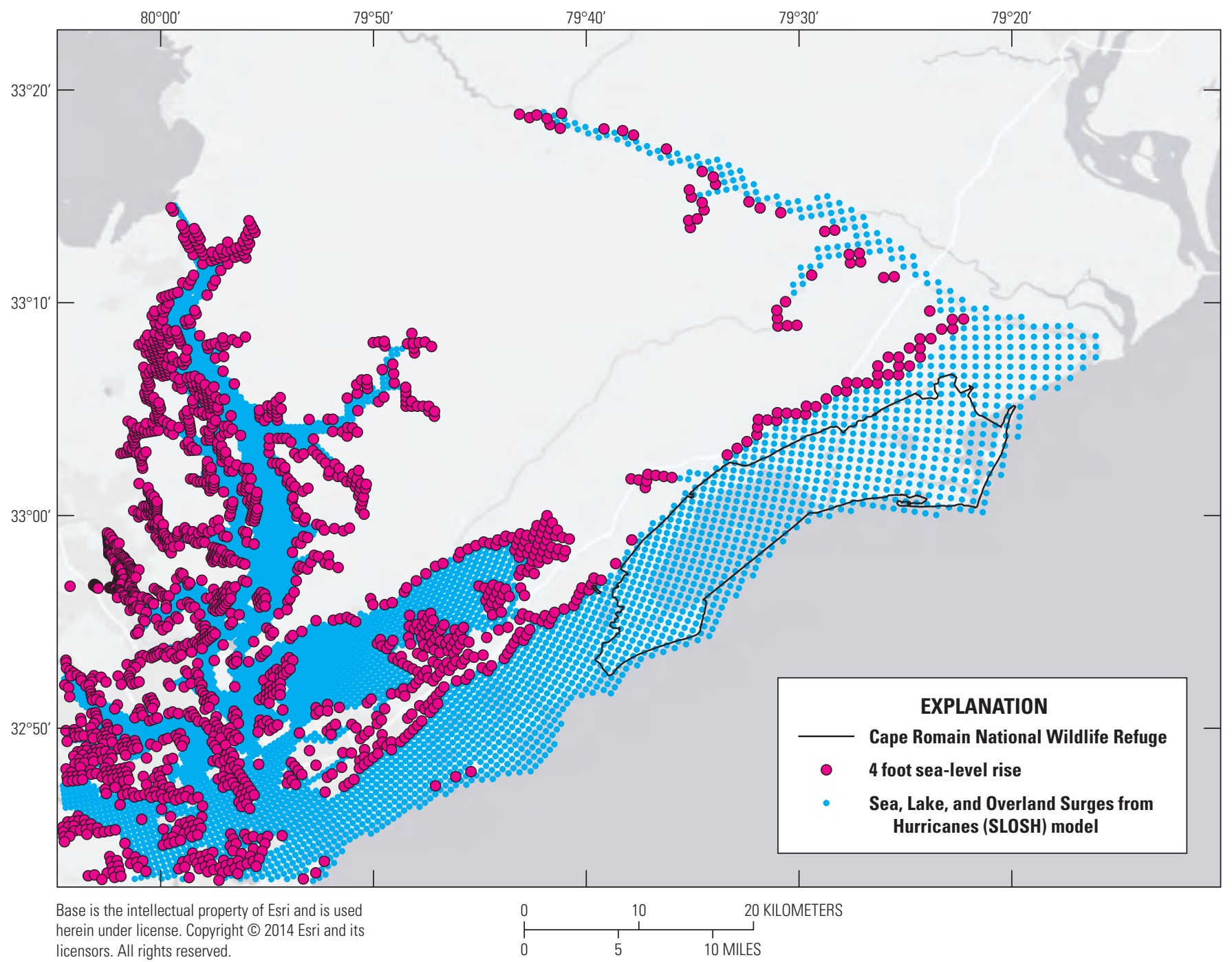

Figure B6.-Continued

\section{B.3. Barrier Islands}

Cape Romain NWR has the largest extent of undeveloped barrier islands along the South Carolina coast and one of the largest capes (fig. A3; U.S. Fish and Wildlife Service, 2010). The Cape Romain NWR barrier islands are generally described by geologists as being in an erosional state, transgressing shoreward in response to SLR (Hayes and Sexton, 1989). These barrier islands are important habitat for dozens of coastal species, including stop-over sites for many migratory shorebird species, most notably the Haematopus palliatus (Temminck, 1820) (American oystercatcher). The sandy beaches also provide nesting habitat for federally listed species, including loggerhead sea turtles and Charadrius melodus (Ord, 1824) (piping plover). The Cape Romain NWR barrier islands have the largest nest counts for loggerhead sea turtles anywhere north of Florida (U.S. Fish and Wildlife Service, 2010). The barrier islands also provide a protective environment for the development of extensive salt marsh habitat, which is absent from the unprotected and deeper waters of Bulls Bay (fig. A3).

Coastal erosion is a major concern in Cape Romain NWR and other coastal areas of South Carolina (U.S. Fish and Wildlife Service, 2010). The physical processes responsible for coastal erosion are complex, and the relative importance of different factors are difficult to measure. A regional and multidecadal perspective is generally needed to understand sediment sources and movements (Cash and Moser, 2000). Important factors include supply of river sediments from large drainage basins, sediment movement due to longshore transport from adjacent areas, sediment exchange between inlets and barrier islands, and erosion and movement between nearshore and onshore deposits (Barnhardt, 2009).

The duration, magnitude, and frequency of different storm types are key factors dictating the long-term sediment flux in the region (Barnhardt, 2009). Tropical cyclones 
generally drive sediments towards the southwest, whereas cold fronts and warm fronts generally drive sediments to the northeast. However, severe winter storms (northeasters), which can be 10 times larger than hurricanes in their spatial extent, affect the South Carolina coastline every year, producing strong winds that blow northeast to southwest. Hurricanes and northeasters produce the strongest winds that can cause extensive erosion. Hayes and others (1979) noted that storm surge is the primary agent of change and argued that, although hurricanes can produce large changes, a more substantial agent of shoreline change is northeasters because of their much higher frequency. Severe storms also can accentuate high tides, which may persist over multiple tidal cycles, resulting in extreme coastal flooding. Even unnamed storms of limited size or strength can have major effects on barrier islands via heavy wave action. Storm effects can result even if storms pass close to the coast without making landfall nearby. The effect of high waters is exacerbated by high waves created by the long fetches associated with offshore storms.

Hayes and Sexton (1989) described Cape Romain as a cuspate foreland retreating behind a submerged obstruction jutting prominently offshore. They suggested that the apparent greater submergence and retreat of this cape, compared to three more northerly capes in South Carolina, may be related to the more pronounced tectonic downwarp in the study area. They also summarized shoreline changes at Cape Romain and Raccoon Key measured by Stephens and others (1976) from six sets of aerial photos between 1941 and 1973 as showing a highly erosional shoreline retreating on average 6 meters per year, except at the distal ends where deposition was occurring.

Cape Romain NWR produced an analysis of coastal erosion for the principal islands in the NWR (fig. B7)—Bulls Island, Raccoon Key, Lighthouse Island, and Cape Island (Faustini and others, 2013). Aerial photography was used to identify barrier island shape and size between 1949 and 2011 (years available: 1949, 1954, 1963, 1979, 1989, 1994, 1999, 2006, 2007, 2010, and 2011), and historical coastal topographic surveys were used for 1875, 1929, and 1933. The coastal erosion analysis indicated that change in barrier island acreage was relatively small between 1875 and 1954 but indicated a stepwise loss of acreage thereafter (fig. B8). Three of four individual barrier islands show substantial losses of area (Bulls Island, fig. B9; Raccoon Key, fig. B10; Cape Island, fig. B11), with the exception being Lighthouse Island (fig. B12). The northern tip of Cape Island increased in acreage, which may be attributed to the loss of sand from its more southerly section (fig. B11) or proximity to the primary source of sediments from the Santee River (see fig. A2). Although most of the South Carolina coastline shows progressive southwestward deposition, associated with wave-driven longshore currents to the southwest (Hayes and Sexton, 1989), the presence of the large ebb-tidal Santee River delta probably results in wave diffraction, shifting current direction locally to the northwest where deposition is occurring on the north end of

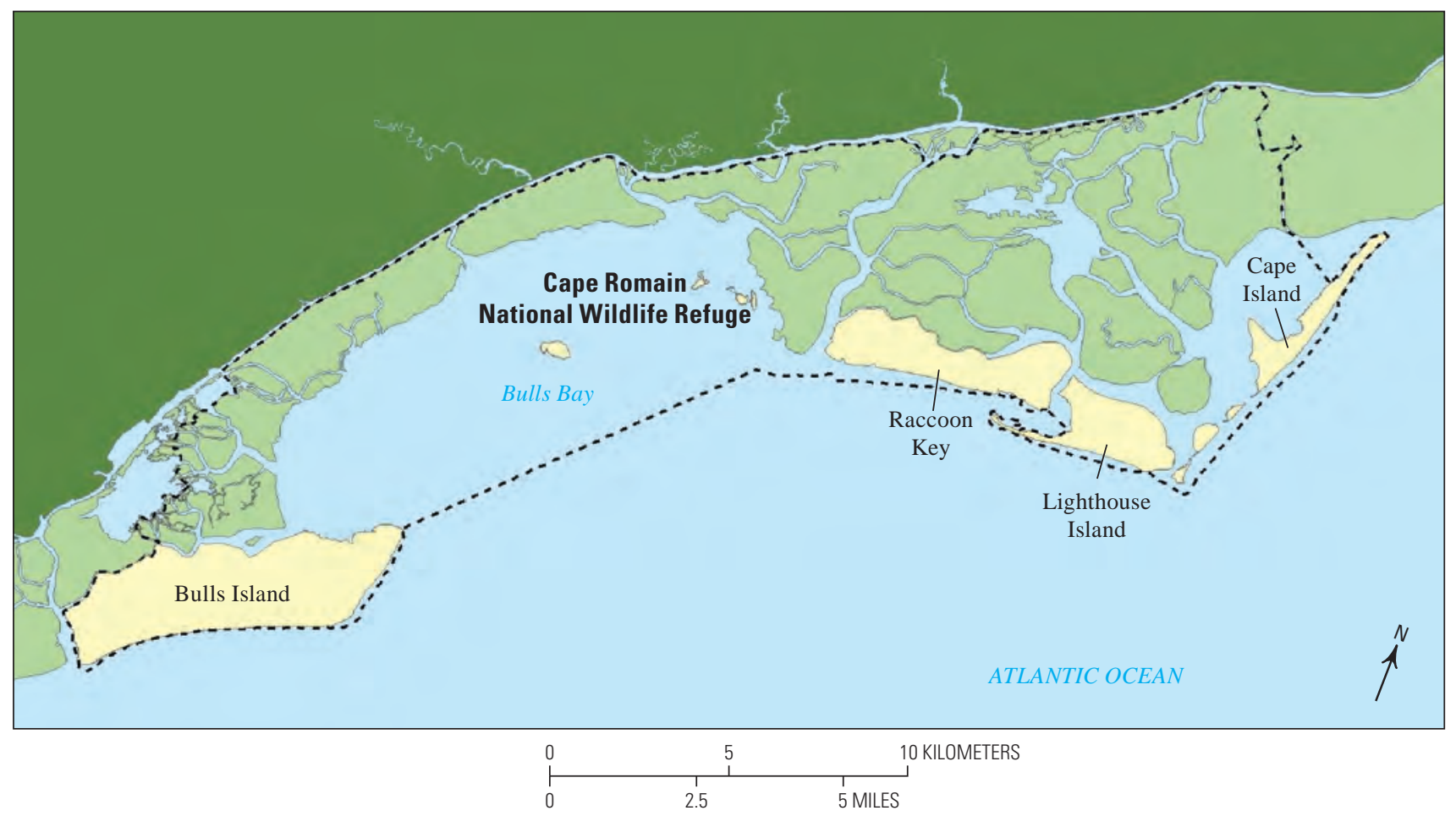

Figure B7. Four major islands (Bulls Island, Raccoon Key, Lighthouse Island, and Cape Island) that were analyzed for coastal erosion based on aerial photography and historical charts (1875-2011). Map is courtesy of Cape Romain National Wildlife Refuge; used with permission. 
Cape Island (fig. B13). By contrast, the southern part of Cape Island lost substantial acreage, which may have been captured by Lighthouse Island (directly down current from Cape Island; fig. B12).

Kana and others (2013) compared different sections of South Carolina beaches during 1980-2010 and determined that the wilderness beaches (including Cape Romain NWR) were generally eroding, whereas the developed beaches were stable or increasing. They characterized Cape Romain as sand-starved beaches rolling over the interior marsh or lagoon and concluded that SLR is a minor factor in the observed beach volume changes. They did not discuss possible future effects of increased rates of SLR and did not mention the role of damming on sediments, presumably because the sediment rate was not changed by damming during the study period.
They characterized Cape Romain NWR as undergoing high erosion because of limited new sand inputs, sand losses to the lagoon (lack of inlet bypassing), winnowing of muddy marsh deposits outcropping across the receding beach, and longshore transport losses to adjacent inlets. They identified Cape Island, Raccoon Key, and Bull Island as areas along the cape subject to breaches and washovers. The only areas of accretion occur at the northern tip of Cape Island and southern tip of Lighthouse Island, which are receiving sediment from the formerly connected central part of the two islands, which have experienced severe erosion.

Hayes and others (1979) described the northern barrier islands as part of the Santee River delta, the largest deltaic complex on the east coast of the United States. Washover terraces and truncated beach ridges provide evidence of rapid

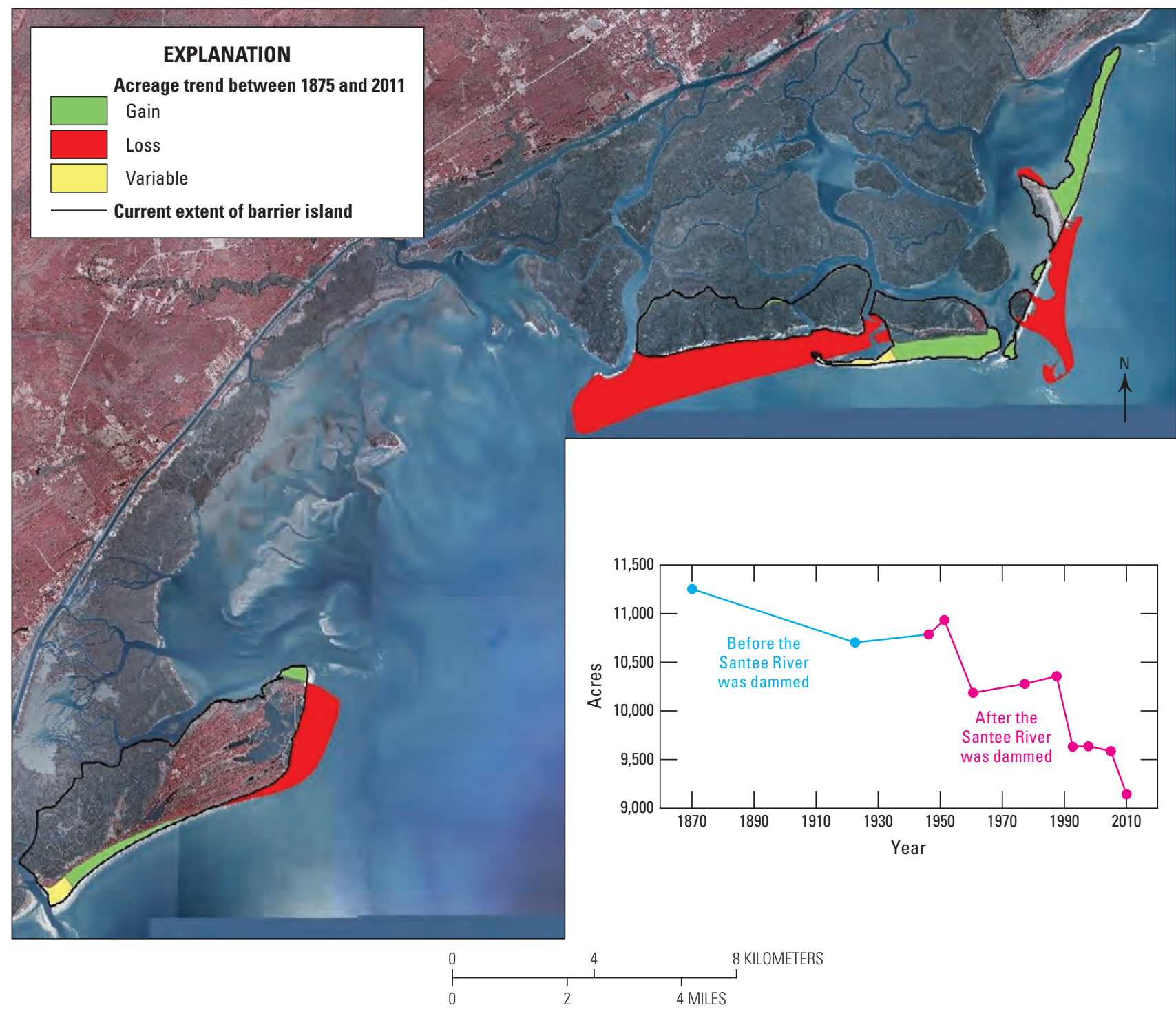

Figure B8. Losses and gains in island acreage between 1875 and 2011 for four barrier islands in Cape Romain National Wildlife Refuge. Inset graph shows overall trend for all acreage combined. Map is courtesy of Cape Romain National Wildlife Refuge; used with permission. 


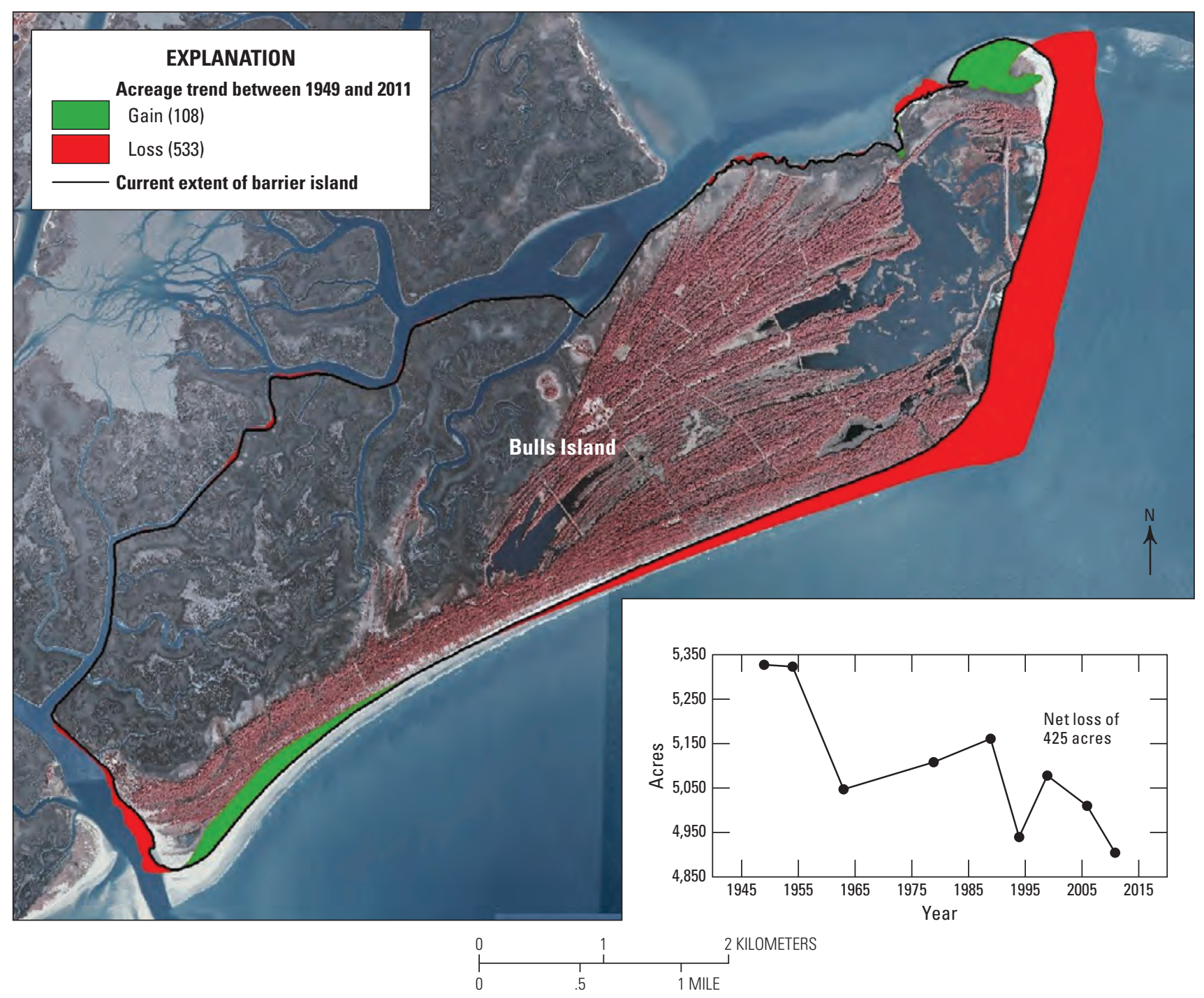

Figure B9. Losses and gains in island acreage between 1949 and 2011 for Bulls Island. Inset graph shows overall trend for island acreage. Map is courtesy of Cape Romain National Wildlife Refuge; used with permission.

shoreward movement or transgression. The sand of the delta complex was originally supplied by the Santee River, but erosion of the Santee delta complex has been related to the decreased sediment supply after damming of the Santee River in 1942 (Hayes and others, 1979). Stephens and others (1976) documented a series of dams that affected the Santee River Basin, starting with the first hydroelectric plant built in 1895 and ending with the Lake Marion Dam in 1942, and concluded that the reductions in discharge and reservoir trapping of sediments transformed the Santee River deltaic platform from a progradational to a regressive-stage delta.
McCarney-Castle and others (2010) estimated historic and recent coastal sediment flux from five South Carolina basins, including the Santee River and Pee Dee River Basins, using modeling and data for three historic periods (pre-European: 1680-1700, pre-dam: 1905-25, and postdam:1985-2005). The general pattern for the three periods indicated that sediment flux was highest during the pre-dam period (1905-25), when massive deforestation was occurring, which lead to accelerated soil erosion throughout the region. However, the Santee River had substantially reduced flux during the post-dam period (1985-2005) compared to 


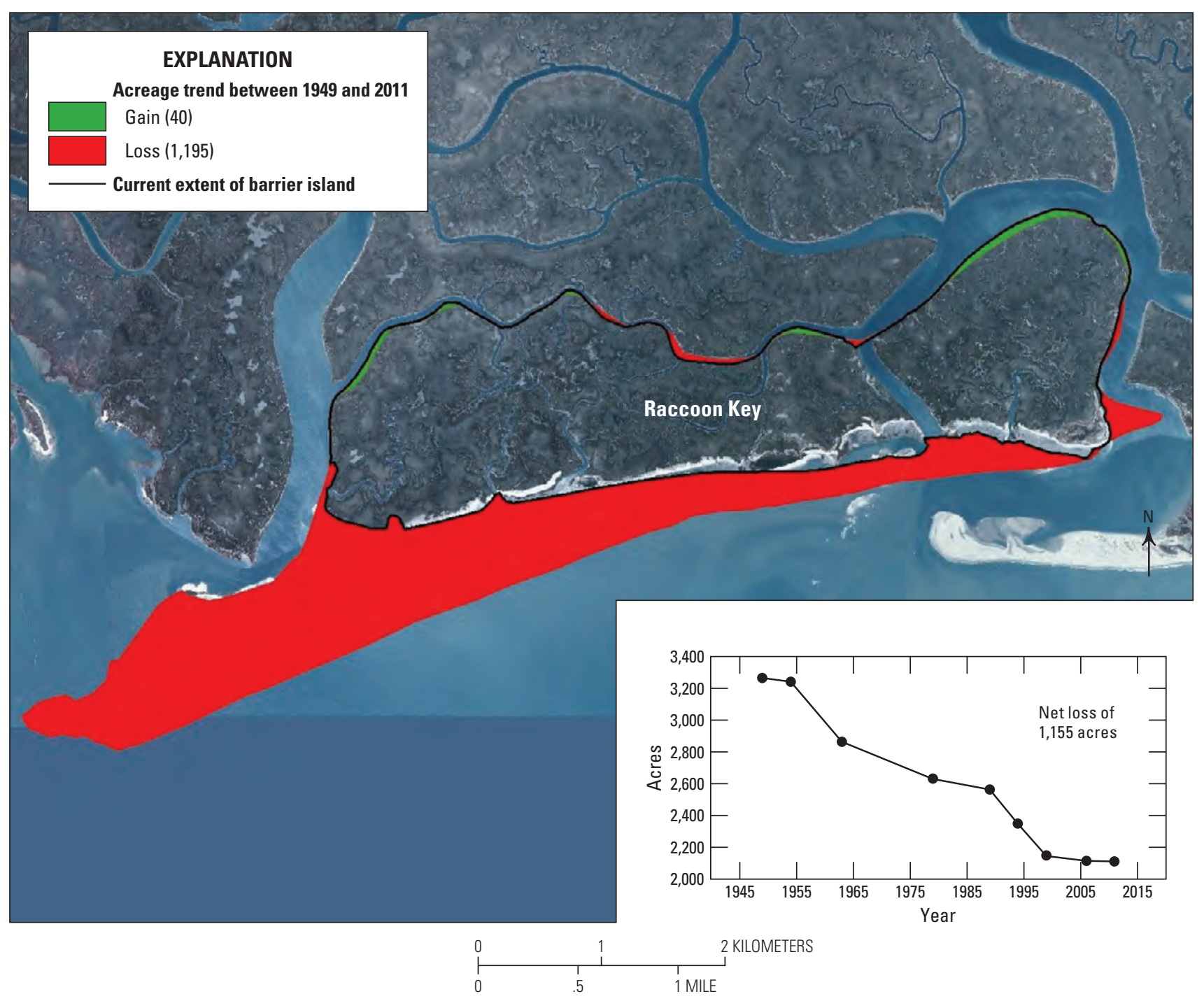

Figure B10. Losses and gains in island acreage between 1949 and 2011 for Raccoon Key. Inset graph shows overall trend for island acreage. Map is courtesy of Cape Romain National Wildlife Refuge; used with permission.

pre-European flux, a result they attributed to extensive dam construction and river diversion in the basin. Uncertainty remains about the importance of the reduced sediment input for maintaining barrier islands versus other sediment sources, but most authors seem to agree that damming has been a substantial factor.

Hughes and others (2009) documented a new pattern of tidal creek dissection of marshes within Cape Romain NWR that is suggestive of SLR effects caused by headward erosion of the marsh platform at a rapid rate. They suggested that the growth of tidal creeks is a manifestation of marsh accretion failing to keep pace with rapid SLR (locally 3.3 millimeters per year) and the increasing tidal prism. Their conclusions are consistent with the SLAMM, which forecasts the conversion of much of the marsh to open water (see chap. F.2). 


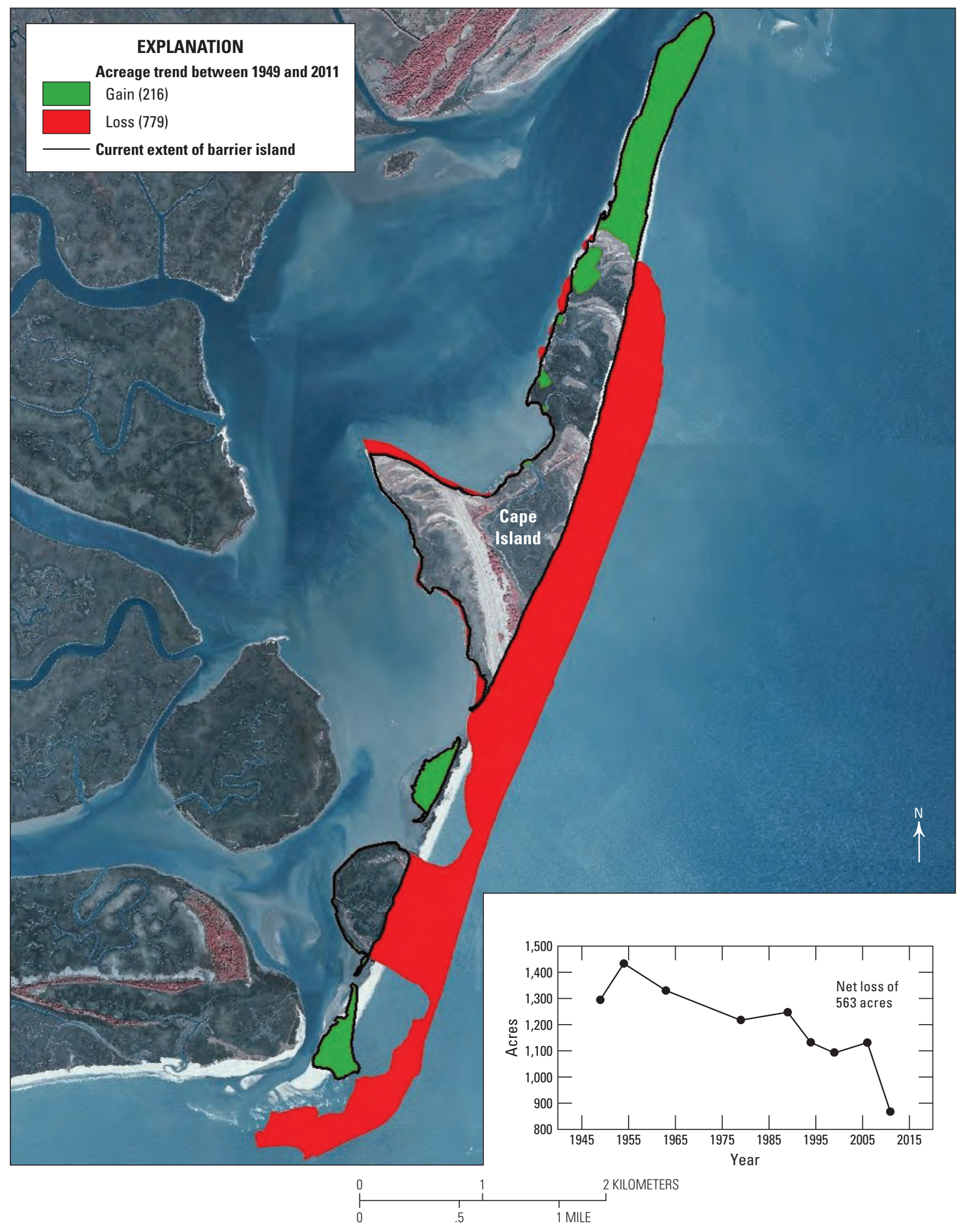

Figure B11. Losses and gains in island acreage between 1949 and 2011 for Cape Island. Inset graph shows overall trend for island acreage. Map is courtesy of Cape Romain National Wildlife Refuge; used with permission. 


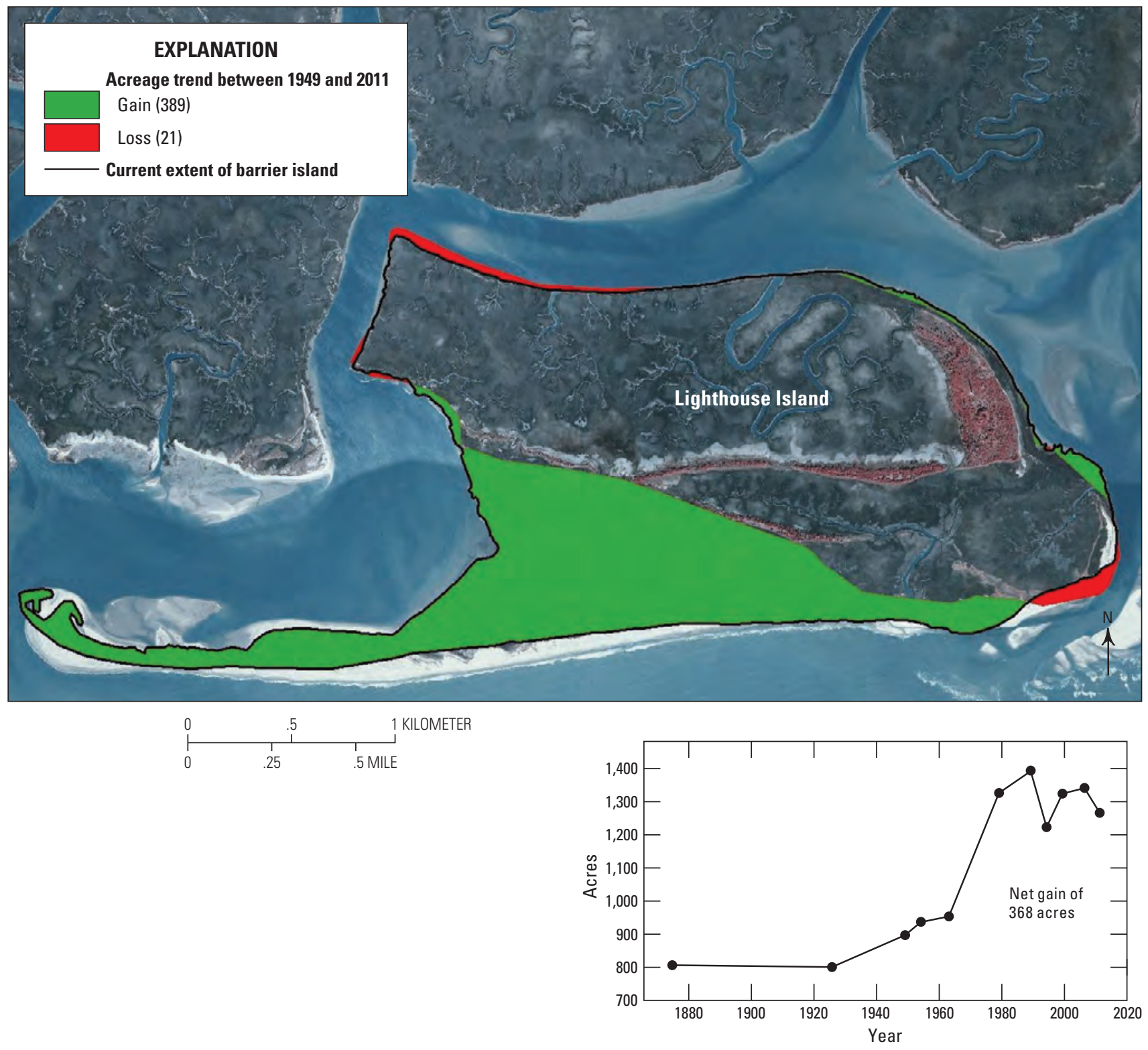

Figure B12. Losses and gains in island acreage between 1949 and 2011 for Lighthouse Island. Inset graph shows overall trend for island acreage beginning in 1875. Map is courtesy of Cape Romain National Wildlife Refuge; used with permission. 


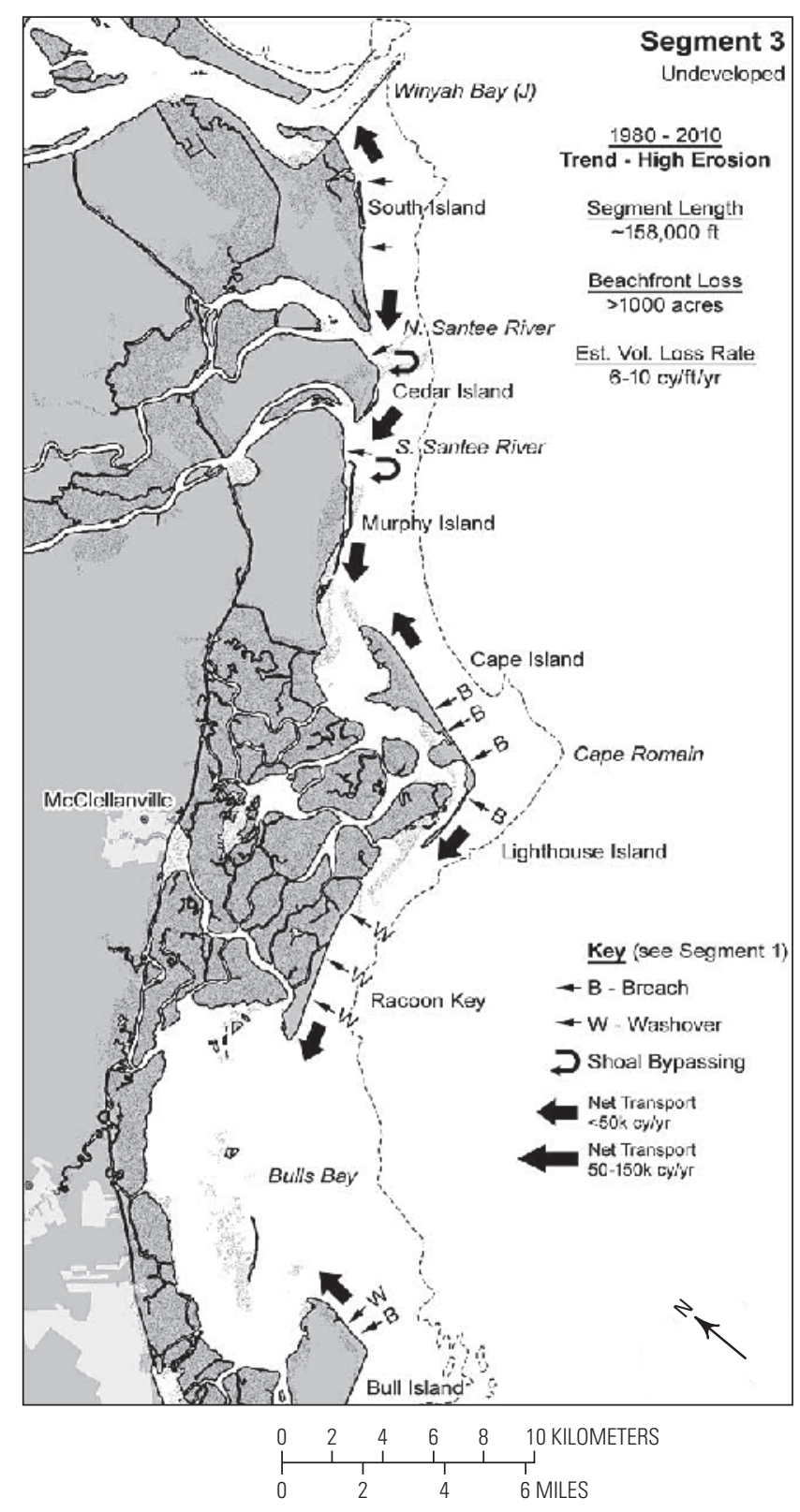

Figure B13. Sediment transport directions, rates of erosion, and areas prone to breaches and washovers at Cape Romain National Wildlife Refuge and the Santee River, which supply much of the sediment. Map from Kana and others (2013); used with permission.

\section{B.4. Population Growth and Urbanization}

\section{B.4.1. Introduction}

The southeast region has the largest part of the U.S. population and the second fastest growth rate after the western United States. Since 1900, South Carolina has grown at 11.7 percent per decade on average, with net migration into
South Carolina accounting for 52 percent of total population growth per decade since 1970. Unlike natural increases, which tend to change gradually over time, migration can result in more dramatic changes to a population, often driven by sudden shifts in economic opportunities, natural disasters, or other events. Migrants typically settle in urban rather than in rural areas (94 percent of foreign-born migrants lived in urban areas in 1990; Chiswick and Miller, 2004). Southeastern cities, including those of South Carolina, have grown rapidly in the recent past and are expected to continue expanding into the near future. As cities grow, associated urban expansion (called "suburban sprawl") away from the city core occurs even more rapidly (Terando and others, 2014). As a consequence of this low-density, widely dispersed, and highly connected development footprint, suburban sprawl affects ecosystem function, processes, and services. The fragmentation of habitat and loss of species connectivity directly degrades ecosystems and also constrains the ability of species and habitats to adapt (in other words, migrate) to changing conditions such as SLR, increased flooding, and rapid habitat succession. Thus, urbanization and accompanying suburban growth represent a substantial threat to natural systems and the production of essential ecosystem goods and services in coastal systems.

Here, we describe recent trends in population growth in South Carolina and, in particular, for the three-county area of concern in this project. We then summarize a selection of projections of future population spread produced by urban growth models. Understanding the possible spatial distribution of development effects is essential for conservation management planning and maximizing the potential for species and habitats to adapt to changing climates and land-use demands.

\section{B.4.2. Past Trends in Population Growth and Land-Use Land Change}

In the first half of this decade, South Carolina had the 11th largest population gain in the country, growing faster than the national average at 3.3 percent. Population growth has been uneven, with metropolitan and coastal areas growing faster (at 6 to greater than 9 percent; U.S. Census Bureau, 2010). Growth in the Charleston metropolitan area was greater than expected, gaining nearly as many new residents between 2010 and 2014 as was forecast for the entire decade. During this same period, nearly half of the State's counties actually decreased in population size (Tippett, 2015).

Population growth over the last half of the 20th century differed among coastal counties. The three counties of interest to this project (Berkeley, Charleston, and Georgetown) all had positive population growth during 1950-2010 (fig. B14A) Berkeley County demonstrated the greatest average 10-year growth record at 35.6 percent, translating to a nearly six-fold increase in the county's population over 50 years. This growth rate was followed by Charleston County at 13.7 percent per decade, more than doubling its population (112 percent 

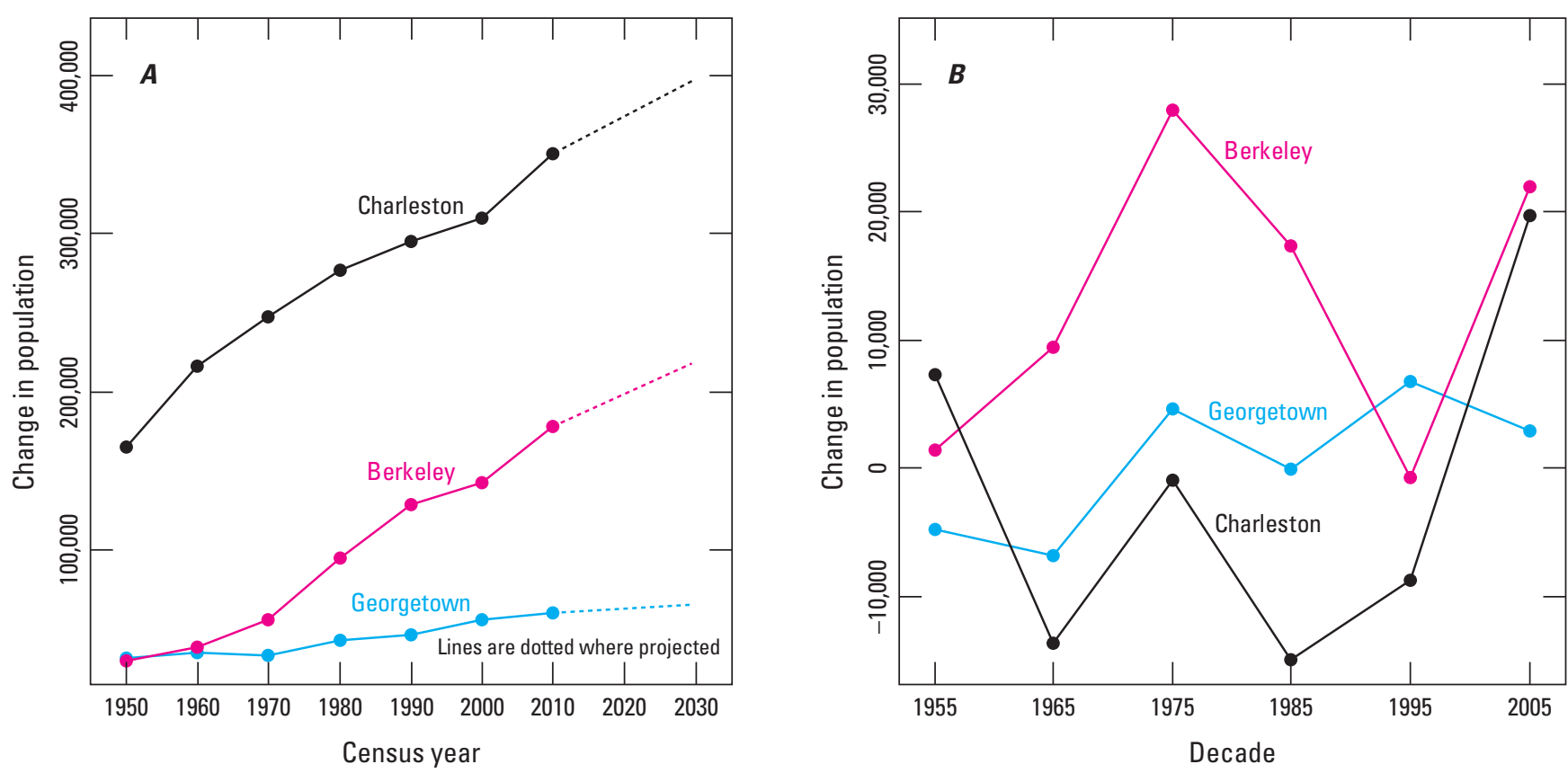

Figure B14. Population growth and net migration during 1950-2010 for three South Carolina coastal counties. Data are from U.S. Census Bureau (2010). $A$, population growth. $B$, net migration.

growth) over 50 years. Georgetown County nearly doubled its population over this period with an average growth rate of 11.7 percent per decade (U.S. Census Bureau, 2010).

Population growth is driven by a combination of "natural increase" (births minus deaths) and migration (immigration minus emigration). Although these three counties demonstrated strong overall growth during the last 50 or more years, the source of that growth has varied widely among counties. Berkeley County experienced nearly continuous net positive migration, with an overall influx of greater than 77,000 new residents during the second half of the 20th century (fig. B14B). Georgetown County began the period with several decades of negative net migration from the county but has experienced positive net influx in the decades since. Charleston County has seen substantial migration fluctuations, with a net loss of migrants before the 1970s, after which hightech industrialization began to attract migrants back to South Carolina (seen in the overall increase in immigration during that decade, fig. B14B). Since 2000, Charleston County has seen high immigration rates, partially attributed to a general trend of population movement into urban areas (U.S. Census Bureau, 2010).

\section{B.4.2.1. Past Spatial Growth Patterns and Drivers}

Although population growth in coastal counties was slower than for the Nation as a whole, the percentage of South Carolina's population living in coastal counties (including Charleston and Georgetown) increased from 2.7 to 19.6 percent between 1960 and 2008, respectively, indicating a demographic shift from interior counties to the coast (U.S. Census
Bureau, 2010). Although Charleston County as a whole grew 25 percent during 1970-2000, the city of North Charleston (fig. B15) expanded nearly 273 percent. Much of this growth rate is attributed to an aggressive program of land annexation, enlarging the land area of North Charleston from less than 8 square miles at its founding in 1972 to more than 30 square miles in only 8 years (fig. B15). Part of North Charleston lies in Dorchester County, which experienced rapid growth during this period (particularly in more recent years), due in large part to urban flight. Similarly, the city of Mt. Pleasant (fig. F6) more than doubled in population size over each decade from 1970 to 1990 and was among the fastest growing cities in the metropolitan region in the decades following.

These patterns of rapid urban growth in coastal South Carolina are partly the result of a rapid transformation over the past several decades from a service-based economy to a science- and technology-based economy (Chamber of Commerce, 2016). This transformation includes expansion of hi-tech industries including Boeing, Mercedes, Google, and Volvo, which have attracted high-skill labor to the region. Because of this job growth, other manufacturing and professional service labor markets have expanded, including in construction, retail, healthcare, and education. Other sectors including tourism, forestry, commercial fishing, and boat manufacturing are strongly coastal based and have produced additional jobs and economic impacts to the area. In 2012, South Carolina's 8 coastal counties accounted for 64 percent of the State's tourisms revenues, contributing 72,000 jobs and a direct economic impact of $\$ 5.4$ billion to the State (Willis and Straka, 2016). 


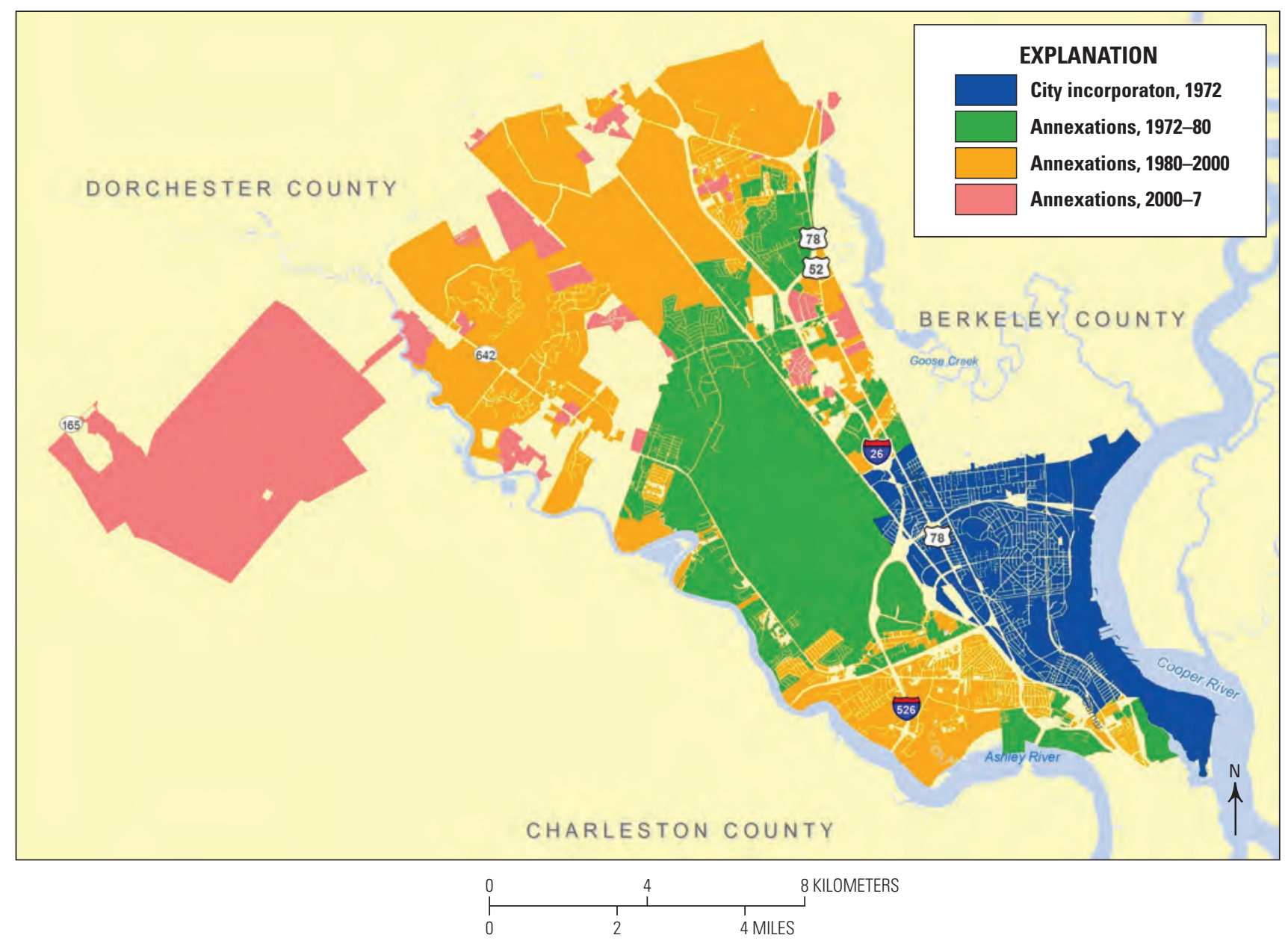

Figure B15. North Charleston as an example of rapid urban growth, 1972-2007.

\section{B.4.3. Predictions of Future Urban Growth and Development}

The 2008 collapse of the housing market and ensuing recession had substantial impacts in South Carolina, with a 20-percent decline in immigration to the State and lower natural population growth (U.S. Census Bureau, 2010). Despite these losses and the downturn in housing markets, coastal counties continued to grow during this decade (fig. B14A). The pace of urban and suburban expansion is exemplified during this period of recession, with the two northeastern-most planning areas of North Charleston experiencing growth rates of 47-74 percent during 2000-10, whereas the more southerly urban areas of the city declined between 5 and 6 percent (City of North Charleston Planning Department, 2015). After improvements to the economy in 2010, redevelopment projects began in Charleston and surrounding areas to increase housing and infrastructure. Projections for the State estimate population growth of 8.5 percent for the current decade, nearly all of which is expected to be in major metropolitan regions (for example, Charleston is anticipated to receive 18 percent of the State's new growth; Tippett, 2015). Estimates for the 3-county region surrounding the City of Charleston project a total population size of more than 800,000 by 2030 , representing a 47 percent growth since 2000 . Relatively low-cost housing and the growing economic base of cities like North Charleston will continue to drive incentives for strong suburban growth away from the metropolitan center.

When planning a long-term strategy for adaptation to environmental changes such as SLR, we must consider other drivers of change and possible impediments to implementing this strategy. Dynamic land-use change, and especially the seemingly permanent state of conversion to developed use, has important implications for achieving natural-resource based objectives in the future. Anticipating where and when the human development footprint is likely to expand will help us determine where and when investments in conservation (for example, acquisition, protection, and restoration of land) will be most effective. Projecting urban and suburban growth along with expected habitat transitions (and their associated production of ecosystem goods) also provide the opportunity to affect how this growth trajectory might be modified to meet human development needs and continued provision of valued ecosystem services for residents and visitors. 


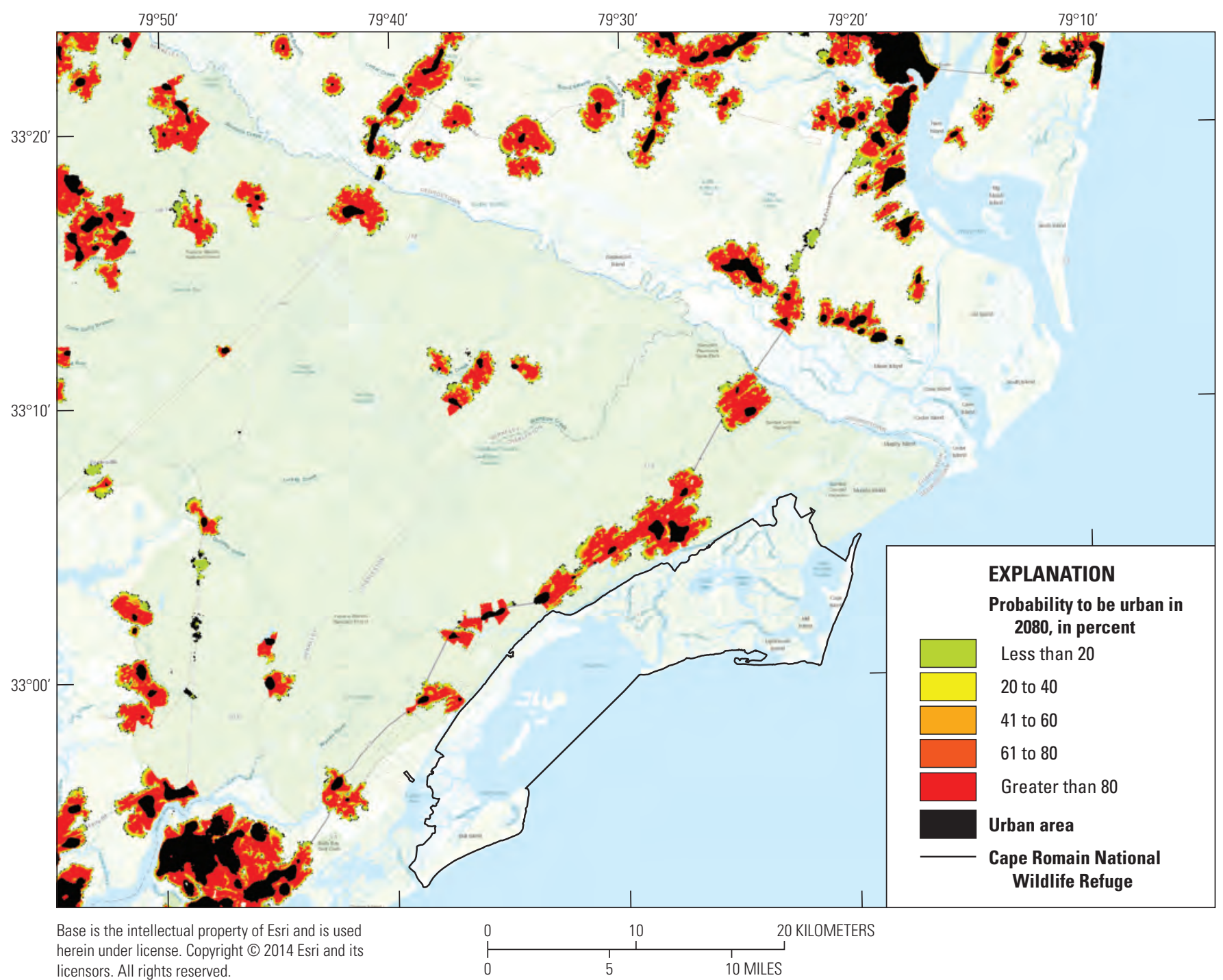

Figure B16. Predictions of urban growth in 2080 based on the Slope, Land use, Excluded, Urban, Transportation and Hillshade cellular automata model (Jantz and others, 2010) for the Santee River region in the South Carolina Lowcountry.

In an attempt to inform our future landscape design modeling, designed to increase the probability of maintaining representative habitat for future species given the uncertainty of climate change, we have developed an approach to consider development projections when identifying high-value land parcels for possible protection. We base our projections on a simple urban growth model that simulates several forms of growth, including outward growth from urban areas, growth along transportation corridors, and spontaneous new urban centers, applying cellular automata dynamics, terrain mapping, and predictions of land-cover change (Jantz and others, 2010; Biodiversity and Spatial Information Center, 2013; Terando and others, 2014). The Slope, Land use, Excluded, Urban, Transportation and Hillshade model (Jantz and others, 2010) accounts for land-cover types that are resistant to (for example, wetlands and dunes) or excluded from (for example, water bodies and protected areas) growth, changes in transportation networks that facilitate growth, topographic relief, and changes in historic urban extent. The model does not account for other drivers of growth (for example, economic or demographic factors). The algorithm integrates growth rules to model the rate and pattern of development and produces annual projections of growth for each map pixel (60-meter resolution) as Monte Carlo probabilities of conversion to urban cover, discretized into increments ranging from 2.5 to 10 percent.

For our study area, we estimated the current urban footprint as covering about 1,000 square kilometers. To account for the threat of future development of currently unprotected land parcels, we produced model estimates in year 2080 for the study area (fig. B16). Based on model predictions and confidence intervals, the extent of urbanization for the region is expected to range from 1,900 square kilometers (97.5 percent of simulated runs) to more than 3,000 square kilometers 
(2.5 percent of simulations; fig. B17) by 2080. Because of the difference in spatial scale between model probability estimates (60-meter pixels) and land parcels of various size, we computed estimates of overall probability of urban conversion at the parcel level to evaluate the risk of loss to development. We intersected a geographic information system layer of parcel boundaries (currently protected and unprotected) with the 2080 Slope, Land use, Excluded, Urban, Transportation and Hillshade urbanization probability model and extracted from each parcel the count of pixels in 1-percent increments. Summing this count, weighted by the mid-point of the probability increments provided an area-weighted average probability of development by year 2080 . We used this probability to adjust the estimated value of parcels in the conservation reserve design analysis (chap. F.2) by increasing the value of parcels proportional to the possibility they will be permanently converted to developed land. In this manner, the decision model will favor a parcel with higher risk of loss over a parcel with equivalent habitat value but less development risk. This value-modification factor, however, was set to zero for parcels that are currently greater than or equal to 50 percent developed, reflecting the assumption that this level of development would negatively affect any remaining habitat contribution such that the parcel value should not be inflated.

The method described here represents a fairly simple, accessible modeling approach to produce land-use change probabilities at a fine scale over a large geographic area with minimal data requirements (Terando and others, 2014). The goal of this effort was to provide input for other modeling exercises, namely modifying the value function to adjust a parcel selection algorithm specifically concerned with maximizing habitat representation into the future (see chap. F.2.4). Another objective of predicting land-use change and urbanization dynamics is to link policy decisions to implications for changes in ecosystem function and provision of services. Such

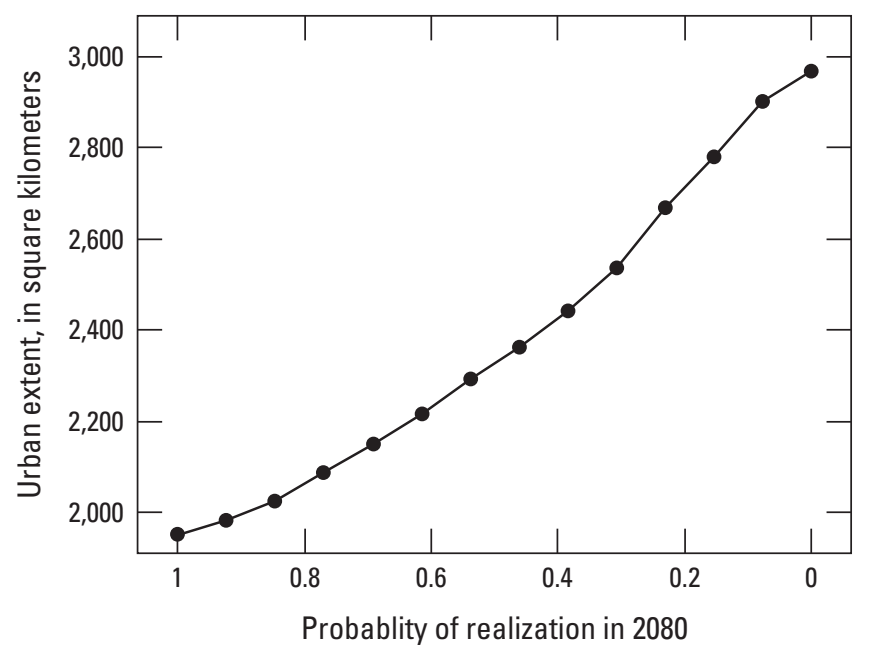

Figure B17. Predicted urban footprint by 2080 based on the Slope, Land use, Excluded, Urban, Transportation and Hillshade model (Terando and others, 2014). an approach, requiring more intensive data collection and analysis to understand economic behavior as a driver of development, provides the means to simulate the ability of alternate land-use policies and economic incentives to affect growth trajectories to meet multiple objectives. In appendix 4 we describe the work to date on a spatial econometric model that integrates predictions of land value, resulting decisions about land use, and feedback effects on ecosystem services. This model will allow us to explore the implications of changes in policy (for example, zoning) on achieving conservation targets or other ecosystem objectives.

\section{References Cited}

Barnhardt, W.A., ed., 2009, Coastal change along the shore of northeastern South Carolina-The South Carolina coastal erosion study, U.S. Geological Survey Open-File Report 2008-1206, 77 p. [Also available at https://doi.org/10.3133/ ofr20081206.]

Bender, M.A., Knutson, T.R., Tuleya, R.E., Sirutis, J.J., Vecchi, G.A., Garner, S.T., and Held, I.M., 2010, Modeled impact of anthropogenic warming on the frequency of intense Atlantic hurricanes: Science, v. 327, no. 5964, p. 454-458. [Also available at https://doi.org/10.1126/ science.1180568.]

Biodiversity and Spatial Information Center, 2013, Designing sustainable landscapes: North Carolina State University, web page, accessed February 14, 2018, at http://www.basic.ncsu.edu/dsl/index.html.

Brennan, J.W., 1991, Meteorological summary of Hurricane Hugo: Journal of Coastal Research, v. 8, no. Special Issue, p. 1-12. [Also available at https://www.jstor.org/ stable/25735403.]

Carter, L., Terando, A., Dow, K., Hiers, K., Kunkel, K.E., Lascurain, A., Marcy, D., Osland, M., and Schramm, P., 2018, Southeast, in Reidmiller, D.R., Avery, C.W., Easterling, D.R., Kunkel, K.E., Lewis, K.L.M., Maycock, T.K., and Stewart, B.C., eds., Impacts, risks, and adaptation in the United States-Fourth National Climate Assessment [vol. II]: Washington, D.C., U.S. Global Change Research Program, p. 743-808., accessed January 2019 at https://doi.org/10.7930/NCA4.2018.CH19.

Cash, D.W., and Moser, S.C., 2000, Linking global and local scales_-Designing dynamic assessment and management processes: Global Environmental Change, v. 10, no. 2, p. 109-120. [Also available at https://doi.org/10.1016/ S0959-3780(00)00017-0.] 
Chamber of Commerce, 2016, Economic outlook forecast-2017-2018: Charleston Metro Chamber of Commerce, $20 \mathrm{p}$. [Also available at https://experiencemountpleasant.com/ wp-content/uploads/2017/04/2017-Economic-Outlook-Forecast_final.pdf.]

Chiswick, B.R., and Miller, P.W., 2004, Where immigrants settle in the United States: Journal of Comparative Policy Analysis, v. 6, no. 2, p. 185-197. [Also available at https://doi.org/10.1080/1387698042000273479.]

City of Charleston, 2015, Sea level rise strategy: City of Charleston, 20 p., accessed April 2018 at https://www.charleston-sc.gov/DocumentCenter/ View/10089/12_21_15_Sea-Level-Strategy_v2_ reduce?bidId $=$.

City of North Charleston Planning Department, 2015, City of North Charleston comprehensive plan update 2015: North Charleston, S.C., City of North Charleston Planning Department, 14 p.

Crossett, K., Ache, B., Pacheco, P., and Haber, K., comps., 2013, National coastal population report-Population trends from 1970 to 2020: National Oceanic and Atmospheric Administration, State of the Coast Report Series, accessed April 2018 at https://coast.noaa.gov/digitalcoast/training/ population-report.html.

Faustini, J., Thom, T.A., Hunt, K.J., Nilius, R., and Burns, R.E., 2013, Water resource inventory and assessmentCape Romain National Wildlife Refuge, Charleston County, South Carolina: Atlanta, Ga., U.S. Fish and Wildlife Service, Southeast Region, $84 \mathrm{p}$.

Frazier, T.G., Wood, N., Yarnal, B., and Bauer, D.H., 2010, Influence of potential sea level rise on societal vulnerability to hurricane storm-surge hazards, Sarasota County, Florida: Applied Geography, v. 30, no. 4, p. 490-505. [Also available at https://doi.org/10.1016/j.apgeog.2010.05.005.]

Hayes, M.O., Moslow, T.F., and Hubbard, D.K., 1979, Beach erosion in South Carolina: Coastal Zone Information Center, 99 p.

Hayes, M.O., and Sexton, W.J., 1989, Modern clastic depositional environments, South Carolina-Charleston to Columbia, South Carolina, July 20-25, 1989: Washington, D.C., American Geophysical Union, Field Trip Guidebook, v. T371, 88 p. [Also available at https://doi.org/10.1029/ FT371.]

Helm, A.C., Nicholas, N.S., Zedaker, S.M., and Young, S.T., 1991, Maritime forests on Bull Island, Cape Romain, South Carolina: Bulletin of the Torrey Botanical Club, v. 118, no. 2, p. 170-175. [Also available at https://doi.org/10.2307/2996858.]
Hirsch, M.E., DeGaetano, A.T., and Colucci, S.J., 2001, An East Coast winter storm climatology: Journal of Climate, v. 14 , no. 5, p. 882-899. [Also available at https://doi.org/10.1175/1520-0442(2001)014<0882:AECW SC>2.0.CO;2.]

Horton, R., and Bader, D., 2014. Sea level rise projection for Cape Romain, South Carolina: Columbia University, unpublished report to the Northeast and Southeast Department of Interior Climate Science Centers, 2 p. [Also available at https://www.sciencebase.gov/catalog/file/get/5654ed9ae4b0 $71 \mathrm{e} 7 \mathrm{ea} 53 \mathrm{~d} 702 \mathrm{f}=$ disk $\quad 72 \% 2 \mathrm{~F} 7 \mathrm{~d} \% 2 \mathrm{Fa} 4 \% 2 \mathrm{~F} 727 \mathrm{da} 4383$ ad26bfed0a3fb72065215436f6c2aa7.]

Hughes, Z.J., FitzGerald, D.M., Wilson, C.A., Pennings, S.C., Więski, K., and Mahadevan, A., 2009, Rapid headward erosion of marsh creeks in response to relative sea level rise: Geophysical Research Letters, v. 36, no. 3, 5 p. [Also available at https://doi.org/10.1029/2008GL036000.]

Jantz, C.A., Goetz, S.J., Donato, D., and Claggett, P., 2010, Designing and implementing a regional urban modeling system using the SLEUTH cellular urban model: Computers, Environment and Urban Systems, v. 34, no. 1, p. 1-16. [Also available at https://doi.org/10.1016/j.compenvurbsys.2009.08.003.]

Kana, T.W., Traynum, S.B., Gaudiano, D., Kaczkowski, H.L., and Hair, T., 2013, The physical condition of South Carolina beaches 1980-2010: Journal of Coastal Research, v. 69, p. 61-82. [Also available at https://doi.org/10.2112/ SI_69_6.]

Kirwan, M.L., and Megonigal, J.P., 2013, Tidal wetland stability in the face of human impacts and sea-level rise: Nature, v. 504, no. 7478, p. 53-60. [Also available at https://doi.org/10.1038/nature12856.]

Knutson, T.R., McBride, J.L., Chan, J., Emanuel, K., Holland, G., Landsea, C., Held, I., Kossin, J.P., Srivastava, A.K., and Sugi, M., 2010, Tropical cyclones and climate change: Nature Geoscience, v. 3, no. 3, p. 157-163. [Also available at https://doi.org/10.1038/ngeo779.]

Kopp, R.E., Horton, R.M., Little, C.M., Mitrovica, J.X., Oppenheimer, M., Rasmussen, D.J., Strauss, B.H., and Tebaldi, C., 2014, Probabilistic 21st and 22nd century sealevel projections at a global network of tide-gauge sites: Earth's Future, v. 2, no. 8, p. 383-406. [Also available at https://doi.org/10.1002/2014EF000239.]

McCarney-Castle, K., Voulgaris, G., and Kettner, A.J., 2010, Analysis of fluvial suspended sediment load contribution through anthropocene history to the South Atlantic Bight coastal aone, U.S.A: The Journal of Geology, v. 118, no. 4, p. 399-416. [Also available at https://doi.org/10.1086/652658.] 
Myers, V.A., 1975, Storm tide frequencies on the South Carolina coast: National Oceanic and Atmospheric Administration, Technical Report NWS-16. 79 p. [Also available at https://www.nws.noaa.gov/ohd/hdsc/Technical reports/ TR16.pdf.]

National Oceanic and Atmospheric Administration [NOAA], 2008, Sea, Lake, and Overland Surges from Hurricanes (SLOSH): National Oceanic and Atmospheric Administration, National Hurricane Center and Central Pacific Hurricane Center web page, accessed April 2018 at https://www.nhc.noaa.gov/surge/slosh.php.

National Weather Service [NWS], 2020, Tropical cyclone history for southeast South Carolina and northern portions of southeast Georgia: National Weather Service web page, accessed August 2020 at https://www.weather.gov/chs/ TChistory.

Post, Buckley, Shuh and Jernigan, Inc., 1990, Hurricane Hugo assessment - Review of hurricane evacuation studies utilization and information dissemination: U.S. Army Corps of Engineers and Federal Emergency Management Agency, $51 \mathrm{p}$. [Also available at https://www.hsdl.org/?abstract\&did=30896.]

Runkle, J., Kunkel, K., Stevens, L., Frankson, R., Stewart, B., and Sweet, W., 2017: South Carolina state summary: National Oceanic and Atmospheric Administration, Technical Report NESDIS 149-SC, 4 p. [Also available at https://statesummaries.ncics.org/downloads/ SC-screen-hi.pdf.]

Schuck-Kolben, R.E., 1990, Storm-tide elevations produced by Hurricane Hugo along the South Carolina coast, September 21-22, 1989: U.S. Geological Survey Open File Report 90-386, 50 p. [Also available at https://doi.org/10.3133/ofr90386.]

Sexton, W.J., and Hayes, M.O., 1991, The geologic impact of Hurricane Hugo and post-storm shoreline recovery along the undeveloped coastline of South Carolina, Dewees Island to the Santee Delta: Journal of Coastal Research, v. 8, no. Special Issue, p. 275-290. [Also available at https://www.jstor.org/stable/25735421.]

Sheffield, R.M., and Thompson, M.T., 1992, Hurricane Hugo-Effects on South Carolina's forest resource: Asheville, N.C., U.S. Department of Agriculture, Forest Service, Southeastern Forest Experiment Station, Research Paper SE-284, 51 p. [Also available at https://doi.org/10.2737/SE-RP-284.]
Shellenbarger Jones, A., Bosch, C., and Strange, E., 2009, Vulnerable species-The effects of sea-level rise on coastal habitats, in Titus, J.G., Anderson, K.E., Cahoon, D.R., Gesch, B., Gill, S.K., Gutierrez, B.T., Thieler, E.R., and Williams, S.J., Coastal sensitivity to sea-level riseA focus on the Mid-Atlantic Region: Washington, D.C., U.S. Environmental Protection Agency, a report by the U.S. Climate Change Science Program and the Subcommittee on Global Change Research, p. 73-84. [Also available at https://nepis.epa.gov/Exe/ZyPDF.cgi/P100483V. PDF?Dockey=P100483V.PDF.]

Sparks, P.R., 1991, Wind conditions in Hurricane Hugo and their effect on buildings in coastal South Carolina: Journal of Coastal Research, v. 8, no. Special Issue, p. 129-162. [Also available at https://www.jstor.org/stable/25735404.]

South Carolina Department of Natural Resources [SCDNR], 2013, Climate change impacts to natural resources in South Carolina: South Carolina Department of Natural Resources, 101 p., accessed April 2018 at https://www.dnr.sc.gov/pubs/ CCINatResReport.pdf.

Stephens, D.G., Van Nieuwenhuise, D.S., Mullin, P., Lee, C., and Kanes, W.H., 1976, Destructive Phase of deltaic development - North Santee River delta: Journal of Sedimentary Research, v. 46, no. 1, p. 132-144. [Also available at https://doi.org/10.1306/212F6ED8-2B24-11D78648000102C1865D.]

Sweet, W.V., Kopp, R.E., Weaver, C.P., Obeysekera, J., Horton, R.M., Thieler, E.R., and Zervas, C., 2017, Global and regional sea level rise scenarios for the United States: National Oceanic and Atmospheric Administration, Technical Report NOS CO-OPS 083, 75 p. [Also available at https://tidesandcurrents.noaa.gov/publications/ techrpt83_Global_and_Regional_SLR_Scenarios_for_the US_final.pdf.]

Sweet, W.V., and Zervas, C., 2011, Cool-season sea level anomalies and storm surges along the U.S. East CoastClimatology and comparison with the 2009/10 El Niño: Monthly Weather Review, v. 139, no. 7, p. 2290-2299. [Also available at https://doi.org/10.1175/MWR-D-1005043.1.]

Tate, C.A., and Frazier, T.G., 2013, A GIS methodology to assess exposure of coastal infrastructure to storm surge and sea-level rise-A case study of Sarasota County, Florida: Journal of Geography \& Natural Disasters, v. S1, no. 1, 12 p. [Also available at https://doi.org/10.4172/2167-0587. S1-001.] 
Teal, J.M., 1986, The ecology of regularly flooded salt marshes of New England-A community profile: Washington, D.C., U.S. Fish and Wildlife Service, Biological Report, v. 85, no. 7.4, 69 p. [Also available at https://hdl.handle.net/2027/mdp.39015086473561.]

Terando, A.J., Costanza, J., Belyea, C., Dunn, R.R., McKerrow, A., and Collazo, J.A., 2014, The southern megalopolis-Using the past to predict the future of urban sprawl in the Southeast U.S: PLoS One, v. 9, no. 7, e102261. [Also available at https://doi.org/10.1371/journal.pone.0102261.]

Tippett, R., 2015, Population growth in the Carolinas-Projected vs. observed trends: Chapel Hill, N.C., Carolina Population Center, Carolina Demography. [Also available at https://www.ncdemography.org/2015/12/08/populationgrowth-in-the-carolinas-projected-vs-observed-trends/.]

U.S. Census Bureau, 2010, Coastline population trends in the United States-1960 to 2008: Washington, D.C., U.S. Department of Commerce, 27 p. [Also available at https://www.census.gov/prod/2010pubs/p25-1139.pdf.]

U.S. Fish and Wildlife Service, 2010, Cape Romain National Wildlife Refuge comprehensive conservation plan: Atlanta, Ga., U.S. Fish and Wildlife Service, 185 p. von Lehe, A., 2008, Climate change and South Carolina's economy: Southeastern Environmental Law Journal., v. 16, no. 2, p. 359-390.

Williams, S.J., Gutierrez, B.T., Titus, J.G., Gill, S.K., Cahoon, D.R., Thieler, E.R., Anderson, K.E., FitzGerald, D., Burkett, V., and Samenow, J., 2009, Sea-level rise and its effects on the coast, in Titus, J.G., Anderson, K.E., Cahoon, D.R., Gesch, B., Gill, S.K., Gutierrez, B.T., Thieler, E.R., and Williams, S.J., Coastal sensitivity to sea-level rise-A focus on the Mid-Atlantic Region: Washington, D.C., U.S. Environmental Protection Agency, a report by the U.S. Climate Change Science Program and the Subcommittee on Global Change Research, p. 11-24. [Also available at https://nepis.epa.gov/Exe/ZyPDF.cgi/P100483V. PDF?Dockey=P100483V.PDF.]

Willis, D.B., and Straka, T.J., 2016, The economic contribution of natural resources to South Carolina's economy: Columbia, S.C., South Carolina Department of Natural Resources, Clemson Experiment Station, 23 p. [Also available at http://dnr.sc.gov/economic/EconomicContributionsSC.pdf.] 



\section{Chapter C. Stakeholder Engagement}

\section{C.1. Introduction}

Addressing "wicked" problems (see chap. A.4) requires a consistent and purposefully organized approach that must include — and ideally integrate- the physical, biological, and social sciences (Rittel and Webber, 1973; Meadow and others, 2015). In this and the following two sections, we describe public engagement strategies and activities based on sound social science research and application. We highlight our culturally focused approach. In particular, we wanted to understand how people make sense of the world around them through their personal lived experience (Schutz, 1967) of landscape change, and we maintain that this cultural and individual sense making should be central to engagement when addressing wicked problems. The application of a human behavior model helped us be systematic in this process and shaped our engagement activities. The use of collaborative scenario planning is described in chapter $\mathrm{D}$; the application of strengths, weaknesses, opportunities, and threats matrices for identification of actions conservation partners may wish to pursue under high levels of uncertainty is presented in chapter $\mathrm{E}$. Through application of a behavior model, the difficult yet vital task of uncovering and addressing researchers' and practitioners' underlying assumptions of what drives and affects human behavior can be uncovered. Considered application of behavior models is helpful in this process because each model comes with its own underlying assumptions, and different models emphasize different interactions with human actors on a complex landscape. Ultimately, we based our approach to engagement by considering the principles of a Transtheoretical Model (TTM). TTM emphasizes the variability in different individuals and groups, and this variability in knowledge, views, and access means that engagement strategies with those different individuals and groups must also vary (Prochaska and Velicer, 1997; Armitage, 2009).

We first discuss what it means to take culture seriously in this sort of work (Cronon, 1996; Gobster and Hull, 2000; Milton, 1996), as well as the behavior model used to help guide our work. These discussions are followed by a summary of engagement activities.

\section{C.2. Taking Culture Seriously}

What does it mean to take culture seriously when addressing complex environmental and landscape changes? These wicked problems challenge the ability of scientists to understand and address problems in ways that conform to traditional scientific methods. These problems force researchers to reconsider their own epistemological underpinnings-a questioning of how and why questions in a given science are asked and what counts as evidence within different knowledge traditions. Wicked problems force practitioners to look to new approaches that require a deeper appreciation for a given place, culture, and the historical moments in which events are occurring (Miller and others, 2008; Game and others, 2014; Meadow and others, 2015). Addressing nonlinear (problems with multiple interactive variables that do not neatly conform to cause and effect understanding), complex, emergent problems that cannot be separated from human society on the ground requires a different approach; in particular, engagement and communication strategies are best achieved when not treated as separate from the physical and biological science research projects but are integrated and integral to those. Several authors have noted that a tendency to be unwilling to address the difficult issues of variability in meaning, or culture, is what leads to the downfall of much work in conservation (Harrison and Burgess, 1994; Cronon, 1996; Leong, 2009). These conflicts that Peterson and others (2002) termed "moral cultures"-frameworks for understanding moral behavior in a given place - are why so much of the work in environmental engagement and communication efforts fail. "Much of the failure to resolve natural resource conflicts can be traced to the human preference for addressing superficial problems while ignoring their "psychological or sociological dynamics” (Yaffee, 1997, p. 329). Cultural frameworks used to make sense of the world are more enduring, harder to uncover, and yet more central to behavioral decisions that people and organizations make. Understanding the importance of these issues requires application of cultural theory and method. Studying meaning making is a nonpositivistic approach to research; that is, an approach that prioritizes qualitative over quantitative and the emergence of theory over confirmation of research paradigms. This approach is not common in much of the work in conservation. Although sea-level rise (SLR) is a global phenomenon and responses and engagement are often framed at a very broad scale, projects addressing these large-scale landscape changes must ultimately focus on the local scale, which is much messier and more complicated because landscape planning projects must move beyond conservation-minded organizations. This need for broader perspectives means that there must be space to accept and contend with nonlinear processes that drive local decision making and actions-perceptions of place, political ideologies, and historic and cultural norms specific to a place. If the Cape Romain National Wildlife Refuge can find partners that are outside of conservation but ultimately still share the same goals - a healthy environment where community members can live, work, and play that provides the continuity of the place - the refuge, conservation-focused organizations, and others on the landscape will benefit in mutualistic ways. We as researchers and practitioners had to abandon positivism, or more simple cause and effect thinking, for a murkier, 
nonlinear, interpretivist understanding of the world; in other words, we had to take culture and meaning-making seriously. This consideration of culture throughout our process helped us identify areas for project improvement that we hope can be applied to other landscape planning, conservation-focused projects in the future.

\section{C.3. Understanding Human Behavior}

We began with the recognition that engaging with people on such complex topics as SLR (due to climate change), landscape change and use, and ecological conservation required a focused approach based on a sound understanding of the complexity of human behavior and behavior change. Underlying theory and assumptions shape the questions asked and the methods of research, just as they shape engagement and communication strategies (Katz and Light, 2013). With that in mind, we considered several models of human behavior used in environmental social science literature (Bell, 2011).

We began by developing a set of criteria upon which to assess popular theories of human behavior used in the conservation field. These criteria included the ability to account for the multiplicity of perspectives, value propositions, and sense and limits of agency (the actual and perceived ability of individuals to act on their own accord) for the variety of stakeholders on a landscape. All these are societal features relative to culture and meaning (Hong and others, 2000). Many entities have a stake in the issues of climate change, SLR, and landuse change - private landowners, public and privately traded businesses, municipalities, residents, recreationists, nature lovers, schools that take field trips to the refuge, conservationists, and the wildlife itself. For all these groups, in different ways, it matters how the local landscape is able to adapt to the multiple global threats it faces. They all bring with them different perspectives, and all will view the issues through differing value propositions (Cheng and others, 2003). Importantly, groups also maintain different levels of actual and perceived agency to act on issues of concern (Ajzen, 2002).
The model itself also needed to be sufficiently complex. For example, a one-to-one assumption of attitude to behavior or increased knowledge to behavior, both often found in environmental behavior models, was not what we were looking for (see for example, Dunlap and others, 2000). Rather, the model needed to be able to account for multiple dependent and independent variables that change at different times. In particular, the complexity inherent in taking cultural variability seriously points to the need for a model that can account for that complexity.

Along with the need for complexity, we also required that the model be nimble enough to accommodate adaption of the broader intervention at specific times for particular stakeholders in response to conditions in places where stakeholders live, work, and play. No models are truly predictive (particularly when dealing with the complexities of human behavior), and they must be able to adapt as new information is uncovered and as change on the ground happens in real time. Climate change and SLR are some of the most complex problems society must address. For models of human behavior to be useful, they must be able to maintain, over time, an approach that allows researchers and those in public outreach efforts to modify and work through complex changes. Put simply, although complexity of the model was necessary, rigidity of the model was not an option. Table C1 provides a list of the environmental models we examined and how they measured up to our criteria.

Ultimately, we determined that the most commonly used models in environmental social science literature came up short for our criteria. So, we next turned to the population health literature. Population health is a similarly complicated topic because there are multiple constraints on behavior, and knowledge, attitudes, identities, and access all interact in complex ways. It is a field that has been working for some time to figure out how to understand human behavior more thoroughly. In the population health literature, we found the TTM. TTM is a "stages of change" model and is one of the most commonly used and most thoroughly researched models in behavioral health literature (Armitage, 2009). This model met our criteria in that it was sufficiently complex and yet not

Table C1. Behavior models commonly used in environmental social sciences and their ability to address our model criteria.

\begin{tabular}{|c|c|c|c|c|}
\hline Model criteria & $\begin{array}{l}\text { Reasonable Persons } \\
\text { Model (Kaplan and } \\
\text { Kaplan, 2009) }\end{array}$ & $\begin{array}{c}\text { Theory of } \\
\text { Planned } \\
\text { Behavior (Ajzen, } \\
\text { 1991) }\end{array}$ & $\begin{array}{c}\text { Attitude models (for } \\
\text { example, Wildlife Values } \\
\text { of the West) (Dunlap and } \\
\text { others, 2000; Fulton and } \\
\text { others, 1996) }\end{array}$ & $\begin{array}{l}\text { Other models (for example, } \\
\text { Value Belief Norms Identity } \\
\text { models) (Stern and others, } \\
\text { 1999; Stets and Biga, 2003) }\end{array}$ \\
\hline $\begin{array}{l}\text { Perspectives, value proposi- } \\
\text { tions, and agency }\end{array}$ & $\begin{array}{l}\text { Yes (perspectives, } \\
\text { value propositions, and } \\
\text { agency) }\end{array}$ & $\begin{array}{l}\text { Yes (value } \\
\text { propositions } \\
\text { and agency) }\end{array}$ & Yes (value propositions) & Yes (variable) \\
\hline $\begin{array}{l}\text { Nimble_-Accounts for change } \\
\text { over time }\end{array}$ & Yes (potential) & No & No & Yes (variable) \\
\hline
\end{tabular}


rigid. It also accounted for multiple dependent and independent variables that may vary over time, space, individual, and group.

TTM can robustly account for multiple meanings and varying perceptions of self and others, as well as address limits on agency, satisfying our first criterion. It is complex enough to robustly account for behavior, in that it contains multiple dependent and independent variables that allows for change over time. Behavior is a process that happens over time, space, and context, and the TTM accounts for time in ways that most behavior models do not. Furthermore, the outcome of the model is not bivariate - change or no changebut rather offers an array of potential outcomes determined by project timeframes and goals. Finally, a behavioral act is not the end of the model; rather, it also accounts for maintenance of behaviors over time. In a broader sense, the TTM operates with some very important and overarching considerations, including where stakeholders are located in the model at the beginning of the intervention and finding where they are in the model as time moves forward. This recognition of where an individual or group is in the model then shapes the engagement strategy and measures of success. For example, an outreach strategy aimed at raising awareness of an issue is only helpful for those who are unaware. In contrast, those who are already concerned about the issue but looking for what to do need a more concrete, action-based intervention.

The application of the TTM stages of change behavior model accounts for numerous social processes for the construction of engagement and communication strategies. Applying the TTM allowed us to keep our focus on culture or meaning making at the local context. In particular, the model forces researchers to consider how people and organizations define the landscape and the problems on that landscape. People in and around Cape Romain National Wildlife Refuge (NWR) may view the issues at hand in different ways but all fundamentally face a similar future in terms of loss of land to SLR. Bridging that gap between the different organizations and lived experience levels requires a consideration of variability in meaning. Furthermore, our application of scenario planning, in particular with its first phase of pluralistic problem definition (as demonstrated in chap. D), provides a potential format for ensuring the incorporation of culture in the study of landscape change.

\section{C.3.1. Transtheoretical Model}

Here we review the TTM overall and then move to the internal components, which are what shape engagement itself (fig. C1). Letters below refer to the labels in figure $\mathrm{C} 1$ :

A. The TTM considers temporal distance to behavior. As an example, having an attitude or idea does not necessarily mean that the corresponding behavior will immediately follow. The TTM addresses this shortcoming of other

\section{TransTheoretical Model}

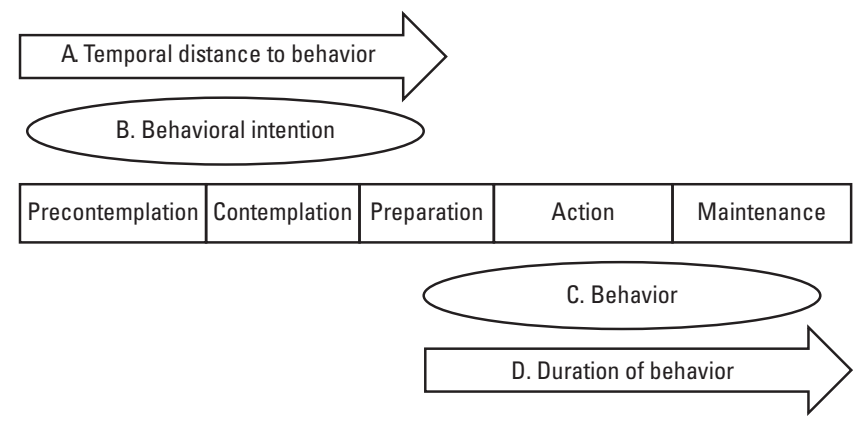

Figure C1. Transtheoretical Model of human behavior. Adapted from Armitage (2009).

models and recognizes that behavior is complex and that movement to behavior is not necessarily adopted simply because information is gained or an attitude is changed.

B. The TTM reflects a complex understanding of behavioral intention. Intentions do not necessarily immediately precede behavior. For some individuals and groups, distance to behavior is still far, whereas for others, distance from intention to behavior is temporally close, depending on where they are within the model. Gauging this distance helps people seeking to make change decide what actions will be most effective in the near and distant future depending on groups they are interacting with and for whom they are creating communication and engagement strategies.

C. The TTM also accounts for the degree of enduring change; changed behavior serves to support an acceptance of the new lived reality. The new reality becomes not a better than or worse than state but rather how things are.

D. Behavior can then become habitual and embedded, a permanent way to live within the landscape.

The power of the TTM model lies in the recognition that all people do not begin at the same starting points and in its use of five internal components. McDuff and Jacobson (2000) noted that different stakeholders need different things to move to behavior. Some just need more information, others need plans for action, and others need connections between those things that already are of immediate concern and the larger issues (in this case of landscape change and SLR) at hand. By beginning with this recognition, practitioners can be better prepared to uncover where people are in the model and can design effective strategies, messages, and engagement actions that align with what is needed in a given area for a given audience. 


\section{C.3.2. Internal Components of the Transtheoretical Model}

People live their daily lives in a sea of meaning, where there are power relations to which researchers are not privy and in which there are group and role identities that people are filling as they go about their day (Abrams and Hogg, 1990; Stets and Burke, 2000; Stryker and Burke, 2000). All this happens in a landscape that is imbued with historical and cultural meaning. Although researchers entering a landscape may have a sense of what some of those things are, they do not experience these lived realities in the same way (rather they experience their own lived realities that may be more or less connected to the landscape where research is taking place). These realities are the daily things taken for granted that must be uncovered and accounted for to create quality engagement and communication strategies (Cunliffe and Scaratti, 2017). A close look at those internal components with hypothetical examples demonstrates how the TTM helps to shape our identification of different types of actions for different groups of stakeholders.

\section{C.3.3. Precontemplation}

In the precontemplation phase, people and organizations are not yet concerned with the issue at hand (in this case, threats of SLR and dramatic changes in the landscape of the South Carolina Lowcountry). Though they may have heard of the issue, it is not something they are actively thinking or concerned about. It may be that they have more pressing concerns and that this is not a salient issue in their lives or for functioning their organization. They may have heard of the problem but view it as something that needs to be addressed far off in the future and not something to be concerned with now. Finally, some may just not know anything about the issue of SLR. Yes, they will have noticed issues of flooding in the area, but this flooding could be viewed as normal or not that concerning. For this last group, they may not have been in the area for long and therefore lack historical context for comparison. There are, of course, also climate change deniers that grapple with these issues in unique ways. These deniers are not in the precontemplation phase, as they have likely had to do some amount of thinking about the issue to deny that it is happening.

\section{C.3.4. Contemplation}

In the contemplation phase, people are concerned about SLR and landscape change issues in the area, but they are not yet close to action. How people in the contemplation phase view the issue will determine how they move through the model. Local meaning-making structures will shape how people view the issue of SLR. Peterson and others (2002) demonstrated this in their work with issues of Odocoileus virginianus clavium (Barbour and G. M. Allen, 1922) (Key deer) conservation, finding that cultural frameworks to make sense of land, land use, wildlife, and human modifications on the landscape were deep seated, much harder to address than simple issues of awareness, and yet fundamental for understanding how conservation work for a given species on a landscape can occur.

\section{C.3.5. Preparation}

In the preparation phase, the problem has been recognized within cultural frameworks relevant to that individual, group, or organization, and they are now preparing to act. Preparing to act often leads groups and individuals to look to important people in their lives to see what they are doing and to think about how those actions align with the identity of the group (Terry and Hogg, 1996). Advertisers understand this better than most in society. If you can convince individuals that the group they identify with is doing something, then they will also be drawn to do that thing or to buy that product (Hogg and Reid, 2006; Schor, 2014). As recognized in behavioral economics and social psychology, in-group and out-group dynamics play an important role in shaping people's behaviors (Schor, 2014).

In this phase, an organization or individual may have identified that SLR in the area is a substantial threat to their wellbeing. They may look at how addressing the issue fits with their own goals and objectives, as well as how other similar groups are addressing the issue. People and organizations will also conduct cost-benefit analyses to determine what actions may be viable.

\section{C.3.6. Action}

It may take time to come to actual action or behavior in the TTM. Actions occur when individuals or groups act to address landscape change in the area. Actions are taken because they fit with the concerns that individuals see and feel in earlier stages of the model, that are consistent with identities they hold, and that are doable within their actual and perceived constraints to act. Actions must reinforce the concerns identified previously. For example, groups will not likely pursue a course of action that is at odds with their mission and goals; similarly, an individual will be less likely to take an action that is not consistent with their identity.

\section{C.3.7. Maintenance}

The TTM underscores the concept that, for behaviors to have large impacts on the landscape, behavior should become habit rather than occurring potentially only as rare, isolated acts. In conservation work, moving people to more conservation-friendly behaviors to only have them go back to the previous behavior is not success. 
For a behavior to be maintained, it must be central to multiple identities and not contradict identities that people or groups hold central to who they are and how they operate. In the case of landscape change around Cape Romain NWR, how land is protected and how long-term planning is conducted cannot be a single act for the landscape to persist through the threats of SLR and increased human usage. Rather, there must be new ways of conducting business and living in the South Carolina Lowcountry that are maintained over time.

\section{C.4. Engagement Activities}

We began this project with the need to better understand the landscape we were preparing to enter. To gain a sense of environmental, and specifically climate change, issues in the area, we first conducted a media review to understand what was being discussed, in what way, and by whom in primarily local media pieces within the previous 2 years or so. This process allowed us to gain a sense of how issues of climate change and SLR were presented broadly in the area around Cape Romain NWR. Importantly, although print and video media do not represent local understanding in its entirety, they do provide a glimpse as to how topics are being discussed in a broad sense in the area. We found that issues of flooding were covered regularly but that connecting those issues to climate change explicitly was rare in local and even national media coverage.

We recognized that place-based experiences and lived power differentials must shape engagement strategies. In other words, groups that operate at levels that are further removed from the immediate landscape of the South Carolina Lowcountry (for example, national-level organizations such as large conservation groups or governmental organizations) are engaged in ways that are different from those groups that operate primarily within local confines (for example, local municipalities, churches, small businesses, and homeowners). Although phone calls with individuals representing nationalor State-level government organizations would be appropriate, we felt that conversations with locally focused organizations should be conducted in face-to-face settings. Furthermore, these differences in operational level also often relate to power differentials - groups that have funding and support of the Federal Government likely have greater power than hyperlocal organizations. The map in figure $\mathrm{C} 2$ demonstrates the extending circles of experience and engagement that we used to apply the TTM for engagement purposes. From the media review and application of the TTM, we created a list of prioritized groups for engagement (table C2).

Cape Romain NWR and the areas immediately surrounding it are the darkest color on the map (fig. C2). This area represents a hyperlocal (community) focus that was very important to our partners at Cape Romain NWR because these are the stakeholders Cape Romain NWR staff interact with on a daily basis. Although this level is not necessarily the level of focus for most Federal conservation work, the household, neighborhood, and at times township levels are the only levels where the changes occurring on the landscape are experienced. Much of the actions identified in the strengths, weaknesses, opportunities, and threats workshop, discussed in chapter E, focus on this level.

The next concentric circle in the map in figure $\mathrm{C} 2$ represents local (city) governments, which have much more control over land use than any one home or business owner by their ability to set zoning laws and more. They are representatives of the hyperlocal level and should be responsive to those communities. The largest circles represent the highest institutional levels of State and Federal governments.

Cape Romain NWR is unique in its hyperlocal experience of landscape change while also existing within the larger Federal Government sphere (as are all NWRs). This uniqueness requires sensitivity to interpersonal relations between NWR staff and surrounding community leaders, as well as sensitivity to how the community views the NWR and its staff. Cognizant of the hierarchy of these relations, we next identified six forms for potential engagement actions that may better reach the intended audience.

Reactive (action 1).--Some groups do not necessarily need to be sought after depending on project and NWR goals at different points in time. For these groups, being prepared to react if contacted is important because they may have concerns about SLR that correspond with Cape Romain NWR's concerns, as well as others in the region. Being prepared to bring in yet unidentified partners is vital for a communitybased approach.

Scientific papers and presentations (action 2).-Papers and presentations created as a result of scientific pursuits of this project in particular and other projects focused on SLR are useful for entities that tend to be further removed from the South Carolina Lowcountry.

White papers (action 3).- These more informally produced papers can be a way to share lessons learned with other interested parties in the region and tend to be more accessible than peer-reviewed published papers.

Phone calls and emails (action 4).--Informal conversations and emails with groups and individuals for discovery purposes or to pursue deeper engagement are an important, more relaxed step of any engagement strategy.

Workshops (action 5).--Formal workshops to bring together different groups and individuals to discuss and understand the nature of the problem and potential collaborative pathways forward are important collaborative learning opportunities. This type of engagement was the focus for the tenure of this project.

Face-to-face (action 6).--More formal conversations for discovery and deeper engagement purposes with groups and individuals who may or may not also attend a workshop will be important moving forward to address SLR collaboratively in the area. 


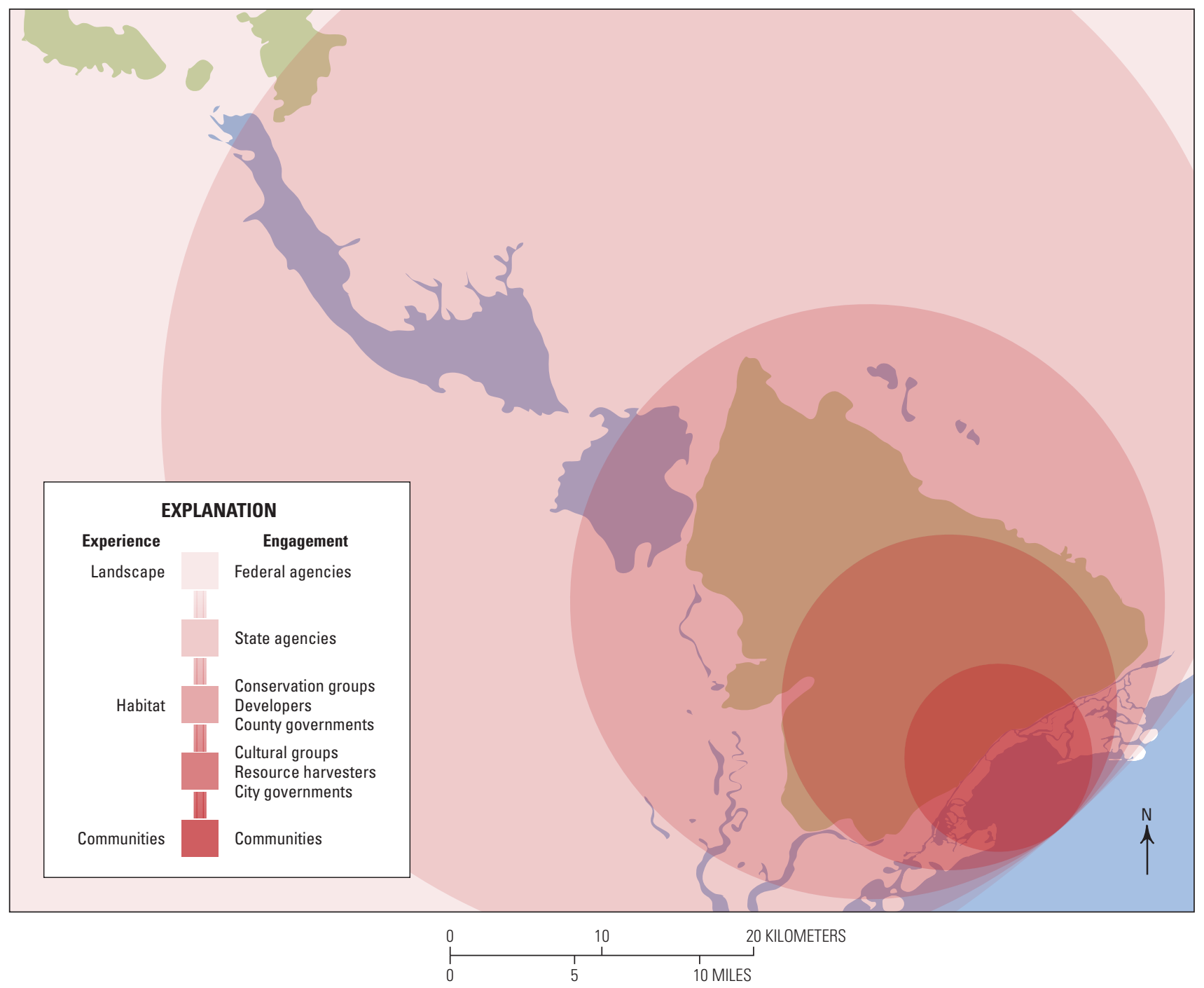

Figure C2. Geographical representation for application of the Transtheoretical Model to Cape Romain National Wildlife Refuge.

By identifying NWR stakeholders based on their geographic proximity and scale of influence or operation (demonstrated in fig. C2), we illustrate how different types of stakeholders in different places may be better suited to diverse engagement interactions (table C2). For example, when working with practitioners in the conservation community, we know that they are not in the precontemplation phase of the TTM but are quite obviously already in the action phase. However, finding new and unique actions is something that these groups may be eager to engage in. As a further example, community members may be within any of the internal components of the TTM, so face-to-face interactions and creative engagement strategies, such as a mapping exercise described in chapter C.4.2, are better suited than simply distributing fliers or providing information with the assumption that this broad group of stakeholders only lacks enough information on the issues of SLR in the South Carolina Lowcountry.

\section{C.4.1. Face-to-Face Meetings}

We conducted several stakeholder engagement activities. To begin, conversations with Cape Romain NWR staff, and our own personal experiences working on complex environmental issues, revealed a need to better identify the conservation players in the area, as well as what actions those groups were focused on. Duplication of efforts is a major pitfall of work on environmental issues. We did not want to fall into this trap and recognized the need to better connect with and understand the conservation and environmental organizations in the area. For our first round of meetings, we chose face-to-face discussions lasting 1-2 hours. They were purposefully informal and designed to be informative for all who gathered. We met with a total of seven highly active conservation focused groups in the South Carolina Lowcountry. These included Federal agencies, State agencies, national and local nongovernmental organizations, and more research-focused groups 
Table C2. Linking stakeholders and actions.

[Note that the closer positioned to on-the-ground experience by stakeholders (fig. C2), actions correspondingly move to more direct, on-the-ground interaction. USFWS, U.S. Fish and Wildlife Service; X, engagement strategy of choice; --, not recommended as an engagement strategy; USFS, U.S. Forest Service; USGS, U.S. Geological Survey; NPS, National Park Service, NOAA, National Oceanic and Atmospheric Administration; FEMA, Federal Emergency Management Agency; TNC, The Nature Conservancy; LCC, Landscape Conservation Cooperative; SCDNR, South Carolina Department of Natural Resources; SC, South Carolina; LOA, Local Operating Agency]

\begin{tabular}{|c|c|c|c|c|c|c|}
\hline Stakeholder & $\begin{array}{c}\text { Action } 1 \\
\text { (reactive) }\end{array}$ & $\begin{array}{l}\text { Action } 2 \text { (scien- } \\
\text { tific papers and } \\
\text { presentations) }\end{array}$ & $\begin{array}{l}\text { Action } \\
3 \text { (white } \\
\text { papers) }\end{array}$ & $\begin{array}{l}\text { Action } 4 \text { (phone } \\
\text { calls and } \\
\text { emails) }\end{array}$ & $\begin{array}{l}\text { Action } 5 \text { (work- } \\
\text { shops) }\end{array}$ & $\begin{array}{c}\text { Action } 6 \\
\text { (face-to- } \\
\text { face) }\end{array}$ \\
\hline \multicolumn{7}{|c|}{ Federal } \\
\hline National USFWS & $\mathrm{X}$ & $\mathrm{X}$ & $\mathrm{X}$ & -- & -- & -- \\
\hline National USFS & $\mathrm{X}$ & $\mathrm{X}$ & $\mathrm{X}$ & -- & -- & -- \\
\hline National USGS & -- & $\mathrm{X}$ & $\mathrm{X}$ & -- & -- & -- \\
\hline Gullah Geechee Corridor (NPS) & $\mathrm{X}$ & -- & -- & $\mathrm{X}$ & -- & -- \\
\hline NOAA & -- & $\mathrm{X}$ & $\mathrm{X}$ & $\mathrm{X}$ & $\mathrm{X}$ & $\mathrm{X}$ \\
\hline FEMA & -- & -- & -- & $\mathrm{X}$ & -- & -- \\
\hline TNC, National & $\mathrm{X}$ & $\mathrm{X}$ & $\mathrm{X}$ & -- & --- & -- \\
\hline National Media & $\mathrm{X}$ & -- & -- & -- & -- & -- \\
\hline Regional USFWS/LCCs & $\mathrm{X}$ & -- & -- & -- & -- & -- \\
\hline \multicolumn{7}{|c|}{ State } \\
\hline SCDNR & -- & $\mathrm{X}$ & $\mathrm{X}$ & $\mathrm{X}$ & $\mathrm{X}$ & $\mathrm{X}$ \\
\hline Ducks Unlimited & -- & -- & $\mathrm{X}$ & $\mathrm{X}$ & $\mathrm{X}$ & -- \\
\hline Friends of Coastal SC & -- & -- & $\mathrm{X}$ & $\mathrm{X}$ & $\mathrm{X}$ & -- \\
\hline Charleston County & -- & -- & -- & $\mathrm{X}$ & $\mathrm{X}$ & -- \\
\hline Georgetown County & -- & -- & -- & $\mathrm{X}$ & $\mathrm{X}$ & -- \\
\hline \multicolumn{7}{|c|}{ County } \\
\hline Santee Cooper Power & $\mathrm{X}$ & -- & -- & - & $\mathrm{X}$ & -- \\
\hline Timber Companies & $\mathrm{X}$ & -- & -- & -- & $\mathrm{X}$ & -- \\
\hline TNC & -- & $\mathrm{X}$ & $\mathrm{X}$ & -- & $\mathrm{X}$ & $\mathrm{X}$ \\
\hline Sea Grant & -- & $\mathrm{X}$ & $\mathrm{X}$ & -- & $\mathrm{X}$ & $\mathrm{X}$ \\
\hline Coastal Conservation League & -- & -- & -- & $\mathrm{X}$ & $\mathrm{X}$ & -- \\
\hline Low Country Land Trust & -- & -- & -- & -- & $\mathrm{X}$ & $\mathrm{X}$ \\
\hline Other land trusts & -- & -- & -- & -- & $\mathrm{X}$ & $\mathrm{X}$ \\
\hline Center for Heirs Property & -- & -- & -- & $\mathrm{X}$ & $\mathrm{X}$ & $\mathrm{X}$ \\
\hline \multicolumn{7}{|c|}{ City } \\
\hline Charleston & -- & -- & -- & $\mathrm{X}$ & $\mathrm{X}$ & \\
\hline Awendaw & -- & -- & -- & $\mathrm{X}$ & $\mathrm{X}$ & $\mathrm{X}$ \\
\hline McClellanville & -- & -- & -- & $\mathrm{X}$ & $\mathrm{X}$ & \\
\hline Commercial resource harvesters & -- & -- & -- & -- & $\mathrm{X}$ & $\mathrm{X}$ \\
\hline Local media & $\mathrm{X}$ & -- & -- & -- & -- & -- \\
\hline Cape Romain & -- & $\mathrm{X}$ & $\mathrm{X}$ & $\mathrm{X}$ & $\mathrm{X}$ & $\mathrm{X}$ \\
\hline Francis Marion & -- & $\mathrm{X}$ & $\mathrm{X}$ & $\mathrm{X}$ & $\mathrm{X}$ & $\mathrm{X}$ \\
\hline Bulls Bay Chamber & $\mathrm{X}$ & -- & -- & -- & -- & -- \\
\hline \multicolumn{7}{|c|}{ Community } \\
\hline Recreational outfitters & -- & -- & -- & -- & $\mathrm{X}$ & -- \\
\hline LOAs & -- & -- & -- & -- & $\mathrm{X}$ & -- \\
\hline Schools & -- & -- & -- & -- & -- & $\mathrm{X}$ \\
\hline
\end{tabular}


Table C2. Linking stakeholders and actions.-Continued

[Note that the closer positioned to on-the-ground experience by stakeholders (fig. C2), actions correspondingly move to more direct, on-the-ground interaction. USFWS, U.S. Fish and Wildlife Service; X, engagement strategy of choice; --, not recommended as an engagement strategy; USFS, U.S. Forest Service; USGS, U.S. Geological Survey; NPS, National Park Service, NOAA, National Oceanic and Atmospheric Administration; FEMA, Federal Emergency Management Agency; TNC, The Nature Conservancy; LCC, Landscape Conservation Cooperative; SCDNR, South Carolina Department of Natural Resources; SC, South Carolina; LOA, Local Operating Agency]

\begin{tabular}{lcccccc}
\hline Stakeholder & $\begin{array}{c}\text { Action 1 } \\
\text { (reactive) }\end{array}$ & $\begin{array}{c}\text { Action 2 (scien- } \\
\text { tific papers and } \\
\text { presentations) }\end{array}$ & $\begin{array}{c}\text { Action } \\
\mathbf{3} \text { (white } \\
\text { papers) }\end{array}$ & $\begin{array}{c}\text { Action 4 (phone } \\
\text { calls and } \\
\text { emails) }\end{array}$ & $\begin{array}{c}\text { Action } 5 \text { (work- } \\
\text { shops) }\end{array}$ & $\begin{array}{c}\text { Action } 6 \\
\text { (face-to- } \\
\text { face) }\end{array}$ \\
\hline Churches & -- & -- & -- & -- & -- & $X$ \\
\hline & & Community-Continued & & & & \\
\hline Private resource harvesters & -- & -- & -- & -- & $X$ & $X$ \\
Basket makers & -- & -- & -- & -- & -- & $X$ \\
Property owners & -- & -- & -- & -- & -- & $X$ \\
Residents & -- & -- & -- & -- & -- & $X$ \\
\hline
\end{tabular}

(Francis Marion National Forest; The Nature Conservancy, Charleston, South Carolina; Low Country Land Trust; National Oceanic and Atmospheric Administration (NOAA), Charleston, South Carolina; South Carolina Sea Grant; and Center for Heirs Property).

From these meetings, we learned that, as expected, there is an active and engaged conservation community concerned and active around the issue of SLR and the concomitant problems. We also learned there is still plenty of work to be done and that there are, as of yet, limited projects that focus explicitly on Cape Romain and the immediate surrounding areas. Although there is already a tight collaboration between Cape Romain NWR and Francis Marion National Forest regarding land acquisition to better connect the two entities, there is still much work to do. Perhaps unsurprisingly, NOAA is conducting the most sophisticated landscape modeling level research in the area. South Carolina Department of Natural Resources is very active on multiple issues across the State, with SLR posing major challenges for their mandate to protect natural resources.

Lowcountry Land Trust and The Nature Conservancy are conducting somewhat similar efforts in terms of placing land into conservation easement for posterity. In addition, Sea Grant works to bridge the ecological and the social milieus in ways that are important for conservation efforts at all levels. Finally, Center for Heirs Property offered a much more on-theground and in-touch local perspective; in particular, they work with and represent underserved and often underrepresented minorities in conservation efforts.

\section{C.4.2. Creative Engagement Opportunities- Seizing Opportunities to Learn}

Early in the process, we also seized on an opportunity to engage with (though in a limited matter) people who enjoy Cape Romain NWR as a recreational space in their area. The Bulls Bay Nature Festival, a yearly event that brings together multiple organizations working on Bulls Bay environmental issues to provide information and fun activities to the public, was the perfect opportunity. We created a quick and fun engagement activity designed to understand how people who live in the area and come to Bulls Bay at least once per year value the area and their level of concern for the landscape. For these purposes, two maps were provided to anyone who wished to participate at the Cape Romain information table. The first map asked people to mark their favorite spots in Bulls Bay, and the second map asked people to mark areas they were worried about. We took the data from the maps completed by 21 Bulls Bay Nature Festival attendees and created composite maps that use color shading to demonstrate areas with greater density of marks (figs. C3 and C4).

As figures C3 and C4 demonstrate, some of the most threatened areas (the outer points) are those people most often marked as the most special to them. Furthermore, the maps demonstrate a broad and consistent understanding (of those who participated) of the threats to Bulls Bay.

This mapping activity was an easy, low-cost engagement that collected valuable information. However, we must note the glaring shortcoming of selection bias. People who filled out these maps chose to come to the Bulls Bay Nature Festival and chose to visit the Cape Romain NWR information table. Most unfortunately, we were not able to engage in short conversations with those who filled out the maps, so we do not know what people are worried about in the areas they marked, nor do we know what it is they value about the areas they said mean the most to them. When we discuss the responsibility of taking culture seriously, we more deeply address these shortcomings.

\section{C.4.3. Workshops}

Our other stakeholder engagement actions included conducting the two workshops discussed in more depth in chapters D and E of this report. Here we will note a few features of these workshops relative to our overall engagement strategy. First, those individuals that attended the workshop 


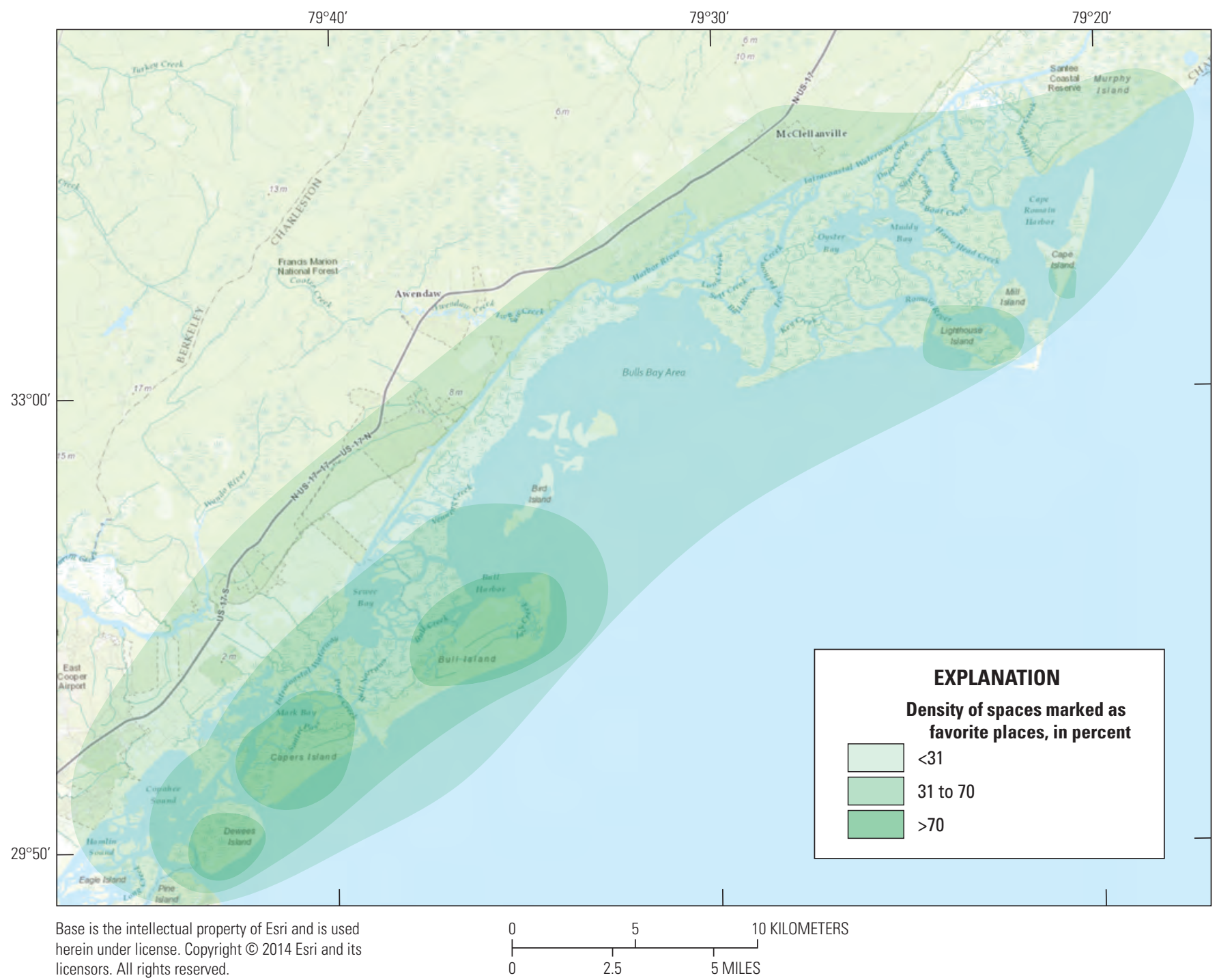

Figure C3. Density of spaces marked as favorite places by participants in the mapping activity at the Bulls Bay Nature Festival.

in face-to-face meetings. Establishing relations before the workshops makes for a more enjoyable experience because attendees feel heard and have a role in creating the workshops before they are held.

Secondly, we strove to create a setting where discussion was prioritized over rigid process, and relationship building was prioritized over top-down knowledge sharing. The workshops were held in a nature center that gave the workshops a low-key feel and made things like parking easy for the participants. Furthermore, we strove to not spend hours giving presentations. Rather, although the workshops did begin with a few short presentations, they primarily provided time for group discussions. This proved to be fruitful and more engaging for workshop participants.

Overall engagement efforts for this project focused on conservation and cultural organizations. The primary reason for this was because in our early meetings we uncovered the need for better coordination between multiple groups working towards similar goals. It also provided an opportunity to ensure that connections between Cape Romain NWR staff and these other organizations were robust and would continue when this project was complete. However, it must be noted that the limited groups and individuals with whom we engaged were a shortcoming of this project; because of this, we were not able to apply the TTM fully. In chapter G, we discuss how the TTM could be used moving forward with more community-level and nonconservation-based organization engagement.

\section{C.5. Lessons Learned}

Hegemonic depictions (depictions that are top down and rooted in positions of power) of a place on a map are not the end of the story. Maps are very useful in scenario planning, 


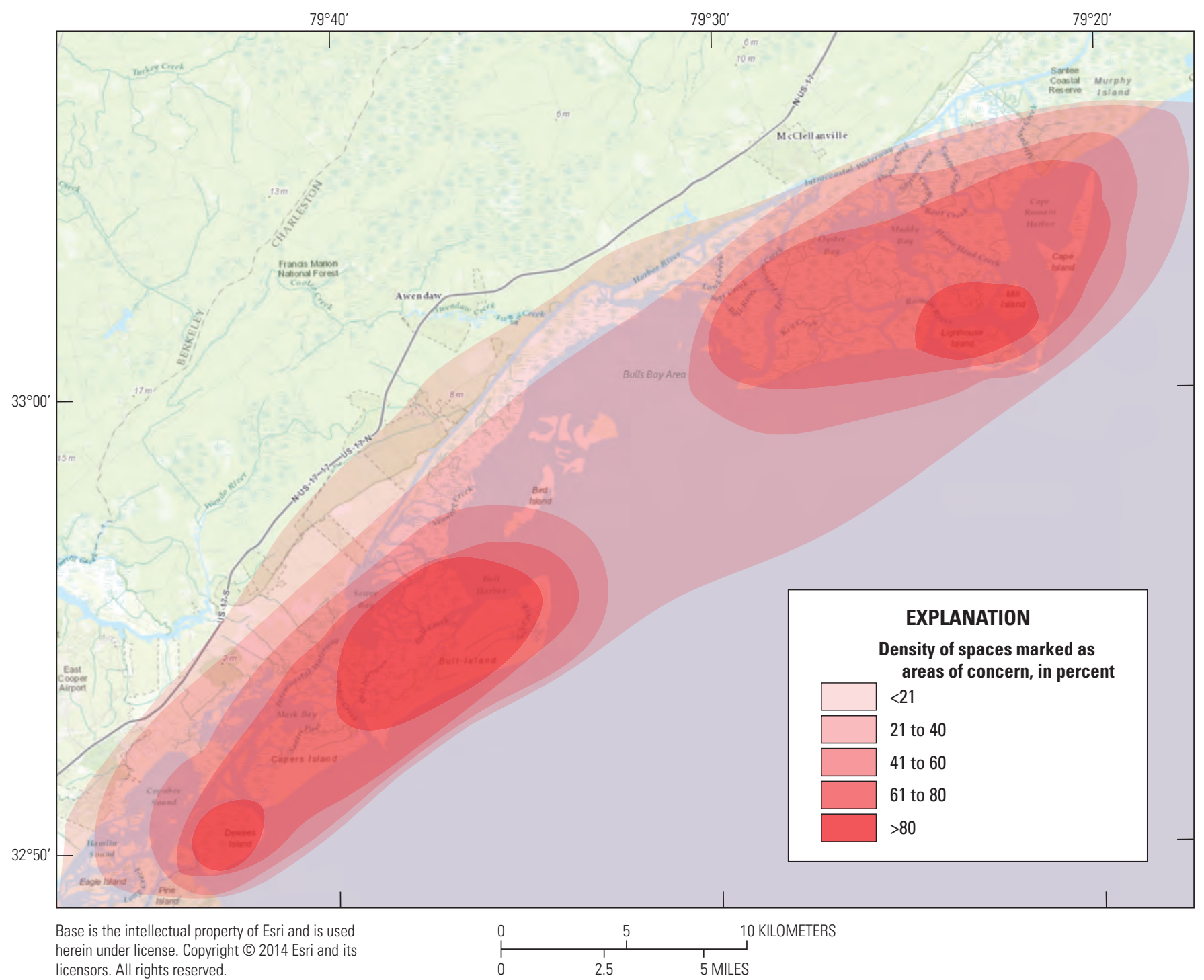

Figure C4. Density of spaces marked as areas of concerns by participants in the mapping activity at the Bulls Bay Nature Festival.

but we must be aware of the hegemony often inherent in mapmaking. Depending on whom one is engaging with, practitioners must recognize the power and potential repression inherent in mapping (Wood and Fels, 1992). Place-based experience should be valued in a way that is consistent with and in addition to information contained in geographic information system map layers.

There are several examples of when this came to light in our work. At all face-to-face meetings with different organizations, we noted how the first thing anyone wanted to do was to find their house on the maps we presented, particularly on the maps representing projections for SLR. We also realized that how people read maps can vary greatly, not just in aptitude but also in interpretation. Furthermore, at the scenario workshop when a plethora of maps were available online and taped to the walls of the meeting rooms, it was instead the stories of personal experience that shaped how people talked about the changes on the landscape. Finally, one workshop participant pointed to the very important step of ground-truthing maps. Maps depicting development are quickly out of date in an area experiencing growth at the rate seen in and around Charleston, S.C. All these examples point to the need to think more critically about how and what maps are being used in different engagement activities. These issues lead to our next lesson learned.

Researchers need to be on the ground — not being placebased is a major shortfall of this project. The social capital, networks, and experiential knowledge will fall short when researchers can only come to the place for short periods. Deep understanding (Hochschild, 2016) and the uncovering of multiple meanings and ways of making sense of a place and the changes happening there requires ethnographic, 
participant-observation methods. This is costly, but so is most research, and this on-the-ground approach should be prioritized when addressing wicked problems.

The Community of Inquiry approach (Haynes, 2018), which offers a radically democratic approach to engagement, allows for meaning to unfold through interaction in informal conversation and also in workshop settings. However, this means that practitioners conducting workshops must be prepared for the unpredictable nature of these types of workshops. If the goal is to create space for shared meaning making and not to dictate outcomes (as supported by a Community of Inquiry approach), then the process will be messy. For some, this is what they train for; qualitative social scientists are particularly suited due to their training to embrace this messiness, and good facilitators are also important for this process. A workshop forum that is not overly rigid from the outset will help this sort of process to unfold.

In the scenario-planning workshop, which occurred in January 2017, the recent presidential inauguration represented a powerful influence. By allowing for open discussion, we could see how concerns and opportunities regarding the new administration's priorities might affect the setting of conservation goals and real effects to the landscape. We learned from the effort of scenario construction that on-the-ground experience allowed the local organizations to see that community cohesion would be central for the region to address changes into the future. None of the researchers would have predicted this, and yet social and community resilience and cohesion were viewed in many ways more important than the physical changes on the landscape. We learned this because we created a space for open dialogue in the workshop.

Thinking and planning critically when determining group composition is important. Of course there are individual personalities; but, more importantly, we had to keep in mind that when dealing with a group of professionals coming to the workshops to represent their given institution, they would bring with them their own training and institutional cultures, as well as their own personal identities and worldviews. Planning and thinking about how professional identities affect group cohesion and group dynamics is not a predictive science but does require forethought and planning. Of course, some people do not participate as well in groups as they do at an individual level-overcoming this requires good facilitation skills more than anything.

We experienced quick group cohesion and easy group processes, but our group was composed of people who already knew each other because they all worked in similar fields. Conducting workshops with community-level individuals and institutions that do not necessarily share the same goals, skills, and identities as the Cape Romain NWR staff would require development of trust for open communication- $\mathrm{a}$ process that takes time (note this also relates to point number two and the need for social capital and trust to be built). Furthermore, researchers cannot and should not ask people for whom it is not part of their job description to take 8-hour blocks out of their days to come to a workshop if they want good representation. Long workshops during work hours constrains who can participate. We propose that scenario planning would be effective as a tool to be used across several meetings, held over several months, for working with community-level organizations.

Furthermore, awareness of how individual identities may shape group outcomes at scenario planning workshops is important. Our workshops were fairly homogenous in that nearly all participants were professionals in the conservation field. These individual identities heavily affect what is seen as important. For example, one of the scenario planning groups saw the sustainability and local food movements as potential major drivers for positive change in the region-which they very well may be, and there is certainly reason to support these movements. But a different group with different lived experience may or may not see these movements as important to them (DuPuis and Goodman, 2005). The scenarios created were plausible, but it will take moving out to other organizations and individuals to see if they resonate with the community at large.

Finally, researchers and practitioners must keep in mind that professional identities and roles in each individual's given institution also affects interactions. We had some negative reactions to the scenario workshop process because people were hoping for more robust and apparent next steps. For those who work on the ground in action-oriented jobs, the process of scenario planning felt a bit tedious, and it was unclear what benefit it provided to them (at least in the immediate term).

If culture matters, include those that deal with culture in the planning workshops. We received several compliments in our workshop for the consideration we gave to those who study the human side of environmental change, and we do believe that this mix of people from different academic traditions made the workshops more interesting and more useful. In fact, in the scenario planning workshop as we identified resources, one participant said, "but this is all culture"-a very anthropological view of culture and one needed for these processes. Having people at workshops who are explicitly concerned with meaning making helps us to move away from simplistic solutions, such as the notion that simply increasing knowledge leads to behavior change. The social world is much more complex than this notion. In one of the workshop groups, a participant suggested that if you bring people knowledge of a given issue, they are so thankful. A more community-based individual disagreed and noted that people need to be involved in defining the problem, not just brought information about a problem that has been defined by outsiders. However, even with this variability of perspectives and depth of consideration of communities, our workshop groups still came up with solutions like "use interns for outreach." This still suggests that the cultural is an afterthought. Outreach and bridge-building is one of the hardest parts of conservation work. Solutions will ultimately need actual commitment from conservation organizations. Tasks that involve the building of trust and social ties should not be done by short-term interns. 
Finally, if culture matters, then the team of researchers themselves must include those who study culture from the outset. Throwing in a social scientist as an afterthought happens much too often (Miller and others, 2008). For this project we must credit the funding agency and primary investigators' desire to approach this problem differently from the beginning.

Allowing for and embracing culture beside an open dialogic process (as with the Community of Inquiry approach) means that historical moments matter in unpredictable ways. This is always true and should not necessarily be surprising, but we were caught off guard with issues that arose in the scenario-planning workshop only 5 days after inauguration. The workshop was originally scheduled for October 2016 and had to be canceled last minute because of Hurricane Matthew. We prepared for Hurricane Matthew's impact, but instead the more pressing historical moment was a new, uncertain president. Practitioners must understand global, national, regional, and local events or at least have a willingness to allow them to shape the process in ways that may be unexpected.

This point also interacts with point number four above; individual identities interact with large-scale issues in many ways. The very livelihood of those in the conservationoriented group could be at stake because of changes in conservation and environmental funding. Identity and identity politics will be part of any workshop. How that identity is managed and used to help achieve goals depends on those leading the workshop, but it should be viewed as beneficial and something worth exploring.

\section{C.6. Conclusion}

In chapters $\mathrm{D}$ and $\mathrm{E}$ of this report, we present a more in-depth discussion of the workshops held with conservation professionals. Finally, in chapter F, we provide ideas for future work addressing complex problems, wicked problems in general, and continued collaboration for the Cape Romain Partnership for Coastal Protection. From an engagement standpoint, next steps must include moving beyond conservation-focused organizations and casting a broader net for engagement. We provide ideas for these actions based on lessons learned during our tenure on this project and application of the TTM.

\section{References Cited}

Abrams, D.E., and Hogg, M.A., eds., 1990, Social identity theory - Constructive and critical advances: Springer-Verlag Publishing, $224 \mathrm{p}$.
Ajzen, I., 1991, The theory of planned behavior: Organizational Behavior and Human Decision Processes, v. 50, no. 2, p. 179-211. [Also available at https://doi.org/10.1016/0749-5978(91)90020-T.]

Ajzen, I., 2002, Perceived behavioral control, self-efficacy, locus of control, and the theory of planned behavior: Journal of Applied Social Psychology, v. 32, no. 4, p. 665-683. [Also available at https://doi.org/10.1111/j.1559-1816.2002. tb00236.x.]

Armitage, C.J., 2009, Is there utility in the transtheoretical model?: British Journal of Health Psychology, v. 14, no. 2, p. 195-210. [Also available at https://doi.org/10.1348/135910708X368991.]

Bell, M.M., 2011, An invitation to environmental sociology 4th ed.: Los Angeles, SAGE Publications, Inc., 400 p.

Cheng, A.S., Kruger, L.E., and Daniels, S.E., 2003, "Place” as an integrating concept in natural resource politicsPropositions for a social science research agenda: Society \& Natural Resources, v. 16, no. 2, p. 87-104. [Also available at https://doi.org/10.1080/08941920309199.]

Cronon, W., 1996, The trouble with wilderness-Or, getting back to the wrong nature: Environmental History, v. 1, no. 1, p. 7-28. [Also available at https://doi.org/10.2307/3985059.]

Cunliffe, A.L., and Scaratti, G., 2017, Embedding impact in engaged research-Developing socially useful knowledge through dialogical sensemaking: British Journal of Management, v. 28, no. 1, p. 29-44. [Also available at https://doi.org/10.1111/1467-8551.12204.]

Dunlap, R.E., Van Liere, K.D., Mertig, A.G., and Jones, R.E., 2000, New trends in measuring environmental attitudes-Measuring endorsement of the new ecological paradigm-A revised NEP scale: The Journal of Social Issues, v. 56, no. 3, p. 425-442. [Also available at https://doi.org/10.1111/0022-4537.00176.]

DuPuis, E.M., and Goodman, D., 2005, Should we go "home" to eat?-Toward a reflexive politics of localism: Journal of Rural Studies, v. 21, no. 3, p. 359-371. [Also available at https://doi.org/10.1016/j.jrurstud.2005.05.011.]

Fulton, D.C., Manfredo, M.J., and Lipscomb, J., 1996, Wildlife value orientations-A conceptual and measurement approach: Human Dimensions of Wildlife, v. 1, no. 2, p. 24-47. [Also available at https://doi.org/10.1080/10871209609359060.] 
Game, E.T., Meijaard, E., Sheil, D., and McDonald-Madden, E., 2014, Conservation in a wicked complex world-Challenges and solutions: Conservation Letters, v. 7, no. 3, p. 271-277. [Also available at https://doi.org/10.1111/ conl.12050.]

Gobster, P.H., and Hull, R.B., eds., 2000, Restoring naturePerspectives from the social sciences and humanities: Washington, D.C., Island Press, 321 p.

Harrison, C.M., and Burgess, J., 1994, Social constructions of nature-A case study of conflicts over the development of Rainham Marshes: Transactions of the Institute of British Geographers, v. 19, no. 3, p. 291-310. [Also available at https://doi.org/10.2307/622324.]

Haynes, F., 2018, Trust and the community of inquiry: Educational Philosophy and Theory, v. 50, no. 2, p. 144-151. [Also available at https://doi.org/10.1080/00131857.2016.1 144169.]

Hochschild, A.R., 2016, Strangers in their own land-Anger and mourning on the American right: New York, The New Press, 416 p.

Hogg, M.A., and Reid, S.A., 2006, Social identity, self-categorization, and the communication of group norms: Communication Theory, v. 16, no. 1, p. 7-30. [Also available at https://doi.org/10.1111/j.1468-2885.2006.00003.x.]

Hong, Y.Y., Morris, M.W., Chiu, C.Y., and Benet-Martinez, V., 2000, Multicultural minds-A dynamic constructivist approach to culture and cognition: The American Psychologist, v. 55, no. 7, p. 709-720. [Also available at https://doi.org/10.1037/0003-066X.55.7.709.]

Kaplan, S., and Kaplan, R., 2009, Creating a larger role for environmental psychology - The Reasonable Person Model as an integrative framework: Journal of Environmental Psychology, v. 29, no. 3, p. 329-339. [Also available at https://doi.org/10.1016/j.jenvp.2008.10.005.]

Katz, E., and Light, A., 2013, Environmental pragmatism (1st ed.): London, Routledge, 368 p. [Also available at https://doi.org/10.4324/9780203714140.]

Leong, K.M., 2009, The tragedy of becoming commonLandscape change and perceptions of wildlife: Society \& Natural Resources, v. 23, no. 2, p. 111-127. [Also available at https://doi.org/10.1080/08941920802438642.]

McDuff, M., and Jacobson, S., 2000, Impacts and future directions of youth conservation organizations - Wildlife clubs in Africa: Wildlife Society Bulletin, v. 28, no. 2, p. 414-425. [Also available at https://www.jstor.org/stable/3783699.]
Meadow, A.M., Ferguson, D.B., Guido, Z., Horangic, A., Owen, G., and Wall, T., 2015, Moving toward the deliberate coproduction of climate science knowledge: Weather, Climate, and Society, v. 7, no. 2, p. 179-191. [Also available at https://doi.org/10.1175/WCAS-D-14-00050.1.]

Miller, T., Baird, T., Littlefield, C., Kofinas, G., Chapin, F.S., III, and Redman, C., 2008, Epistemological pluralism-Reorganizing interdisciplinary research: Ecology and Society, v. 13, no. 2, art. 46, accessed April 2018 at https://doi.org/10.5751/ES-02671-130246.

Milton, K., 1996, Environmentalism and cultural theoryExploring the role of anthropology in environmental discourse: London, Routledge, 288 p.

Peterson, M.N., Peterson, T.R., Peterson, M.J., Lopez, R.R., and Silvy, N.J., 2002, Cultural conflict and the endangered Florida Key deer: The Journal of Wildlife Management, v. 66, no. 4, p. 947-968. [Also available at https://doi.org/10.2307/3802928.]

Prochaska, J.O., and Velicer, W.F., 1997, The transtheoretical model of health behavior change: American Journal of Health Promotion, v. 12, no. 1, p. 38-48. [Also available at https://doi.org/10.4278/0890-1171-12.1.38.]

Rittel, H.W.J., and Webber, M.M., 1973, Dilemmas in a general theory of planning: Policy Sciences, v. 4, no. 2, p. 155-169. [Also available at https://doi.org/10.1007/ BF01405730.]

Schor, J.B., 2014, Born to buy-The commercialized child and the new consumer cult: New York, Simon and Schuster, 275 p.

Schutz, A., 1967, The phenomenology of the social world: Evanston, Ill., Northwestern University Press, 255 p.

Stern, P.C., Dietz, T., Abel, T.D., Guagnano, G., and Kalof, L., 1999, A value-belief-norm theory of support for social movements - The case of environmentalism: Human Ecology Review, v. 6, no. 2, p. 81-97. [Also available at https://cedar.wwu.edu/hcop_facpubs/1.]

Stets, J.E., and Biga, C.F., 2003, Bringing identity theory into environmental sociology: Sociological Theory, v. 21, no. 4, p. 398-423. [Also available at https://doi.org/10.1046/ j.1467-9558.2003.00196.x.]

Stets, J.E., and Burke, P.J., 2000, Identity theory and social identity theory: Social Psychology Quarterly, v. 63, no. 3, p. 224-237. [Also available at https://doi.org/10.2307/2695870.] 
Stryker, S., and Burke, P.J., 2000, The past, present, and future of an identity theory: Social Psychology Quarterly, v. 63, no. 4, p. 284-297. [Also available at https://doi.org/10.2307/2695840.]

Terry, D.J., and Hogg, M.A., 1996, Group norms and the attitude-behavior relationship - A role for group identification: Personality and Social Psychology Bulletin, v. 22, no. 8, p. 776-793. [Also available at https://doi.org/10.1177/0146167296228002.]
Wood, D., and Fels, J., 1992, The power of maps: New York, The Guilford Press, 248 p.

Yaffee, S.L., 1997, Why environmental policy nightmares recur: Conservation Biology, v. 11, no. 2, p. 328-337. [Also available at https://doi.org/10.1046/ j.1523-1739.1997.95204.x.] 


\section{Chapter D. Scenario Planning-Possible Futures in the South Carolina Lowcountry}

\section{D.1. Introduction}

Scenario planning was developed in the 1960 s as a way for organizations to cope with an uncertain future (Millett, 1988). Scenarios are plausible descriptions of possible future states of the world, but they are not predictions or forecasts (Berkhout and others, 2002; Peterson and others, 2003b; Rounsevell and Metzger, 2010). Rather, they are intended to offer insights into what the future might hold in terms of the threats and opportunities facing an organization. Scenarios are typically formulated as narrative storylines, although they often are based on quantitative information. Organizations use alternative scenarios to foster a shared perspective of possible futures, from which robust solutions to complex problems can arise.

Scenario planning is increasingly being used to explore adaptation to climate and global change (Peterson and others, 2003a; Duinker and Greig, 2007; Tompkins and others, 2008; Rosentrater, 2010; Sheppard and others, 2011; Cobb and Thompson, 2012; Carlsen and others, 2013; National Park Service, 2013). In this context, scenario planning can be a useful tool to explore highly uncertain events; to incorporate diverse knowledge, interests, and opinions; as a method of collective learning; and as a communication tool for working with a diversity of stakeholders who may have widely varying interests (Berkhout and others, 2002; Peterson and others, 2003b; Wiseman and others, 2011).

Our goal was to use scenario planning as a way to bring conservation interests together (a) to identify and work with those already affected by, and engaged with, global-change issues in the South Carolina Lowcountry; (b) to look beyond traditional conservation objectives to address a broad spectrum of concerns, values, and desired services associated with the coastal region; (c) to work together to reveal possible collaborations and identify sources of conflict; and (d) to use the bestavailable science to understand and guide decisions to achieve goals for the future of the South Carolina Lowcountry.

\section{D.2. Methods}

We conducted a 2-day scenario-planning workshop January 26-27, 2017, with participants from Cape Romain National Wildlife Refuge, South Carolina Department of Natural Resources, South Carolina Sea Grant, Lowcountry Land Trust, The Nature Conservancy, National Oceanic and Atmospheric Administration, University of South
Carolina, Francis Marion National Forest, South Carolina Aquarium, Center for Heirs Property, and the South Carolina Environmental Law Project.

Before the workshop, participants were provided a variety of internet resources describing climate-change effects, population growth, and social vulnerability (table D1). A variety of maps were also provided, including the following:

- Protected Area Database (Esri and U.S. Geological Survey, 2016),

- Sea Level Affecting Marshes Model (U.S. Geological Survey, 2020),

- Sea, Lake, and Overland Surges from Hurricanes (National Oceanic and Atmospheric Administration, 2017),

- Sea Level Rise Viewer (National Oceanic and Atmospheric Administration, 2020),

- SLEUTH urbanization model (North Carolina State University, 2016),

- Social vulnerability (Esri and Hazards \& Vulnerability Research Institute, 2018), and

- Property parcels (Charleston Water System and others, 2017).

Participants individually identified ecological goods and services of value to help focus development of the scenarios (Keeney 1992). A shorter list of values was subsequently constructed based on the frequency with which various goods and services were mentioned. The participants were then divided into two groups to develop scenarios. Scenarios were developed for so-called "tailored exploration," in which a participatory process is used to identify key drivers and trends that will shape the future of ecological goods and services in the South Carolina Lowcountry through the year 2050 (Wiseman and others 2011). We used the intuitive logics scenario process or driving forces method (Goodwin and Wright, 2014) that addresses an external environment largely beyond the control of the decision maker. Strategic actions are evaluated against the resulting scenarios; as such, actions are not considered part of the scenarios themselves.

Workshop participants relied on social, technological, environmental, economic, and political indicators to help identify important drivers of ecological goods and services (Rounsevell and Metzger, 2010; Wiseman and others, 2011; National Park Service, 2013). Drivers were considered in terms of degree of impact and degree of uncertainty (Wiseman and others, 2011; Wright and others, 2013; Goodwin and 
Table D1. Internet resources provided to participants before the scenario planning workshop, January 26-27, 2017.

[NOAA, National Oceanic and Atmospheric Administration]

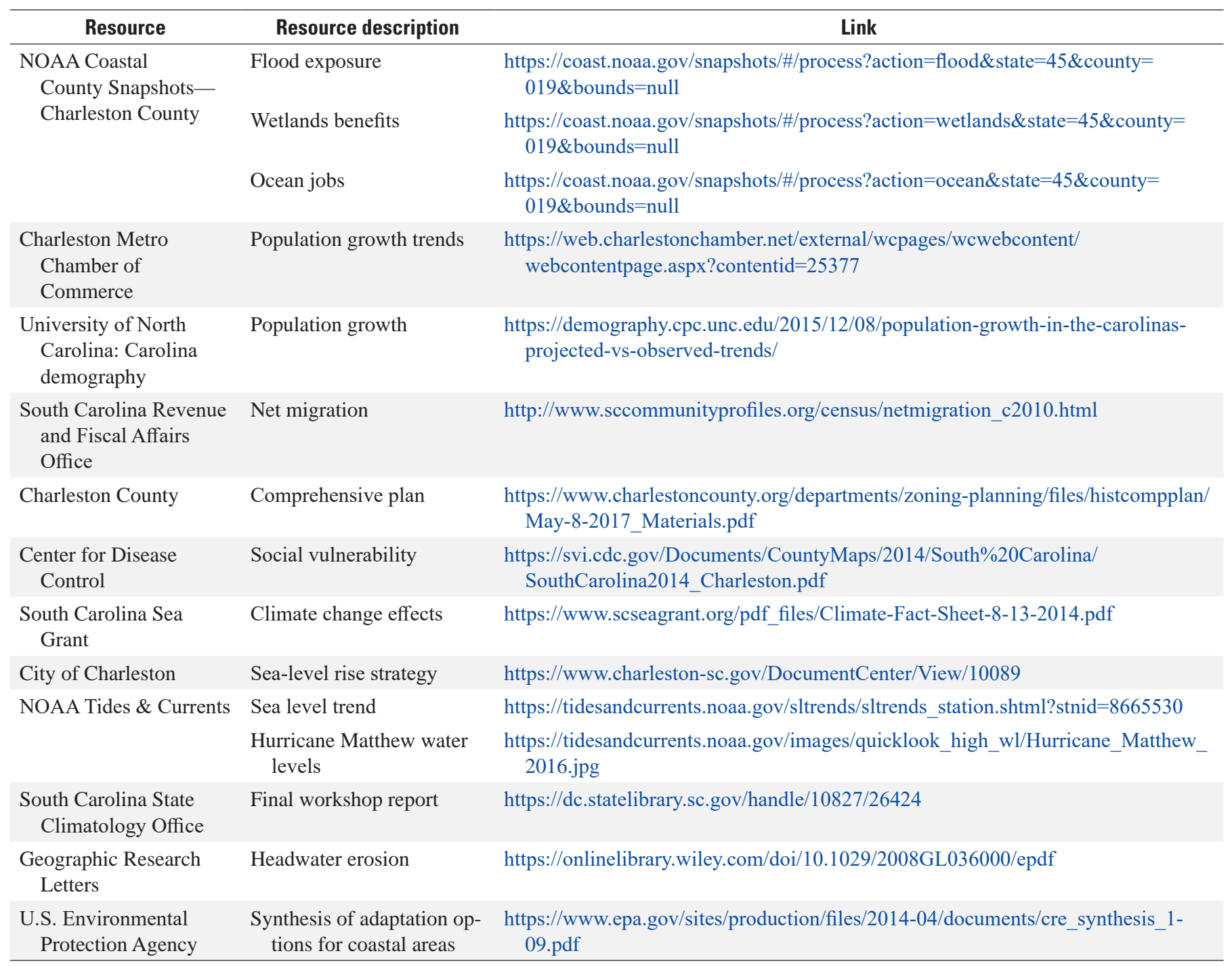

Wright, 2014). Participants assessed and prioritized drivers, recognizing the importance of governance (Berkhout and others, 2002; Tompkins and others, 2008) at multiple scales (Rounsevell and Metzger, 2010; Sheppard and others, 2011), as well as how perceptions are mediated by culture (Ney and Thompson, 2000; Crane, 2010; Cobb and Thompson, 2012; Adger and others, 2013). We used information from the workshop to designate three principal drivers and four alternative scenarios. Scenarios were used in a followup workshop to help develop strategic actions to help mitigate the effects of global change.

\section{D.3. Results}

A large array of ecological goods and services of value were identified by workshop participants (table D2). Based on the frequency with which they were mentioned, cultural values and provisioning services seem to be of greatest concern. Even among conservation interests, cultural values and provisioning services tended to be mentioned more than traditional values like biodiversity. Strong place attachment and interest in provisioning services provided by the landscape brought together a broad array of interests. 
Table D2. Summary of ecological goods and services of value identified by participants of the scenario planning workshop, January 26-27, 2017.

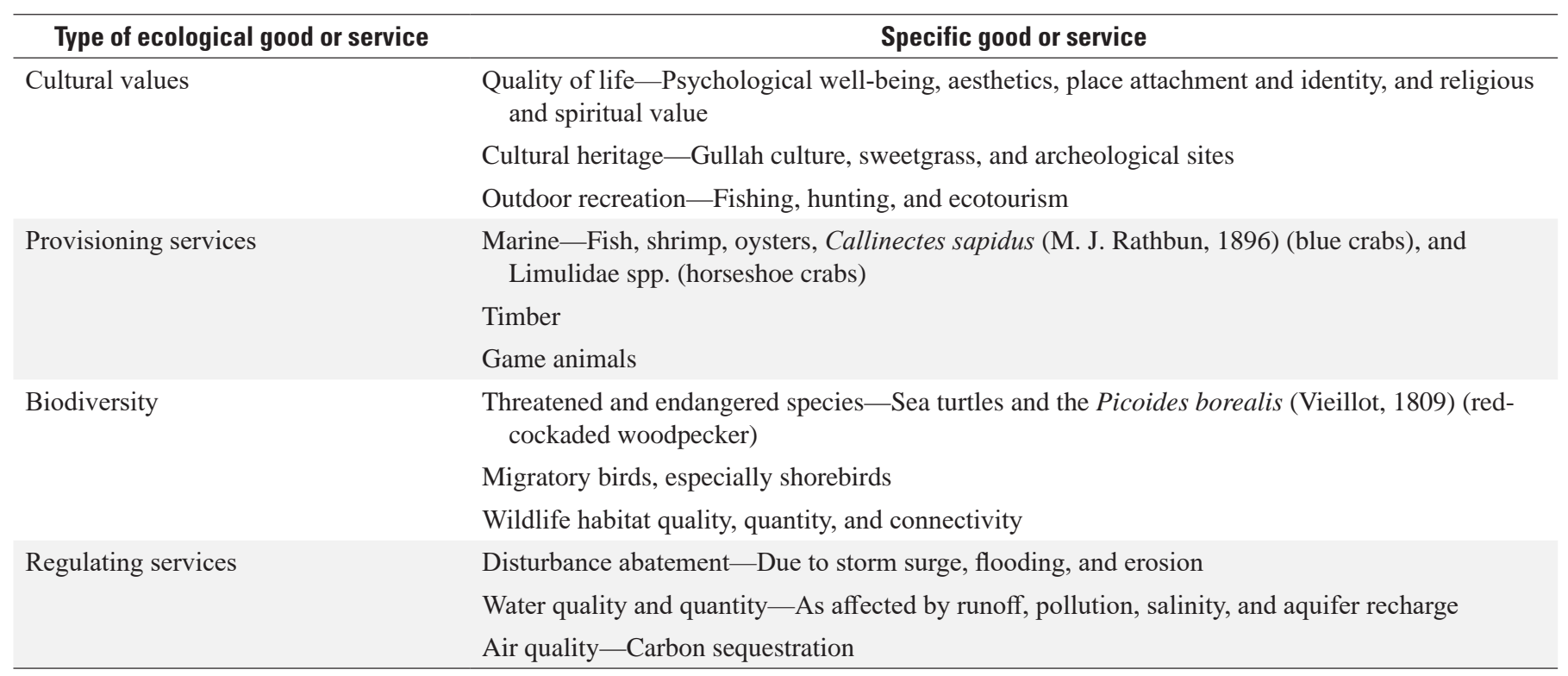

Several potential drivers of change in the South Carolina Lowcountry were identified by workshop participants. All were considered of high impact. Sea-level rise and population growth were considered the most certain, whereas economic opportunity, climate variability, and politics were considered the least certain. We eventually identified three principal drivers that encapsulated the diverse drivers identified at the workshop: climate change, changing world order, and local values and power structures.

The severity of climate change was considered a major driver for both workshop groups. This was the easiest driver to define and all specifics of climate change (for example, sea-level rise, frequency of extreme weather events, and so on) were combined into one driver.

Much of the workshop discussion (occurring, as it was, only 5 days after the January 2017 presidential inauguration) was underscored by a theme of national and global social-political shifts and upheaval. Recognizing that such changes can have important implications at the local level, we struggled with how to capture this complexity. How the United States responds to ongoing trends in globalization will affect the state and direction of the national economy, immigration patterns, political polarization, and cultural identity. The feeling that these features are changing in unpredictable ways that exclude certain segments of the population and worsen environmental degradation was discussed at length during the workshop. Because they were described as major drivers of change at a local level, we tried to capture their root cause as an uncertain but primary driver.
The local and regional cultural milieu and social systems were perceived by both groups as key areas where major drivers could be mitigated or made worse. This driver tries to capture the idea of social resilience, how forces such as identity unite or divide individuals and communities, how these entities mobilize resources, and how they are organized by some form of institutionalized hierarchy (power structures).

All scenarios assumed population growth will continue at pace through 2050 - this did not seem to be highly uncertain (South Carolina Revenue and Fiscal Affairs Office, 2019). How this influx of people affects the area, both in terms of infrastructure and societal reaction, will depend on other drivers at the local and regional scale.

Before articulating scenarios, we characterized the nature of moderate and severe changes that might be expected for the three principal drivers of change (table D3). For climate change, characterizations were based largely on observed trends and forecasts for the South Carolina Lowcountry available on the internet and from our own analyses (chap. B). Characterizations of a changing world order and local values and power structures were based more on theoretical arguments (Harrison and Burgess, 1994; Ney and Thompson, 2000; Lambin and others, 2001; Demeritt, 2002; Frank, 2016; Gardels and Berggruen, 2017).

The four scenarios depict two extreme and two intermediate futures. The figures associated with the following scenarios describe the characterization of the three principal driving forces. The colloquial names of the scenarios are intended as memes, which the partnership may or may not find useful. 
Table D3. Characterizations of "moderate" and "severe" climate change used to develop alternative future scenarios.

$\left[\leq\right.$, less than or equal to; >, greater than; SLR, sea-level rise; ${ }^{\circ}$ F, degree Fahrenheit]

\begin{tabular}{|c|c|}
\hline Moderate & Severe \\
\hline \multicolumn{2}{|c|}{ Climate change } \\
\hline $\begin{array}{l}\text { - } \quad \text { SLR of } \leq 1 \text { foot by } 2050 \text {. } \\
\text { - } \quad \text { No change in average precipitation but moderately increased fre- } \\
\text { quency of extreme events (drought, rain bombs, and tornadoes). } \\
\text { - Average annual temperature increase will be moderate, slightly } \\
\text { increasing competition for freshwater. } \\
\text { - Only minimal changes in seawater pollution, temperature, acidity, } \\
\text { and salinity. } \\
\text { - Frequency of tropical storms continues at historic rate of about } \\
\text { one landfall every } 3 \text { years, with most storms being category } 1 \text { or } \\
\text { less; even with more moderate SLR, this increases the potential } \\
\text { for widespread damage from storm surge. }\end{array}$ & $\begin{array}{l}\text { - SLR of about } 2 \text { feet by } 2050 \text {. } \\
\text { - } 270 \text { tidal floods per year in Charleston, S.C. } \\
\text { - } \text { quency of extreme events (drought, rain bombs, and tornadoes). } \\
\text { - Average annual temperature will increase } 3-4^{\circ} \mathrm{F} \text {, increasing } \\
\text { the frequency and severity of heat waves and competition for } \\
\text { freshwater. } \\
\text { - Substantial increase in seawater pollution, temperature, acidity, } \\
\text { and salinity. } \\
\text { - Frequency of tropical storms continues at historic rate of about } \\
\text { one landfall every } 3 \text { years, but more storms will be category } 2 \\
\text { and higher; with high SLR, this increases the potential for cata- } \\
\text { strophic storm surge. }\end{array}$ \\
\hline
\end{tabular}

Changing world order

- A responsible nationalism emerges (that is, the United States desires to maximize the welfare of its citizens but within a global community of interests); America takes strong leadership role in global response and directions, including economic, social equality, and environment.

- Nations increase societal safety nets and access to lifelong learning to combat the downsides of globalization, fostering rapid growth of entrepreneurship in information and internet technology in which more can participate in an expanding economy.

- Effective institutions of global governance emerge, as the world's largest economies (particularly China, India, and America) find ways to work together.

- Equitable trade policies are negotiated, increasing economic stability and sustaining growth.

- People feel more empowered as democracy and other participatory forms of governance expand.

- A greater sense of empowerment leads to more trust in institutions and the media, and this helps moderate the social, economic, and political upheaval associated with unchecked globalization.

- An effective global governance promotes sustainability, moderates the severity of climate change, keeps national and corporate power in check, and reduces the chance of regional conflict.
- Global backlash to globalization deepens and spreads, accompanied by rise of nationalism, authoritarianism, and government corruption.

- Shifting power relationships foster continued breakup of traditional alliances, leading to new geopolitical spheres of influence, which in turn fosters higher potential for regional wars, refugee crises, and nuclear proliferation.

- Distrust of governments, institutions, and the media deepens.

- Xenophobia, intolerance, and religious fundamentalism deepen and spread as cultures struggle to cope with social, economic, and political upheaval.

- Possibility of trade wars among economic powers increases.

- Global corporations exert growing power because of vacuum in global governance; this fosters rapid growth in mostly carbon heavy sectors and the military-industrial complex.

- Global cooperation on combating climate change languishes as more authoritarian-style leadership focuses on quick solutions to local problems; environmental regulations are weakened.

Local values and power structures

- Focus is more on community-based values, with more emphasis on maintaining social and economic regulations and safety nets.

- Place-based values and identity enhance social cohesion despite immigration, resulting in more power sharing, participatory forms of local governance, and government accountability.

- Social and environmental values are of high priority, with emphasis on egalitarianism and community- and incentive-based solutions.

- Society is buffered against the worst effects of global change because of a strong emphasis on education and community-based, proactive planning (for example, smart growth).
- Focus is on individual-based values, with limited regulations on social and economic policies.

- Historic tradition of paternalistic politics in the South Carolina Lowcountry endures, in which those who hold power are rarely challenged; this leads to a high potential for political corruption.

- Large-scale forces and private industry exert a strong influence on local social, economic, and environmental policy; private interests are pursued at the expense of cultural heritage and social cohesion; focus is on economic growth.

- Public services and income equality decline, and immigration and unchecked development make some population segments even more vulnerable to global change.

- Resiliency to even moderate climate change declines as largely regulation-based corrective measures are slow to be implemented. 


\section{D.3.1. Scenario 1-The Three Horsemen}

In scenario 1 (fig. D1), effective global response to climate change is small or nonexistent, and the backlash to globalization deepens and spreads over the coming decades. The United States greatly increases military spending and therefore can afford fewer social services. Isolationist policies embroil the United States in trade wars (leading to increased tariffs and trade barriers) and other protectionist policies. Global order is chaotic. The South Carolina Lowcountry, in turn, is plagued by social, economic, and political upheaval and increased polarization. Population growth continues, but fewer people are moving to the area by 2050 in response to declining environmental values and increasing coastal vulnerability. Society turns more inward looking, with politics becoming increasingly polarized, as people feel less in control of their lives. Local politics become less inclusive, less accountable, and more corrupt. People become more xenophobic; race relations become increasingly problematic. The gap between rich and poor continues to grow, adding to the breakdown of social cohesion. Tidal flooding and storm surge are a constant threat, affecting infrastructure and slowing economic growth. Local regulatory measures to combat local effects of climate change and urban sprawl are mainly too little, too late. A sense of place and appreciation of cultural heritage declines, making community-based solutions increasingly difficult to attain. Unincorporated areas of Charleston County are particularly hard-hit; McClellanville is largely abandoned to the sea. Response to sea-level rise comes largely in the form of

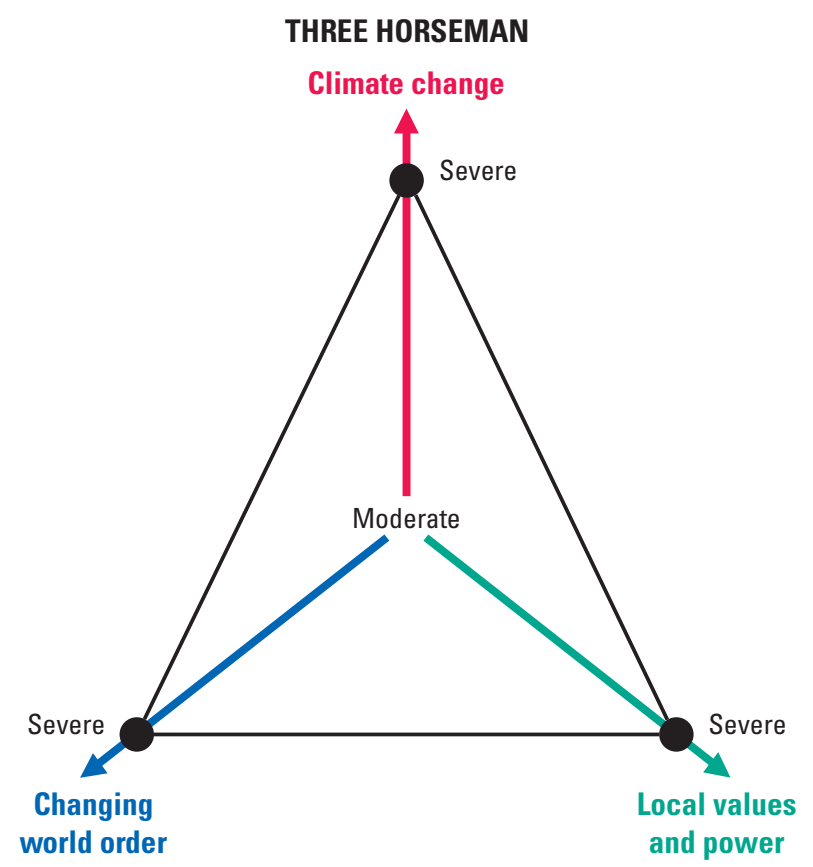

Figure D1. Depiction of future scenario entitled "The Three Horsemen," in which three principle driving forces of climate change, changing world order, and local values and power structure are all anticipated to be severe through 2050. coastal hardening to protect development and infrastructure. Ecotourism declines, and marine transportation jobs are hardhit by increased tariffs and trade barriers. Economic growth is driven mainly by the health sector and increased military spending. Large segments of the population are increasingly vulnerable because of ageing immigrant retirees, rural gentrification, lack of affordable housing, exposure to the effects of climate change, and the inability of public services to keep pace with the rapid changes affecting the area.

Environmental degradation is extensive by 2050 because of a combination of unregulated growth, climate change, and the power wielded by commercial interests. Effects include the rapid loss of barrier islands, accompanied by rapid conversion of marshlands to open water, in turn diminishing the value of commercial and recreational fisheries. The loss of barrier islands also reduces habitat available to migratory birds and sea turtles. Water-quality degradation (especially increases in coliform bacteria and salinity) leads to the commercial collapse of oyster and Callinectes sapidus (M. J. Rathbun, 1896) (blue crab) fisheries. Competition for clean, fresh water intensifies because of more frequent droughts and population growth throughout the State. Changes in precipitation patterns and increased flooding result in increased mosquito populations in low-lying areas, leading to higher risk of insect borne disease outbreaks. Rapid urbanization diminishes the aesthetic quality of the rural landscape and contributes to a decline in forestry.

\section{D.3.2. Scenario 2-United Front}

As in scenario 1, effective global response to catastrophic climate change is small or nonexistent, and the backlash to globalization deepens and spreads over the coming decades; the United States greatly increases military spending and therefore can afford less social services; and isolationist policies embroil the United States in trade wars (leading to increased tariffs and trade barriers) and other protectionist policies. Global order is chaotic because of shifting alliances and regional powers (fig. D2). Population continues to grow in the South Carolina Lowcountry, at least through 2050, attracting immigrants because of the desirability of the environment, culture, and lifestyle. Immigrants are anxious to maintain this lifestyle and assimilate rapidly, which prevents a breakdown in social cohesion. Much of this social cohesion centers on appreciation for natural resources. Government focus is on local economic development. Economic drivers are heavyindustry based (like Volvo, Boeing, and so on) because of isolationist policies of the federal government. These industries are bringing in more workers (educated and skilled) and employ locals as well; however, this also leads to some displacement of locals. For example, many of the infrastructure and road building contractors are bringing in their own people (not hiring locals). On the other hand, supporting industries are stimulated by the large economic drivers, such as the timber industry, which mainly employs local labor. These 


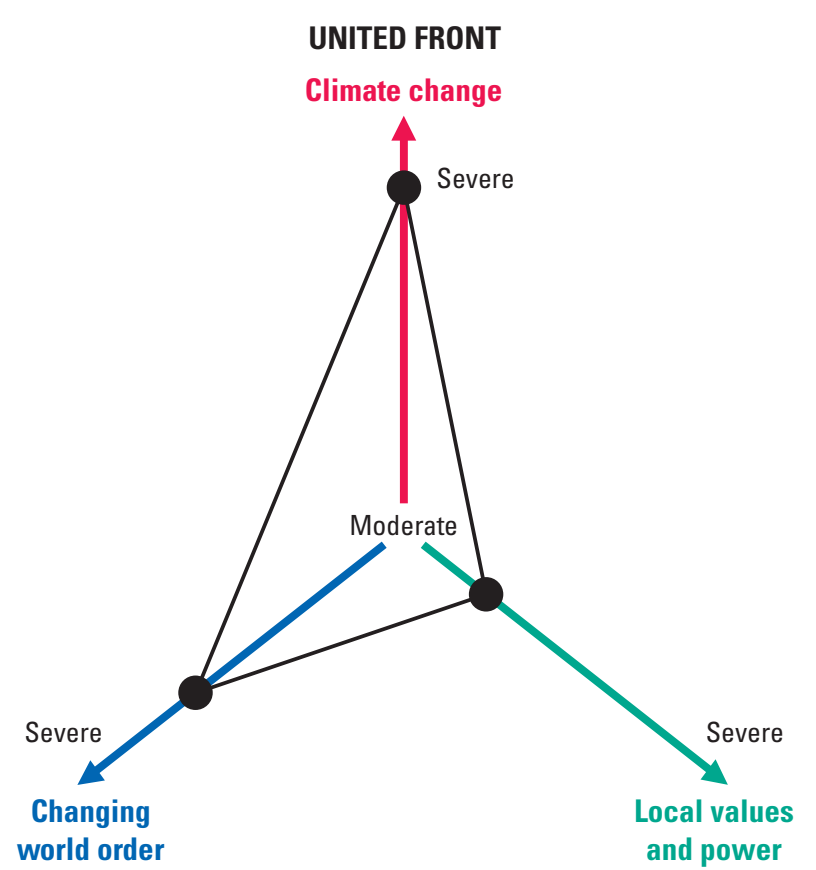

Figure D2. Depiction of future scenario entitled "United Front," in which two principle driving forces of climate change and changing world order are anticipated to be severe, while the third force (local values and power structure) is expected to be a moderate driver of change through 2050.

industries also result in more blue-collar jobs as other associated business opportunities arise (supporting industries include welding, construction, other types of entrepreneurship, and so on). This job increase does not solve income inequality or the urban versus rural divide hence there is variable economic opportunity. Heavy industry increases demand for energy and ecosystem services. This increases the marginal value of ecosystem services, increases development, and increases property values, which can affect access to coastal resources and lead to loss of property for those who cannot afford to live in this area in the new economic climate. Local governments act as necessary to protect the social-ecological system. City planners and administrators improve water treatment facilities and limit coastal development through zoning policies. Mayors and city council make educated zoning decisions based on projected sea-level rise, flood zones, elevation, and so on, along with key community stakeholders; communitybased planning is emphasized. Conservation organizations (all levels) form partnerships to expand the promotion and implementation of environmental education and environmental engagement. South Carolina Lowcountry "Local First" does outreach to promote positive effects of local economic stimulus. Other local organizations promote the positive human health and well-being effects of consuming local (for example, Charleston Good). Nongovernmental organizations and university cultural and historic departments organize training to encourage entrepreneurship to meet increased demand for local culture and heritage. The effectiveness of these activities is enhanced by a strong place identity and social cohesion.

The local effects of climate change on ecosystem goods and services are rather severe, however. An increased frequency of extreme events (rain bombs, drought, and tropical storms) is placing severe strains on public safety, human infrastructure, agriculture, and natural resources. Because of the increased frequency and severity of storms (for example, rain bombs), more impervious cover affects storm water runoff as natural drainage systems are disrupted, providing less opportunity for carbon sequestration. More runoff and less drainage affect access to clean water and affect coastal habitats through erosion and upsetting normal sediment transport systems. A lack of drainage (standing water) has human health implications, resulting in an increased risk of outbreaks of insect borne diseases, and increased storm severity affects access to social services (like hospitals). Bird and turtle nesting failures increase because of more intense storms, which affect the ecosystem services that these species provide (bird watching, aesthetic value, tourism, and wilderness immersion). Changes in precipitation patterns lead to more severe droughts, and infrequent but severe rainstorms result in extreme pollutant loading. Saltwater intrusion affects freshwater aquifers as well as shellfish habitat (oysters and blue crabs). Intrusion also changes marsh composition, which upsets the needs of habitatdependent organisms.

\section{D.3.3. Scenario 3-Real Life}

In scenario 3 (fig. D3), global action and national policies to reduce emissions are helping moderate the worst effects of climate change globally. Although local impacts by 2050 are less than some had feared, they are still placing strains on the resilience of the South Carolina Lowcountry socialecological system. Population continues to grow over the next few decades, principally through movement of people from other areas but then begins to moderate by 2050 because of the cumulative effects of global change and their effect on local ecosystem goods and services, which contributes to a decline in a sense of place. Although the worst of global climate-change effects have been avoided, local effects are still moderately high. Sea level continues to rise, and tidal flooding is approaching 180 times per year in Charleston. Local governments assume a strong role in adaptation to global change, supporting education, providing incentives to landowners, and implementing policies to control growth and protect the population from disasters. Charleston is successful at implementing its sea-level rise strategy of reinvestment, response, and readiness. Local services are also robust to help mitigate the health and infrastructure risks associated with such extremes in climate change. Efforts to stem the decline of social cohesion are being effective. Strong community-based action is led by conservation nongovernmental organizations and local governments with the support of Federal partners including Francis 
REAL LIFE

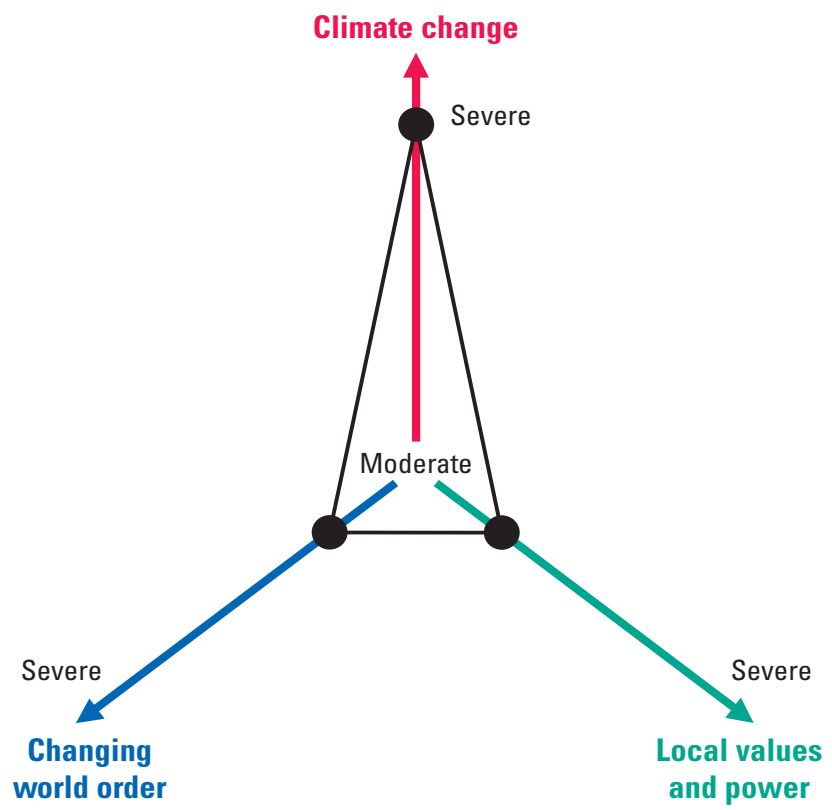

Figure D3. Depiction of future scenario entitled "Real Life," in which climate change is predicted to be a severe driving force, while changing world order and local values and power structure are foreseen to be moderate drivers of change through 2050.

Marion National Forest and Cape Romain National Wildlife Refuge. These groups and institutions provide and support education, communication, and awareness that are helping to bring people together to confront global change.

As seas continue to rise and water quality continues to decline, however, effects are taking their toll on ecosystem goods and services, affecting freshwater supply and quality, fisheries, recreation, tourism, and biodiversity. Nonetheless, with Federal, State, and local support, Francis Marion National Forest and Cape Romain National Wildlife Refuge secure additional properties through fee-title and easement to provide for marsh migration and to enhance habitat area and connectivity. Effective ways are found to use spoil for replenishing beaches and building nesting islands for migratory birds.

\section{D.3.4. Scenario 4-Manna}

In scenario 4 (fig. D4), global action on climate change is strong and effective, in part driven by rapid advances in technology. Developed and developing nations come to agreements about how to share (and enforce) the costs of mitigation and adaptation. Democracy and participatory governance spread in a more stable world order, leading to a greater sense of individual empowerment. Nation states preserve their identities, but they have a greater awareness of global interconnections and their responsibility to future generations. Local political power becomes more distributed

\section{MANNA FROM HEAVEN}

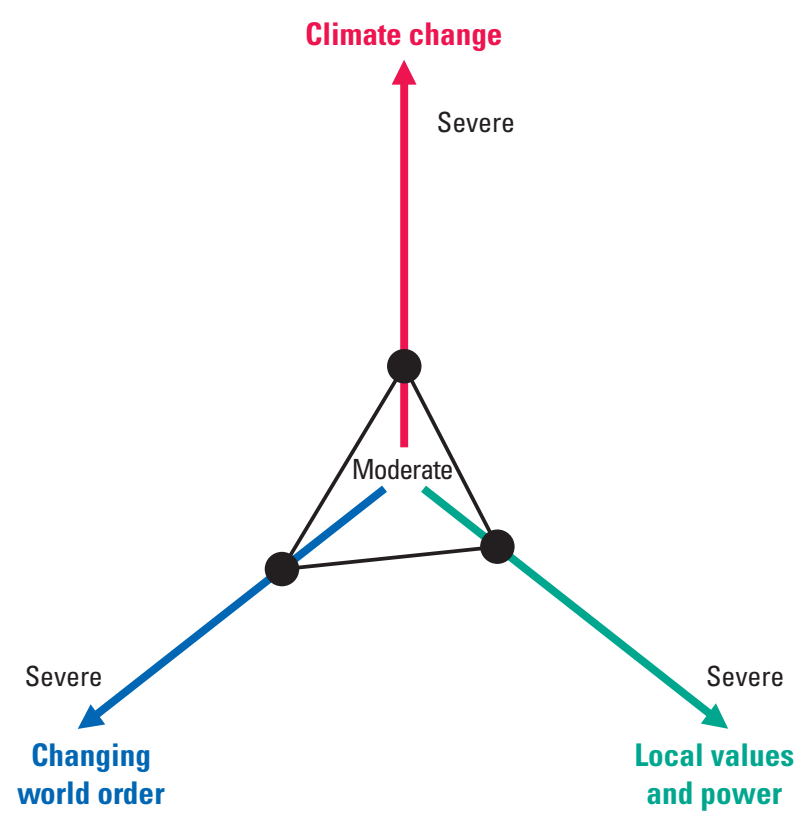

Figure D4. Depiction of future scenario entitled "Manna," in which all three primary driving forces of climate, changing world order and local values and power structure are predicted to be moderate factors through 2050.

because nongovernmental organizations, churches, and other organizations play a large role in generating community-based solutions. With support from the Federal Government (including Francis Marion National Forest, Cape Romain National Wildlife Refuge, and others), communities rely more on incentive-based adaptation measures and less on regulatory ones. Ecotourism continues to flourish, and marine transportation sees strong growth because of modern, fair-trade policies. Economic development is more egalitarian because smart growth is designed to protect a diversity of local values, especially abatement of flooding and storm surge. Federal funding is available to protect or retrofit infrastructure at risk from global change, especially in Charleston to help prevent tidal flooding. Local communities support programs of adult education and training, and the area becomes more attractive to hi-tech industry. Social services are sufficient to support at-risk populations. Community cohesion is high because of the desire to maintain South Carolina Lowcountry local identities; this cohesion fosters support for local and sustainable products.

Less climate change and more geopolitical stability helps South Carolina Lowcountry communities do better at protecting and preserving cultural values and local ecosystem goods and services. Less extreme changes in precipitation patterns leads to fewer threats to human health, and those threats that do emerge are more easily addressed through robust social services. Sea-level rise continues and approaches 1 foot by 2050 and is the principal effect of climate change. Ecosystem goods and services are affected by sea-level rise 
and population growth, but society is spared the worst effects. Fisheries are negatively affected because of loss and degradation of habitat, especially commercial fisheries for oysters and blue crab. Recreational fishing continues to be a strong draw to the area. The timber industry remains viable, and longleaf restoration provides more resilient forests. Some threatened and endangered species do better (Picoides borealis [Vieillot, 1809] [red-cockaded woodpecker]), whereas others (sea turtles) continue to decline. Coastal populations of seabirds continue to decline because of widespread habitat loss on the Atlantic coast.

\section{D.4. Discussion}

Scenarios are stories about how the future might unfold for our organizations, our communities and our world. Scenarios are not predictions. Rather, they are provocative and plausible accounts of how relevant external forces - such as the future political environment, scientific and technological developments, social dynamics, and economic conditions - might interact and evolve, providing our organizations with different challenges and opportunities.

Global Business Network, as quoted in National Park Service (2013).

Stories play an important role in organizational learning, fostering the collaborative diagnosis of complex problems and serving as a repository for accumulated knowledge (Berkhout and others, 2002). Additionally, scenario storylines can be shared by individuals who do not share the same organization and who may have widely divergent interests (Wright and others, 2013). A participatory approach to scenario planning can provide saliency and richness to storylines and become a vehicle for consensus building and problem solving (Rounsevell and Metzger, 2010). It can also enhance legitimacy in the eyes of participants, although credibility may be limited if the participants lack diversity (Rounsevell and Metzger, 2010). Although the ultimate goal of our scenario-planning exercise was to help explore and develop strategies to mitigate the effects of climate change and other global-change factors, perhaps its greatest contribution will be its ability to do the following:

- foster greater awareness of social-ecological change and its effects;

- explore and integrate many different issues and forms of knowledge;

- expose and explore different worldviews;

- consider a broader, more holistic range of options for dealing with social-ecological change; and
- promote greater awareness of the role of human choices and actions in shaping the future (Wiseman and others, 2011).

Scenario planning does have its limitations, however. As in other cases, our workshop lacked diversity in participants (mostly all were part of the conservation community), and the limited perspectives could weaken the scenarios' credibility when communicating them to more diverse groups (Rounsevell and Metzger, 2010). We were subject to other common pitfalls as well, including insufficient time for scenario development, unrealistic goals and expectations of the process and product, and a lack of a clear link with planning processes (Duinker and Greig, 2007). Indeed, how scenarios may be better used to catalyze institutional and behavioral change remains somewhat of an open question (Rosentrater, 2010). For this reason, there has been increasing interest in combining scenario planning with other tools of multicriteria decision analysis (Montibeller and others, 2006; Karvetski and others, 2011). Building on the work of others (Krysanova and others, 2010; Kajanus and others, 2012), we chose to use a strengths, weaknesses, opportunities, and threats analysis to help guide collaborative action based on the results of our scenario planning (chap. E).

Our scenario planning exercise helped highlight the importance of scale in adaptation to social-ecological change, whereby planners must attempt to understand the spatial and temporal scales of ecological goods and services, the ecological scales involved in their production, and the institutional scales at which they are managed (Adger and others, 2005; Hein and others, 2006; Paloniemi and others, 2012). Our experience also emphasized how political and economic trends in far reaches of the globe can affect local adaptation planning (Lambin and others, 2001; Lambin and Meyfroidt, 2011; Meyfroidt and others, 2013). The difficulty facing local adaptation planners is one of scale mismatches, in which the scale of environmental changes and the scale of the social organizations responsible for their management are not aligned (Cumming and others, 2006; Johnson and others, 2015). When environmental changes are taking place on a large scale, and adaptation is being planned in a local setting, planning decisions can lack continuity and consistency, social systems can be disrupted, and essential features of the system can be left unmanaged (Cumming and others, 2006). Adaptive co-management, also called adaptive governance, has been suggested as a framework to help cope with scale mismatches (Cumming and others, 2013). This philosophy emphasizes bottom-up, nonregulatory approaches, broad-based participation, power sharing, and social learning (Armitage and others, 2007, 2009, 2012). This philosophy also focuses on selforganizing social networks, future visioning, building trust and social capital, and capacity building through partnerships (Berkes, 2010; Guerrero and others, 2013). More recently, it has come to embrace the coproduction of knowledge, in which stakeholders and scientists work closely together to construct 
knowledge in a social environment of problem solving (Folke and others, 2005; Berkes, 2009; Armitage and others, 2012; Meadow and others, 2015).

Adaptation to social-ecological change unquestionably qualifies as a response to a wicked problem (see chap. A.4), in which there are competing values, no definitive problem formulation, no exhaustive set of alternatives, and deep uncertainty about the future and the ability to influence it (Rittel and Webber, 1973; Ludwig, 2001; Berkes, 2010; Game and others, 2014). Traditional planning tools like decision analysis are often of little use for these sorts of complex problems, in which a diversity of stakeholders and decision makers are involved who bring with them not only competing priorities but also various ways of perceiving the world. Cultural construction, a central tenet of anthropology, sociology, and cultural geography, suggests that how we view, understand, and experience the world can vary substantially among individuals (Demeritt, 2002). These are not trivial differences which can be overcome by a linear process of decision making. In the end, complex conservation problems can only be solved by society at large; therefore, acceptable solutions will only arise when there is a respect for the pluralities of experience and meaning that stakeholders bring with them to the decisionmaking process (Ney and Thompson, 2000; Adger and others, 2013). Plurality then is not merely a nuisance to be abstracted away but something that must be embraced in any attempt to solve a wicked problem. Scenario planning can be a useful tool in this regard by helping to explore the ecological, social-cultural, political, and economic context of a complex problem. Ultimately, possible solutions to wicked problems will be generated by local actors behaving in accordance with their own particular perception of the social-ecological landscape (Rayner and Malone, 1997; Verweij and others, 2006; Crane, 2010).

\section{References Cited}

Adger, W.N., Arnell, N.W., and Tompkins, E.L., 2005, Successful adaptation to climate change across scales: Global Environmental Change, v. 15, no. 2, p. 77-86. [Also available at https://doi.org/10.1016/j.gloenvcha.2004.12.005.]

Adger, W.N., Barnett, J., Brown, K., Marshall, N., and O'Brien, K., 2013, Cultural dimensions of climate change impacts and adaptation: Nature Climate Change, v. 3, no. 2, p. 112-117. [Also available at https://doi.org/10.1038/ nclimate1666.]

Armitage, D.R., Berkes, F., and Doubleday, N., eds., 2007, Adaptive co-management-Collaboration, learning and multi-level governance: Vancouver, UBC Press, $360 \mathrm{p}$.
Armitage, D.R., de Loë, R., and Plummer, R., 2012, Environmental governance and its implications for conservation practice: Conservation Letters, v. 5, no. 4, p. 245-255. [Also available at https://doi.org/10.1111/ j.1755-263X.2012.00238.x.]

Armitage, D.R., Plummer, R., Berkes, F., Arthur, R.I., Charles, A.T., Davidson-Hunt, I.J., Diduck, A.P., Doubleday, N.C., Johnson, D.S., Marschke, M., McConney, P., Pinkerton, E.W., and Wollenberg, E.K., 2009, Adaptive co-management for social-ecological complexity: Frontiers in Ecology and the Environment, v. 7, no. 2, p. 95-102. [Also available at https://doi.org/10.1890/070089.]

Berkes, F., 2009, Evolution of co-management-Role of knowledge generation, bridging organizations and social learning: Journal of Environmental Management, v. 90, no. 5, p. 1692-1702. [Also available at https://doi.org/10.1016/j.jenvman.2008.12.001.]

Berkes, F., 2010, Devolution of environment and resources governance-Trends and future: Environmental Conservation, v. 37, no. 4, p. 489-500. [Also available at https://doi.org/10.1017/S037689291000072X.]

Berkhout, F., Hertin, J., and Jordan, A., 2002, Socio-economic futures in climate change impact assessment-Using scenarios as "learning machines": Global Environmental Change, v. 12, no. 2, p. 83-95. [Also available at https://doi.org/10.1016/S0959-3780(02)00006-7.]

Carlsen, H., Dreborg, K.H., and Wikman-Svahn, P., 2013, Tailor-made scenario planning for local adaptation to climate change: Mitigation and Adaptation Strategies for Global Change, v. 18, no. 8, p. 1239-1255. [Also available at https://doi.org/10.1007/s11027-012-9419-x.]

Charleston Water System, Berkeley County, Charleston County, and Dorchester County, 2017, Parcels: Esri ArcGIS digital data, accessed August 2020 at https://www.arcgis.com/home/item.html?id=57b993133af54 b9b85576d54c0b16698.

Cobb, A.N., and Thompson, J.L., 2012, Climate change scenario planning-A model for the integration of science and management in environmental decision-making: Environmental Modelling \& Software, v. 38, p. 296-305. [Also available at https://doi.org/10.1016/j.envsoft.2012.06.012.]

Crane, T.A., 2010, Of Models and Meanings-Cultural Resilience in Social-Ecological Systems: Ecology and Society, v. 15, no. 4, art. 19. [Also available at https://doi.org/10.5751/ES-03683-150419.] 
Cumming, G.S., Cumming, D.H.M., and Redman, C.L., 2006, Scale mismatches in social-ecological systems-Causes, consequences, and solutions: Ecology and Society, v. 11, no. 1, art. 14. [Also available at https://doi.org/10.5751/ ES-01569-110114.]

Cumming, G.S., Olsson, P., Chapin, F.S., III, and Holling, C.S., 2013, Resilience, experimentation, and scale mismatches in social-ecological landscapes: Landscape Ecology, v. 28, no. 6, p. 1139-1150. [Also available at https://doi.org/10.1007/s10980-012-9725-4.]

Demeritt, D., 2002, What is the "social construction of nature"? A typology and sympathetic critique: Progress in Human Geography, v. 26, no. 6, p. 767-790. [Also available at https://doi.org/10.1191/0309132502ph402oa.]

Duinker, P.N., and Greig, L.A., 2007, Scenario analysis in environmental impact assessment-Improving explorations of the future: Environmental Impact Assessment Review, v. 27, no. 3, p. 206-219. [Also available at https://doi.org/10.1016/j.eiar.2006.11.001.]

Esri and Hazards \& Vulnerability Research Institute, 2018, Social vulnerability 2010: Esri ArcGIS digital data, accessed August 2020 at https://www.arcgis.com/home/ item.html?id=adcc7996a4564c66bdadf8839a9b45d3.

Esri and U.S. Geological Survey, 2016, PADUS 1.4 data and categories: Esri ArcGIS digital data, accessed August 2020 at https://www.arcgis.com/home/item.html?id=2b2cbb6a6fd 246969f8c36ad7e1746bc.

Folke, C., Hahn, T., Olsson, P., and Norberg, J., 2005, Adaptive governance of social-ecological systems: Annual Review of Environment and Resources, v. 30, no. 1, p. 441-473. [Also available at https://doi.org/10.1146/ annurev.energy.30.050504.144511.]

Frank, T., 2016, The US in a changing world order: Society, v. 53, no. 5, p. 531-537. [Also available at https://doi.org/10.1007/s12115-016-0061-1.]

Game, E.T., Meijaard, E., Sheil, D., and McDonald-Madden, E., 2014, Conservation in a wicked complex world; challenges and solutions: Conservation Letters, v. 7, no. 3, p. 271-277. [Also available at https://doi.org/10.1111/ conl.12050.]

Gardels, N., and Berggruen, N., 2017, Salvaging globalization: New Perspectives Quarterly, v. 34, no. 1, p. 67-79. [Also available at https://doi.org/10.1111/npqu.12070.]

Goodwin, P., and Wright, G., 2014, Decision analysis for management judgment (5th ed.): West Sussex, U.K., John Wiley \& Sons Ltd., 496 p.
Guerrero, A.M., McAllister, R.R.J., Corcoran, J., and Wilson, K.A., 2013, Scale mismatches, conservation planning, and the value of social-network analyses: Conservation Biology, v. 27, no. 1, p. 35-44. [Also available at https://doi.org/10.1111/j.1523-1739.2012.01964.x.]

Harrison, C.M., and Burgess, J., 1994, Social constructions of nature-A case study of conflicts over the development of rainham marshes: Transactions of the Institute of British Geographers, v. 19, no. 3, p. 291-310. [Also available at https://doi.org/10.2307/622324.]

Hein, L., van Koppen, K., de Groot, R.S., and van Ierland, E.C., 2006, Spatial scales, stakeholders and the valuation of ecosystem services: Ecological Economics, v. 57, no. 2, p. 209-228. [Also available at https://doi.org/10.1016/j.ecolecon.2005.04.005.]

Johnson, F.A., Eaton, M.J., McMahon, G., Nilius, R., Bryant, M.R., Case, D.J., Martin, J., Wood, N.J., and Taylor, L., 2015, Global change and conservation triage on national wildlife refuges: Ecology and Society, v. 20, no. 4, 20. [Also available at https://doi.org/10.5751/ES-07986-200414.]

Kajanus, M., Leskinen, P., Kurttila, M., and Kangas, J., 2012, Making use of MCDS methods in SWOT analysisLessons learnt in strategic natural resources management: Forest Policy and Economics, v. 20, p. 1-9. [Also available at https://doi.org/10.1016/j.forpol.2012.03.005.]

Karvetski, C.W., Lambert, J.H., Keisler, J.M., and Linkov, I., 2011, Integration of decision analysis and scenario planning for coastal engineering and climate change-IEEE Transactions on Systems: Management and Cybernetics - Part A: Systems and Humans, v. 41, no. 1, p. 63-73. [Also available at https://doi.org/10.1109/TSMCA.2010.2055154.]

Keeney, R.L., 1992, Value-focused thinking-A path to creative decision making: Cambridge, Mass., Harvard University Press, 432 p.

Krysanova, V., Dickens, C., Timmerman, J., Varela-Ortega, C., Schlüter, M., Roest, K., Huntjens, P., Jaspers, F., Buiteveld, H., Moreno, E., de Pedraza Carrera, J., Slámová, R., Martínková, M., Blanco, I., Esteve, P., Pringle, K., Pahl-Wostl, C., and Kabat, P., 2010, Cross-comparison of climate change adaptation strategies across large river basins in Europe, Africa and Asia: Water Resources Management, v. 24, no. 14, p. 4121-4160. [Also available at https://doi.org/10.1007/s11269-010-9650-8.]

Lambin, E.F., and Meyfroidt, P., 2011, Global land use change, economic globalization, and the looming land scarcity: Proceedings of the National Academy of Sciences of the United States of America, v. 108, no. 9, p. 3465-3472. [Also available at https://doi.org/10.1073/pnas.1100480108.] 
Lambin, E.F., Turner, B.L., Geist, H.J., Agbola, S.B., Angelsen, A., Bruce, J.W., Coomes, O.T., Dirzo, R., Fischer, G., Folke, C., George, P.S., Homewood, K., Imbernon, J., Leemans, R., Li, X., Moran, E.F., Mortimore, M., Ramakrishnan, P.S., Richards, J.F., Skånes, H., Steffen, W., Stone, G.D., Svedin, U., Veldkamp, T.A., Vogel, C., and Xu, J., 2001, The causes of land-use and land-cover change-Moving beyond the myths: Global Environmental Change, v. 11, no. 4, p. 261-269. [Also available at https://doi.org/10.1016/ S0959-3780(01)00007-3.]

Ludwig, D., 2001, The era of management is over: Ecosystems, v. 4, no. 8, p. 758-764. [Also available at https://doi.org/10.1007/s10021-001-0044-x.]

Meadow, A.M., Ferguson, D.B., Guido, Z., Horangic, A., Owen, G., and Wall, T., 2015, Moving toward the deliberate coproduction of climate science knowledge: Weather, Climate, and Society, v. 7, no. 2, p. 179-191. [Also available at https://doi.org/10.1175/WCAS-D-14-00050.1.]

Meyfroidt, P., Lambin, E.F., Erb, K.H., and Hertel, T.W., 2013, Globalization of land use-Distant drivers of land change and geographic displacement of land use: Current Opinion in Environmental Sustainability, v. 5, no. 5, p. 438-444. [Also available at https://doi.org/10.1016/j. cosust.2013.04.003.]

Millett, S.M., 1988, How scenarios trigger strategic thinking: Long Range Planning, v. 21, no. 5, p. 61-68. [Also available at https://doi.org/10.1016/0024-6301(88)90106-9.]

Montibeller, G., Gummer, H., and Tumidei, D., 2006, Combining scenario planning and multi-criteria decision analysis in practice: Journal of Multi-Criteria Decision Analysis, v. 14, no. 1-3, p. 5-20. [Also available at https://doi.org/10.1002/ mcda.403.]

National Oceanic and Atmospheric Administration, 2017, US gulf and east coast catergory 1 sotrm surge inundation (SLOSH maximum of MEOWs): Esri ArcGIS digital data, accessed August 2020 at https://www.arcgis.com/home/ item.html?id=341776546629463186016abb8e672ac7.

National Oceanic and Atmospheric Administration, 2020, Sea level rise inundation - $2 \mathrm{ft}$ above MHHW: Esri ArcGIS digital data, accessed August 2020 at https:/www.arcgis.com/ home/item.html?id=7409c029a3414cc8b323a39ef6c37591.

National Park Service, 2013, Using scenarios to explore climate change-A handbook for practitioners: Fort Collins, Colo., National Park Service, Climate Change Response Program, 57 p. [Also available at https://www.nps.gov/ parkhistory/online_books/climate/CCScenariosHandbookJuly2013.pdf.]
Ney, S., and Thompson, M., 2000, Discourses in the global climate change debate, in Jochem, E., Sathaye, J., and Bouille, D., eds., Society, behavior, and climate change mitigation: New York, Kluwer Academic Publishers, Advances in Global Change Research, v. 8, p. 65-92.

North Carolina State University, 2016, SLEUTH projected urban growth: Conservation Biology Institute, U.S. Geological Survey digital data, accessed August 2020 at https://seregion.databasin.org/datasets/e5860ced8b4844e88431cdbefe425e1a.

Paloniemi, R., Apostolopoulou, E., Primmer, E., Grodzinska-Jurcak, M., Henle, K., Ring, I., Kettunen, M., Tzanopoulos, J., Potts, S., van den Hove, S., Marty, P., McConville, A., and Similä, J., 2012, Biodiversity conservation across scales-Lessons from a science-policy dialogue: Nature Conservation, v. 2, p. 7-19. [Also available at https://doi.org/10.3897/natureconservation.2.3144.]

Peterson, G.D., Beard, T.D., Jr., Beisner, B.E., Bennett, E.M., Carpenter, S.R., Cumming, G.S., Dent, C.L., and Havlicek, T.D., 2003a, Assessing future ecosystem services-A case study of the Northern Highlands Lake District, Wisconsin: Ecology and Society, v. 7, no. 3, 1. [Also available at http://www.consecol.org/vol7/iss3/art1/.]

Peterson, G.D., Cumming, G.S., and Carpenter, S.R., 2003b, Scenario planning - A tool for conservation in an uncertain world: Conservation Biology, v. 17, no. 2, p. 358-366. [Also available at https://doi.org/10.1046/j.15231739.2003.01491.x.]

Rayner, S., and Malone, E.L., 1997, Zen and the art of climate maintenance: Nature, v. 390, no. 6658, p. 332-334. [Also available at https://doi.org/10.1038/36975.]

Rittel, H.W.J., and Webber, M.M., 1973, Dilemmas in a general theory of planning: Policy Sciences, v. 4, no. 2, p. 155-169. [Also available at https://doi.org/10.1007/ BF01405730.]

Rosentrater, L.D., 2010, Representing and using scenarios for responding to climate change: Wiley Interdisciplinary Reviews: Climate Change, v. 1, no. 2, p. 253-259. [Also available at https://doi.org/10.1002/wcc.32.]

Rounsevell, M.D.A., and Metzger, M.J., 2010, Developing qualitative scenario storylines for environmental change assessment: Wiley Interdisciplinary Reviews: Climate Change, v. 1, no. 4, p. 606-619. [Also available at https://doi.org/10.1002/wcc.63.] 
Sheppard, S.R.J., Shaw, A., Flanders, D., Burch, S., Wiek, A., Carmichael, J., Robinson, J., and Cohen, S., 2011, Future visioning of local climate change-A framework for community engagement and planning with scenarios and visualisation: Futures, v. 43, no. 4, p. 400-412. [Also available at https://doi.org/10.1016/j.futures.2011.01.009.]

South Carolina Revenue and Fiscal Affairs Office, 2019, Population projections based on the 2010 census data: South Carolina Revenue and Fiscal Affairs Office, accessed August 2020 at http://www.sccommunityprofiles.org/ census/proj_c2010.html.

Tompkins, E.L., Few, R., and Brown, K., 2008, Scenariobased stakeholder engagement-Incorporating stakeholders preferences into coastal planning for climate change: Journal of Environmental Management, v. 88 , no. 4, p. 1580-1592. [Also available at https://doi.org/10.1016/j.jenvman.2007.07.025.]
U.S. Geological Survey, 2020, SAMBI SLAMM sea level rise model-A2: U.S. Geological Survey ScienceBase catalog, Esri ArcGIS REST services directory, digital data, accessed August 2020 at https://www.sciencebase.gov/arcgis/rest/ services/Catalog/5134ff75e4b0e1603e4fecf0/MapServer.

Verweij, M., Douglas, M., Ellis, R., Engel, C., Hendriks, F., Lohmann, S., Ney, S., Rayner, S., and Thompson, M., 2006, Clumsy Solutions for a complex world - The case of climate change: Public Administration, v. 84, no. 4, p. 817-843. [Also available at https://doi.org/10.1111/j.1540-8159.2005.09566.X-i1.]

Wiseman, J., Biggs, C., Rickards, L., and Edwards, T., 2011, Scenarios for climate adaptation-Guidebook for practitioners: Carlton, Victoria, Australia, University of Melbourne.

Wright, G., Bradfield, R., and Cairns, G., 2013, Does the intuitive logics method - and its recent enhancements - produce "effective" scenarios?: Technological Forecasting and Social Change, v. 80, no. 4, p. 631-642. [Also available at https://doi.org/10.1016/j.techfore.2012.09.003.] 


\section{Chapter E. Strategic Planning Using a Strengths, Weaknesses, Opportunities, and Threats Analysis}

\section{E.1. Introduction}

The strengths, weaknesses, opportunities, and threats (SWOT; sometimes referred to as TOWS) analysis is a tool for situational awareness and strategic planning (Weihrich, 1982). The SWOT analysis is used to examine an organization's internal strengths and weaknesses, and externally generated threats and opportunities, to help formulate effective business strategies. The analysis facilitates an organization's strategic thinking by asking planners such questions as the following:

- What advantages does your organization have?

- What do you do better than anyone else?

- What unique or lowest-cost resources can you draw upon that others cannot?

- What do people see as your strengths?

- What could your organization improve?

- What should you avoid?

-What are people likely to see as weaknesses?

- What factors contribute to your failures?

- What obstacles does your organization face?

- What are other groups with similar goals to yours doing?

- Could any of your weaknesses seriously threaten your organization's viability?

- What interesting trends are you aware of?

- What good opportunities can you spot?

The SWOT analysis has been used extensively in the business world (Helms and Nixon, 2010). It is a simple and practical tool for rapid assessment that can provide insights into the complex interplay of factors affecting an organization's success (Pickton and Wright, 1998; Helms and Nixon, 2010; Nyarku and Agyapong, 2011). The analysis has been used increasingly in natural resource management (Hong and Chan, 2010; Kajanus and others, 2012; Siaosi and others, 2012; Marino and others, 2014; Haryono and Ambariyanto, 2017), although its use in climate-change adaptation seems more limited (Krysanova and others, 2010; Fertel and others, 2013).

The goal of this exercise was to assess conservation partners' organization's strengths and weaknesses in confronting future opportunities and threats using the SWOT analysis, with a focus on sustaining the supply of ecological goods and services in the South Carolina Lowcountry. The demands of the external environment (as portrayed by uncertain future scenarios, chap. B.1) were evaluated and matched with capacities of the organizations involved. Expert opinions of the area, the valuation of ecosystem goods and services based on that knowledge, and personal experiences with climate and other drivers of change were integral to the exercise. At times, partners were asked to represent their organization's perspective, but more important was an individual's perspectives as an expert with local knowledge of conservation issues in the South Carolina Lowcountry.

\section{E.2. Methodology}

A workshop to conduct the SWOT analysis was held November 9, 2017, with many of the same participants from the scenario planning workshop (see chap. D). Organizations represented were Cape Romain National Wildlife Refuge, Francis Marion National Forest, South Carolina Department of Natural Resources, the South Carolina Aquarium, the Lowcountry Land Trust, and the South Carolina Environmental Law Project. We generally followed the process described by Weihrich (1982), which is regarded as the most important methodological reference (Ghazinoory and others, 2011) in that it seeks to make SWOT analyses more effective at generating effective strategies (Helms and Nixon, 2010).

Before the workshop, participants were provided background material about SWOT analyses and requested to think about specific strengths and weaknesses of their respective organizations, with a focus on addressing the current and future conditions, opportunities, needs, and threats facing the Cape Romain landscape. We recommended limiting the list to the four to six most important strengths and weaknesses. At the workshop, individuals listed their organization's strengths and weaknesses on color-coded post-it notes and placed them on an appropriate flip chart (fig. E1). Similar items were combined. Color-coding allowed us to understand how capabilities differed among organizations. In plenary, the articulated strengths and weaknesses were discussed and the top four to six were identified by consensus for the conservation partnership as a single entity. For example, an organization's weakness may have been dropped from the list if it was negated by another organization's strength. The goal was to emphasize the importance of collaboration and the capabilities of the partnership. 


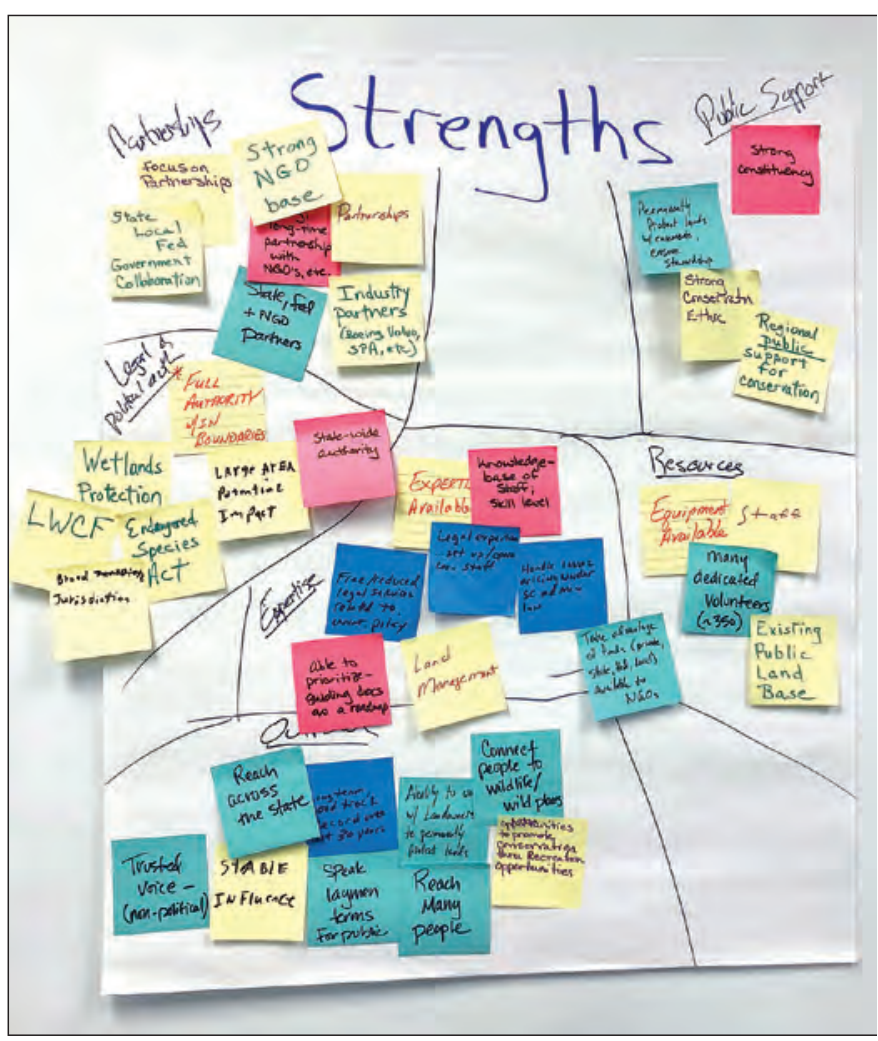

Figure E1. An example of brainstorming partner strengths by organizational affiliation for strengths, weaknesses, opportunities, and threats analysis. Organizational coding included yellow for Federal agencies; pink or red for State agencies; and blue or teal for nongovernmental or other organizations.

Because of time constraints, participants focused largely on scenario 2 (united front; chap. D.3.2) and discussed and developed a list of the most important threats and opportunities. Scenario 2 was considered one of the more likely futures (along with scenario 3, real life; chap. D.3.3). Participants then individually ranked and scored ( 0 to 100 , with 100 being the most important) the SWOT on a handout provided. These scores were summarized after the workshop.

Each pairwise combination of internal and external SWOT factors was then examined, and one or more partnership strategies were developed using a so-called TOWS matrix (simply a reverse ordering of SWOT intended to emphasize the importance of external threats and opportunities of the scenarios; Weihrich, 1982). For each strategy, participants recorded which pairs of SWOT factors the strategy was intended to address. After the workshop, we used the mean of the participants' scores on the individual SWOT factors and summed those scores for the specific pairs of SWOT factors associated with each strategy. Those scores provided a crude measure of the relative importance of each strategy. This exercise was conducted to help address a common criticism of SWOT that it does not assist decision makers with prioritization (Helms and Nixon, 2010; Nyarku and Agyapong, 2011).

\section{E.3. Results}

Organizational strengths included partnership capacity, legal authority, public support, natural resource expertise, resources (especially the conservation land base), and outreach capacity. Weaknesses included communication and marketing, internal alignment (that is, consistent goals and priorities within an organization), institutional inertia, limited funding and staff, and shifting political priorities. Generally, Federal partners indicated they have legal authorities for conservation and good capacity to develop conservation partnerships, but they struggle with limited funding and institutional inertia. State agencies were not well represented at the workshop, but we might expect their strengths and weaknesses to be similar to those of the Federal partners. Nongovernmental organizations indicated they have strong outreach capacity and natural resource expertise, but they have limited staff and lack expertise in marketing.

The primary external threats associated with scenario 2 were unchecked growth and development, effects to human health and well-being, and extreme weather effects to ecological goods and services of value. The most important opportunities were an attractive culture and lifestyle in the South Carolina Lowcountry (social cohesion), a high demand for ecological goods and services, and opportunities for partnerships. Importance scores for the principal SWOT factors are provided in table E1.

Potential partnership strategies were developed for each pairwise combination of strengths/weaknesses and threats/ opportunities (table E2). Virtually all strategies involved stakeholder engagement, outreach, and development of partnerships. Strategies with the highest scores were (a) communicate benefits of existing protected areas in providing ecological goods and services, and (b) increase conservation community self-awareness (expand partnerships and connect expertise with when, where, and how it is needed). Importance scores for all strategies are provided in table E3. Workshop participants also described the most immediate need as increasing conservation community self-awareness and connections through fact-finding missions (who is doing what and where?) and social networking (for example, green-drink socials and mini-conferences).

Because of the limited time available at the workshop, the authors developed additional threats and opportunities associated with all four scenarios (table E4) in the hopes that they will encourage development of additional strategies that may be effective regardless of how the future unfolds. 
Table E1. Mean and standard deviation of importance scores assigned to the principal strengths, weaknesses, opportunities, and threats analysis factors by workshop participants.

[SWOT, strengths, weaknesses, opportunities, and threats]

\begin{tabular}{|c|c|c|}
\hline SWOT factor & Mean & $\begin{array}{l}\text { Standard } \\
\text { deviation }\end{array}$ \\
\hline \multicolumn{3}{|c|}{ Internal strengths } \\
\hline 1. Outreach capacity & 79.4 & 20.6 \\
\hline $\begin{array}{l}\text { 2. Expertise in natural resource man- } \\
\text { agement }\end{array}$ & 66.3 & 30.9 \\
\hline $\begin{array}{l}\text { 3. Partnership experience and com- } \\
\text { petence }\end{array}$ & 88.1 & 12.5 \\
\hline 4. Existing land base & 93.8 & 10.2 \\
\hline \multicolumn{3}{|c|}{ Internal weaknesses } \\
\hline $\begin{array}{l}\text { 1. Expertise in messaging and market- } \\
\text { ing }\end{array}$ & 77.5 & 28.9 \\
\hline 2. Funding and capacity limitations & 95 & 6.2 \\
\hline 3. Institutional inertia & 75 & 18 \\
\hline 4. Internal alignment & 60 & 22.7 \\
\hline \multicolumn{3}{|c|}{ External opportunities } \\
\hline $\begin{array}{l}\text { 1. Culture and lifestyle is attractive } \\
\text { (social cohesion) }\end{array}$ & 89.4 & 10.1 \\
\hline $\begin{array}{l}\text { 2. High demand for ecological goods } \\
\text { and services }\end{array}$ & 86.9 & 15.8 \\
\hline 3. Opportunities for partnerships & 80 & 20.5 \\
\hline \multicolumn{3}{|c|}{ External threats } \\
\hline $\begin{array}{l}\text { 1. Unchecked growth and develop- } \\
\text { ment }\end{array}$ & 98.8 & 3.1 \\
\hline $\begin{array}{l}\text { 2. Impacts to human health and well- } \\
\text { being }\end{array}$ & 79.8 & 16.7 \\
\hline $\begin{array}{l}\text { 3. Extreme weather impacts to eco- } \\
\text { logical goods and services }\end{array}$ & 89.4 & 11.2 \\
\hline
\end{tabular}


Table E2. Primary strengths, weaknesses, opportunities, and threats analysis factors and potential strategies (TOWS matrix) for the Cape Romain conservation partnership, especially as they relate to scenario 2 (united front; chap. D3.1).

[--, not applicable; EGS, ecological goods and services]

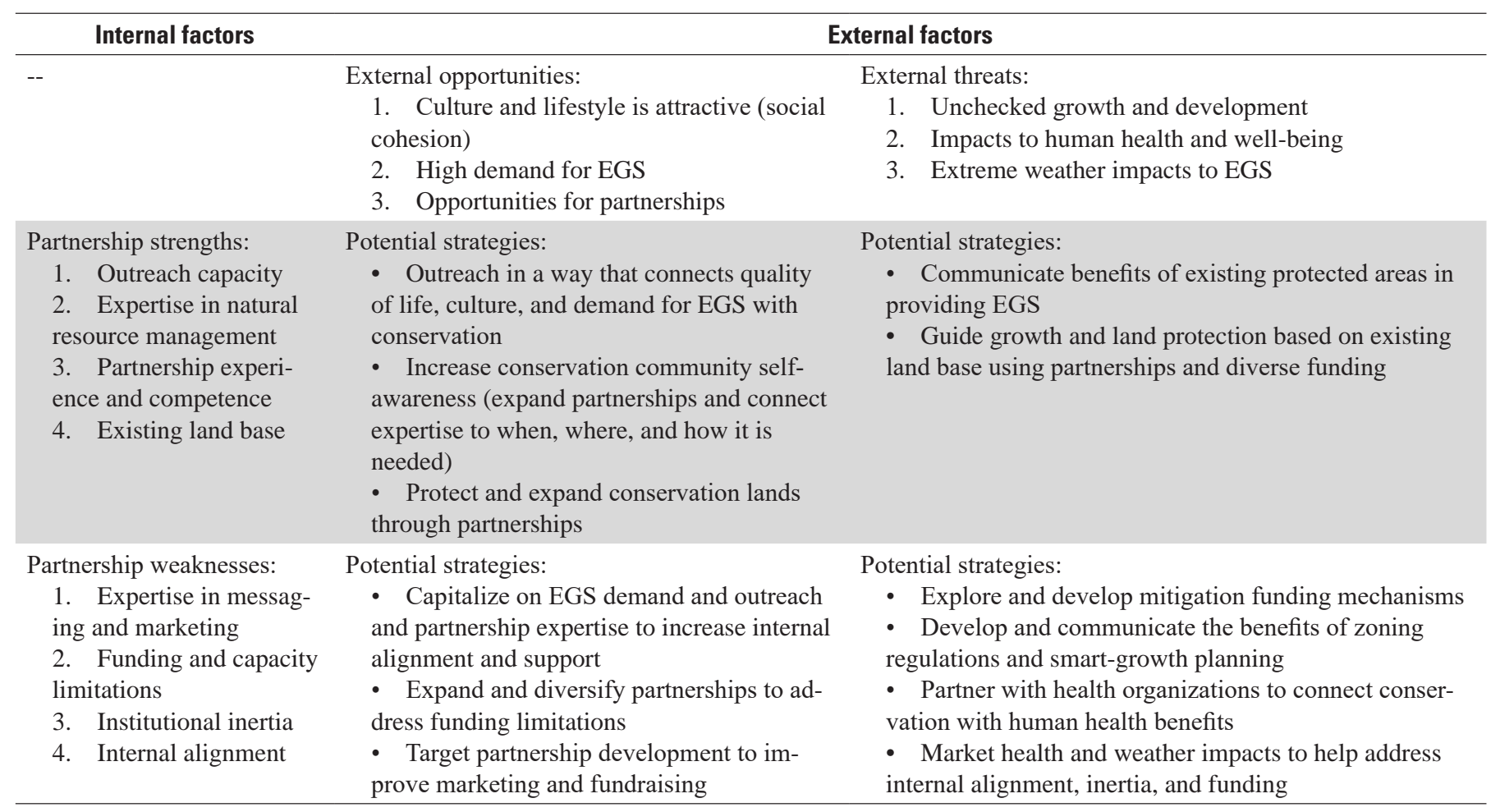


Table E3. Importance scores for strategies developed by the Cape Romain conservation partnership.

[EGS, ecological goods and services]

\begin{tabular}{|c|c|}
\hline Score & Strategy element \\
\hline 595 & $\begin{array}{l}\text { Communicate benefits of existing protected areas in } \\
\text { providing EGS. }\end{array}$ \\
\hline 401 & $\begin{array}{l}\text { Increase conservation community self-awareness (ex- } \\
\text { pand partnerships and connect expertise to when, } \\
\text { where, and how it is needed). }\end{array}$ \\
\hline 350 & $\begin{array}{l}\text { Protect and expand conservation lands through part- } \\
\text { nerships. }\end{array}$ \\
\hline 349 & $\begin{array}{l}\text { Outreach in a way that connects quality of life, cul- } \\
\text { ture, and demand for EGS with conservation. }\end{array}$ \\
\hline 347 & $\begin{array}{l}\text { Guide growth and land protection based on existing } \\
\text { land base using partnerships and diverse funding. }\end{array}$ \\
\hline 339 & $\begin{array}{l}\text { Market health and weather effects to help address } \\
\text { internal alignment, inertia, and funding. }\end{array}$ \\
\hline 253 & $\begin{array}{l}\text { Target partnership development to improve marketing } \\
\text { and fundraising. }\end{array}$ \\
\hline 242 & $\begin{array}{l}\text { Capitalize on EGS demand and outreach and partner- } \\
\text { ship expertise to increase internal alignment and } \\
\text { support. }\end{array}$ \\
\hline 236 & $\begin{array}{l}\text { Develop and communicate the benefits of zoning } \\
\text { regulations and smart-growth planning. }\end{array}$ \\
\hline 194 & Explore and develop mitigation funding mechanisms. \\
\hline 175 & $\begin{array}{l}\text { Expand and diversify partnerships to address funding } \\
\text { limitations. }\end{array}$ \\
\hline 175 & $\begin{array}{l}\text { Partner with health organizations to connect conserva- } \\
\text { tion with human health benefits. }\end{array}$ \\
\hline
\end{tabular}


Table E4. Threats and opportunities produced by workshop facilitators for further exploration for scenarios 1-4 (chap. D.3).

\begin{tabular}{|c|c|}
\hline Threats & Opportunities \\
\hline \multicolumn{2}{|c|}{ Scenario 1-Three horseman } \\
\hline $\begin{array}{l}\text { Economic upheaval: tourism, marine and natural resource-based } \\
\text { incomes decline, increased poverty }\end{array}$ & $\begin{array}{l}\text { Military funding possible source to continue protection of habitats } \\
\text { and resulting EGS }\end{array}$ \\
\hline $\begin{array}{l}\text { Impacts to environment and infrastructure: regulating services } \\
\text { decline (protection and water quality), loss of fish and wildlife }\end{array}$ & $\begin{array}{l}\text { Less development pressure on coast and other vulnerable areas; } \\
\text { conservation funding can go further }\end{array}$ \\
\hline habitat, and extensive flooding and erosion & Opportunities for strong leadership by local nongovernmental orga- \\
\hline and cultural values decline & Desirability of voluntary or incentive-based conservation measures \\
\hline $\begin{array}{l}\text { Governance: laissez-faire economic development with protection pri- } \\
\text { orities focused on infrastructure and business; little environmental } \\
\text { regulatory intervention }\end{array}$ & \\
\hline \multicolumn{2}{|c|}{ Scenario 2-United front } \\
\hline $\begin{array}{l}\text { Impacts to environment and infrastructure: growth increases demand } \\
\text { for EGS; regulating services decline (protection, water quality, and } \\
\text { deepening of Charleston harbor); loss of fish and wildlife habitat; } \\
\text { extensive flooding and erosion }\end{array}$ & $\begin{array}{l}\text { Demand for EGS emphasizes need for smart growth, environmental } \\
\text { planning, better service provision by local governments, take bet- } \\
\text { ter advantage of new technologies for infrastructure growth (for } \\
\text { example, green technology) }\end{array}$ \\
\hline $\begin{array}{l}\text { Development (impervious surfaces) and increased rain frequency } \\
\text { affect water quality, erosion, coastal habitats and fisheries, and } \\
\text { disease prevalence }\end{array}$ & $\begin{array}{l}\text { Strong social cohesion enables nongovernmental organizations, local } \\
\text { government, and communities to work closely together to solve } \\
\text { issues related to community values }\end{array}$ \\
\hline $\begin{array}{l}\text { Sea-level rise and droughts increase saltwater intrusion, further } \\
\text { impacting water quality and potable water, shellfish habitat, and }\end{array}$ & $\begin{array}{l}\text { Appreciation of local culture engenders trust in local knowledge and } \\
\text { valuing legacy benefits }\end{array}$ \\
\hline vulnerable coastal residents & Increase education on economic values of ecological services to \\
\hline $\begin{array}{l}\text { Increasing temperatures result in increased human health concerns } \\
\text { (insect disease transmission and heat-related illness) }\end{array}$ & $\begin{array}{l}\text { generate additional, widespread public support } \\
\text { Promoting ecotourism }\end{array}$ \\
\hline $\begin{array}{l}\text { Lack of trust in government and natural resource management } \\
\text { practices }\end{array}$ & \\
\hline
\end{tabular}

practices

\begin{tabular}{|c|c|}
\hline \multicolumn{2}{|c|}{ Scenario 3-Real life } \\
\hline $\begin{array}{l}\text { Impacts to environment and infrastructure: regulating services } \\
\text { decline (protection and water quality); loss of fish and wildlife } \\
\text { habitat, extensive flooding and erosion, }\end{array}$ & $\begin{array}{l}\text { Continued State and Federal support for conservation, protecting pri- } \\
\text { ority habitats and services. Responsive local govt takes advantage } \\
\text { of opportunities to enact adaptation measures }\end{array}$ \\
\hline $\begin{array}{l}\text { Development and increased rain frequency affect water quality, ero- } \\
\text { sion, coastal habitats and fisheries; increased mosquito pops and } \\
\text { disease prevalence }\end{array}$ & $\begin{array}{l}\text { Strong social cohesion enables nongovernmental organizations, local } \\
\text { government, and communities to work closely together to solve } \\
\text { issues related to community values }\end{array}$ \\
\hline $\begin{array}{l}\text { Growth continues, local appreciation of Lowcountry declines, as } \\
\text { does “sense of place.” Connection to nature no longer seen as } \\
\text { strongly defining region }\end{array}$ & $\begin{array}{l}\text { Education and incentive opportunities by local organizations can } \\
\text { bolster appreciation of natural and cultural resources and foster } \\
\text { sense of place for immigrants and locals alike }\end{array}$ \\
\hline $\begin{array}{l}\text { Environmental degradation impacts resource-based economy- } \\
\text { forestry, fisheries, and tourism. Quality of life suffers; vulnerable }\end{array}$ & $\begin{array}{l}\text { Local power to implement regulatory policies to mitigate or avoid } \\
\text { damages, promotion by community engagement }\end{array}$ \\
\hline
\end{tabular}


Table E4. Threats and opportunities produced by workshop facilitators for further exploration for scenarios 1-4 (chap. D.3).-Continued

\begin{tabular}{|c|c|}
\hline Threats & Opportunities \\
\hline \multicolumn{2}{|c|}{ Scenario 4-Manna } \\
\hline $\begin{array}{l}\text { Sea-level rise impacts fish and wildlife habitat, particularly shell- } \\
\text { fisheries, nesting beaches (turtles and shorebirds). Local routine } \\
\text { flooding continues to be problematic }\end{array}$ & $\begin{array}{l}\text { Fewer environ. threats and social disruptions allow greater focus on } \\
\text { green infrastructure, planned growth and improved EGS, social } \\
\text { services and overall quality of life }\end{array}$ \\
\hline $\begin{array}{l}\text { Continued attractiveness of region promotes high growth rates and } \\
\text { resulting impacts to social, economic and environmental systems }\end{array}$ & $\begin{array}{l}\text { Strong recreational opportunities promote incentives for conserving } \\
\text { habitat, access }\end{array}$ \\
\hline \multirow{2}{*}{$\begin{array}{l}\text { Economic disparities and at-risk populations still present and left } \\
\text { behind by differential impacts from environmental and economic } \\
\text { changes }\end{array}$} & $\begin{array}{l}\text { Strong timber industry allows partnerships to increase beneficiaries } \\
\text { of EGS }\end{array}$ \\
\hline & $\begin{array}{l}\text { Distributed political power gives opportunities for leadership by } \\
\text { environmental orgs and “unofficial” positive influence by active } \\
\text { State and Federal land managers }\end{array}$ \\
\hline
\end{tabular}

\section{E.4. Discussion}

Strategic planning is sometimes approached as a topdown, systematic, and linear process; however, this approach is likely to fail in attempts to address wicked problems (chap. A.4; Rittel and Webber, 1973; Camillus, 2008). Adaptation to social-ecological change qualifies as a wicked problem in that, among other features, it involves many stakeholders who have different ideas about what the problem really is, what its causes are, and what may be acceptable solutions. Scenario planning and SWOT analysis can contribute to more effective strategic planning by recognizing that addressing wicked problems is at its core a social activity, with all its inherent informality, irrationality, and incrementalism (Pickton and Wright, 1998). As such, it is a process that is less mechanistic and more organic than engineering-style approaches (Johnson and others, 2016), but ultimately it can be more successful by embracing the values and powers of those involved (Cash and others, 2003; Verweij and others, 2006; Adger and others, 2013). We believe the scenario planning and SWOT workshops helped contribute to this social dialogue and assisted planners in understanding the advantages of building social networks of scientists and stakeholders to confront social-ecological change in the South Carolina Lowcountry (Ney and Thompson, 2000; Berkes, 2010; Armitage and others, 2012; Kettle and others, 2017).

Overall, the SWOT analysis suggests the partnership may wish to pursue actions that do the following:

- Grow and strengthen the conservation partnership by connecting expertise with when, where, and how it is needed.

- Communicate to the public the benefits of existing protected areas in providing ecological goods and services, while seeking to expand the area of protected lands.
- Conduct outreach in a way that connects quality of life, culture, and demand for ecological goods and services with conservation practice.

Future work could involve examining possible strategies for the other scenarios not examined in the workshop to help identify strategies that are robust to an uncertain future (in other words, no-regret actions that are likely to help mitigate threats regardless of how the future unfolds). Weihrich (1982) offers several strategic approaches to consider (several of these approaches are apparent in the strategies developed for scenario 2):

- Specialization.-Reduce efforts to pursuing a limited number of objectives or opportunities. Goal would be to minimize competition and not spread an organization (or partnership) too thin.

- Diversification.-Venture into new areas that are identified as gaps in existing efforts.

- Innovation.-Refocus organization's mission and objectives to better reflect current and future conditions. Use strengths or correct weaknesses to take advantage of opportunities.

- Status quo.-Concern with unknowns and aversion to risks of making mistakes lead to a no-change approach.

- Liquidation.-Recognizing sunk costs of actions that are likely to be unprofitable in future; that is, a willingness to let go of certain long-held strategies in lieu of others.

- Retrenchment.-A short-term liquidation approach where some operations or actions are restricted for a period. 
- Joint ventures. - - Identifying gaps or poor matchings between pair-wise combinations of strengths/ weaknesses and opportunities/threats leads to seeking partnerships with entities that can fill these gaps.

The SWOT analysis as a tool has been criticized for its vagueness and oversimplified process (Helms and Nixon, 2010) and for its ineffectiveness in developing and prioritizing strategies (Pickton and Wright, 1998; Panagiotou, 2003; Nyarku and Agyapong, 2011). We used a crude weighting scheme to help with prioritization, but combining the SWOT analysis with more formal multicriteria decision analysis has potential (Kajanus and others, 2012; Haryono and Ambariyanto, 2017; Ghazinoory and others, 2011). Additional limitations of the SWOT analysis in our context include the dependency on the particular individuals attending the workshop (the strategies may well have differed with different participants and conservation organizations) and the somewhat static nature of the effort (strategic planning needs to be an ongoing, dynamic endeavor) (Pickton and Wright, 1998).

The methods of Weihrich (1982) can overcome some of these limitations, and the SWOT analysis is nonetheless praised for its ease of use, its ability to foster brainstorming, and its potential to focus on the process of strategic planning rather than on any specific outputs (Pickton and Wright, 1998; Helms and Nixon, 2010). Thus, the key benefit of the SWOT analysis is in helping stakeholders develop a shared perspective of challenges and opportunities facing on organization attempting to meet its goals in an uncertain future. In this sense, the SWOT analysis is a natural complement to the scenario planning described in chapter $\mathrm{D}$.

\section{References Cited}

Adger, W.N., Barnett, J., Brown, K., Marshall, N., and O'Brien, K., 2013, Cultural dimensions of climate change impacts and adaptation: Nature Climate Change, v. 3, no. 2, p. 112-117. [Also available at https://doi.org/10.1038/ nclimate1666.]

Armitage, D.R., de Loë, R., and Plummer, R., 2012, Environmental governance and its implications for conservation practice: Conservation Letters, v. 5, no. 4, p. 245-255. [Also available at https://doi.org/10.1111/j.1755-263X.2012.0023 8.x.]

Berkes, F., 2010, Devolution of environment and resources governance-Trends and future: Environmental Conservation, v. 37, no. 4, p. 489-500.[Also available at https://doi.org/10.1017/S037689291000072X.]

Camillus, J.C., 2008, Strategy as a wicked problem: Harvard Business Review, v. 86, p. 98-101.
Cash, D., Clark, W.C., Alcock, F., Dickson, N.M., Eckley, N., and Jäger, J., 2003. Salience, credibility, legitimacy and boundaries_Linking research, assessment and decision making: Harvard University, Kennedy School of Government, Faculty Research Working Papers Series, RWP02046, 24 p. [Also available at https://doi.org/10.2139/ ssrn.372280.]

Fertel, C., Bahn, O., Vaillancourt, K., and Waaub, J.-P., 2013, Canadian energy and climate policies-A SWOT analysis in search of federal/provincial coherence: Energy Policy, v. 63, p. 1139-1150. [Also available at https://doi.org/10.1016/j. enpol.2013.09.057.]

Ghazinoory, S., Abdi, M., and Azadegan-Mehr, M., 2011, SWOT methodology-A state-of-the-art review for the past, a framework for the future: Journal of Business Economics \& Management, v. 12, no. 1, p. 24-48. [Also available at https://doi.org/10.3846/16111699.2011.555358.]

Haryono, F.E., and Ambariyanto, A., 2017, Genetic diversity approach to fishery management spiny lobster southern waters of Java based on SWOT analysis and AHP: Omni-Akuatika, v. 13, no. 1, p. 26-33. [Also available at https://doi.org/10.20884/1.oa.2017.13.1.163.]

Helms, M.M., and Nixon, J., 2010, Exploring SWOT analysis-Where are we now? A review of academic research from the last decade: Journal of Strategy and Management, v. 3, no. 3, p. 215-251. [Also available at https://doi.org/10.1108/17554251011064837.]

Hong, C., and Chan, N., 2010, Strength-weakness-opportunities-threats analysis of Penang National Park for strategic ecotourism management: World Applied Sciences Journal, v. 10, p. $136-145$.

Johnson, F.A., Case, D.J., and Humburg, D.D., 2016, Learning and adaptation in waterfowl conservation-By chance or by design?: Wildlife Society Bulletin, v. 40, no. 3, p. 423-427. [Also available at https://doi.org/10.1002/wsb.682.]

Kajanus, M., Leskinen, P., Kurttila, M., and Kangas, J., 2012, Making use of MCDS methods in SWOT analysisLessons learnt in strategic natural resources management: Forest Policy and Economics, v. 20, p. 1-9. [Also available at https://doi.org/10.1016/j.forpol.2012.03.005.]

Kettle, N.P., Trainor, S.F., and Loring, P.A., 2017, Conceptualizing the science-practice interface-Lessons from a collaborative network on the front-line of climate change: Frontiers in Environmental Science, v. 5, p. 33. [Also available at https://doi.org/10.3389/fenvs.2017.00033.] 
Krysanova, V., Dickens, C., Timmerman, J., Varela-Ortega, C., Schlüter, M., Roest, K., Huntjens, P., Jaspers, F., Buiteveld, H., Moreno, E., de Pedraza Carrera, J., Slámová, R., Martínková, M., Blanco, I., Esteve, P., Pringle, K., Pahl-Wostl, C., and Kabat, P., 2010, Cross-comparison of climate change adaptation strategies across large river basins in Europe, Africa and Asia: Water Resources Management, v. 24, no. 14, p. 4121-4160. [Also available at https://doi.org/10.1007/s11269-010-9650-8.]

Marino, E., Hernando, C., Planelles, R., Madrigal, J., Guijarro, M., and Sebastián, A., 2014, Forest fuel management for wildfire prevention in Spain-A quantitative SWOT analysis: International Journal of Wildland Fire, v. 23, no. 3, p. 373-384. [Also available at https://doi.org/10.1071/ WF12203.]

Ney, S., and Thompson, M., 2000, Discourses in the global climate change debate, in Jochem, E., Sathaye, J., and Bouille, D., eds., Society, behavior, and climate change mitigation: New York, Kluwer Academic Publishers, Advances in Global Change Research, v. 8, p. 65-92.

Nyarku, K., and Agyapong, G., 2011. Rediscovering SWOT analysis - The extended version: Academic Leadership: The Online Journal, v. 9, no. 2, art. 28. [Also available at https://scholars.fhsu.edu/alj/vo19/iss2/28.]

Panagiotou, G., 2003, Bringing SWOT into focus: Business Strategy Review, v. 14, no. 2, p. 8-10. [Also available at https://doi.org/10.1111/1467-8616.00253.]
Pickton, D.W., and Wright, S., 1998, What's swot in strategic analysis?: Strategic Change, v. 7, no. 2, p. 101-109. [Also available at https://doi.org/10.1002/(SICI)10991697(199803/04)7:2<101:AID-JSC332>3.0.CO;2-6.]

Rittel, H.W.J., and Webber, M.M., 1973, Dilemmas in a general theory of planning: Policy Sciences, v. 4, no. 2, p. 155-169. [Also available at https://doi.org/10.1007/ BF01405730.]

Siaosi, F., Huang, H.-W., and Chuang, C.-T., 2012, Fisheries development strategy for developing Pacific Island Countries - Case study of Tuvalu: Ocean and Coastal Management, v. 66, p. 28-35. [Also available at https://doi.org/10.1016/j.ocecoaman.2012.04.021.]

Verweij, M., Douglas, M., Ellis, R., Engel, C., Hendriks, F., Lohmann, S., Ney, S., Rayner, S., and Thompson, M., 2006, Clumsy solutions for a complex world-The case of climate change: Public Administration, v. 84, no. 4, p. 817-843. [Also available at https://doi.org/10.1111/j.1540-8159.2005 .09566.x-i1.]

Weihrich, H., 1982, The TOWS matrix-A tool for situational analysis: Long Range Planning, v. 15, no. 2, p. 54-66. [Also available at https://doi.org/10.1016/0024-6301(82)90120-0.] 



\section{Chapter F. Decision Support Tools to Assist with Adaptation to Sea-Level Rise and Urbanization}

Sea-level rise (SLR) and urbanization have been identified as threats to the Cape Romain National Wildlife Refuge (NWR) and South Carolina Lowcountry Refuge Complex (see chaps. B.1 and B.4). Decision analysis can be used to assist refuge and other land managers to identify the best management decisions with respect to their management objectives. Decision analysis has a long tradition in business, engineering, and medicine, but it is becoming increasingly used for addressing natural-resource management problems (Kirkwood, 1996; Williams and others, 2002). Decision analysis is a formal method for analyzing a decision by breaking down the decision problem into key components: management objectives, potential management actions, models to project the consequences of the actions, and an optimization approach to identify decisions that are optimal with respect to the objectives (Williams and others, 2002; Nichols and Williams, 2006; Martin and others, 2009).

To properly define the decision problem and to appropriately identify each of the components, we convened a workshop (June 2-6, 2014) with refuge managers, U.S. Geological Survey scientists, and academics. During the workshop, we identified several fundamental objectives that reflected the overall mission of Cape Romain NWR: protecting threatened and endangered species, protecting migratory birds in decline, and connecting people with nature (Nilius and others, 2014). The team agreed that a priority project would be to develop an approach for selecting land parcels in Cape Romain NWR that would maximize refuge values specified by the fundamental objectives. This project is essentially a conservation planning project (Schloss and others, 2011). Potential acquisition of parcels should consider changes in habitats and potential loss to SLR and urbanization. Because of the long-time horizon considered for this project (about 30 years), including uncertainty in SLR and urbanization estimates is important. We also wanted to account for the risk attitude of the managers.

We developed two separate approaches that included these special considerations. Both viewed the refuge as a collection of parcels, including current holdings and new acquisitions, and optimized a value function that described the refuge objectives in units of services supplied by the refuge. However, these value functions and the techniques for optimizing them differed in scope. The first approach identified an optimal set of parcels to acquire to compensate for losses because of SLR at a minimal cost. The second approach used modern portfolio theory (MPT; Markowitz, 1952, 1959; see chap. F.2). The first approach was implemented with a user-friendly software and could be applied by biologists working for the refuge (Ball and others, 2009). The second approach involved more complex methods and accounted for uncertainty in SLR scenarios and considered the risk attitude of managers. Because the second method involved complex optimization methods, it required the input of optimization experts.

\section{F.1. Reserve Design Using Marxan}

Historically, protected areas were commonly established opportunistically or using ad hoc approaches, but over the last few decades, managers have used more rigorous and systematic approaches (Schloss and others, 2011). These more rigorous approaches involve decision-support tools to select parcels that meet conservation objectives (for example, maximize biodiversity given a fixed budget). These more systematic approaches to conservation planning fit nicely under the decision analytical framework outlined in chapters $\mathrm{D}$ and $\mathrm{E}$. The key components of this decision analytical approach in our case include specifying objectives, actions, and models:

Objectives.-The management objective in our case is to maximize refuge values specified by the fundamental objectives. Here, as a simplification, we are considering how conserving different configurations and amounts of habitat types valued by managers can meet their fundamental objectives. Each habitat type may be valued differently, which is reflected in the habitat conservation targets. In this application, we are aiming to meet some conservation targets at the lowest cost.

Actions - The potential actions consist of acquiring or protecting land (for example, through a purchase or easement).

Models.-The models allow us to compute the composite expected values based on predictions of the spatial extent of future habitats under SLR projection.

The purpose of this analysis is to determine which set of parcels in the region to acquire to replace the area of habitats that we anticipated to be lost in the refuge under SLR projection by 2050, either for the least cost possible or for a set budget. To do this, we defined an objective function that includes terms representing the cost of offsetting habitat loss (that is, purchase price) and penalties for failing to offset. The overall goal of the optimization is to minimize the sum of costs and penalties.

\section{F.1.1. Methods}

\section{F.1.1.1. Objective Function for Optimal Reserve Design}

We used a simulated annealing approach to identify nearoptimal reserve design solutions (implemented with program Marxan; Ball and others, 2009) to solve the minimum set 
problem, determining which set of parcels to acquire to meet conservation targets for the least cost possible. The objective function to be minimized is as follows:

$$
\sum_{p u} \operatorname{Cost}+\sum_{C F} s p f \times \text { penalty }+C T P
$$

where

$$
\begin{aligned}
& p u \text { is the parcel, } \\
& \text { Cost } \text { is the cost of each parcel acquired, } \\
& \text { CF } \text { is the conservation feature, } \\
& \text { spf } \text { is the species penalty factor } \\
& \text { penalty } \text { is the penalty for the amount of each target } \\
& \text { missing, and } \\
& \text { CTP } \text { is the cost threshold penalty. }
\end{aligned}
$$

The first term represents the sum of the costs of each parcel, $p u$, acquired. We had no reasonable basis for estimating the costs to protect land (fee simple or cost of easements), nor future budgets likely to be available to a new partnership. For this analysis, we simplify by assuming the parcel cost is equal to parcel area and use this as a proxy for the average cost of protection. Such a proxy does not consider the variation in cost-per-unit area, nor possible economies of scale of purchasing larger plots, but we assume the relation between size and average cost of protection is positive. The second term (penalty) adds a penalty for the amount of each target (or conservation feature, $C F$ ) missing, multiplied by a factor for each target (or species penalty factor, $s p f$ ), which enforces the management objective of reaching each conservation target. If the species penalty factor for each habitat target is sufficiently large, it will enforce the habitat target constraints. We determined that a value of 10 was sufficient to enforce these constraints. The last term (cost threshold penalty, CTP) is an optional term that ensures that the total cost remains below a budget or cost threshold.

\section{F.1.1.2. Index of Habitat in Cape Romain National Wildlife Refuge and the Surrounding Region}

To represent the current and future projected habitats under SLR in the region, we used geographic information system (GIS) files from the Sea Level Affecting Marshes Model (SLAMM, version 5.0.1), which has habitat categories based on the National Wetland Inventory wetlands data. SLAMM projects future habitat distributions under marsh migration on the regional scale on the basis of the climate-change scenarios designated by the Intergovernmental Panel on Climate Change (IPCC; Houghton and others, 2001). For this analysis, we calculated the expected habitat change in the refuge in 2050 compared to present day (2010) by comparing two SLAMM projection scenarios: the current habitats in the refuge (based on scenario B1, 2010 described in Houghton and others, 2001) and the projected future habitats in the study area for year 2050 (this was effectively a 1 -foot SLR scenario) using the SLAMM files for the IPCC scenario and year that most closely matched the SLR median projection in the region (Horton and
Bader, 2014, table B1 in chap. B.1; in this case the scenario B1 for 2040; table B2 in chap. B.1; fig. F1). The value of acquiring each parcel in the decision analysis was based on the expected habitat areas in each parcel for 2050 (using the B1 2040, 1-foot SLR SLAMM scenario). The 16 habitat categories considered in our analyses include: developed uplands, undeveloped uplands, swamp, inland fresh marsh, scrub shrub transition, salt marsh, estuarine beach, tidal flat, ocean beach, ocean flat, inland open water, estuarine open water, open ocean, brackish marsh, inland shore, and tidal swamp (fig. F1).

\section{F.1.1.3. Target Setting and Geospatial Processing}

The goal of acquiring new parcels is to replace the habitat area in the refuge that is expected to be lost under SLR in 2050 for the least cost possible. Habitat targets for this objective function were derived from geospatial data near the refuge in three steps: (1) estimate current relative composition of habitats (in square meters), (2) estimate future predicted composition under SLR, and (3) calculate the total loss of each habitat accrued by comparing predictions from the estimates in steps 1 and 2.

To determine the area of current habitats in the refuge, we intersected a GIS layer of the refuge boundary with the habitat layer for the current scenario $(B 1,2010)$ and dissolved with respect to habitat code. We then exported the attribute table of the layer that contained the total habitat in each category in Cape Romain NWR.

To determine the area of projected habitats in the refuge in 2050 (1-foot SLR scenario), we repeated this process using the SLAMM layer for scenario B1, 2040 (which corresponds to a 1-foot increase). We calculated the change in area for each habitat type under the 2050 SLR scenario in the refuge, focusing on habitat loss (table F1). We set these values of habitat loss in the refuge under SLR as the targets to reach when acquiring new parcels to minimize expected loss. We then determined the amount of available habitat in each parcel for the 2050 habitat projection scenario by repeating the above steps with a GIS layer of the land parcels. To determine if the habitat targets are possible to reach, we calculated the total amount of each habitat across all the parcels. The target for salt marsh was adjusted to the amount anticipated to be available in land parcels by 2050 within this particular decision context (table F1). We note that additional habitat could become available for acquisition if the spatial scale of the area under consideration was enlarged.

Targets are based on projected changes in Cape Romain NWR habitat with increased SLR between 2010 and 2050 and the amount of available habitat (in hectares) in candidate land parcels. Negative values indicate projected habitat loss in Cape Romain NWR under SLR (that is, loss to currently protected lands). If there are insufficient tracts available to replace a given habitat (indicted by whether the target is possible), then the new target is the total amount of available tracts. For those habitats projected to increase in area, no target is identified. 

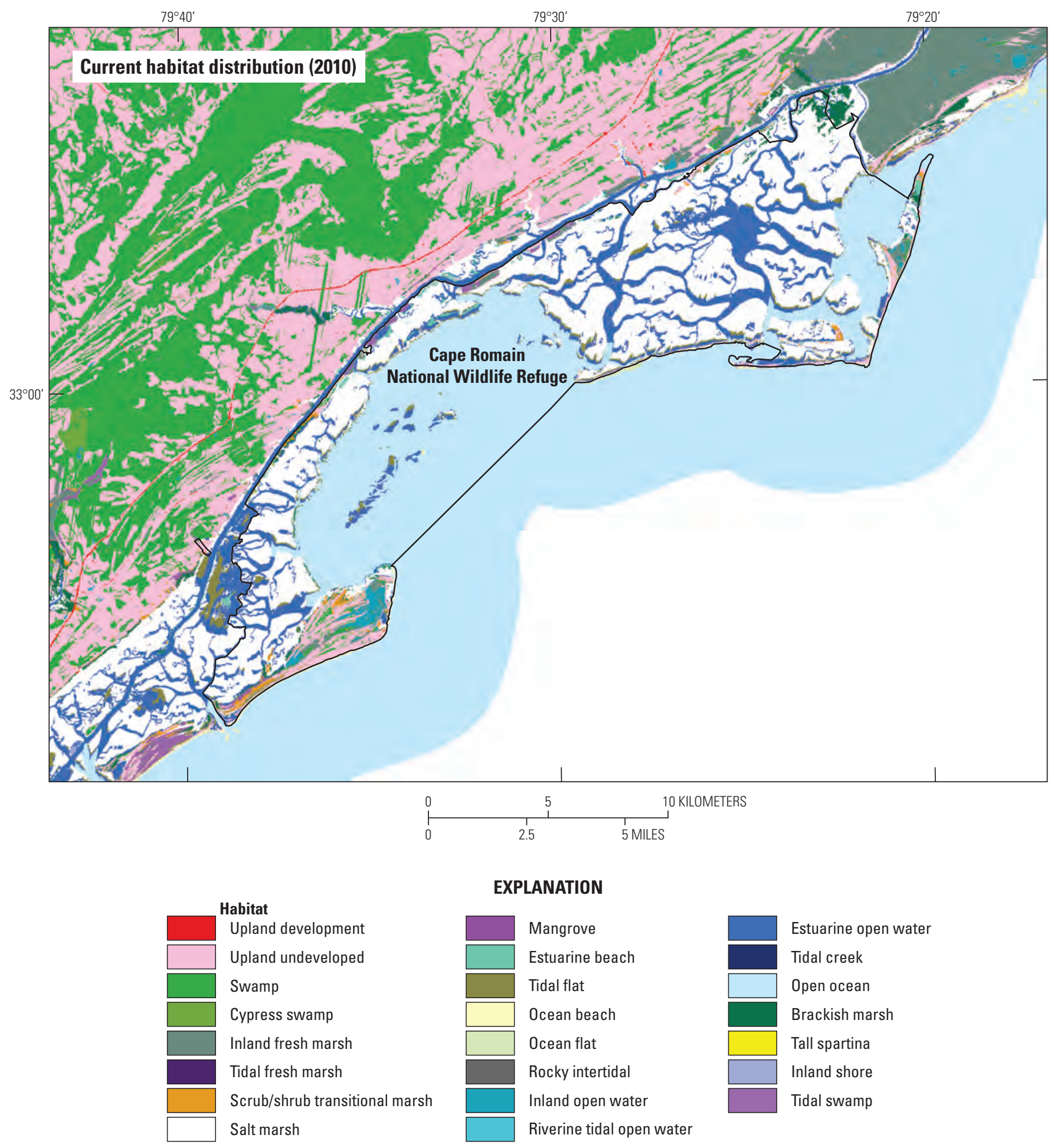

\section{EXPLANATION}

Mangrove

Estuarine beach

Tidal flat

Ocean beach

Ocean flat

Rocky intertidal

Inland open water

Riverine tidal open water

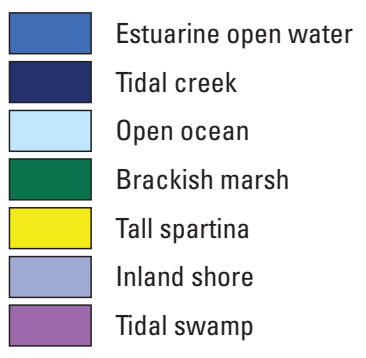

stuarine open water

Tidal creek

Open ocean

Brackish mars

Tall spartina

Tidal swamp

Figure F1. Habitat distribution in the region of Cape Romain National Wildlife Refuge based on local sea-level rise projections and Sea Level Affecting Marshes Model output scenario B1 (2040). A, current habitat distribution (2010). B, projected habitat distribution (2050). 


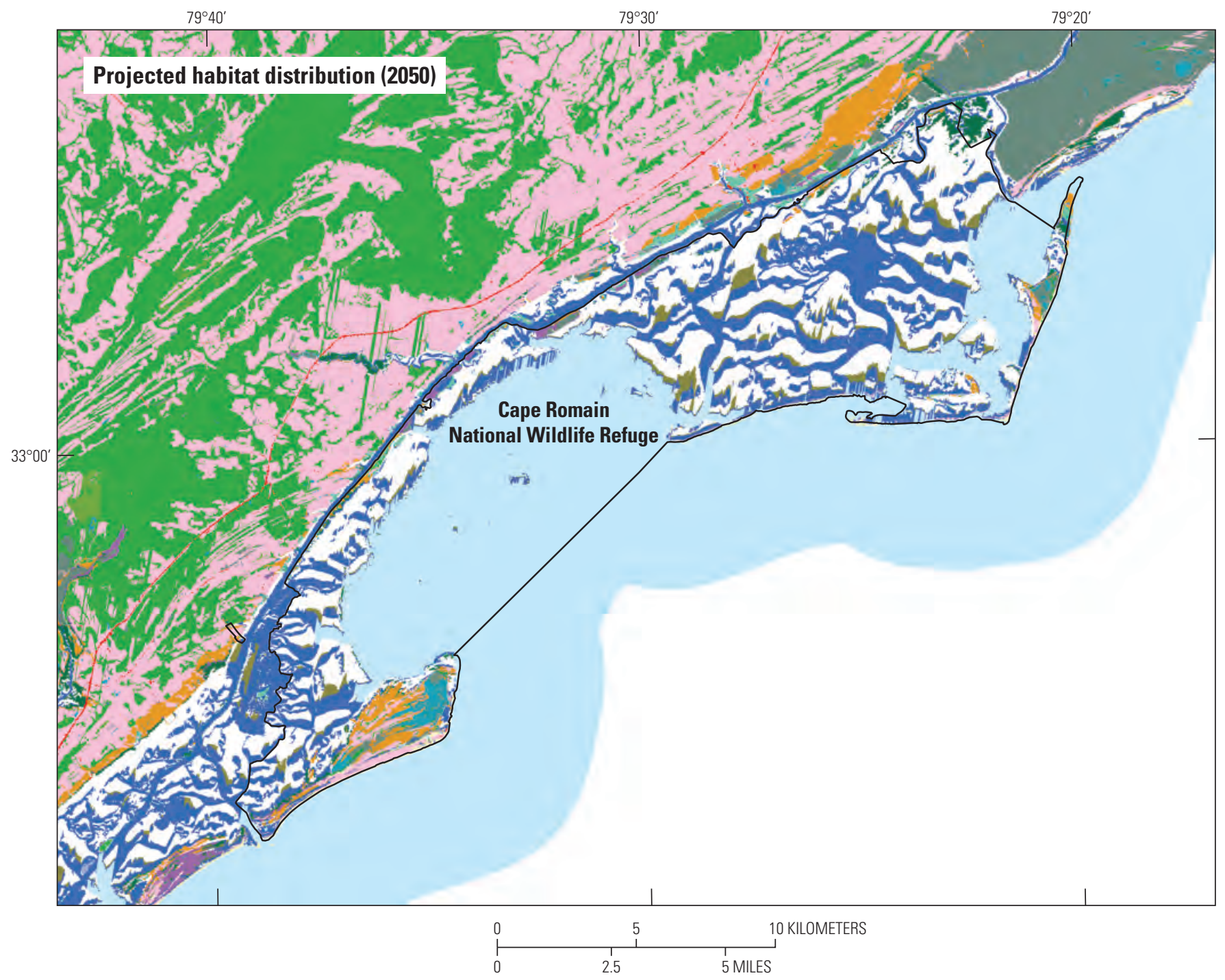

EXPLANATION

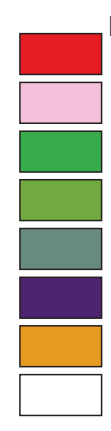

Habitat

Upland development

Upland undeveloped

Swamp

Cypress swamp

Inland fresh marsh

Tidal fresh marsh

Scrub/shrub transitional marsh

Salt marsh

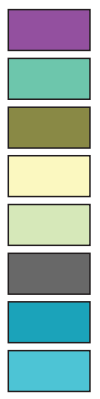

Mangrove

Estuarine beach

Tidal flat

Ocean beach

Ocean flat

Rocky intertidal

Inland open water

Riverine tidal open water

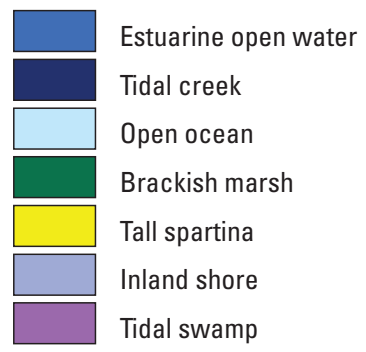

Figure F1.-Continued 
Table F1. Habitat category targets for the Marxan analysis.

[SLR, sea-level rise; NA, not applicable]

\begin{tabular}{lcclc}
\hline \multicolumn{1}{c}{ Habitat category } & Change under SLR & Available in tracts & Target possible & $\begin{array}{c}\text { New } \\
\text { target }\end{array}$ \\
\hline Developed uplands & 0 & NA & NA & NA \\
Undeveloped uplands & -382.1 & $2,123.1$ & Yes & NA \\
Swamp & -57.8 & $1,110.3$ & Yes & NA \\
Inland fresh marsh & 1 & 166.1 & NA & NA \\
Scrub shrub transition & 264.1 & 182.6 & NA & NA \\
Salt marsh & $-2,800$ & 340.2 & No & 340.2 \\
Estuarine beach & -25.2 & 74.8 & Yes & NA \\
Tidal flat & 346.1 & 0.6 & NA & NA \\
Ocean beach & 36.7 & 0 & NA & NA \\
Ocean flat & -1.2 & 0 & No & 0 \\
Inland open water & -2.3 & 31.4 & Yes & NA \\
Estuarine open water & $1,857.3$ & 152.3 & NA & NA \\
Open ocean & 756.6 & 0 & NA & NA \\
Brackish marsh & -2.5 & 29.1 & Yes & NA \\
Inland shore & -0.1 & 0 & No & 0 \\
Tidal swamp & -13.9 & 20 & Yes & NA \\
\hline
\end{tabular}

\section{F.1.1.4. Optimization Analysis}

For the optimization analysis, we ran two different scenarios. In the first, we only considered the parcels along the highway US-17 north of Cape Romain NWR (fig. F2). In the second, we consider these parcels along with additional parcels nearby along the Santee River (fig. F3). We used the targets calculated in the previous steps and parcel information (amount of each habitat and cost) to determine the optimal selection of parcels. We used a budget of 25 percent of the total available area in the parcels, ran the optimization for 1,000 iterations, and used the best solution as the output. This corresponded to a budget of 1,060 hectares when using the highway tracts only and 5,995 hectares when all parcels (including the Santee River tracts) were included.

\section{F.1.2. Results Using Only the Highway Parcels North of Cape Romain National Wildlife Refuge}

The results of the optimization for the highway parcels north of Cape Romain NWR are presented in figure F2. The habitat targets and total amount of newly acquired parcels are shown in table F2. Interestingly, several contiguous sites were selected, and most of these were along the refuge boundary, although we did not specify a connectivity metric in the model. All habitat targets were met for the proposed expanded refuge boundary except for salt marsh (94 percent of target met), tidal swamp (83 percent of target met), and undeveloped uplands (59 percent of target met). The total area of parcels selected was 1,060.5 hectares, which corresponded to the proxy for "total cost." This total area was close to the budget (1,060 hectares), indicating that the solution was constrained by the budget, which explains the shortfall of some of the habitat targets. The solution, of course, was also constrained by estimation of habitat availability (that is, a constraint imposed by the spatial extent considered).

The results of the optimization that included the Santee River parcels with the highway parcels are presented in figure F3. The habitat targets and total amount of newly acquired parcels are shown in table F3. All habitat targets were met for the proposed expanded refuge boundary except for salt marsh (99.9 percent of target met). However, the target for salt marsh corresponds to the total amount in the study area; thus, reaching 100 percent is unlikely. The total area of parcels selected was 1,380.2 hectares, which was far less than the total budget of 5,995 hectares, indicating all habitat targets can be met with a budget of 1,380.2 hectares. The projected future habitats in the region for year 2050 suggested that the salt marsh habitats would be most affected (loss of 2,800 hectares, table F1). However, only 340 hectares of this habitat category was available for protection (table F1).

The optimal reserve was very similar whether or not we included the Santee River parcels. In fact, none of the Santee River parcels was selected, so the results vary only because of the difference in total budget (1,060.5 versus 5,995 hectares). The reason Santee River parcels were likely not selected is because the types of habitat lost in Cape Romain NWR under SLR are not present in high amounts in the Santee River parcels. If, however, the goal is to represent some percentage of 


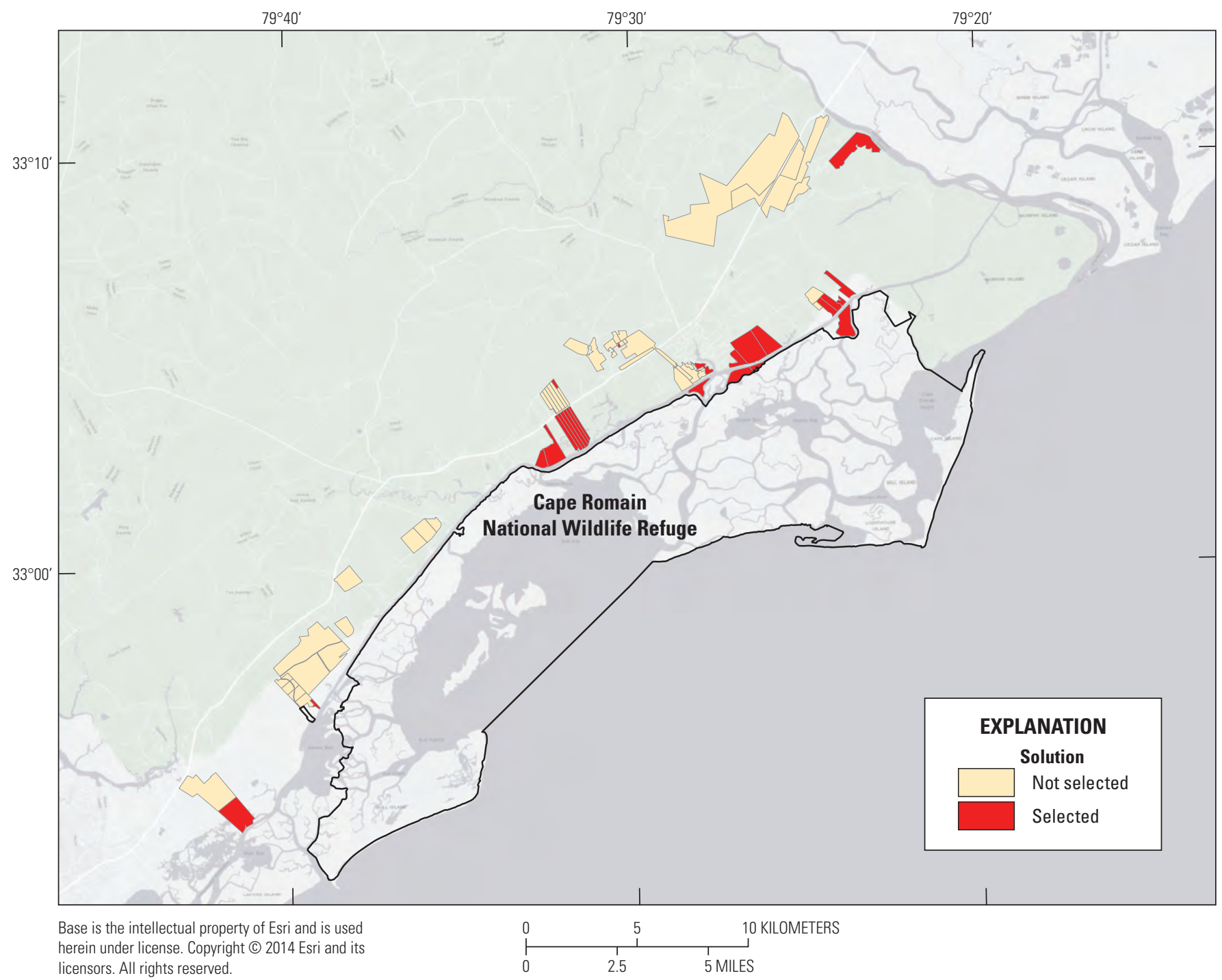

Figure F2. Selected parcels north of Cape Romain National Wildlife Refuge obtained from the optimization analysis (does not include the parcels along the Santee River). The reserve design had a total cost of 1,060.5 hectares (which is a proxy for "total cost").

all marsh types present in the region, the Santee River parcels become more important. For example, tidal swamp habitat is highly abundant in the Santee River parcels but were not target habitats for this analysis because they were not present in Cape Romain NWR in 2010.

\section{F.1.3. Discussion}

The analyses presented in this chapter provide a first step to addressing the issue of adaptation to climate change for Cape Romain NWR. We used an optimization approach to identify sites that would provide the greatest conservation value at the lowest cost. The management objective in our case was to maximize refuge values specified by the fundamental objectives. As a simplification, we considered how conserving habitat types valued by managers can meet their fundamental objectives. Each habitat type can be valued differently (as reflected by objective targets). In our application, we aimed to meet some conservation targets at the lowest cost possible (that is, up to our budget constraint). Our specified goal was to acquire new parcels to replace the habitat area in the refuge that would potentially be lost under SLR in 2050 (in this case, a 1-foot SLR increase) at the lowest cost. We used parcel area as a proxy for cost, which is a common approach used in the conservation planning literature. Based on the models that we used, the projected future habitats in the region for year 2050 suggested that the salt marsh habitats would be most affected (loss of 2,800 hectares, table F1). However, only 340 hectares of this habitat type were available for protection given the specified solution space (areas next to the refuge and the Santee River Basin; table F1). This is an example of scale mismatch (Cumming and others, 2006) in that the refuge may not be able to meet its objectives of maintaining salt marsh habitat given the limited decision context that was considered. Two 


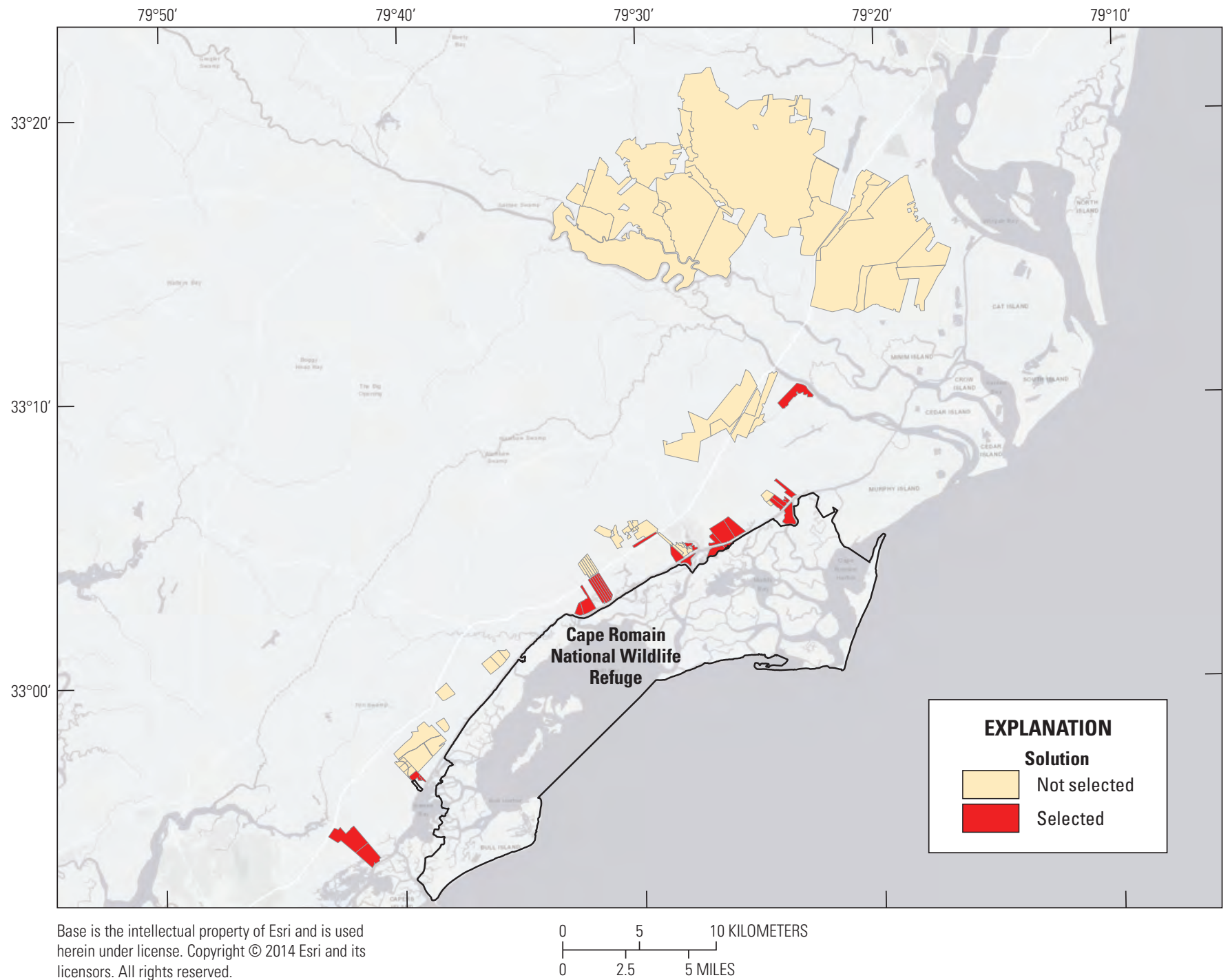

Figure F3. Selected parcels north of Cape Romain National Wildlife Refuge and along the Santee River obtained from the optimization analysis. Habitat types based on sea-level rise for 2050 are displayed. The reserve design had a total cost of 1,380.2 hectares (which is a proxy for "total cost").

Table F2. Partial Marxan habitat outcomes for highway parcels.

\begin{tabular}{lrcc}
\hline \multicolumn{1}{c}{ Habitat category } & $\begin{array}{c}\text { Target, in } \\
\text { hectares }\end{array}$ & $\begin{array}{c}\text { Amount } \\
\text { protected, in } \\
\text { hectares }\end{array}$ & $\begin{array}{c}\text { Target } \\
\text { achieved }\end{array}$ \\
\hline Tidal swamp & 13.9 & 11.5 & No \\
Brackish marsh & 2.5 & 22.1 & Yes \\
Inland open water & 2.3 & 21.7 & Yes \\
Estuarine beach & 25.2 & 43.5 & Yes \\
Salt marsh & 340.2 & 317.4 & No \\
Swamp & 57.8 & 103.8 & Yes \\
Undeveloped uplands & 382.1 & 225.3 & No \\
\hline
\end{tabular}

Table F3. Partial Marxan habitat outcomes for Santee River parcels.

\begin{tabular}{lccc}
\hline Habitat category & $\begin{array}{c}\text { Target, in } \\
\text { hectares }\end{array}$ & $\begin{array}{c}\text { Amount } \\
\text { protected, in } \\
\text { hectares }\end{array}$ & $\begin{array}{c}\text { Target } \\
\text { achieved }\end{array}$ \\
\hline Tidal swamp & 13.9 & 18.4 & Yes \\
Brackish marsh & 2.5 & 28.2 & Yes \\
Inland open water & 2.3 & 29.6 & Yes \\
Estuarine beach & 25.2 & 64.8 & Yes \\
Salt marsh & 340.2 & 340 & No \\
Swamp & 57.8 & 98.5 & Yes \\
Undeveloped & 382.1 & 384 & Yes \\
$\quad$ uplands & & & \\
\hline
\end{tabular}


possible alternatives are to (1) modify the objectives or (2) to expand the scope of the project by considering a larger extent of parcels and bringing in other partners who would have the means to acquire them. An example of the first alternative is to replace less marsh habitat, whereas the second would require partners with additional funding and authority.

As with any optimization exercise, the proposed solutions are only optimal with respect to the objectives that were specified and given the model projections that were considered. For example, alternative projections of the effect of SLR on habitat changes or different targets assigned to the habitats considered may lead to different optimal solutions. Managers may modify the habitat targets based on their stated preference on certain habitat characteristics. Alternatively, they could substitute habitat types with provisioning of specific ecosystem services (for example, acres of oyster reefs; see app. 3). These solutions should by no means be viewed as prescriptions. Instead, managers could use this optimization framework to better understand their decision problems and how decision outcomes could vary because of how the objectives are framed and how the actions are met. This optimization framework approach could also help narrow down the large number of reserve design acquisition options. As an example, with only 20 sites and 2 possible options (purchase or not) for each site, there are greater than 1 million possible reserve portfolio options to select from. Our example considered 84 sites when including the Santee River parcels; thus, using an optimization tool could help decision makers grapple with the many possible choices. One benefit of the approach that we have presented is that it can be implemented with a user-friendly software (for example, Marxan) and therefore may empower managers by allowing them to do some of these analyses by themselves (Ball and others, 2009).

The approach we have described, however, has several limitations. First, the model projections from the SLAMM software are based on version 5.0.1. Although, more recent implementations of the SLAMM software have been developed, the outputs for Cape Romain NWR are currently not available. It is worth noting that the output from the SLAMM software has been criticized by several marsh migration experts. Key criticisms include (1) some fundamental assumptions about how habitat is expected to transition under SLR scenarios may often be violated, and a more mechanistic modeling approach may ultimately provide better projections; (2) the accretion rates for habitat types should ideally be obtained from sampling the study area, and this is rarely the case (we did not correct for local accretion in our study); and (3) the initial elevation information is based on light detection and ranging (lidar) data, which may substantially overestimate elevation (Kevin Buffington, UGSG, oral commun.; Doyle and others, 2015). Another limitation of this analysis is that it does not consider important sources of uncertainty. For example, uncertainty about SLR projections, uncertainty about marsh migration transitions, or uncertainty about our ability to purchase sites were not included in this study. We also did not consider the threat posed by urban expansion, which could affect Cape Romain NWR. Finally, we did not explicitly consider the risk attitude of decision makers. In the next chapter (chap. F.2), we addressed some of these limitations by implementing more complex analyses. Specifically, the analyses in the next chapter consider uncertainty about SLR projections, incorporate risks from urbanization, and provide a process for considering the risk attitude of managers.

\section{F.2. Portfolio Decision Analysis- Reserve Design Using Modern Portfolio Analysis}

The reserve design analysis described in chapter F.1 assumed a single decision maker (the U.S. Fish and Wildlife Service) with an interest in designing an expansion plan so that the refuge continues to meet its mission by adapting to future changes. Given a refuge expansion plan would likely only consider nearby areas, this model was of limited spatial scope. More importantly, the previous analysis was unable to account for uncertainty of climate change, subsequent future habitat conditions, and the inherent risks of investing in land acquisition. Because refuge managers recognized a mismatch between their authority to implement an expansion plan and the spatial scale of processes affecting changes in the region, we expanded the spatial domain of this problem to include areas beyond the refuge that may be of interest to a broader range of decision makers. After identifying uncertainty as a major impediment to decision making, we looked for an alternate modeling framework that could explicitly consider stakeholders risk tolerance when seeking an optimal design solution.

To support wise investment decisions that will maximize future conservation returns while addressing important sources of uncertainty and risk, we borrowed theory from the fields of economics and finance and, by considering climate change as analogous to an uncertain financial market, estimated the expected return on conservation design investments while accounting for risk. MPT, first introduced in economics by Markowitz $(1952,1959)$, put forth the principles that an asset should not be evaluated and selected in isolation but, instead, that an assessment of an asset portfolio should be based on (1) its composite estimated benefits and (2) how each asset in the portfolio is expected to co-vary with all others as market conditions fluctuate. This approach is referred to as the "meanvariance portfolio problem," where the benefits and risk of investing under market uncertainty can be measured in terms of expected return and variance for the overall portfolio rather than in terms of individual assets. One important advancement provided by this approach is explicitly representing the covariance of a portfolio to describe how strongly assets are expected to move in synchrony when the system is subject to shocks. This characterization expands on a commonly held understanding of risk (that is, the expected loss as a function 
of the probability of an undesired outcome) by representing risk as portfolio volatility; that is, the degree of deviation from the expected return (weighted mean) and the amount of correlation among asset pairs. The importance of this work was to shift focus from reliance on diversifying assets, which is only a proxy for guarding against risk, to identifying portfolios with minimal correlation between assets. Translating these economic concepts into ecological terms, we emphasized the idea that simply protecting a diversity of habitat types is not sufficient to guard against an uncertain future - if an unexpected outcome negatively affects a set of land parcels similarly, this adds increased risk to investing in the protection of these parcels. Instead, identifying a collection of parcels to protect that, together, will provide benefit to wildlife or ecosystems services regardless of the future is a means to bet hedge against uncertainty. We can view landscape planning in the same light as investment portfolio planning - evaluating land protection decisions as a collection of aggregated and interdependent assets by which the manager aims to achieve an overall benefit by accumulating a diversity of resources.

We assumed decision makers are interested in maximizing the composite benefit of multiple resources. Because resources may not be of equal value and managing for one may negatively affect another, we used a multicriteria decision analysis (MCDA, Wallenius and others, 2008; Steele and others, 2009) at the asset level to evaluate the composite, expected ecosystem benefit provided by individual land parcels over future uncertainty. In this case study, the Cape Romain NWR and its partners are interested in preserving a representative collection of different habitat types in sufficient quantity to provide for future species' needs. We assumed, however, that the decision makers would also like to minimize risk when selecting a portfolio of assets (for example, designing a protected-area network). As economic theory suggests (von Neumann and Morgenstern, 1947), expected return and risk are positively correlated; therefore, these two preferences represent competing objectives that require explicit tradeoffs. Here, we combined an MCDA analysis with MPT to evaluate tradeoffs inherent in these decisions, which can be visualized by plotting the expected benefit and quantified risk of each possible portfolio. In a hypothetical example (fig. F4), most portfolios (gray points) are dominated (that is, a better choice can be found that improves on one objective without loss to the other). Points $\mathrm{R}$ and $\mathrm{T}$ are dominated solutions because points $\mathrm{Q}$ and $\mathrm{S}$ represent alternatives that improve on expected return or risk, respectively, without compromising the value of the other objective. The cloud of available portfolios is finite and identifies a set of nondominated alternatives that forms a performance boundary, termed the Pareto or efficient frontier, where improvement on one objective necessitates surrendering value on the other (that is, alternatives identified by the bold line in fig. F4). On the frontier, point Q represents a portfolio with higher expected return relative to point $\mathrm{S}$, but this increased benefit is achieved only at the cost of greater risk. In our case, the portfolios along this Pareto frontier describe the
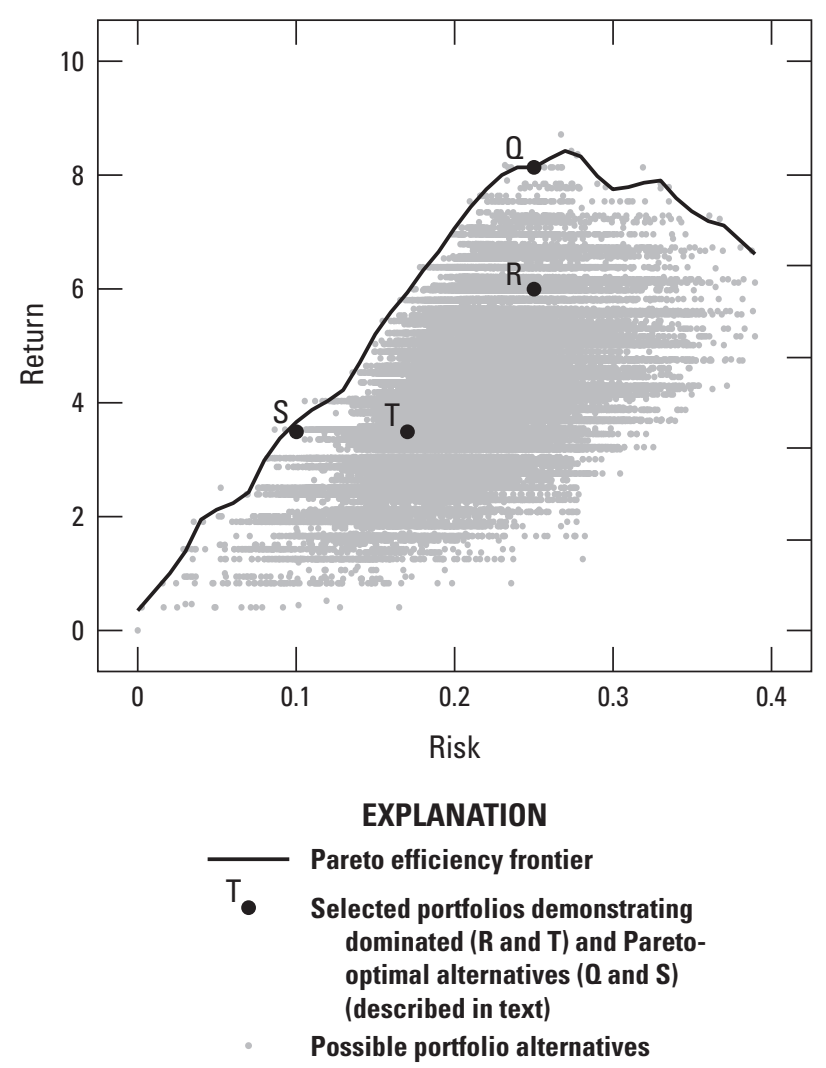

Figure F4. Evaluation of hypothetical portfolio alternatives with objectives of maximizing return and minimizing risk.

unique and optimal set of tradeoffs between risk and return, where risk is minimized for a given benefit or the return is maximized for any stated level of risk.

Although the general MPT framework was developed for financial applications, its application has increased in recent decades for natural-resource management (Koellner and Schmitz, 2006; Moore and others, 2010; Schindler and others, 2010; Ando and Mallory, 2012; Convertino and Valverde, 2013; Anderson and others, 2015). Here, we have modified the analytical approach to be more explicit in supporting decision making. For example, previous conservation applications of MPT have simplified the decision variable to reduce computational complexity (for example, Ando and Mallory [2012] evaluated allocation of conservation efforts among three large subregions). These approaches are not mathematically generalizable to large problems, which is a limitation we have sought to address here. Additionally, we believe this to be one of the first applications of MPT that considers tradeoffs between acquiring new land parcels and divesting from currently protected parcels when evaluating overall conservation benefit. Although recognizing that, in many cases, it may be untenable to surrender protected lands, this analysis explores the possibility that in a dynamically evolving system not all conserved parcels may be worth retaining in perpetuity. This approach may also encourage consideration of more flexible 
conservation instruments, such as fixed-term easements (Thompson, 2004). Below, we briefly outline the problem and summarize the analytical steps taken. A detailed description of methods is provided in chapter F.2.5 (see also Eaton and others, 2019a).

\section{F.2.1. Problem Definition and Analysis}

As a simplification of possible objectives that could originate from decision makers, we considered a goal of protecting particular habitat types into the future. To measure the contribution of an individual parcel to a protected area, we quantified the area of each habitat it contains. To account for the priorities of a hypothetical land manager, we represented the relative value of each habitat cover type by a vector of criteria weights and applied MCDA to compute parcel and portfolio returns. Figure F5 offers a conceptual depiction of our spatial planning model. For each planning unit (parcel $j$ ) and future SLR scenario $(k)$, MCDA is used to evaluate the achievement of discrete habitat objectives as a function of the predicted area of habitat cover types $(h 1-h 4)$, weighted by relative stakeholder preference for each habitat type. The expected portfolio return for each SLR scenario is calculated as the cumulative weighted sum of all parcels included in the portfolio. Parcels are identified as currently protected (set S) or currently unprotected lands (set B) and for each candidate reserve design (that is, divestment decisions from set $\mathrm{S}$ and acquisition from set B), the MPT analysis quantifies the accumulated benefits and risks associated with SLR-induced variance and spatial correlation. A heuristic search algorithm identifies the efficiency frontier, defining the set of Pareto-optimal designs (blue line) and dominated alternatives (gray points; see fig. F4). Because future habitat distribution varies under each SLR scenario, we calculated the habitat contributions of a given parcel as the expected value over three SLAMM scenarios (see chap. B.1, table B2 for scenario description). Similarly, we expressed risk in terms of variance and covariance associated with differences in habitat composition as a function of SLR scenarios (for details, see chap. F.2.5).

Here, we considered a larger region than for the reserve design problem described in chapter F.1; our analysis extended north past the Santee River and westward beyond Francis Marion National Forest. We considered 1,244 parcels, including currently protected and unprotected tracts greater than 3 hectares in size. Although SLAMM datasets include additional land-cover categories, 19 distinct habitat types compose our study area. To characterize a plausible conservation goal of maintaining relative habitat composition into the future, we used the current proportions of each habitat type to derive a set of habitat criteria weights ( $w_{h}$, table F4). At the end of a 50-year time horizon, we quantified the expected value of each parcel as well as the variance in this value over the three SLR scenarios (table F4). We scaled parcel values by size and modified values by the expected probability that the parcel will be lost to urban development such that the value of parcels at higher risk of future development increases proportionally with this probability (see chaps. B.4.3 and F.2.4 for details). In this formulation, portfolio value is a function of habitat composition, stakeholder preference, and risk of opportunity loss (development), whereas portfolio risk is driven by uncertainty of future habitat composition as a function of SLR.

Because of computational limitations of evaluating all possible portfolio combinations, we subdivide the 1,244 parcels into 14 groups of less than or equal to 100 parcels each, clustered into roughly similar habitat biomes based on distance from the coast (fig. F6; see chap. F.2.5.4). We first quantified predicted habitat changes and their implications for conservation under the current Federal, State, and private protectedarea network. This was followed by three potential reserve designs, based on scenarios of stakeholder risk, applying an unconstrained portfolio optimization. We then reported on a comparative evaluation of future conservation benefits under one optimal reserve design relative to the existing protectedarea network. Finally, we modified this analysis by constraining the optimization to include four hypothetical budget scenarios to explore inferences in tradeoffs among expected benefits, risk, and cost. We concluded by discussing the benefits and limitations of the MCDA-MPT approach, as well as additional factors that could be considered before implementing this decision-support tool.

\section{F.2.2. Results}

\section{F.2.2.1. Habitat Predictions}

Model projections for our study region predicted significant habitat transition and substantial changes in the composition and extent of wetlands and other important habitat types (table F4). Within the study area, the total extent of existing wetland habitat, combined across types, was estimated to exceed 1,300 square kilometers, of which 82 percent is in protected status. The projected loss in total wetland habitat ranges from less than 1 percent under the low SLR scenario to nearly 7 percent under high SLR. The predicted loss of wetlands, weighted by SLR probability, was 20 square kilometers, or 1.5 percent of total extant wetland area. Future conversion of any existing habitat to open water is more dramatic, ranging from an additional 14-percent to180-percent increase from current area of open water. Ocean beach nesting habitat, currently estimated to compose about 264 hectares, is expected to increase in area under moderate SLR (10 percent) but decline otherwise, by 13 and 14 percent under low and high SLR, respectively. Tidal flats, in contrast, will increase substantially under all SLR scenarios, between 38 and 184 percent and with a weighted average of more than double in size from its current 830 hectares.

Based on the current protected-area design, we evaluated the change in protected wetland habitat under the three SLR scenarios. Differences in SLR projections result in variable habitat outcomes as a function of wetland type and the degree of SLR. Extent of intertidal scrub/shrub transition marsh 


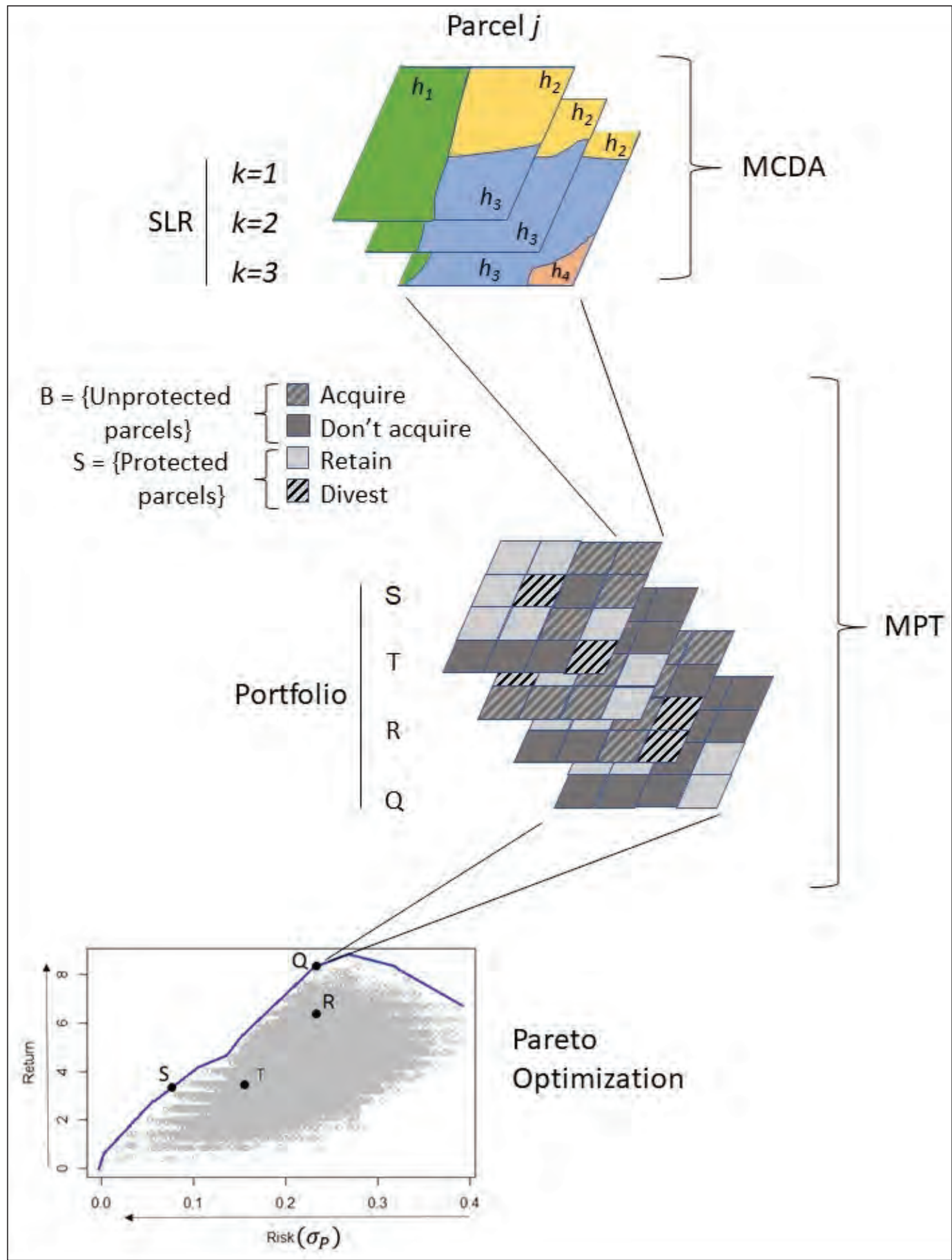

Figure F5. Conceptual spatial planning model using multicriteria decision analysis (MCDA) and modern portfolio theory (MPT). From Eaton and others (2019a); used with permission 


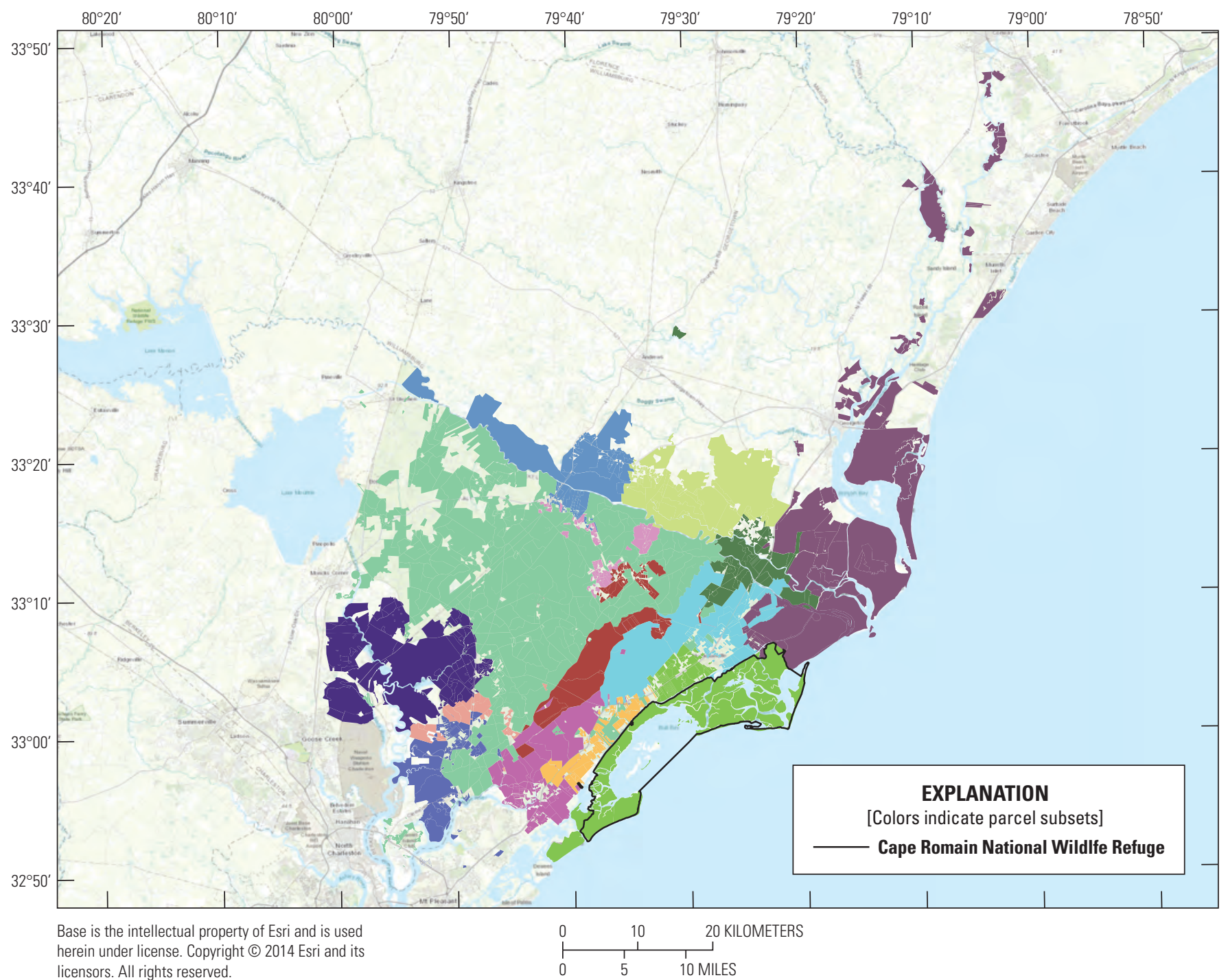

Figure F6. Spatial orientation of study area division ( $n=1,244$ land units) into 14 subgroups of less than or equal to 100 parcels each for reserve design analysis.

and brackish marsh are predicted to increase under all SLR scenarios, whereas salt marsh and tidal swamp habitats decline proportionally with the sea level in all cases. Other habitats, including swamp and inland fresh marsh either increase or decrease in area depending on the scenario (fig. F7A). Changes in salt marsh and scrub/shrub transition marsh represent the most substantial impacts, with as much as 13,900 hectares of salt marsh lost and more than 9,000 hectares of scrub/ shrub transition marsh gained under a high SLR scenario. Combined, an overall loss of marsh habitat is predicted regardless of future scenario, with totals ranging from an average of 1,100 hectares ( 0.3 percent) under low SLR to more than 10,000 hectares (9.5 percent) under high SLR (fig. F7B).

\section{F.2.2.2. Pareto-Optimal Reserve Design- Unconstrained Budget}

We computed Pareto-optimal efficient frontiers independently for each of the 14 parcel subsets (fig. F6) under scenarios without fiscal constraint. To produce a global solution for all 1,244 parcels, we developed three scenarios corresponding to different risk attitudes of a hypothetical decision maker. These included a balanced risk-reward scenario calculated as a Nash bargaining solution (Nash, 1950; Santín and others, 2017; see chap. F.2.4) and two cases representing low-risk, low-reward and high-risk, high-reward tradeoffs. A low-risk scenario places greater emphasis on minimizing uncertainty 
Table F4. Current habitat distribution and future predictions under current and optimal protected area designs.

\begin{tabular}{|c|c|c|c|c|c|c|c|c|c|c|}
\hline \multirow{2}{*}{$\begin{array}{l}\text { Habitat } \\
\text { category }\end{array}$} & \multicolumn{2}{|c|}{$\begin{array}{l}2010 \text { habitat distribution, } \\
\text { in hectares }\end{array}$} & \multicolumn{4}{|c|}{$\begin{array}{l}2050 \text { total habitat distribution per SLR projection, in } \\
\text { hectares }\end{array}$} & \multirow{2}{*}{$\begin{array}{c}2050 \\
\text { existing } \\
\text { protected } \\
\text { area, } \\
\text { weighted } \\
\text { averages }\end{array}$} & \multirow{2}{*}{$\begin{array}{c}2050 \\
\text { optimal } \\
\text { weighted } \\
\text { average, in } \\
\text { hectares }\end{array}$} & \multirow{2}{*}{$\begin{array}{c}\text { Optimal:2010 } \\
\text { protected } \\
\text { area ratio }^{3}\end{array}$} & \multirow{2}{*}{$\begin{array}{c}\text { Optimal } \\
\text { 2050: } \\
\text { existing } \\
\text { protected } \\
\text { area ratio }\end{array}$} \\
\hline & Total & Protected & Low & Medium & High & $\begin{array}{l}\text { Weighted } \\
\text { average }\end{array}$ & & & & \\
\hline $\begin{array}{c}\text { Developed } \\
\text { uplands }\end{array}$ & 518.2 & 243.9 & 566.1 & 566.1 & 566.1 & 566.2 & 261.8 & 520.3 & 2.13 & 1.99 \\
\hline $\begin{array}{l}\text { Estuarine } \\
\text { beach }\end{array}$ & 367.4 & 280.5 & 388 & 591.1 & 859.9 & 602.1 & 369.8 & 548.2 & 1.95 & 1.48 \\
\hline Tidal flat & 829.1 & 817.8 & $1,146.90$ & $1,824.20$ & $2,352.80$ & 1,799.60 & $1,756.30$ & $1,683.40$ & 2.06 & 0.96 \\
\hline Ocean beach & 263.8 & 263 & 230.8 & 291.4 & 226.5 & 270.5 & 270.5 & 270.5 & 1.03 & 1 \\
\hline $\begin{array}{l}\text { Estuarine } \\
\text { open water }\end{array}$ & $4,861.50$ & $4,574.50$ & $6,087.20$ & $9,842.70$ & $19,946.30$ & $10,901.90$ & $10,200.90$ & $10,360.60$ & 2.26 & 1.02 \\
\hline Open ocean & 850.6 & 830.3 & 862.2 & $1,461.50$ & $3,722.10$ & 1,738.60 & $1,714.10$ & $1,691.60$ & 2.04 & 0.99 \\
\hline Inland shore & 28.6 & 24 & 28.6 & 28.6 & 24.6 & 27.9 & 23.2 & 27.5 & 1.14 & 1.19 \\
\hline Swamp & $79,486.80$ & $65,964.70$ & $79,327.10$ & $81,636.20$ & $77,368.10$ & $80,547.90$ & $66,536.90$ & $68,424.20$ & 1.04 & 1.03 \\
\hline $\begin{array}{r}\text { Brackish } \\
\text { marsh }\end{array}$ & $5,101.70$ & 4,434.30 & $5,718.20$ & $6,750.10$ & $6,981.70$ & $6,617.40$ & $5,789.80$ & $4,116.80$ & 0.93 & 0.71 \\
\hline $\begin{array}{l}\text { Cypress } \\
\text { swamp }\end{array}$ & 431.7 & 392.6 & 429.7 & 430.4 & 384.8 & 422.7 & 386 & 386.9 & 0.99 & 1 \\
\hline Salt marsh & $19,486.40$ & $18,020.00$ & $18,055.70$ & $14,258.50$ & $4,752.20$ & $13,308.20$ & $12,168.10$ & $12,857.50$ & 0.71 & 1.06 \\
\hline Tidal swamp & $11,846.60$ & $5,820.40$ & $11,134.40$ & $9,862.40$ & $8,301.00$ & $9,815.10$ & $4,036.70$ & $9,211.80$ & 1.58 & 2.28 \\
\hline $\begin{array}{l}\text { Total wet- } \\
\text { land }\end{array}$ & $132,584.70$ & $108,680.40$ & $131,470.70$ & $132,056.20$ & $123,692.10$ & $130,577.50$ & $105,719.00$ & $112,496.20$ & 1.04 & 1.06 \\
\hline
\end{tabular}

${ }^{1}$ Estimates the extent of weighted-average habitat protected under the current designation of protected areas in the study region.

${ }^{2}$ Estimates habitat categories protected under a future optimal reserve design evaluated in this study.

${ }^{3}$ Calculates the ratio of expected 2050 habitat protected under an optimal reserve design to the distribution of currently protected habitat.

${ }^{4}$ Evaluates expected 2050 habitat distribution protected under an optimal design relative to 2050 habitat protected under the existing protected area design.

and spatially correlated outcomes than on conservation returns, whereas a high-risk scenario focuses on maximizing expected habitat-composition benefits while discounting the potential downside risk that an unlikely future results in undesired habitat outcomes. For each scenario, we combined the 14 identified portfolios and summarized these spatially (fig. F8). The low-risk, low-reward scenario leads to extensive divestments and moderate acquisition decisions (fig. F8A). The divestments include most of the current footprint of low-lying Cape Romain NWR, suggesting that the perceived value of coastal habitats may be highly sensitive to uncertainty and levels of risk tolerance. In contrast, lands just inland from the coast are identified as important to retain because of their ability to support future wetland transition. Certain low-lying parcels along the Santee River are also identified as candidates for divestment given their higher probability of future inundation and conversion to open waterways, which reduces their value relative to terrestrial and wetland cover types. 


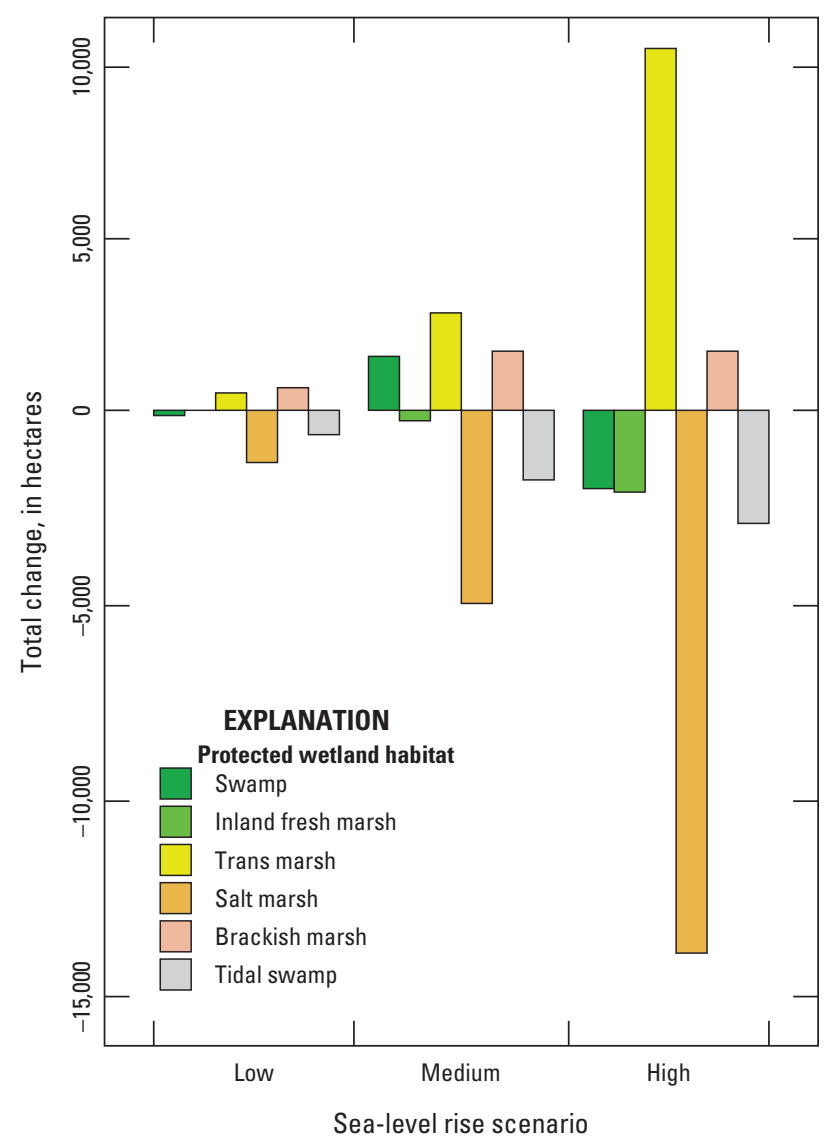

$B$

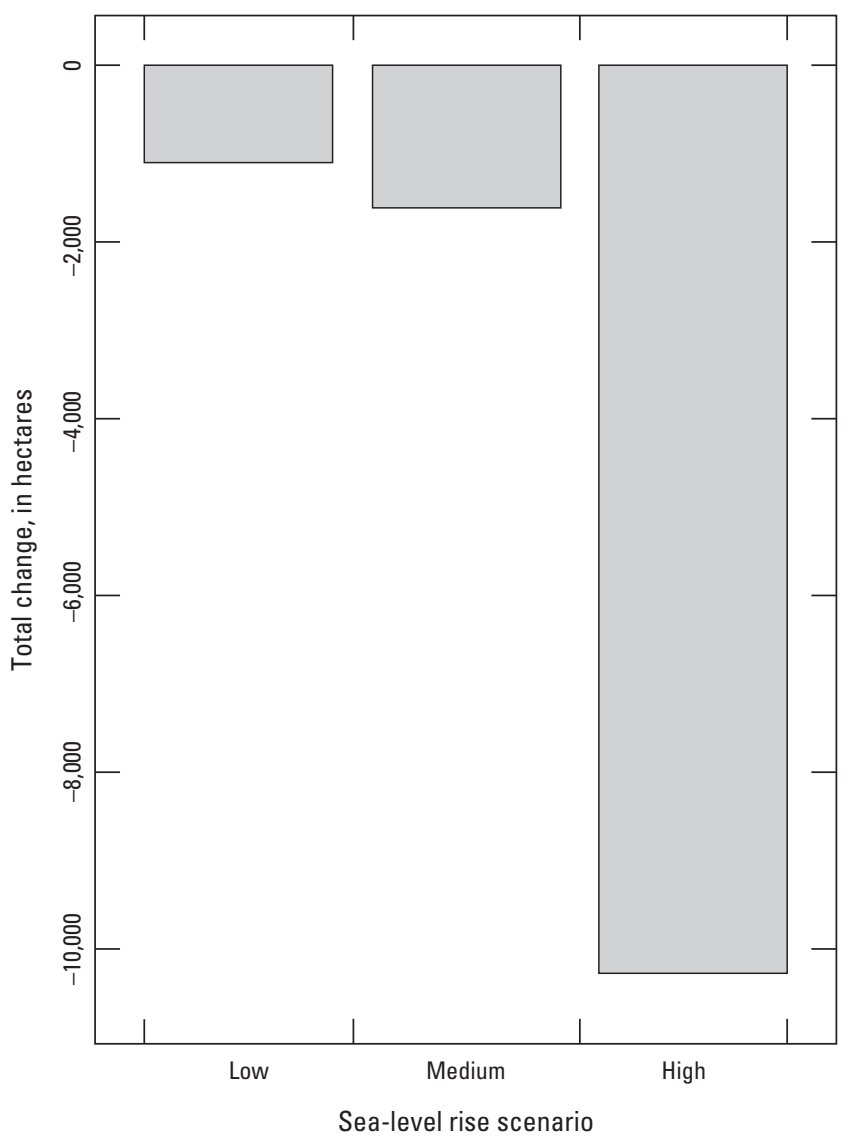

Figure F7. Predicted changes in the distribution of wetland habitat types protected to 2050 under the current reserve network for three sea-level rise scenarios. $A$, Individual wetland cover types. $B$, overall combined wetland habitat extent.

Parcels farther from the existing river channel are favored under this scenario because they are less likely to transition to open water. Conversely, the high-risk, high-reward scenario involves extensive land acquisition with minimal divestment (fig. F8B). Both extremes may be impractical to implement but demonstrate the sensitivity of the optimal solutions to subjective attitudes towards risk. Not surprisingly, the intermediate case for risk-reward as determined by the balanced (Nash) solution demonstrates a reserve design that is intermediate between the low and high risk-reward scenarios (fig. F8C). In this case, there are several large, protected parcels near the Cape Romain NWR that are identified for divestment. The largest of which (6,000 hectares of national forest) is estimated to be composed of freshwater swamp (63 percent) and upland habitat (37 percent) and is not expected to transition substantially to a greater diversity of desired habitat types. This outcome is likely due to the preponderance of swamp habitat expected elsewhere in the study area, thus reducing the contribution of this and other swamp-dominated parcels to the overall portfolio value. Based on the objective function, the algorithm suggests a greater value for habitat diversity can be obtained by divesting from this parcel and acquiring other tracts expected to include underrepresented habitat types. Our analysis does not account for the potential contribution of this large parcel to support marsh migration further inland (that is, as a "stepping stone"), which is an important factor for consideration when acting on any reserve design strategy.

Although this preliminary analysis was limited to only three risk scenarios (that is, we do not include more extreme risk attitudes), we used these to identify the set of parcel decisions that are robust to this degree of risk uncertainty - that is, parcels for which the decision does not change over these risk attitudes. We found that most parcel-specific decisions (70.6 percent) did not change as a function of decision-maker risk preference (fig. F9). The pattern of these robust decisions offers insights regarding risk-reward tradeoffs. Future high-valued and currently unprotected parcels are just inland from the coastal refuge, along the lower reaches of the Santee River, and upland from the Santee and Cooper River Basins. High-valued and currently protected parcels follow a similar pattern; the Santee Delta and some Cape Romain NWR barrier islands are expected to be important future habitat, along with protected lands farther inland from the coast. Only 14 parcels (1.1 percent of the total parcel set) identified as candidates for divestment are common across the three risk scenarios and are not near the coast. 


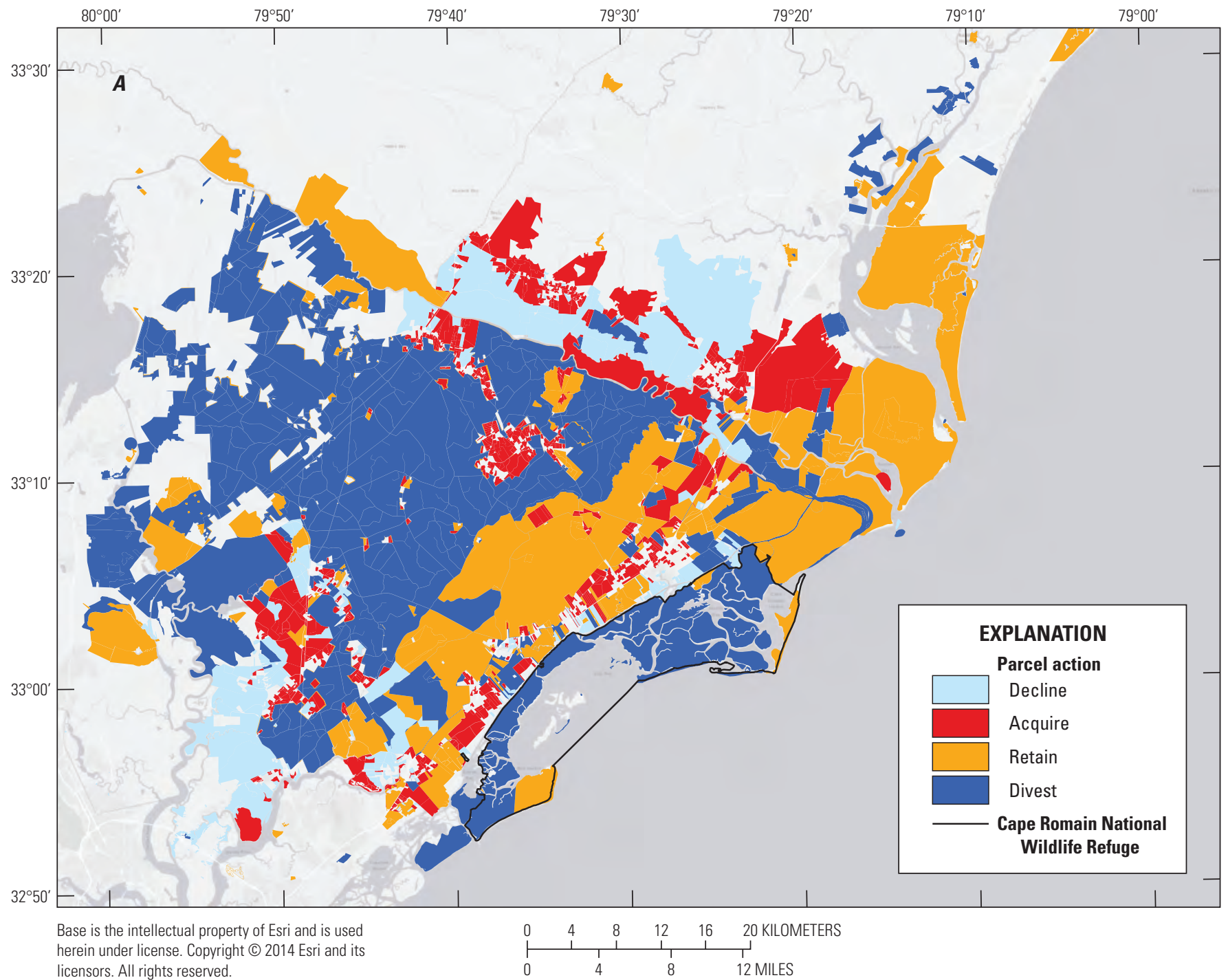

Figure F8. Potential reserve designs optimized using a modern portfolio theory analysis when the decision maker is looking at risk and reward options. A, low risk-low reward. $B$, high risk-high reward. $C$, the Nash solution, or intermediate risk and reward. 


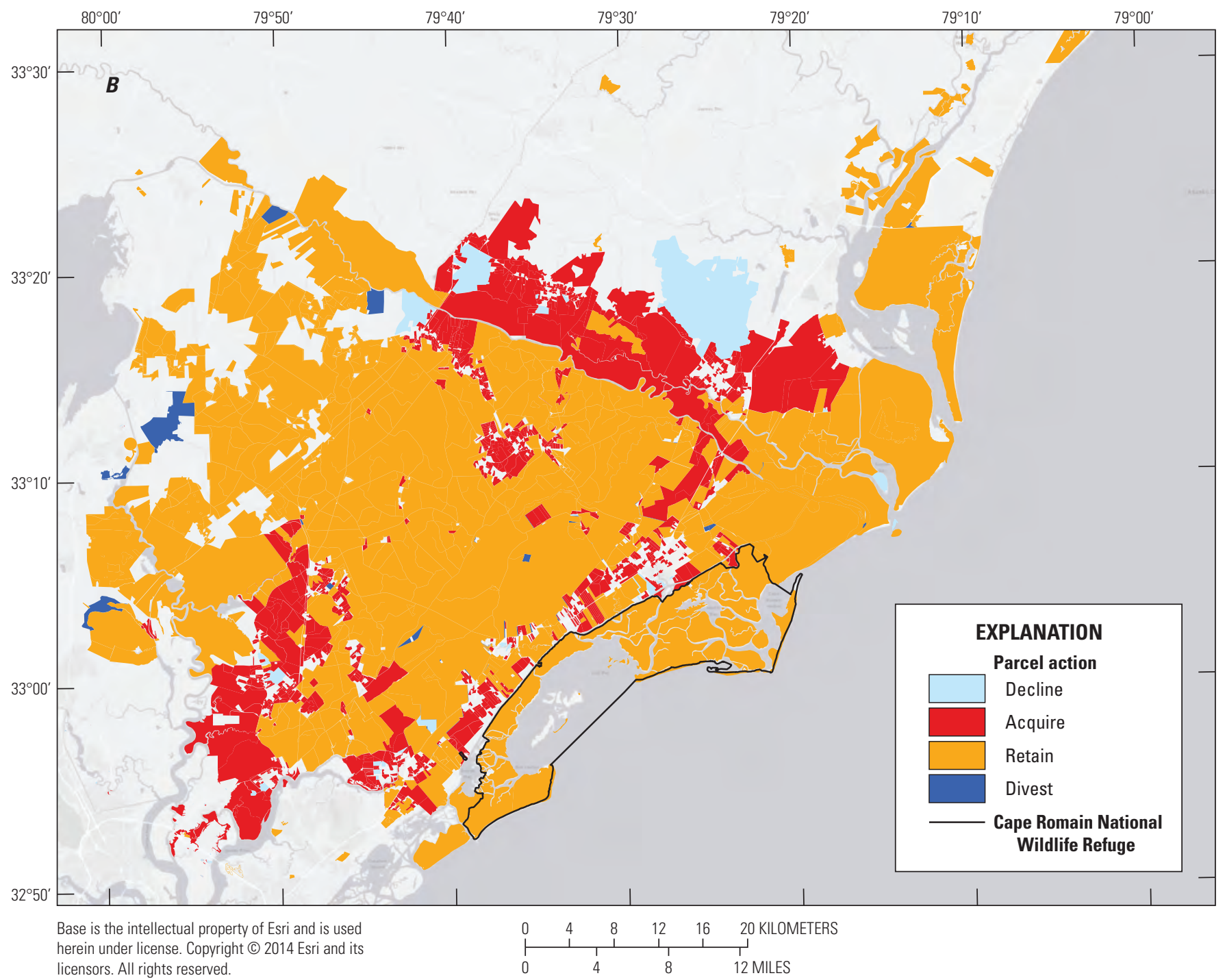

Figure F8.-Continued 


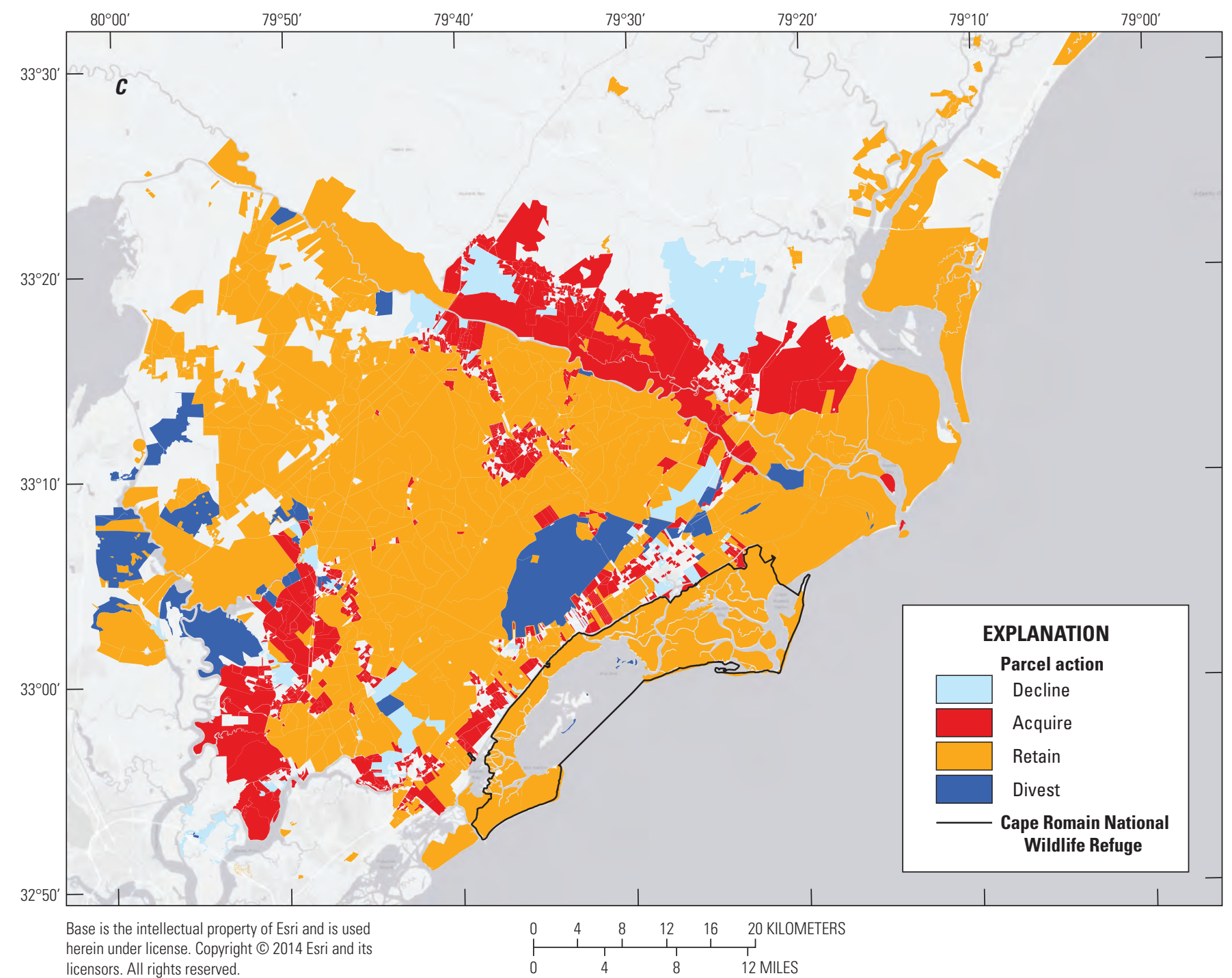

Figure F8.-Continued

As a counterfactual, we also compared the differences in the amount of protected future habitat under an optimal design relative to the current reserve network, while accounting for uncertainty in SLR. Gains in most wetland types under an optimal reserve design were substantial and less sensitive to SLR uncertainty (fig. F10). The extent of protected tidal swamp more than doubles relative to that protected under the current reserve network, irrespective of SLR projection. The three most extensive marsh habitat types in the study area (freshwater swamp, inland marsh, and salt marsh) increased in protected extent by an average of 3-6 percent over the current reserve design (fig. F10, table F4). Brackish marsh was the only wetland habitat expected to decline in area conserved relative to the existing reserve footprint; the average difference was about 1,600 hectares ( 39 percent). Overall, expected wetland protection increases by an average of 6 percent under an optimal reserve design relative to the existing footprint. Counterfactual results are provided in table F4 (last column) for all 19 habitat types as the ratio of optimal to current design. Notable results include a near 50-percent increase in protection of estuarine beach, a 19-percent increase in inland shore habitat, and a 22-percent increase in protection of upland undeveloped lands.

\section{F.2.2.3. Budget-Constrained Optimization}

We constrained the model to a set of hypothetical budget limitations to explore the effects of various levels of financial resources on tradeoffs between expected habitat benefits and risk. A constrained optimization is also more likely to provide insights into decisions to divest from currently conserved areas to fund acquisition of parcels that better meet future habitat 


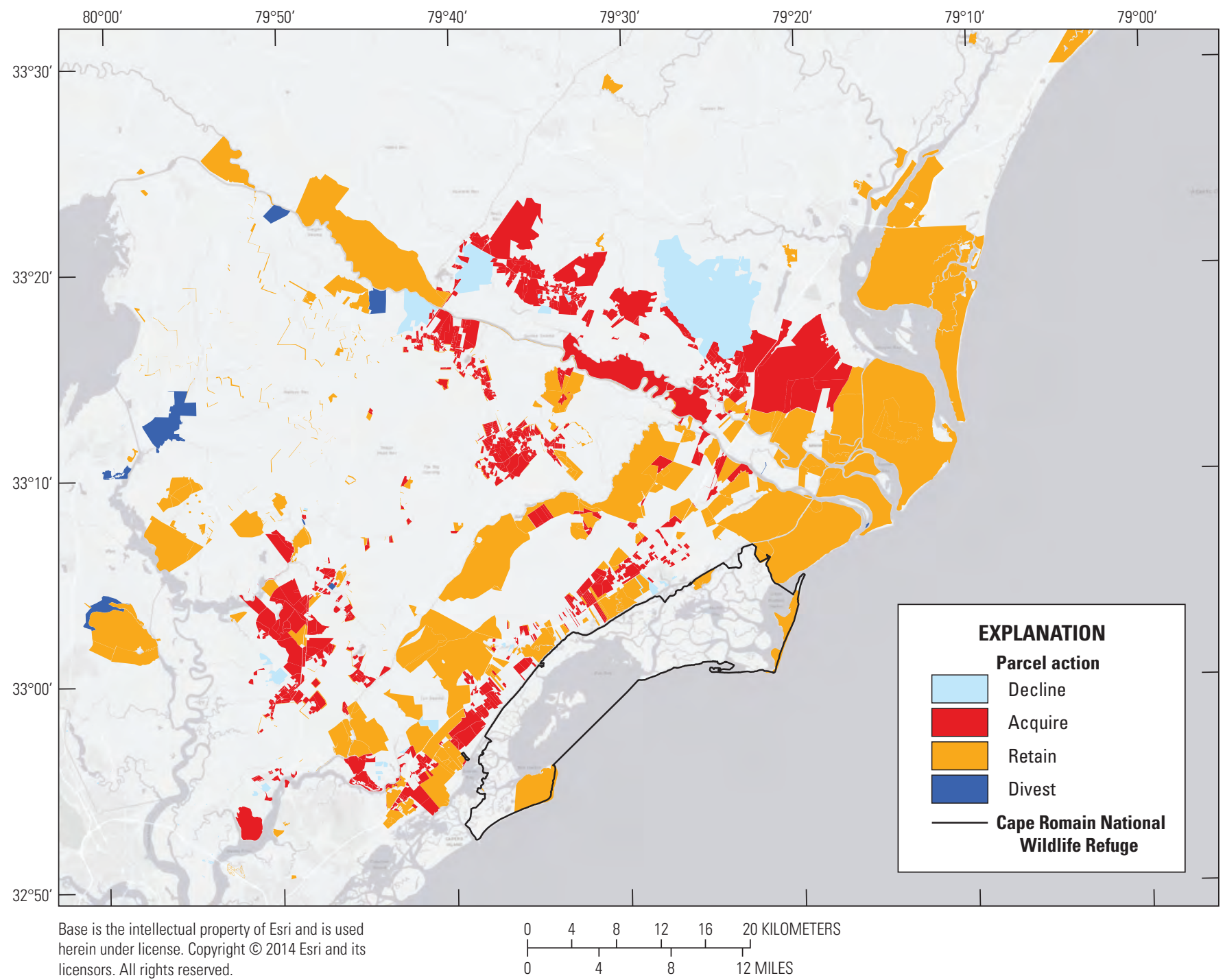

Figure F9. Reserve design solutions that are robust to uncertainty related to risk attitude of the decision maker (that is, representing a "no regret" set of candidate decisions for this spectrum of subjective risk).

needs. Therefore, we do not analyze specific habitat outcomes in the same level of detail as chapter F2.2.2 but provide a more general synthesis of inference gained when adding additional constraints to the reserve design optimization.

Based on allocations of total available budget under each of four fiscal scenarios (table F5), we identified a set of Pareto-optimal portfolio solutions for each of the 14 parcel subgroupings. Applying the balanced-risk Nash bargaining algorithm, we combined and summarized the global solution for each scenario and portrayed these graphically (fig. F11). As expected, the number of divestment decisions for lesser-valued (or higher-risk) parcels, which allow acquisition of other parcels for a greater overall portfolio benefit, declined as the total budget increased. The switch from divest to keep for currently protected parcels was most pronounced in the nearshore area (less than or equal to 20 kilometers from coastline) and along the Santee and Cooper Rivers. With increasing budgets, land acquisition decisions also seem to be focused near river channels but also for nearshore land lying inland between the Cape Romain NWR and the national forest. Both of these areas are likely candidates for future wetland habitat that will replace other wetlands lost to SLR. Taking a weighted average across the three SLR scenarios, table F6 provides a summary of expected habitat area in protected status under the four budget scenarios. Substantial gains in absolute habitat protection appear to be realized with the moderate budget increase from 10 percent to 20 percent of available land, including gains of 6 percent or more in estuarine beaches, tidal flats, freshwater and tidal swamps, and salt marsh habitat. Overall protected habitat increased by 5.2 percent with this budget increase, compared to a 1.8 percent gain when increasing the budget to 35 percent of total available lands and 3.7 percent increase with a budget of 50 percent. 


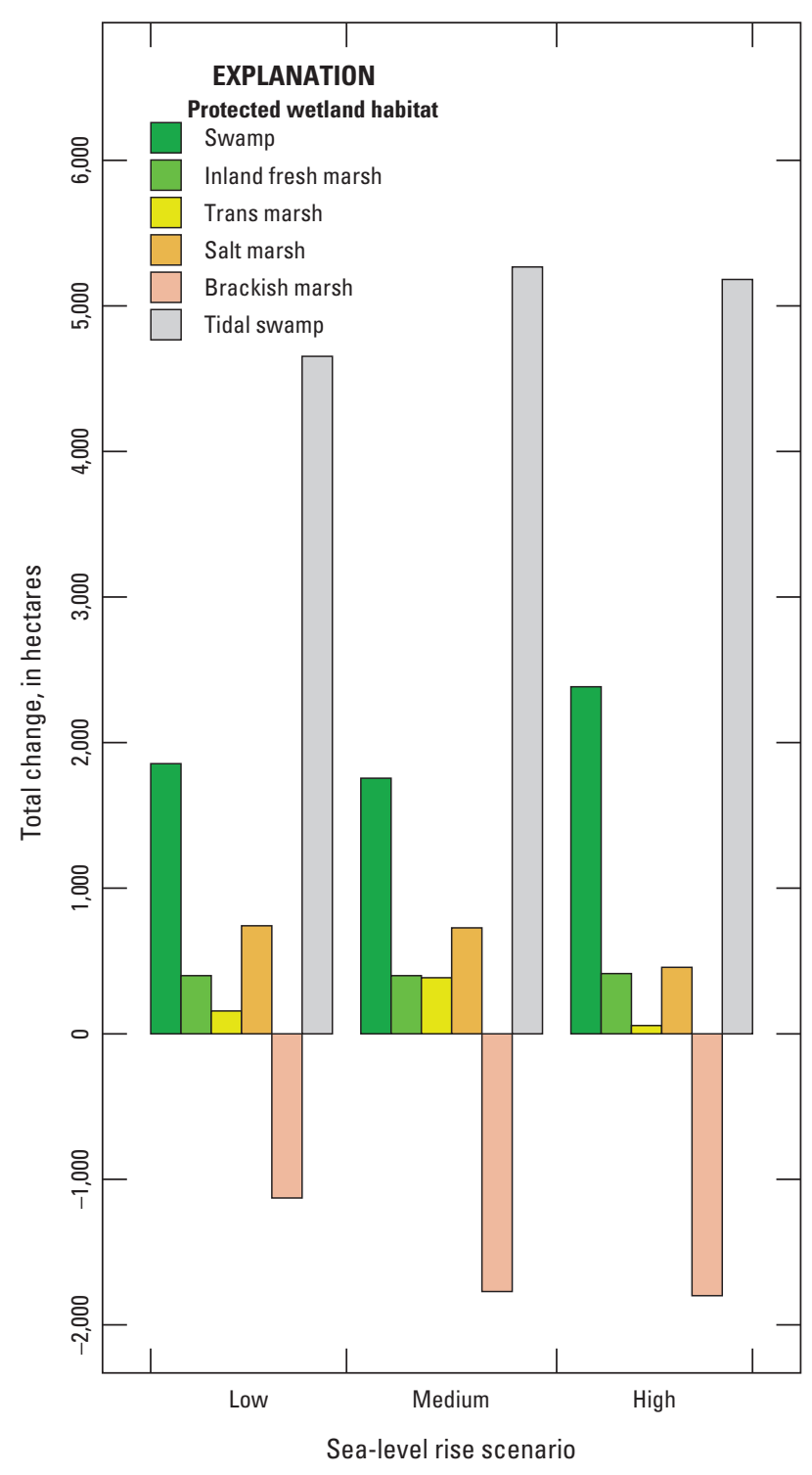

Figure F10. Predicted differences (year 2050) under low, medium, and high sea-level rise scenarios (table F1) of protected wetland habitat types under an optimal reserve design relative to the current protected area network.

Table F5. Budget scenarios hypothesizing a range of fiscal constraints on protected area design.

\begin{tabular}{lcc}
\hline Scenario & $\begin{array}{c}\text { Proportion of total unpro- } \\
\text { tected land }{ }^{1} \text {, in percent }\end{array}$ & $\begin{array}{c}\text { Scenario con- } \\
\text { straint, in hectares }\end{array}$ \\
\hline 1 & 10 & 5,940 \\
2 & 20 & 11,880 \\
3 & 35 & 20,790 \\
4 & 50 & 29,700 \\
\hline
\end{tabular}

${ }^{1}$ Budgets are expressed as a percentage of the total land area of unprotected parcels in the study area (59,400 hectares).
Viewing budget scenario outcomes using the multicriteria portfolio metrics of composite reward and risk allows us to evaluate more directly the tradeoffs between anticipated benefits, associated risks, and the costs attributed to any reserve design strategy. Based on the selection of balancedrisk portfolios from the set of nondominated (Pareto-optimal) alternatives, the marginal habitat benefit from a 10- to 20-percent increase in budget was accompanied by a substantial decrease in risk and a proportional increase in reserve design cost (fig. F12). Habitat benefits increased steeply to a budget of 35 percent of available land and thereafter seemed to level (including under an unconstrained budget scenario). After the initial decline, portfolio risk also seemed to stabilize with minor fluctuations following a pattern similar to portfolio benefits. Cost, however, demonstrated a monotonic, nearly linear increase over the unconstrained and four additional budget scenarios.

Although the results presented are based on many assumptions that will require additional attention before such an approach is implemented, a decision maker can assess the relative tradeoffs depicted by the dynamics of these three variables when deciding on a land acquisition strategy that best meets their agency's mission. For example, when the ability to acquire available land increases from 10 to 20 percent, associated purchase costs slightly outpace that of benefits but results in a higher probability that the land manager is able to meet conservation objectives regardless of future conditions (that is, lower relative risk). Further investments (beyond 20 percent of available land) results in sharp gains in return with potential improved cost efficiency and only marginal increases in portfolio risk. In this analysis, a target of conserving between 20 and 35 percent of unprotected land resulted in the fastest rate of accumulated management gains while portfolio costs and risks increased at lower rates over this range of investment.

\section{F.2.3. Discussion}

The stability, resilience, and adaptability of a system, whether a community, an ecosystem, or a financial system, has been strongly linked to diversification (Markowitz, 1952; Holling, 1973, 2001; Figge, 2004). Indeed, resilience theory posits that maintenance of diversity (be they assets, processes, or governance structures) is an essential component for ensuring the transformability (or "capacity to cross thresholds into new development trajectories"; Folke and others, 2010, p. 1) and adaptability of complex systems (Holling, 2001; Folke, 2006). Presaging the concerns of later resilience thinking regarding the potential dangers of reducing system heterogeneity through an "aggressive pursuit of efficiency" (Johnson and others, 2013, p. 1), Markowitz (1952) rejected the hypothesis that an investor should seek to maximize a discounted return because optimizing for an expected value (that is, pursuing efficiency) will fail to propose diversification as preferred strategy. MPT provides a means for optimizing allocation 


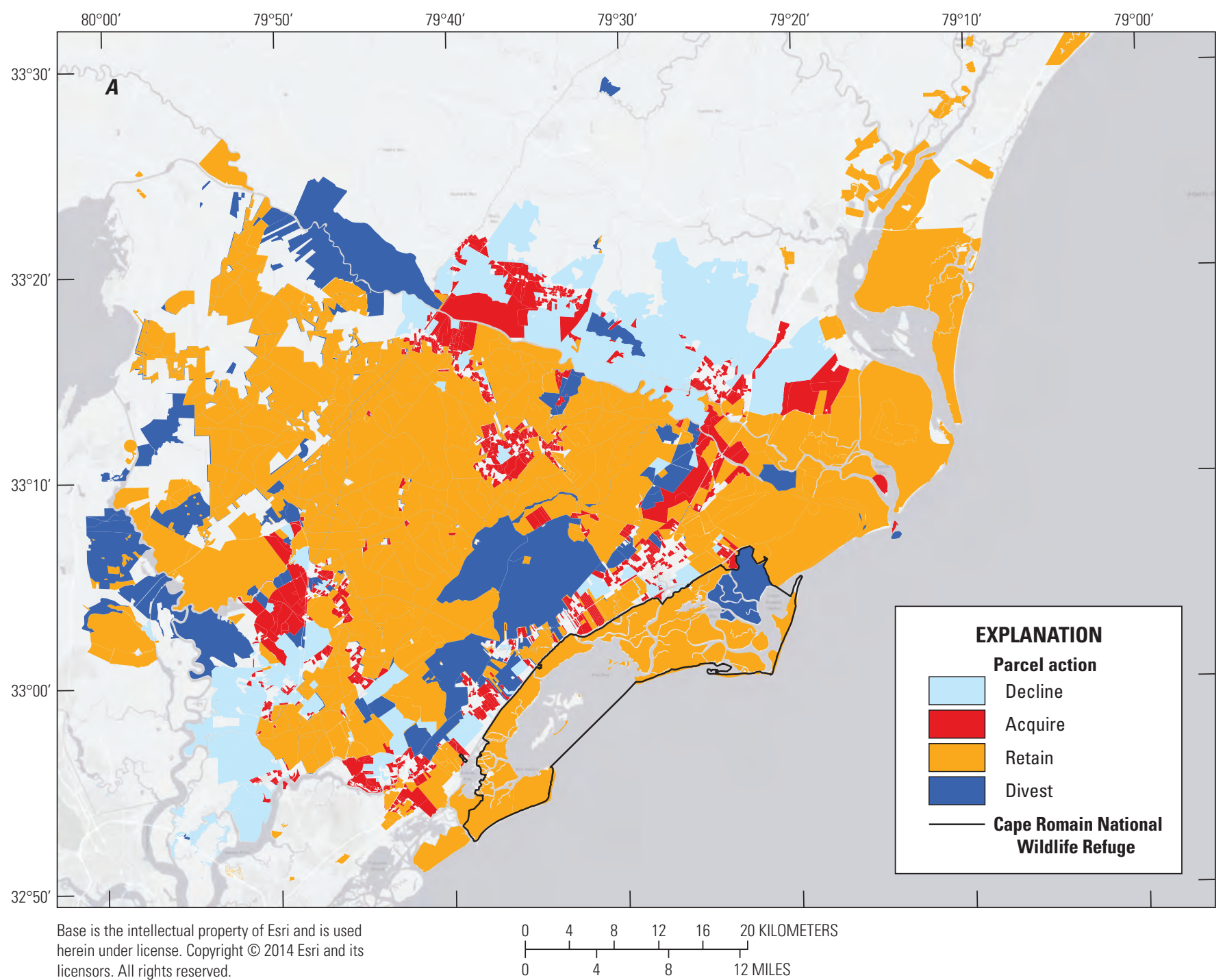

Figure F11. Effect of budget constraints on optimal modern portfolio theory reserve design portfolios. Budget constraints are represented as a proportion of the total area of land in unprotected status (that is, available for acquisition). Budgets were allocated to 14 subgroupings of parcels based on the relative proportion of land acquisition decisions recommended for an unconstrained analysis. The Nash solution was selected for each subgroup to formulate the global reserve design. Highlighted parcels for budget scenario acquisition of $B, 20$ percent; $C, 35$ percent; and $D, 50$ percent of available land depict changes in the optimal decision relative to that under a scenario of acquiring up to, $A, 10$ percent of available lands.

decisions by accounting for both expected returns and the risks associated with uncertain outcomes. This approach treats risk more comprehensively than traditional diversification approaches by considering the synchrony of future outcomes between asset pairs (Ando and Mallory, 2012). Thus, greater management of risk is achieved than by considering individual investment decisions or by selecting a portfolio with diverse representation of expected future ecological characteristics.

The integration of MCDA with a mean-variance portfolio optimization to account for the risks of an uncertain future offers a powerful analytical framework for making efficient allocation decisions for multiple conservation objectives and with limited budgets. The ability to identify a relatively small subset of nondominated (Pareto-optimal) portfolios from the practically infinite number of possible alternatives represents, in itself, a substantial benefit to decision makers who can become overwhelmed with so many choices. An additional advantage of this approach is the flexibility of making explicit tradeoffs among competing management criteria at the parcel level and between management rewards and risk for the portfolio. The latter tradeoff, along the efficiency frontier, will be based on risk preferences, beliefs about the likelihood of future climate conditions, or the desired level of management benefits with the knowledge that all identified 


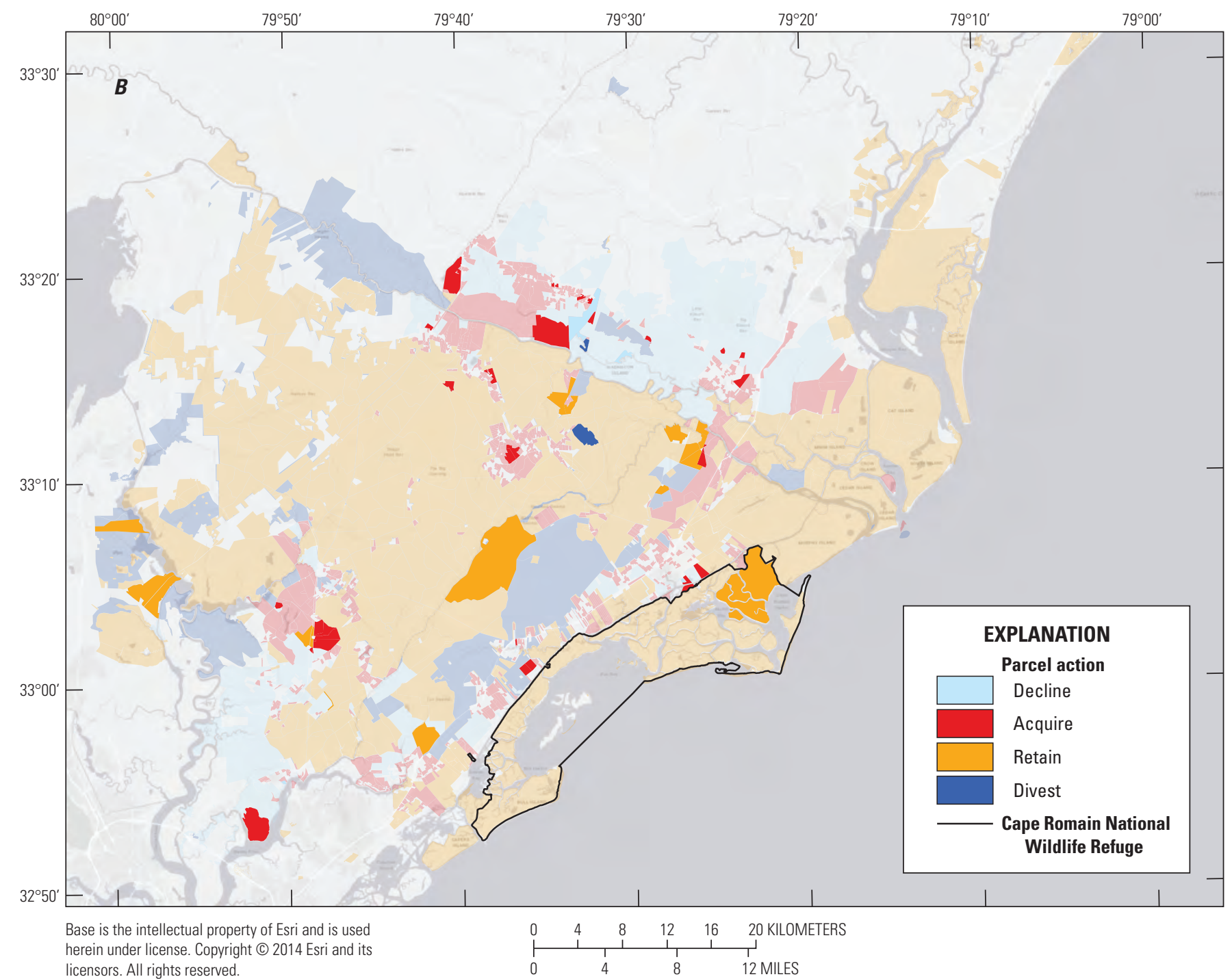

Figure F11.-Continued

options are Pareto optimal. Other studies have contributed important methodological advances to climate change adaptation strategies by recognizing the benefits of portfolio theory (with or without MCDA) to spatial conservation planning. Many of these studies, however, either did not take full advantage of MPT's analytical power by selecting case studies in which correlation among assets were assumed to be small (Convertino and Valverde, 2013) or invariant (Marinoni and others, 2011) or by reducing the dimensionality of the decision variable to be computationally tractable but possibly less useful to decision makers (Ando and Mallory, 2012).

Here, we applied a detailed MCDA-MPT analysis to a case study using simplified resource objectives and a few climate-change scenarios to demonstrate an approach that may be useful in supporting coordination of conservation planning at the scale of actual decisions across a diverse set of State, Federal, and nongovernmental land managers. The results from our study suggest that changes in important habitat categories could be substantial in coastal South Carolina and that losses to protected wetlands under the current conservation network could be highly variable as a function of SLR, possibly exceeding 9 percent of current extent. The expected improvements to future habitat preservation under an optimal portfolio design are able to counteract many of these losses; importantly, expected benefits when implementing an MPT solution show substantially less variability to uncertainty in climate change relative to outcomes predicted for the existing reserve network. Our analysis revealed that parcel-level decisions may be somewhat robust to differences in risk attitudes with nearly 75 percent of parcel decisions remaining unchanged across a moderate range of risk tolerance. Evaluating the dynamics of portfolio cost, risk, and return over five hypothetical budget scenarios provided additional insights into the tradeoffs and interactions among management 


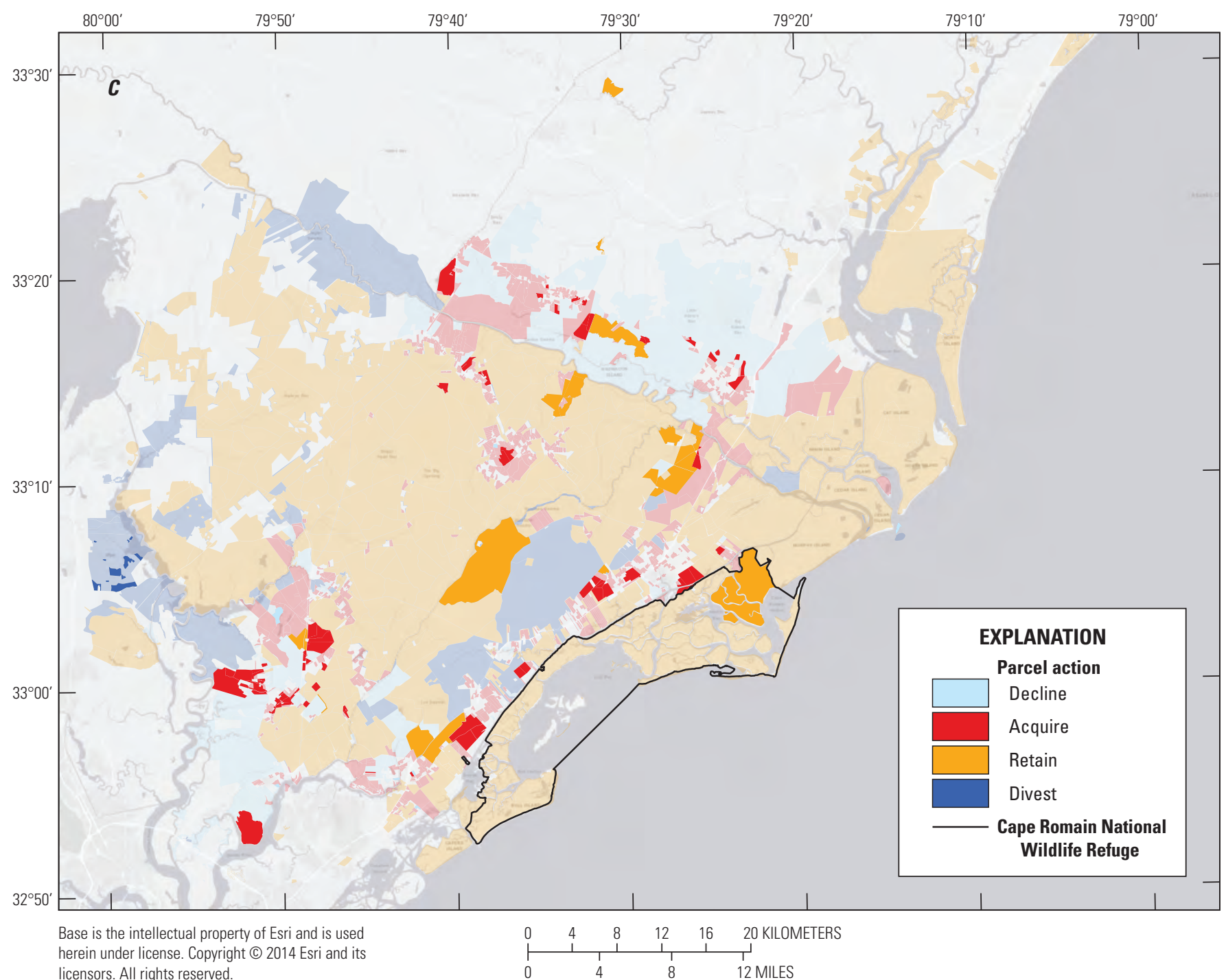

Figure F11.-Continued

objectives when constraints were considered. Identifying inflection points in marginal returns as investment increases is an additional benefit of portfolio analysis.

There are several limitations to this portfolio optimization approach, as well as additional considerations, that should be addressed before implementing any decisions based on this framework. We acknowledge that the basis by which reserve portfolios were evaluated was a function of SLR predictions and subsequent habitat transitions, which were output from simple SLAMM projections. Although widely used, SLAMM has been criticized for limitations with how input data (for example, digital elevation models) are used; for a lack of predictive hydrodynamic modeling, simplistic assumptions regarding erosion, storm impacts, accretion, and sedimentation processes; and for the lack of feedback mechanisms between SLR and system responses (Craft and others, 2009; Donoghue and others, 2013). We acknowledge numerous recent advances in SLR modeling research, particularly marsh migration modeling that accounts for finer-scale details of local conditions, such as hard boundaries (for example, levees) and other dynamics (for example, colonization by wetland flora) to provide more accurate predictions of habitat changes in this region (Thorne and others, 2015). However, we chose to use the SLAMM because it is freely available and easily interpreted, making it a sensible choice to demonstrate principles and gain inferences using an MPT analysis. An additional limitation of constrained portfolio optimization is computational complexity; the general problem is notoriously described by computer scientists as non-deterministic polynomial-time difficult (NP-hard; Sarkar and others, 2006). This complexity resulted in the need to subdivide available parcels into smaller groupings to allow for tractability. Although we stratified parcel groups using an ad hoc logical approach, portfolio evaluations are not able to account for tradeoffs among subgroups. 


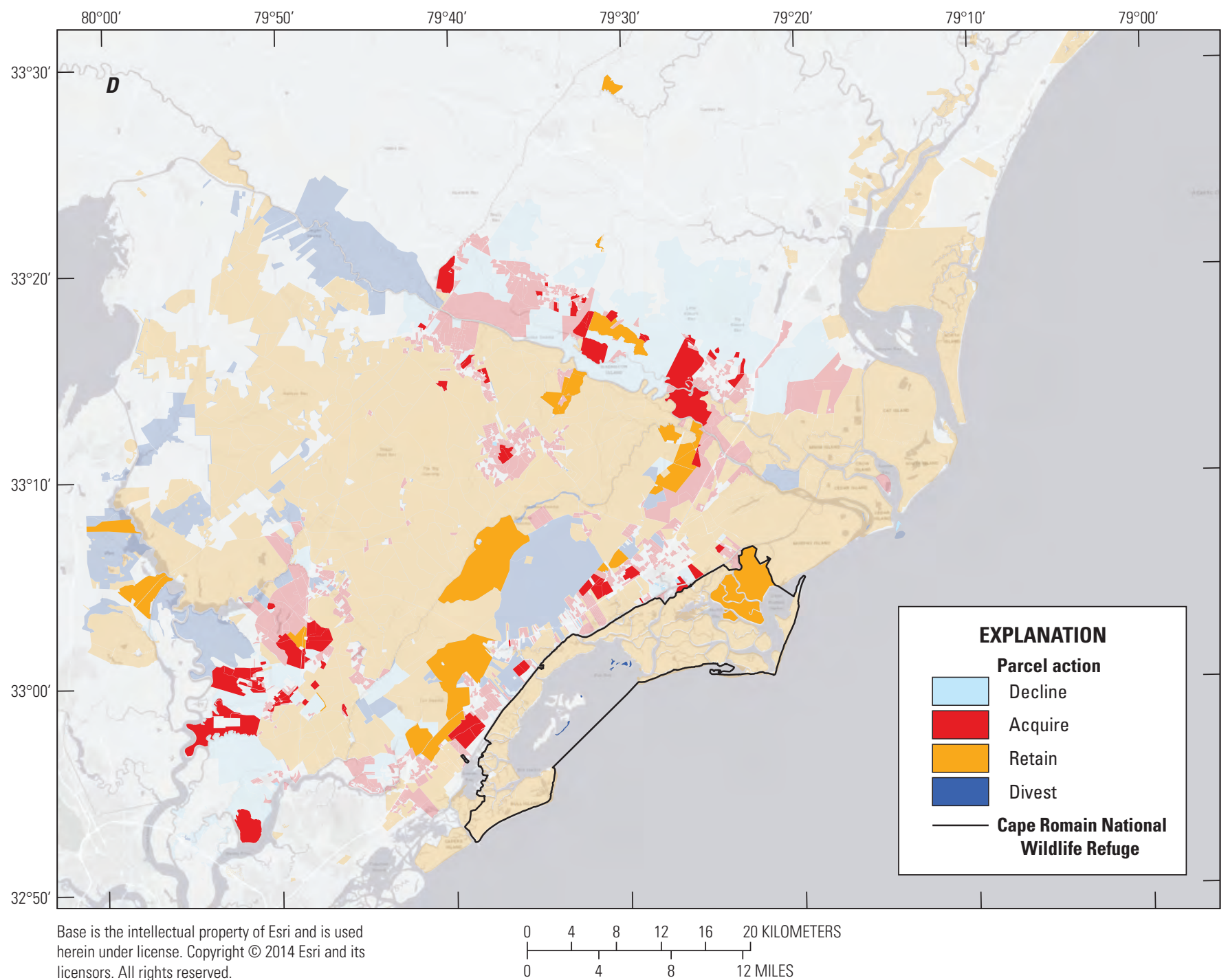

Figure F11.-Continued

Such limitations precluded consideration of parcel connectivity as an optimization criterion for evaluating portfolio benefits. Connectivity is a well-recognized design criterion in spatial planning (Sarkar and others, 2006; Pressey and others, 2007); however, contiguous parcels are more likely to exhibit positive correlation in expected future benefit. Therefore, an evaluation of the tradeoffs between connectivity and risk criteria may be a useful topic for future research.

Important considerations specific to our model formulation include the treatment of projected urbanization probabilities and the significance of divestment decisions for currently protected lands. In spatial conservation planning, urbanization is viewed as a threat leading to permanent loss of a parcel for consideration as a portfolio asset. One approach to address this issue is by framing the problem as a sequential reserve design (that is, the scheduling problem) whereby a site-ordering algorithm is used to identify the sequence in which parcels might be acquired to maximize portfolio return while accounting for the risk of parcel loss (Sarkar and others, 2006; Moilanen and Cabeza, 2007). Rather than adopt this approach, we have simplified our problem to a single-stage optimization in which higher risk of urbanization raises a parcel's value above its habitat contribution to increase the likelihood of selecting the parcel for conservation. Valuing parcels as a linear function of urbanization risk may be a reasonable approach in some circumstances, but there are other approaches for addressing development risk (Costello and Polasky, 2004). Divestment from publicly or privately held conservation lands may be an undesirable or untenable action (but see Alagador and others, 2014). Removing the protected status of Federal lands would require an act of U.S. Congress, and although there are no examples of entire national parks or NWRs being surrendered, agencies are authorized to modify their holdings or exchange small parcels for others of equal value (Thompson, 2004). 
Table F6. Expected habitat extent in protected status using modern portfolio theory optimization.

\begin{tabular}{|c|c|c|c|c|}
\hline \multirow[b]{2}{*}{ Habitat } & \multicolumn{4}{|c|}{ Expected habitat area, ${ }^{1}$ in hectares } \\
\hline & Low (10 percent) & $\begin{array}{l}\text { Medium-low (20 per- } \\
\text { cent) }\end{array}$ & $\begin{array}{l}\text { Medium-high } \\
\text { (35 percent) }\end{array}$ & High (50 percent) \\
\hline Developed uplands & 219 & 228 & 410 & 431 \\
\hline Undeveloped uplands & 76,428 & 79,120 & 81,299 & 83,934 \\
\hline Estuarine beach & 451 & 481 & 495 & 494 \\
\hline Tidal flat & 1,511 & 1,685 & 1,685 & 1,683 \\
\hline Ocean beach & 271 & 271 & 270 & 270 \\
\hline Ocean flat & 11 & 11 & 11 & 11 \\
\hline Inland open water & 2,457 & 2,442 & 2,350 & 2,467 \\
\hline Riverine tidal open water & 112 & 116 & 116 & 146 \\
\hline Estuarine open water & 9,500 & 10,224 & 10,163 & 10,249 \\
\hline Open ocean & 1,657 & 1,685 & 1,661 & 1,620 \\
\hline Inland shore & 23 & 23 & 24 & 26 \\
\hline Swamp & 51,243 & 54,789 & 56,566 & 58,750 \\
\hline Brackish marsh & 3,741 & 3,874 & 3,823 & 3,940 \\
\hline Cypress swamp & 368 & 370 & 369 & 380 \\
\hline Inland fresh marsh & 11,423 & 11,507 & 11,601 & 12,179 \\
\hline Tidal fresh marsh & 2 & 2 & 2 & 2 \\
\hline Scrub shrub transition & 4,434 & 4,608 & 4,504 & 4,744 \\
\hline Salt marsh & 11,579 & 12,730 & 12,741 & 12,733 \\
\hline Tidal swamp & 5,116 & 5,759 & 5,235 & 6,516 \\
\hline Total wetland area & 87,906 & 93,638 & 94,842 & 99,244 \\
\hline Total protected area ${ }^{2}$ & 180,545 & 189,924 & 193,326 & 200,576 \\
\hline
\end{tabular}

${ }^{1}$ Expected habitat area expressed as a weighted mean over three sea-level rise projections.

${ }^{2}$ Protected area was estimated as a function of budget constraint scenarios and a reserve design using modern portfolio theory optimization.

Precedent also exists for transferring public lands to resolve conflicts or address greater societal needs, such as a 2012 Congressional Act to transfer nearly 800 acres of Olympic National Park to help the Quileute Tribe relocate from rising seas, erosion, and tsunami threats (16 U.S.C. 1131 and 1132, 25 U.S.C. 2701). Possibly more feasible is the ability of Federal and State agencies, private-sector conservation organizations, and land trusts to engage in flexible conservation contracts with private landowners. If landowners begin to recognize the impending effects of SLR and land-use change, the opportunity to divest may become an increasingly desirable alternative as the perceived benefits provided by their properties decline. Term-limited conservation easements would allow organizations to evaluate the expected longevity of benefits provided by a parcel and negotiate for this period. This would allow limited financial resources, which would otherwise be tied-up in perpetuity to manage the parcel, to later be used for conserving other, high-value areas. There are risks to fixed-term contracts, however, including added transaction costs, increased instability in land-use planning, and possible disincentives for landowners wishing to provide a long-term conservation legacy (Thompson, 2004).

\section{F.2.4. Conclusion}

Expanding or altering existing protected area networks is a necessary adaptation strategy to sustain conservation objectives and mitigate the effects of climate change and land conversion. Securing diversified assets in a conservation portfolio is an excepted strategy for increasing system resilience to offset unknown future conditions. We have expanded the use of MPT for spatial conservation planning to account explicitly for the rationale underlying diversification, which is to maximize future complementarity of a collection of protected lands by minimizing potentially correlated outcomes. This reserve design framework offers several benefits relevant for supporting conservation problems beyond our application to coastal South Carolina. Our model approach includes an optimization 


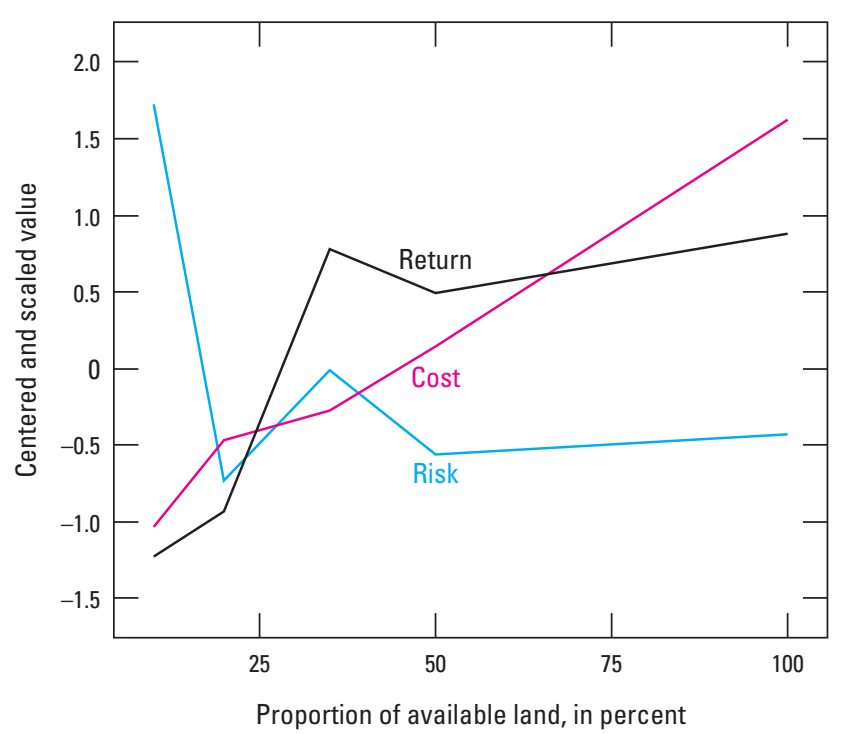

Figure F12. Tradeoff comparisons among the primary metrics of the modern portfolio theory analysis: portfolio reward, risk, and cost. Here, cost is measured as land area acquired and budget constraints were based on a proportion of land-area available for acquisition. To compare across independently derived metrics, we centered each variable on zero and scaled by one standard deviation.

algorithm that accommodates large, multiobjective decision problems and an axiomatic selection method (the Nash bargaining solution) to equitably balance tradeoffs when negotiating among different risk attitudes is not practical. We also consider the potential benefits of investment and divestment of assets. Identifying Pareto-optimal solutions over climate and budget uncertainties, and across a spectrum of stakeholder preferences, provides critical insights on the sensitivity of conservation strategies to risk and risk attitudes. The effect of differing levels of risk tolerance in driving management policy is rarely considered in environmental decision making (Greiner and others, 2009). Our approach is not limited to spatial conservation planning but could be applied to a wide range of resource allocation or investment decisions for which unresolvable uncertainty requires strategic risk management. Examples include allocating research or monitoring funding to maximize learning to directly inform management decisions, evaluating the risks of introducing disease or unwanted species in translocation or restoration programs, spatially managing invasive species or communities of conservation concern, and assessing the success and risks of alternative urban planning policies in response to uncertain threats. Data and optimization portfolio outcomes from this study can be obtained from Eaton and others (2019b).

\section{F.2.5. Methods}

\section{F.2.5.1. Data Requirements and Structuring}

As input to the optimization, we first need to calculate the cost and total expected benefits provided by an individual land parcel (termed an "asset"). We used MCDA (Kurth and others, 2017) to account for the multiple and possibly unevenly valued objectives that must be traded off to derive a composite value for each parcel. Because future parcel conditions are not known with certainty, we calculate the expected benefits over the uncertainty of future climate (SLR) and then consider the variance of the expected value as one component of our risk assessment. The basic unit of data for our analysis is $d_{h j k}$, representing the number of hectares of habitat type $h$ in parcel $j$ under SLR scenario $k$. These variables come from index sets: $h \in \mathrm{H}$ habitat types (with $|H|=19$ ), $j \in N$ parcels (with $|N|=1$,244), and $k \in R$ SLR scenarios (with $|R|=3$ ) (table F7). Thus, the data required for each of $N$ parcels are habitat extents as elements of an $H \times R$ matrix. For each $h \in H, j \in N$, and $k \in R$, we perform the following preprocessing steps on the raw data, $d_{h j k}$ :

1. We normalize $d_{h j k}$ across parcels to take values between 0 and 1 , denoted by $n_{h j k}$ :

$$
n_{h j k}=\frac{d_{h j k}-\min _{j \in N} d_{h j k}}{\max _{j \in N} d_{h j k}-\min _{j \in N} d_{h j k}}
$$

2. For each parcel $j$, we calculate the weighted sum of its constituent habitat types, using habitat objective criteria weights $w_{h}$, and denote expected parcel values for each SLR scenario $k$ by $m_{j k}$ :

$$
m_{j k}=\sum_{h \in H} w_{h} n_{h j k}
$$

3. We then incorporate the probability of urbanization (see chap. C.4.3) as a deterministic parameter to modify each parcel value and denote the outcome as $l_{j k}$. In this formulation, parcel value increases proportionally with increased probability of being lost to development. This strategy promotes anticipating development by conserving parcels before they are lost, but we do not posit that this is the best or only way to treat development threats:

$$
l_{j k}=\frac{m_{j k}}{1-u_{j}}
$$


Table F7. Notation of parameters and variables used in the portfolio analysis and optimization.

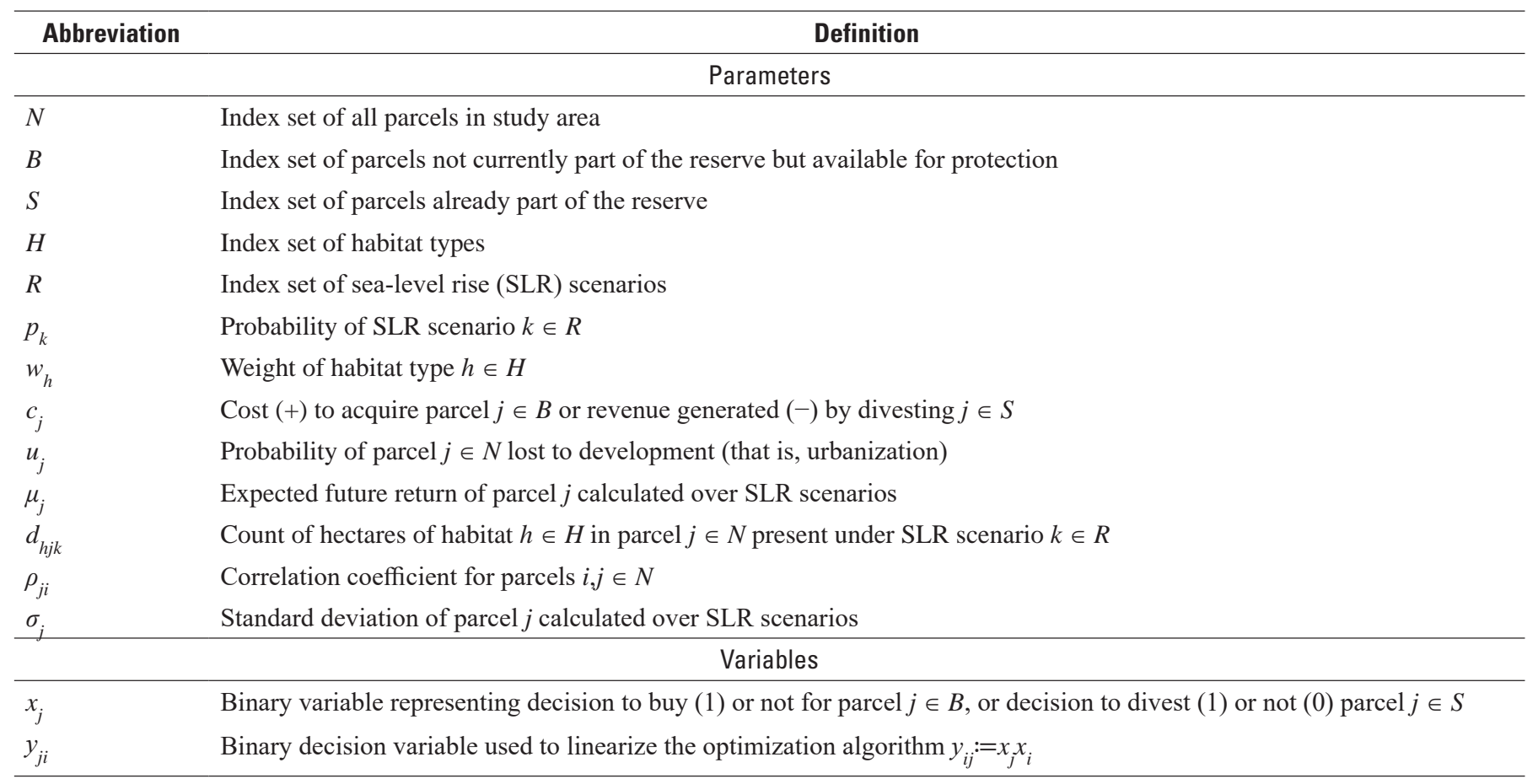

4. We scale the value of a parcel by its cost to standardize benefits by cost and denote by $r_{j k}$. We note that equations 3 and 4 treat the objective function values as linear combinations of input variables; other, nonlinear formulations are possible:

$$
r_{j k}=\frac{l_{j k}}{C_{j}}
$$

5. We consider the uncertainty in habitat outcomes resulting from alternative SLR scenarios (chap. B.1.3). Conditional on the SLR estimate, with probabilities $\left(p_{\mathrm{k}}\right)$ associated with the 10th, 50th and 90th percentile of the full distribution estimated for South Carolina by 2050 (Horton and Bader, 2014), SLAMM predicts differences in the distribution and extent of coastal habitat cover types, resulting in distinct parcel values $\left(r_{j k}\right)$. For each $j \in N$, the expected return, denoted by $\mu_{j}$, is calculated as a weighted sum of $r_{j k}$ values over the three SLR scenarios:

$$
\mu_{j}=\sum_{k \in R} p_{k} r_{j k}
$$

6. Finally, from the $r_{j k}$ and $p_{\mathrm{k}}$, we derive a weighted variance-covariance matrix using the cov.wt function in R (R Core Team, 2018). The function calculates the covariance matrix and a matrix of correlation coefficients, producing the variance $\sigma_{j}^{2}$ for each parcel and correlation coefficients $\rho_{i j}$ for all parcel pairs. Using these values, we quantify the risk associated with any possible portfolio of parcels (see chap. F2.5.2).

Many of the values for the expected return and covariance were small (about $1 \times 10^{-6}$ ). To make our model easier to solve, we assumed that coefficients of the two objectives are integers. To that effect, we multiplied the small return and covariance values with large numbers (that is, $1 \times 10^{5}$ and $1 \times 10^{8}$, respectively) and rounded them to produce integer values. This results in some loss of precision, but we determined this loss had little effect on the outcomes.

\section{F.2.5.2. Portfolio Optimization-Acquiring Parcels for Reserve Design}

To define the problem of parcel selection using portfolio optimization, we introduce some additional notation. Let us consider a set $N$ of predefined parcels of land. For the basic portfolio optimization problem in which only parcel acquisition decisions are evaluated, the decision to acquire a parcel of land depends on its current protected status and its contribution to future habitat within the reserve. Let $S$ be the set of parcels currently composing the reserve, and let $B$ represent the set of parcels being considered for addition into the reserve. Without loss of generality, we start by assuming $B=N$. The decision then is which set of parcels $j \in N$ to acquire. 
The basic formulation of our MPT optimization begins with identifying the Pareto set of portfolios, which maximizes the expected return while minimizing the risk associated with a given combination of parcels, expressed as:

$$
\begin{gathered}
\max \sum j \in N x j E(\mu j), \\
\min \sum_{j \in N} x_{j} \sigma_{j}^{2}+\sum_{j \in N} \sum_{i \in N: i>j} 2 y_{j i} \sigma_{j} \sigma_{i} \rho_{j i},
\end{gathered}
$$

where

$u_{j}$ is defined as in equation 6 ,

$x_{j}$ is a binary variable representing the decision to acquire $(x=1)$ or not acquire $(x=0)$ parcel $j$, and

$y_{j i}$ is a binary variable used to linearize the formulation (where $y_{j i}$ is defined as equivalent to $x_{i} x_{i}$ ) and is subject to the following constraints for all parcel pairs $i$ and $j$ (see table F7 for full description of parameters and variables):

$$
\begin{aligned}
& x_{j} \geq y_{j i} \leq x_{i} \forall i \in B, \forall j \in B, j>i \\
& y_{j i} \geq x_{j}+x_{i}-1 \forall i \in B, \forall j \in B, j>i \\
& 1-x_{j} \geq y_{j i} \leq 1-x_{i} \forall i \in S, \forall j \in S, j>\mathrm{i} \\
& y_{j i} \geq 1-x_{j}-x_{i} \forall i \in S, \forall j \in S, j>i \\
& 1-x_{i} \geq y_{j i} \leq x_{j} \forall i \in S, \forall j \in B \\
& y_{j i} \geq x_{j}-x_{i} \forall i \in S, \forall j \in \mathrm{B} \\
& x_{j} \in\{0,1\} \forall j \in N \\
& y_{j i} \in\{0,1\} \forall i \in B, \forall j \in B, j>i \\
& y_{j i} \in\{0,1\} \forall i \in S, \forall j \in S, j>i \\
& y_{j i} \in\{0,1\} \forall i \in S, \forall j \in B
\end{aligned}
$$

\section{F.2.5.3. Extending the Portfolio Optimization to Consider Acquisition and Divestment}

We extended the formulation presented above to consider a more complex set of decisions involving the acquisition and divestment from parcels to design a future protected area. The basic premise and structure of the formulation changes only slightly from the previous formulation, and the decision variable for each parcel remains binary. As before, the decision to acquire or divest from a parcel of land depends on the current protected status and the effects on portfolio return and risk of either decision. Parcels are divided into two subsets based on their current status. As above, let $S$ be the set of parcels that make up the reserve network (that is, part of the Cape Romain NWR, national forest, or privately protected), and the decision maker can decide whether to keep or divest any member of the set. Divesting results in a loss of all habitat benefit but increases the available budget (less a 6 percent transaction cost) which can then be used to acquire other parcels. Keeping a parcel incurs no additional cost, and future habitat benefit is retained. For $j \in S, x_{j}$ is 1 if the parcel is sold and 0 if parcel $j$ is kept. Note that in equation 5 we use the absolute value of $c_{j}$ because we are interested in $r_{j k}$ as a measure of per unit value (or size) of a parcel. Here, relative to a budget constraint, the cost of acquiring is negative, whereas a positive income is realized by selling a parcel.

Similarly, let the complement set $B$ be the set of parcels that are currently unprotected and under consideration for addition into the reserve network; the decision is whether or not to acquire each parcel in $B$. Acquiring and converting a parcel to protected status (that is, through fee-simple purchase or easement) adds to the overall reserve benefit through its contribution of habitat and its cost (calculated here as proportional to its size) and reduces the available budget by the same amount. Not acquiring a parcel incurs no cost but because it remains unprotected it also contributes no conservation benefit. For $j \in B, x_{j}$ is 1 if the parcel $j$ is acquired and 0 if it is not. We assume that $S \cup B=N$ and $S \cap B=\varnothing$. Equations 7 and 8 are modified slightly to reflect this new formulation:

$$
\begin{aligned}
& \max \sum j \in B x j \mu j+\sum j \in S(1-x j) \mu j \\
& \min \sum_{j \in B} x_{j} \sigma_{j}^{2}+\sum_{j \in B} \sum_{i \in B: i>j} 2 y_{j i} \sigma_{j} \sigma_{i} \rho_{j i} \\
& +\sum_{j \in S}\left(1-x_{j}\right) \sigma_{j}^{2}+\sum_{j \in S} \sum_{i \in S:>>j} 2 y_{j i} \sigma_{j} \sigma_{i} \rho_{j i} \\
& +\sum_{j \in B} \sum_{i \in S} 2 y_{j i} \sigma_{j} \sigma_{i} \rho_{j i} \\
& \text { s.t. } \\
& x_{j} \geq y_{j i} \leq x_{i} \\
& y_{j i} \geq x_{j}+x_{i}-1 \\
& 1-x_{j} \geq y_{j i} \leq 1-x_{i} \\
& y_{j i} \geq 1-x_{j}-x_{i} \\
& y_{j i} \geq x_{j}-x_{i} \\
& x_{j} \in\{0,1\} \\
& y_{j i} \in\{0,1\} \\
& x_{j} \in\{0,1\} \\
& y_{j i} \in\{0,1\} \\
& x_{j} \in\{0,1\} \\
& y_{j i} \in\{0,1\}
\end{aligned}
$$

Later, we include considerations of budget constraints in our model to reflect fiscal and other limitations to conserving large areas of habitat and to explore the possible benefits of divesting from less valuable parcels to increase the ability to acquire other lands that may otherwise be out of reach (see chap. F.2.5.6 for details). 


\section{F.2.5.4. Optimization Algorithm for Computing the Pareto-Optimal Frontier}

One challenge in applying a portfolio optimization to problems of large dimensionality is the exponentially increasing number of possible portfolios to evaluate $\left(2^{N}\right)$. Our case study includes an extensive dataset of 1,244 parcels available for numerical experiments, which renders the problem impossible to solve in reasonable amount of time, especially with the number of linearization constraints required. After structuring the raw data (see chap. F.2.5.1) to calculate the integer return and risk coefficients for our objective function, we then divide our full set of parcels into computationally manageable subsets of less than 100, with the selections based on distance from the coast as an approximation of grouping parcels into similar habitat communities or biomes (fig. F6). We used an existing heuristic algorithm (Feasibility Pump Based Heuristic; Pal and Charkhgard, 2017a, b) to compute the Pareto-optimal frontier from equations 9 and 10. Based on empirical testing and statistical measures used to evaluate the quality of an approximated Pareto frontier, this heuristic approach finds good estimates of the true frontier in terms of the average distance between points on the approximate and true frontier (coverage), the spread of approximated points relative to the true range (uniformity), and identification of high benefit-risk ratios (density) (Kohli and others, 2004; Pal and Charkhgard, 2017b). We have used the biobjective Julia package (https://github.com/ aritrasep/FPBH.jl) to find an approximate frontier of our portfolio problem.

\section{F.2.5.5. Selecting Among Pareto-Efficient Portfolios-Possible Global Solutions}

Because any solution found on the Pareto frontier represents a compromise, selecting a final portfolio design from among the set of Pareto optimal portfolios requires either (1) eliciting additional criteria from the decision maker to represent the desired balance between objectives represented by the axes of the decision space or (2) identifying an alternative found along the frontier that represents a fair trade or as equal a benefit as possible between objectives. In our application, the first case refers to a values-based determination by the decision maker to trade off their aversion to risk with a desire to design the reserve network for achieving maximal benefit. The second case represents a bargaining solution among actors to identify an agreed-upon tradeoff to share benefits and risks. In practice, the solution can be negotiated among two or more decision makers, but analytic approaches also exist (Nash, 1950; Cela and Bollaín, 2012). Analytic approaches do not require additional information from the decision makers but instead rely on properties of the Pareto space to determine a fair point along the frontier that represents an equitable compromise between the competing benefit functions. We note that all points on the Pareto frontier represent acceptable solutions, and that this fair point is no more optimal than any other along the frontier. In our case study, the decision of designing a conservation reserve network will be negotiated among many decision makers over time, which was impractical to consider for our current analysis. Instead, we use an analytical method to identify a fair point along the Pareto frontier for each of the subregions designated for the portfolio optimization that maximizes a balanced benefit for each rather than requiring subjective discrimination between objectives.

To select objectively from the set of Pareto efficient portfolios in producing a reserve-design solution for the full study area, we chose the axiomatic Nash bargaining solution (Nash, 1950) as the most utilitarian and equitable (Santín and others, 2017) from several available compromise solution approaches (Cela and Bollaín, 2012). Among its appealing properties, the Nash solution satisfies Pareto efficiency (for example, no objective can be improved upon without penalizing the other) and symmetry (for example, egalitarian, or no discrimination among objectives); the solution finds that point on the frontier that represents improvement (in the Pareto sense) over the largest number of dominated solutions in the decision space (fig. F13).

The Nash bargaining solution identifies the point on the Pareto frontier with coordinates $\left(v_{1}{ }^{*}, v_{2}{ }^{*}\right)$ by maximizing:

$$
\begin{aligned}
& \max _{\substack{* \\
\left(v_{1}^{*}, v_{2}^{*}\right)}}\left(v_{1}\left(\theta_{2}^{*}\right)-v_{1}^{*}\right)\left(v_{2}\left(\theta_{1}^{*}\right)-v_{2}^{*}\right) \\
& \text { s.t. } \\
& v_{1}^{*} \leq v_{1}\left(\theta_{2}^{*}\right) \\
& v_{2}^{*} \leq v_{2}\left(\theta_{1}^{*}\right)
\end{aligned}
$$

where

$$
\begin{array}{cc}
v_{1} \text { and } v_{2} & \begin{array}{c}
\text { represent the range of value functions for } \\
\text { objective criteria } 1 \text { and } 2, \text { respectively; and } \\
\text { represent optimal values for each function, } \\
v_{1}\left(\theta_{1}^{*}\right) \text { and } v_{2}\left(\theta_{2}^{*}\right), \text { as determined } \\
\text { independently of the other objective. }
\end{array}
\end{array}
$$

The coordinates of $v_{1}\left(\theta_{1}^{*}\right)$ and $v_{2}\left(\theta_{2}^{*}\right)$ represent the unobtainable utopia point that maximizes benefits for both objectives, whereas the points $D_{1}=v_{1}\left(\theta_{2}^{*}\right)$ and $D_{2}=v_{2}\left(\theta_{1}^{*}\right)$ represent the optimal values of each criteria on the axis of its competitor (the disagreement points). Thus, equation 11 maximizes the product of the differences $v_{1}\left(\theta_{2}^{*}\right)-v^{*}{ }^{*}$ and $v_{2}\left(\theta_{1}^{*}\right)-v_{2}{ }^{*}$ to identify the unique Pareto solution $\left(v_{1}{ }^{*}, v_{2}{ }^{*}\right)$ on the efficiency frontier (bold line defining solution space of dominated alternatives in light and dark grey) that benefits both objectives by ensuring the maximal total distance from each disagreement point (distances $a$ and $b$ that maximize the volume of dominated solutions [dark grey]; fig. F13). Using this set of Nash bargaining portfolios, we produce a possible reserve design for the Cape Romain region that represents an optimal solution with regard to risk-reward tradeoff but does not favor either objective. We compare the anticipated outcomes of this 


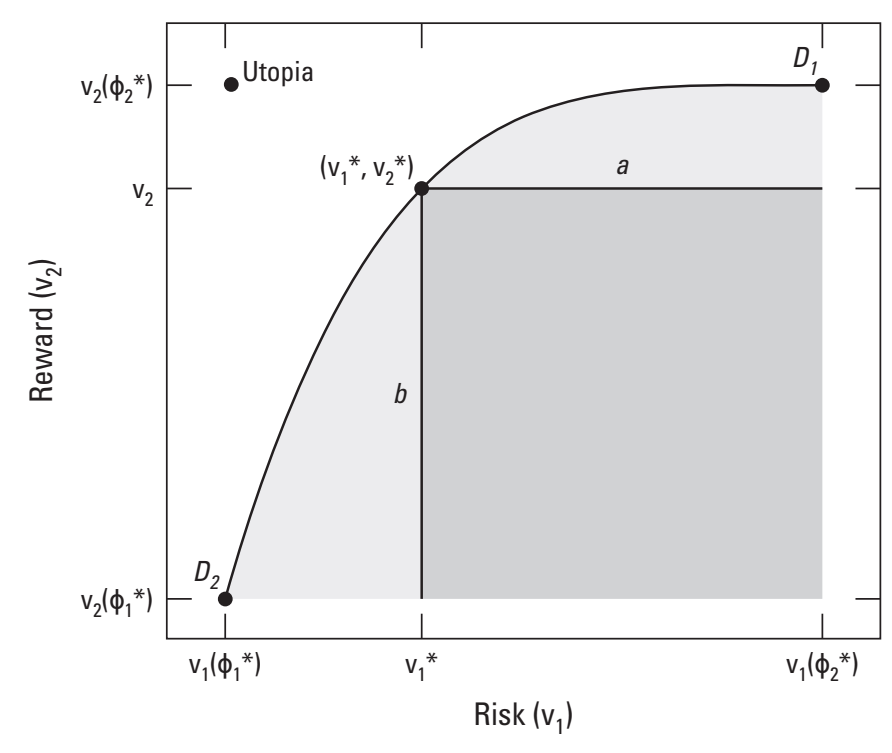

Figure F13. Properties of the Nash Bargaining Solution (Nash, 1950).

design to additional scenarios representing more risk adverse and risk seeking attitudes by shifting the selection point to the left or right, respectively, on the Pareto curves for each subregion. We attempted to select points equally distant to the left (risk adverse) and right (risk seeking) of the Nash solution (fig. F14). Finally, we identify patterns of no regret solutions that seem to be robust across this spectrum of risk.

\section{F.2.5.6. Budget-Constrained Optimization Scenarios}

Because our analysis is not dynamic (in other words, does not take into consideration that parcel acquisition decisions are likely to be made annually over a long period), we are unable to anticipate a realistic budget to represent the time horizon of the static problem. Instead, we proposed a series of hypothetical fiscal scenarios as a function of the proportion of total land area in the study area not currently in conservation status. This approach assumes a positive relation between parcel size and its market value and recognizes two constraints on the desire to secure additional land for conservation purposes: (1) not all unprotected parcels in the study area will be available for protection (either through purchase or conservation easements), and (2) even with multiple partners involved in conservation reserve design efforts, it is unlikely that sufficient funds will be acquired to conserve all desired land. For 59,400 hectares of currently unprotected parcels composing the study area, we evaluated four fiscal scenarios, ranging from a pessimistic (10 percent) to an optimistic (50 percent) outlook for funds acquired over the planning horizon to conserve future habitat (table F5).

The second consideration we make with respect to budget scenarios is that the portfolio optimization of parcel subgroups is conducted independently. Therefore, any budget scenario was allocated across these subgroups. Rather than distributing this budget equally, we envision decision makers might weight parcel subgroups by their proximity to the coast, by expected habitat composition, or by some other value judgement. Absent such input, our procedure for allocating budgets was as follows. We began by optimizing subgroup portfolios with no budget constraint, applying the Nash bargaining solution to each group as above. We then computed the proportion of parcels identified for acquisition in each group and normalize this value across all subgroups to obtain an initial set of weights to inform budget allocations under each scenario. 

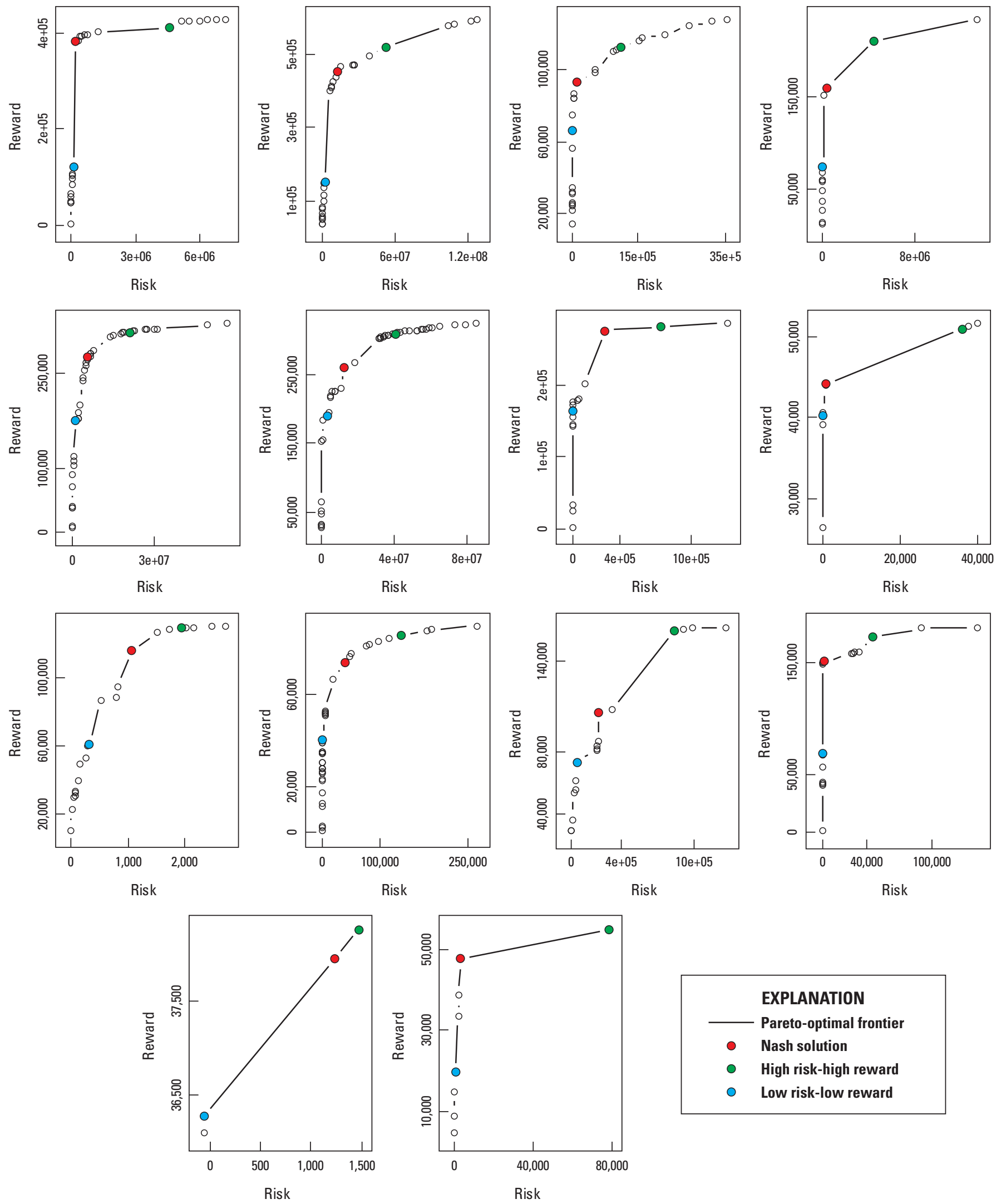

Figure F14. Pareto-optimal frontiers computed for 14 parcel subgroups. 


\section{References Cited}

Alagador, D., Cerdeira, J.O., and Araújo, M.B., 2014, Shifting protected areas-Scheduling spatial priorities under climate change: Journal of Applied Ecology, v. 51, no. 3, p. 703-713. [Also available at https://doi.org/10.1111/1365-2664.12230.]

Anderson, S.C., Moore, J.W., McClure, M.M., Dulvy, N.K., and Cooper, A.B., 2015, Portfolio conservation of metapopulations under climate change: Ecological Applications, v. 25 , no. 2 , p. 559-572. [Also available at https://doi.org/10.1890/14-0266.1.]

Ando, A., and Mallory, M., 2012, Optimal portfolio design to reduce climate-related conservation uncertainty in the Prairie Pothole Region: Proceedings of the National Academy of Sciences of the United States of America, v. 109, no. 17, p. 6484-6489. [Also available at https://doi.org/10.1073/ pnas.1114653109.]

Ball, I.R., Possingham, H.P., and Watts, M.E., 2009, Marxan and relatives - Software for spatial conservation prioritization, chap. 14 of Moilanen, A., Wilson, K.A., and Possingham, H.P., eds., Spatial conservation prioritization-Quantitative methods and computational tools: Oxford, U.K., Oxford University Press, p. 185-195.

Cela, R., and Bollaín, M., 2012, New cluster mapping tools for the graphical assessment of non-dominated solutions in multi-objective optimization: Chemometrics and Intelligent Laboratory Systems, v. 114, p. 72-86. [Also available at https://doi.org/10.1016/j.chemolab.2012.03.005.].

Convertino, M., and Valverde, L.J., Jr., 2013, Portfolio decision analysis framework for value-focused ecosystem management: PLoS One, v. 8, no. 6, p. e65056. [Also available at https://doi.org/10.1371/journal.pone.0065056.]

Costello, C., and Polasky, S., 2004, Dynamic reserve site selection: Resource and Energy Economics, v. 26, no. 2, p. 157-174. [Also available at https://doi.org/10.1016/j.reseneeco.2003.11.005.]

Craft, C., Clough, J., Ehman, J., Joye, S., Park, R., Pennings, S., Guo, H., and Machmuller, M., 2009, Forecasting the effects of accelerated sea-level rise on tidal marsh ecosystem services: Frontiers in Ecology and the Environment, v. 7, no. 2, p. 73-78. [Also available at https://doi.org/10.1890/070219.]

Cumming, G.S., Cumming, D.H.M., and Redman, C.L., 2006, Scale mismatches in social-ecological systemsCauses, consequences, and solutions: Ecology and Society, v. 11, no. 1, 14. [Also available at https://doi.org/10.5751/ ES-01569-110114.]
Donoghue, J.F., Elsner, J.B., Hu, B.X., Kish, S.A., Niedoroda, A.W., Wang, Y., and Ye, M., 2013, Effects of near-term sea-level rise on coastal infrastructure: Alexandra, Va., Strategic Environmental Research and Development Program, 172 p. [Also available at https://www.hsdl.org/?abstract\&did=793718.]

Doyle, T.W., Chivoiu, B., and Enwright, N.M., 2015, Sealevel rise modeling handbook-Resource guide for coastal land managers, engineers, and scientists: U.S. Geological Survey Professional Paper 1815, 76 p. [Also available at https://doi.org/10.3133/pp1815.]

Eaton, M.J., Yurek, S., Haider, Z., Martin, J., Johnson, F.A., Udell, B.J., Charkhgard, H., and Kwon, C., 2019a, Spatial conservation planning under uncertainty-Adapting to climate change risks using modern portfolio theory: Ecological Applications, v. 29, no. 7, p. e01962. [Also available at https://doi.org/10.1002/eap.1962.]

Eaton, M.J., Yurek, S., Haider, Z., Martin, J., Johnson, F.A., Udell, B.J., Charkhgard, H., Kwon, C., 2019b, Parcel cost benefit and portfolio selection data for reserve design optimization using modern portfolio analysis: U.S. Geological Survey data release, https://doi.org/10.5066/P91XU2ON.

Figge, F., 2004, Applying portfolio theory to biodiversity: Biodiversity and Conservation, v. 13, no. 4, p. 827-849. [Also available at https://doi.org/10.1023/ B:BIOC.0000011729.93889.34.]

Folke, C., 2006, Resilience-The emergence of a perspective for social-ecological systems analyses: Global Environmental Change, v. 16, no. 3, p. 253-267. [Also available at https://doi.org/10.1016/j.gloenvcha.2006.04.002.]

Folke, C., Carpenter, S.R., Walker, B.H., Scheffer, M., Chapin, T., and Rockström, J., 2010, Resilience thinking-Integrating resilience, adaptability and transformability: Ecology and Society, v. 15, no. 4, art. 20. [Also available at https://doi.org/10.5751/ES-03610-150420.]

Greiner, R., Patterson, L., and Miller, O., 2009, Motivations, risk perceptions and adoption of conservation practices by farmers: Agricultural Systems, v. 99 , no. $2-3$, p. $86-104$. [Also available at https://doi.org/10.1016/j.agsy.2008.10.003.]

Holling, C.S., 1973, Resilience and the stability of ecological systems: Annual Review of Ecology and Systematics, v. 4, no. 1, p. 1-23. [Also available at https://doi.org/10.1146/ annurev.es.04.110173.000245.] 
Holling, C.S., 2001, Understanding the complexity of economic, ecological, and social systems: Ecosystems, v. 4, no. 5, p. 390-405. [Also available at https://doi.org/10.1007/ s10021-001-0101-5.]

Horton, R., and Bader, D., 2014, Sea level rise projection for Cape Romain, South Carolina: Columbia University, unpublished report to the Northeast and Southeast Department of Interior Climate Science Centers, 2 p. [Also available at https:/www.sciencebase.gov/catalog/file/get/5654ed9ae4b0 $71 \mathrm{e} 7 \mathrm{ea} 53 \mathrm{~d} 702 \mathrm{f}=$ _ disk $\quad 72 \% 2 \mathrm{~F} 7 \mathrm{~d} \% 2 \mathrm{Fa} 4 \% 2 \mathrm{~F} 727 \mathrm{da} 4383$ ad26bfed0a3fb72065215436f6c2aa7.]

Houghton, J.T., Ding. Y., Griggs, D.J., Noguer, M., van der Linden, P.J., Dai, X., Maskell, K., and Johnson, C.A., eds., 2001, Climate change 2001-The scientific basis: Cambridge, Cambridge University Press, 881 p.

Johnson, F.A., Williams, B.K., and Nichols, J.D., 2013, Resilience thinking and a decision-analytic approach to conservation-Strange bedfellows or essential partners?: Ecology and Society, v. 18, no. 2, 27. [Also available at https://doi.org/10.5751/ES-05544-180227.]

Kirkwood, C.W., 1996, Strategic decision making: Belmont, Calif., Wadsworth Publishing Company.

Koellner, T., and Schmitz, O.J., 2006, Biodiversity, ecosystem function, and investment risk: BioScience, v. 56, no. 12, p. 977-985. [Also available at https://doi.org/10.1641/ 0006-3568(2006)56[977:BEFAIR]2.0.CO;2.]

Kohli, R., Krishnamurti, R., and Mirchandani, P., 2004, Average performance of greedy heuristics for the integer knapsack problem: European Journal of Operational Research, v. 154, no. 1, p. 36-45. [Also available at https://doi.org/10.1016/S0377-2217(02)00810-X.]

Kurth, M.H., Larkin, S., Keisler, J.M., and Linkov, I., 2017, Trends and applications of multi-criteria decision analysis-Use in government agencies: Environment Systems \& Decisions, v. 37, no. 2, p. 134-143. [Also available at https://doi.org/10.1007/s10669-017-9644-7.]

Marinoni, O., Adkins, P., and Hajkowicz, S., 2011, Water planning in a changing climate-Joint application of cost utility analysis and modern portfolio theory: Environmental Modelling \& Software, v. 26, no. 1, p. 18-29. [Also available at https://doi.org/10.1016/j.envsoft.2010.03.001.]

Markowitz, H.M., 1952, Portfolio selection: The Journal of Finance, v. 7, no. 1, p. 77-91. [Also available at https://www.jstor.org/stable/2975974.]

Markowitz, H.M., 1959, Portfolio selection-Efficient diversification of investments: New Haven, Yale University Press, 368 p.
Martin, J., Runge, M.C., Nichols, J.D., Lubow, B.C., and Kendall, W.L., 2009, Structured decision making as a conceptual framework to identify thresholds for conservation and management: Ecological Applications, v. 19, no. 5, p. 1079-1090. [Also available at https://doi.org/10.1890/08-0255.1.]

Moilanen, A., and Cabeza, M., 2007, Accounting for habitat loss rates in sequential reserve selectionSimple methods for large problems: Biological Conservation, v. 136, no. 3, p. 470-482. [Also available at https://doi.org/10.1016/j.biocon.2006.12.019.]

Moore, J.W., McClure, M., Rogers, L.A., and Schindler, D.E., 2010, Synchronization and portfolio performance of threatened salmon: Conservation Letters, v. 3, no. 5, p. 340-348. [Also available at https://doi.org/10.1111/ j.1755-263X.2010.00119.x.]

Nash, J.F., Jr., 1950, The bargaining problem: Econometrica, v. 18, no. 2, p. 155-162. [Also available at https://doi.org/10.2307/1907266.]

Nichols, J.D., and Williams, B.K., 2006, Monitoring for conservation: Trends in Ecology \& Evolution, v. 21, no. 12, p. 668-673. [Also available at https://doi.org/10.1016/j. tree.2006.08.007.]

Nilius, R., Dawsey, S., Eaton, M., Martin, J., Romanach, S., Baird, S., Bryant, M., Case, D., Johnson, F., McMahon, G., Pau, N., Pienaar, E., Ratnaswamy, M., Seibert, S., Wingrove, P., and Wood, N., 2014, Maximizing the social and ecological value of Cape Romain National Wildlife Refuge, South Carolina as the effects of global change processes increase: National Conservation Training Center Structured Decision Making Workshop, Shepherdstown, W.V., June 2-6, 2014, workshop report, 20 p. [Also available at https://raining.fws.gov/courses/ALC/ALC3159/ reports/final-reports/2014FR/CRNWR_workshop_report_ FINAL.pdf.]

Pal, A., and Charkhgard, H., 2017a, A feasibility pump and local search based heuristic for bi-objective pure integer linear programming: INFORMS Journal on Computing, v. 31, no. 1, p. 1-192. [Also available at https://doi.org/10.1287/ ijoc.2018.0814.]

Pal, A., and Charkhgard, H., 2017b, FPBH.jl—A feasibility pump based heuristic for multi-objective mixed integer linear programming in Julia: Tampa, Fla., University of South Florida, 38 p.

Pressey, R.L., Cabeza, M., Watts, M.E., Cowling, R.M., and Wilson, K.A., 2007, Conservation planning in a changing world: Trends in Ecology \& Evolution, v. 22, no. 11, p. 583-592. [Also available at https://doi.org/10.1016/j. tree.2007.10.001.] 
R Core Team, 2018. R-A language and environment for statistical computing. R Foundation for Statistical Computing, Vienna, Austria, accessed May 2018 at https://www.R-project.org/.

Santín, I., Pedret, C., and Vilanova, R., 2017, Pareto optimality, appendix A of Santín, I., Pedret, C., and Vilanova, R., eds., Control and decision strategies in wastewater treatment plants for operation improvement: Springer International Publishing Switzlerland, Intelligent Systems, Control and Automation: Science and Engineering, v. 86, p. 115-124.

Sarkar, S., Pressey, R.L., Faith, D.P., Margules, C.R., Fuller, T., Stoms, D.M., Moffett, A., Wilson, K.A., Williams, K.J., Williams, P.H., and Andelman, S., 2006, Biodiversity conservation planning tools - Present status and challenges for the future: Annual Review of Environment and Resources, v. 31, no. 1, p. 123-159. [Also available at https://doi.org/10.1146/annurev.energy.31.042606.085844.]

Schindler, D.E., Hilborn, R., Chasco, B., Boatright, C.P., Quinn, T.P., Rogers, L.A., and Webster, M.S., 2010, Population diversity and the portfolio effect in an exploited species: Nature, v. 465, no. 7298, p. 609-612. [Also available at https://doi.org/10.1038/nature09060.]

Schloss, C.A., Lawler, J.J., Larson, E.R., Papendick, H.L., Case, M.J., Evans, D.M., DeLap, J.H., Langdon, J.G.R., Hall, S.A., and McRae, B.H., 2011, Systematic conservation planning in the face of climate change-Bet-hedging on the Columbia Plateau: PLoS One, v. 6, no. 12, p. e28788. [Also available at https://doi.org/10.1371/journal.pone.0028788.]
Steele, K., Carmel, Y., Cross, J., and Wilcox, C., 2009, Uses and misuses of multicriteria decision analysis (MCDA) in environmental decision making: Risk Analysis, v. 29, no. 1, p. 26-33. [Also available at https://doi.org/10.1111/ j.1539-6924.2008.01130.x.]

Thompson, B.H., 2004, The trouble with time-Influencing the conservation choices of future generations: Natural Resources Journal, v. 44, p. 601-620.

Thorne, K.M., Buffington, K.J., Elliott-Fisk, D.L., and Takekawa, J.Y., 2015, Tidal marsh susceptibility to sea-level rise-Importance of local-scale models: Journal of Fish and Wildlife Management, v. 6, no. 2, p. 290-304. [Also available at https://doi.org/10.3996/062014-JFWM-048.]

von Neumann, J., and Morgenstern, O., 1947, Theory of games and economic behavior ( $2 \mathrm{~d}$ ed.): Princeton, N.J., Princeton University Press, 625 p.

Wallenius, J., Dyer, J.S., Fishburn, P.C., Steuer, R.E., Zionts, S., and Deb, K., 2008, Multiple criteria decision making, multiattribute utility theory-Recent accomplishments and what lies ahead: Management Science, v. 54, no. 7, p. 1336-1349. [Also available at https://doi.org/10.1287/ mnsc.1070.0838.]

Williams, B.K., Nichols, J.D., and Conroy, M.J., 2002, Analysis and management of animal populations: San Diego, Calif., Academic Press, 817 p. 



\section{Chapter G. Cape Romain Partnership for Coastal Protection- Parting Thoughts}

Change is an enduring feature of South Carolina's Lowcountry. Historic events like the Civil War and Great Depression, and natural disasters such as Hurricane Hugo, have forced local communities to become resilient and adaptable. What has emerged is an active and vibrant conservation community that focuses as much on culture and quality of life as on ecological concerns (Halfacre, 2013). The rich cultural heritage of the South Carolina Lowcountry, fostered by a strong bond to the land and sea, has helped shape a conservation movement that is remarkably successful, especially in light of entrenched social and political conservatism and deference to private property rights (Johnson and others, 2009; Halfacre, 2013). The conservation community is extremely diverse, with many sophisticated nongovernmental organizations providing strong leadership and promoting land-based livelihoods that help sustain the area's cultural heritage (Halfacre, 2013). The conservation community in the South Carolina Lowcountry embraces social learning, uses a diversity of approaches, and takes advantage of strong social cohesion and mechanisms for collective action - all essential features of resilient and adaptive social-ecological systems (Adger and others, 2005).

The South Carolina Lowcountry's environmental wealth, rich cultural heritage, and quality of life have been a doubleedged sword, however. Expanding tourism and migrationdriven population growth have placed strains on infrastructure, fueled urban sprawl, increased social vulnerability (for example, gentrification), amplified economic inequalities, and fanned racial tensions (Faulkenberry and others, 2000; Johnson and Floyd, 2006; Johnson and others, 2009; Halfacre, 2013). Climate change is exacerbating these and other problems. Coastal systems are naturally dynamic, but the confluence of rapid changes and increasing numbers of people and additional infrastructure exposed to such changes equates to higher risk. Rapid sea-level rise is driving more tidal flooding in the Charleston metropolitan area and is contributing to the loss of coastal environments that provide multiple ecological goods and services, including critical habitat for fish and wildlife. Although the effect of climate change on the frequency of coastal storms is uncertain, sea-level rise amplifies the effect of recurrent hurricanes and nor'easters, which are rapidly eroding the sediment-depleted barrier islands that provide protection for the landscape and people from the force of the open ocean. The large-scale nature of climate change presents the South Carolina Lowcountry conservation community with a "problem of fit," in which the scale of the environmental problem is not matched by the scale at which local institutions can easily adapt to or mitigate effects (Cumming and others, 2006, 2013).
Scale and recognition of the problem of fit have often been ignored in traditional conservation practice, which is characterized by a top-down, command-and-control, political process of legislation and agency rule making (Holling and Meffe, 1996; Ludwig, 2001; Cheng and others, 2003; Berkes, 2010a, b). By the 1980s, however, there were serious concerns about the ability of centralized governments to address large-scale problems facing local social-ecological systems. Beginning in the 1990s, devolution of resource governance (co-management by governments and engaged stakeholders) became popular. The intent was to bring government closer to the governed, such that those affected by decisions would have more of a say in them (Berkes, 2010b). Broad participation in problem solving at the lowest feasible level of institutional organization came to be considered part of good governance (Berkes, 2010b). The track record of decentralized governance is mixed, however, in part because of the problem of fit (inability to act) and because even at a local scale the problems remain wicked (Rittel and Webber 1973, Armitage and others, 2007; Berkes, 2010b; Chaffin and others, 2014; Hopkinson and others, 2017). When confronted with wicked problems, planning processes can quickly be overwhelmed by the difficulty of accounting for multiple decision makers; diverse, often competing, values; complex interactions of social and ecological systems; and profound uncertainties regarding the future and society's ability to influence it. Wicked problems have thus forced practitioners to look to new approaches, in which there is a deeper appreciation for a given place, culture, and historical context (Miller and others, 2008; Game and others, 2014; Meadow and others, 2015).

Notions of place attachment, sense of place, and the role of culture in social discourse are increasingly being used to understand the complex interactions between society and the environment (Demeritt, 2002; Cheng and others, 2003; Crane, 2010) and how societies respond and adapt to climate change (Ney and Thompson, 2000; Adger and others, 2009, 2013). Indeed, Cheng and others (2003, p. 98) argue that "natural resource politics is as much a contest over place meanings as it is a competition over the allocation and distribution of scarce resources among interest groups.” A sense of place is constructed — and continuously reconstructed — through the interaction of biophysical attributes and processes, social and cultural meanings, and social and political processes (Burnett, 1976; Canter, 1977; Cheng and others, 2003). According to Cheng and others (2003), the emerging interest in place as an integrating concept in conservation is best explained by Kemmis (1992, p. 119):

"Places have a way of claiming people. When they claim very diverse kinds of people, then those people must eventually learn to live with each other; they 
must learn to inhabit their place together, which they can only do through the development of certain practices of inhabitation which both rely upon and nurture the old-fashioned civic virtues of trust, honesty, justice, toleration, cooperation, hope, and remembrance.”

Halfacre (2013, p. 75) presents sense of place as a unifying theme of the conservation movement and argues that "love of place remains the most compelling rationale for [environmental] preservation." Indeed, the social cohesion resulting from a strong sense of place in the South Carolina Lowcountry was a recurring theme in our scenario planning exercises (chap. D).

New theories of governance in social-ecological systems have many implications for protecting the attributes of the South Carolina Lowcountry that are valued by residents and visitors alike. In this chapter, we present six propositions for engaging individuals and organizations interested in adapting to the uncertain future of the South Carolina Lowcountry. These propositions are based on an extensive literature review, as well as our own experiences with this project (see also Johnson and others, 2020). They comport with the emerging view that practical solutions to wicked problems will ultimately be generated by local actors behaving in accordance with their own particular perception of the social-ecological landscape (Rayner and Malone, 1997; Verweij and others, 2006; Crane, 2010). This is a fundamentally different perspective from that in much of conservation and climate change planning, which tend to be linear and positivistic, strategic, and hierarchical (Berkes, 2010a).

\section{G.1. Proposition 1-Effective Adaptation May Rely More on Bottom-Up Governance than Centralized Governments}

Government and governance are not the same thing. Governing of the "commons" (Wall, 2014) has traditionally been led by central governments, in which scientists and managers are portrayed as independent, objective experts (Ludwig, 2001; Berkes, 2010a). Governance, on the other hand, refers to the broader processes by which institutions, organizations, and individuals make decisions to protect the environment (Armitage and others, 2012; Chaffin and others, 2014). There is increasing interest in more community-based governance of the commons, in which broad stakeholder participation and power sharing are key elements. This devolution of governance is characterized by the involvement of multiple institutions and self-organizing social networks that promote a culture of knowledge sharing, problem solving, and learning (Armitage and others, 2007; Bodin and Crona, 2009; Berkes, 2010b; Chaffin and others, 2014).
This new governance takes time, patience, and a willingness to share power, characteristics not often associated with centralized governments. And the state can impede the devolution process by limiting funding and power sharing, and by favoring local institutions that have perspectives in line with their own (Berkes, 2010b). Yet governments are not monolithic; different agencies have different roles, responsibilities, and approaches, and individuals within agencies have varying perspectives about the role of government in environmental decision making (Berkes, 2010b). Bridging organizations often provide the leadership necessary to bring together relevant government agencies and institutions, private organizations, and individuals in a productive process of problem solving (Cash and others, 2003; Folke and others, 2005; Berkes, 2009). Bridging organizations act as honest brokers (Pielke, 2007) by facilitating a process of interaction, which to be effective must be seen as salient, credible, and legitimate by those involved (Cash and others, 2003).

In a real sense, the Cape Romain Partnership for Coastal Protection played the role of bridging organization during this project by participating in a minimally structured process of knowledge coproduction, sense making, and problem solving. The partnership also identified a need to increase self-awareness among the broader conservation community as members of which are often not familiar with one another, with the goal of expanding the conservation network and better connecting expertise with when, where, and how it is needed. Ultimately, the partnership may find it productive to extend the network to other stakeholders, whose interest in conservation per se may be limited, but who share a sense of place and a desire for maintaining the quality of life in the South Carolina Lowcountry. This will require strong and diverse leadership and collaborative networks to produce an atmosphere of trust, social learning, and problem solving among disparate interests and authorities (Folke and others, 2005; Berkes, 2010b; Halfacre, 2013).

\section{G.2. Proposition 2-Recognize that Conservation is Integral to a Broader Set of Governance Issues, Which Include Social, Economic, and Cultural Values}

Over the last two decades (2000s and 2010s), a major shift has occurred in how management of the commons is perceived. The traditional view of humans as apart from, and managers of, nature has been replaced by the recognition that humans and the environment interact in complex ways over many levels of organization and scales of space and time (Gunderson and others, 1995; Holling, 2001; Ludwig, 2001; Walker and Salt, 2006). This human and nature perspective (Mace, 2014) means that the social-ecological system is the 
fundamental unit of analysis (Berkes, 2010a) with all the complexity that entails. Accompanying this shift in perspective has been the emergence of the concept of resilience, which posits that all complex systems go through repeating, adaptive cycles of exponential change, stasis, collapse, and renewal, which is a process that ultimately sustains the system and its functions over time (Holling, 2001; Gunderson and Holling, 2002; Folke, 2006). A panarchy is defined as a nested set of these adaptive cycles across space and time, such that phases of a cycle at one scale exert influence on the progression of phases at another (Holling, 2001). In principle, large scales constrain and small scales innovate. For example, rules, laws, treaties, and cultural norms represent large-scale governance features through which we manage natural resources. These social systems encode a memory of past experiences and help guide the search for solutions (Folke, 2006); however, they may also constrain what is possible in seeking change at smaller scales and often are highly resistant to change. Novel solutions in response to crises rarely originate from this level of organization (Lee, 1993; Levin, 1999). Usually it is at finer scales (for example, local spatial and governance scales, shorter timeframes) where creative individuals or small groups challenge the status quo and provide the novel ideas that are the mutations necessary for adaptation.

Panarchy theory has profound implications for governance of social-ecological systems. First, it suggests there is no unique or manifest scale at which environmental problems can be analyzed and addressed. Although the focus of the Cape Romain Partnership for Coastal Protection is on the South Carolina Lowcountry and sustaining its flow of ecological goods and services, events happening at other scales, whether in a local community or in global trade, shape and constrain what is possible. Recognition of multiple scales of influence was apparent in our scenario planning exercises, in which local cultural differences, national politics, and globalization shaped discussions about the region's future.

Second, timing is critical. An example is the destruction wrought by Hurricane Hugo in 1989, which provided an opportunity for local leaders to reflect and act upon the effect of unconstrained growth on the quality of life (Halfacre, 2013). Moreover, the conservation movement in the South Carolina Lowcountry has shown a long-term pattern of punctuated equilibrium, in which relatively long periods of stability were interrupted by periods of significant innovation (Halfacre, 2013). Examples of disruptive events spawning such innovations include sprawl shock and zoning regulations in response to the largely unregulated growth of the 1970s and 1980s, Hurricane Hugo, and the increasing frequency of sea-level rise-mediated nuisance flooding in the city of Charleston (Halfacre, 2013). Each of these events has resulted in increased social organization and the establishment of some form of novel measure to enhance local resiliency to such disturbances. The lessons from panarchy theory are to recognize when the social-ecological system is positioned for change and then to be prepared as a catalyst by having a strong network of ideas, actors, and institutions.
Third, old notions of systems in equilibrium, with fixed forms of governance, are not congruent with the dynamic and unpredictable nature of social-ecological systems. The flow of ecological goods and services is constantly in flux and subject to occasional shocks. Learning to live with this uncertainty requires more explicit assessments of risk and adoption of robust policies and actions that are likely to produce an acceptable flow of goods and services regardless of how the future unfolds.

Finally, the conservation movement might come to see its activities as integral to the broader governance of social-ecological systems, in which responses to the forces of global change are mediated through culture, economics, and politics. There are tentative signs that the conservation movement, rather than directly competing with other interests, can promote social justice by concerning itself with how wealth, opportunities, and privileges are distributed within society (Brechin and others, 2002; Martin and others, 2013; Shoreman-Ouimet and Kopnina, 2015). This implies an interpretation of conservation in which the fundamental objective is the quality of human life rather than environmental protection per se (Biedenweg and Gross-Camp, 2018) or that conservation and values of social justice are not necessarily competing goals. The Cape Romain Partnership seemed sympathetic to this approach by identifying as important opportunities for conservation an attractive culture and lifestyle in the South Carolina Lowcountry and a high demand for ecological goods and services (chap. E), and by recognizing the value of social cohesion (chap. D). By social cohesion, we mean the willingness of members of a society to cooperate with each other to survive and prosper (Stanley, 2003).

\section{G.3. Proposition 3-Approach Land Protection in a Way that is Consistent with the Preservation of the Lowcountry's Cultural Heritage and the Long-Standing Deference to Private Property Rights}

An original goal of this project was to identify lands that, if protected, could offset the anticipated loss of habitats at Cape Romain National Wildlife Refuge because of sealevel rise. Given political sentiments in the region, fee-simple (that is, full title transfer) purchases of land by the Federal Government may not be strongly supported by local communities. Other options, including State-level land conservation and encouragement of working landscapes, which accommodate traditional, land-based livelihoods like forestry, agriculture, and commercial fisheries, could help sustain the flow of ecological goods and services that support the quality of life in the South Carolina Lowcountry. Flexible and voluntary 
conservation instruments, such as rolling easement, fixed-term easements, and possibly divestment of publicly held properties, are likely more consistent with the politics of the region and the uncertain environmental changes it will experience.

Any expansion of conservation lands risks an ideological conflict between development and protection, a situation well known to the South Carolina Lowcountry conservation community (Halfacre, 2013). Demonstration of how conservation lands improve or conserve the provision of key regulating services of importance to residents (for example, protection of infrastructure and water quality) is more likely to have broader public appeal than traditional calls to conserve fish and wildlife habitat. The provisioning of recreational opportunities on public lands is another ecosystem service that should not be overlooked, especially as an increasing human population further drives demand for private property. Conservationists might also consider a perspective that suggests lost habitats and public recreational space need to be replaced not only for their ecological goods and services but also for their contribution to the South Carolina Lowcountry's rural character and sense of place (for example, Hart and others, 2004). For example, the preservation of historic architecture is common for preserving the historical character of a place, and the same is true for habitats that help define a place (Stedman, 2003). We acknowledge that this contribution to sense of place can be hard to define; and although the optimization tools we used can help identify potential conservation lands (chap. F), they may not easily capture these nuances of value that may be important in prioritizing lands for conservation.

\section{G.4. Proposition 4-Engage Stakeholders with the Understanding that Variation in Behavior Reflects Diverse Social-Cultural Perceptions}

People live their daily lives in a sea of meaning, where power relations and individual and group identities are not necessarily evident to those seeking engagement. Considerations of the role of behavior models (chap. C.3) encourages an appreciation of the diverse ways in which people and organizations perceive the social-ecological systems in which they are embedded and, in so doing, can facilitate more effective engagement and communication strategies (Armitage, 2009). The power of the transtheoretical model lies in the recognition that not all people begin at the same starting place in behavior modification (which is after all, the point of engagement). By beginning with this recognition, conservation practitioners can design effective messages and activities that better align with what is most appropriate for a specific area, issue, and audience. Traditional engagement and communication often starts with the notion that stakeholders simply need more information to make "appropriate" decisions, sometimes resulting in a surplus of information and a dearth of action (Kollmuss and Agyeman, 2002; Cox, 2012). In chapter C, we provided some initial guidance on using the Transtheoretical model to engage stakeholders from local through Federal scales. Our stakeholder engagement in this project, however, was limited to a relatively small representation of the broader conservation community, in which many participants are well beyond the earlier phases of behavioral change and are most interested in action to address changes being experienced by the Lowcountry. That such participants had well-developed concerns for impending threats and were prepared to act would explain why scenario planning may not have resonated strongly with some participants (that is, those who were at a stage of action implementation). We believe, however, that scenario planning to envision alternative futures could be a useful approach to help a broader, more diverse stakeholder group, with members at various stages of behavioral change, develop a shared perspective of the changes and associated challenges confronting the South Carolina Lowcountry. Our particular experience with scenario planning highlights the importance of understanding the perspectives and sense of agency among stakeholders and the value of applying a model of human behavior when proposing engagement and learning activities.

\section{G.5. Proposition 5-Decision Makers, Scientists, and Stakehoders Work Together to Coproduce Knowledge and Meaning}

Coproduction has been defined in at least two related ways (van Kerkhoff and Lebel, 2015). In the first, science and governance are seen to interact, whereby scientific information must be dropped into contexts that produce distinctive cultural responses (Jasanoff, 2004). This implies that the diversity, richness, and challenges of local contexts are paramount in understanding how scientific information is acted upon (Hulme, 2010). We touched upon these ideas in propositions 1 and 2. A more recent view of coproduction is of a normative approach, in which experts and users have equal ownership in the process and collaborate to develop a shared body of knowledge (Mitchell and others, 2004). In this view, scientists work with stakeholders to help frame questions, design research, and collect and analyze data (Klenk and others, 2015). Such sustained collaborations are increasingly believed to be an effective way to produce useable (or "actionable") science (Meadow and others, 2015). When these collaborations are combined with a community-of-inquiry (in other words, self-organizing) approach to learning, knowledge and sense making unfolds through complex interactions of social, cognitive, and teaching elements (Swan and Ice, 2010). This approach differs dramatically from engagement activities 
that envision learning as a unidirectional, teacher-to-student process. Irrespective of any specific view of coproduction is the belief that allowing participants to interpret information in a way that resonates more clearly with their lived experiences, while enabling them to empathize with competing perspectives, can help overcome the gap between scientific knowledge and policy action in climate-change adaptation (Schuttenberg and Guth, 2015). Key to any coproduction approach is the involvement of social scientists who can analyze social interactions in a given decision context and inform the development of participatory scientific inquiry and collective decision making (Weaver and others, 2014).

Successful coproduction can be quite difficult, however, because of differences among participants (for example, scientists, decision makers, and other stakeholders) in timeframes, reward structures, goals, process cycles, and epistemologies (Hegger and Dieperink, 2014). The challenge is to facilitate a shift from disparate, self-focused perspectives of a problem based on the interests of individual members to a holistic, collective framework for knowledge production in which stakeholders are given an equal voice so that trust, creativity, and a shared perspective can develop (Schuttenberg and Guth, 2015). Boundary organizations (or individuals) are considered an effective way to enable this social learning because science is viewed within the context of values and political processes (Bidwell and others, 2013; Hegger and Dieperink, 2014). We highlighted the importance of bridging organizations in proposition 1, and note here how organizations like Sea Grant (see table A1) can serve as a bridging organization and a facilitator of boundary networks, in which evolving communities of decision makers and scientists can be connected within a network of local bridging organizations to link communities of researchers and decision making for addressing dynamic problems (Guston, 2001; Bidwell and others, 2013).

Finally, we note that scenario planning can be a useful tool for coproduction and an effective tactic for coping with wicked problems (Peterson and others, 2003; Camillus, 2008). A participatory approach to scenario planning can provide saliency, credibility, and legitimacy to scenario narratives, as well as a vehicle for consensus building and problem solving (Rounsevell and Metzger, 2010). Scenario planning acts to promote social learning by fostering greater awareness of social-ecological change and its effects by exploring and integrating many different issues and forms of knowledge, by exposing and exploring different worldviews, and by encouraging greater awareness of the role of human choices and actions in shaping the future (Wiseman and others, 2011).

\section{G.6. Proposition 6-Build Adaptive Capacity}

Adaptive capacity is defined as the ability to prepare for environmental stressors in advance or to adjust and respond to stressor effects (Engle, 2011). The greater the adaptive capacity, the greater the resilience to disturbances like sealevel rise, tropical storms, economic downturns and other sources of social disruption. Adaptive capacity depends on the ability to act collectively, and social capital, trust, and organization greatly affect the capacity to act (Adger, 2003). The presence of strong social networks, coordination and deliberation among diverse stakeholders, applications of adaptive management methods, and emphasis on social learning are key elements contributing to adaptive capacity (Dietz and others, 2003; Olsson and others, 2004; Pahl-Wostl, 2009).

The Cape Romain Partnership for Coastal Protection has taken important steps towards building adaptive capacity by networking with various conservation interests and by exploring the coproduction of knowledge and meaning. By engaging in directed learning processes such as scenario planning and formalized evaluation of organization and partnership strengths, weaknesses, opportunities and risks, this coalition has initiated development of a more resilient and integrated network. By assessing strengths and weaknesses of its constituent members, it has begun to understand the extent of diversity and redundancy - essential features of adaptive capacity - within the conservation community. Moreover, its stated intent is to network with additional conservation interests and with larger societal interests to help ensure the sustainability of ecological goods and services in the South Carolina Lowcountry. The partnership also has been forward looking by anticipating the threats and opportunities presented by varying scenarios of the future. Adaptive capacity could be further enhanced by developing more formal mechanisms for feedback. Which approaches worked and why? Which approaches were less or unsuccessful and should be discarded? Such institutional learning is essential from a tactical and strategic perspective, and ultimately for developing governance regimes that are more effective at navigating periods of rapid change in social-ecological systems (Pahl-Wostl, 2009).

\section{G.7. Conclusions}

A draft Cape Romain National Wildlife Refuge Climate Change Action Plan emphasizes the protection and acquisition of fish and wildlife habitat in partnership with Francis Marion National Forest. We sought to develop decision-making tools to support this effort (chap. F) but ultimately focused more on governance and collective decision making within the larger social-ecological system that is the South Carolina Lowcountry. This focus on process over product differs from the strategic guidance provided by the refuge system, which emphasizes training employees in climate-change adaptation, providing technical assistance (U.S. Fish and Wildlife Service, 2010), educating the public about climate change, protecting infrastructure, and using energy wisely (Czech and others, 2014). Strategic guidance from scholars is likewise very much refuge-centric (Griffith and others, 2009; Iguchi, 2011; Magness and others, 2012). Yet even when a refuge is 
clear about the systemic and individual refuge objectives it wishes to pursue (Iguchi, 2011), the tradeoffs the refuge must make and actions it takes involve considering multiple levels of governance, from local stakeholders to regional institutions and national politics. The view of this governance landscape will vary widely among refuges (Gunderson and Holling, 2002), sometimes engendering feelings of isolation, hopelessness, and despair in refuges facing the local effects of climate change and other stressors (Bryant and others, 2012).

We believe this sense of isolation can be overcome in part by engaging local conservation interests and, perhaps more importantly, those who depend on the ecological goods and services that support quality of life throughout the South Carolina Lowcountry. This is likely to be unfamiliar territory for some refuge staff, whose principal focus is keeping the refuge running and trying to mitigate or adapt to effects of climate change on the refuge (Johnson and others, 2015). Fortunately for Cape Romain National Wildlife Refuge, there is a diverse, active, and vibrant conservation community in the South Carolina Lowcountry (Halfacre, 2013). Opportunities for engagement abound and, if seized upon, can minimize the problem of fit and enhance the capacity for collective action.

Central to the emerging perspective of governance of the commons is the recognition that social and ecological systems are coupled; the issues and problems of one cannot be addressed without considering the consequences for the other. Moreover, a dominant theme emerging from our research and that of other scholars is the importance of place attachment, which generates social cohesion and facilitates problem solving. These ideas have important implications for when, where, and how stakeholders are engaged to address the rapid changes being experienced by the South Carolina Lowcountry.

A central tenet of anthropology, sociology, and cultural geography suggests that how we view, understand, and experience the world (defined as our "cultural construction") can vary greatly among individuals (Demeritt, 2002; Crane, 2010). These are not trivial differences a linear process of decision making can overcome. In the end, complex conservation problems can only be solved by society at large; therefore, acceptable solutions will only arise when there is a respect for the pluralities of experience and meaning that stakeholders bring with them to the decision-making process. Such differences then are not merely a nuisance to be abstracted away but something that must be embraced in any attempt to solve a wicked problem.

\section{References Cited}

Adger, W.N., 2003, Social capital, collective action, and adaptation to climate change: Economic Geography, v. 79, no. 4, p. 387-404. [Also available at https://doi.org/10.1111/j.1944-8287.2003.tb00220.x.]
Adger, W.N., Barnett, J., Brown, K., Marshall, N., and O'Brien, K., 2013, Cultural dimensions of climate change impacts and adaptation: Nature Climate Change, v. 3, no. 2, p. 112-117. [Also available at https://doi.org/10.1038/ nclimate1666.]

Adger, W.N., Dessai, S., Goulden, M., Hulme, M., Lorenzoni, I., Nelson, D.R., Naess, L.O., Wolf, J., and Wreford, A., 2009, Are there social limits to adaptation to climate change?: Climatic Change, v. 93 , no. 3-4, p. 335-354. [Also available at https://doi.org/10.1007/ s10584-008-9520-z.]

Adger, W.N., Hughes, T.P., Folke, C., Carpenter, S.R., and Rockström, J., 2005, Social-ecological resilience to coastal disasters: Science, v. 309, no. 5737, p. 1036-1039. [Also available at https://doi.org/10.1126/science.1112122.]

Armitage, C.J., 2009, Is there utility in the transtheoretical model?: British Journal of Health Psychology, v. 14, no. 2, p. 195-210. [Also available at https://doi.org/10.1348/135910708X368991.]

Armitage, D.R., Berkes, F., and Doubleday, N., eds., 2007, Adaptive co-management-Collaboration, learning and multi-level governance: Vancouver, UBC Press, $360 \mathrm{p}$.

Armitage, D.R., de Loë, R., and Plummer, R., 2012, Environmental governance and its implications for conservation practice: Conservation Letters, v. 5, no. 4, p. 245-255. [Also available at https://doi.org/10.1111/ j.1755-263X.2012.00238.x.]

Berkes, F., 2009, Evolution of co-management-Role of knowledge generation, bridging organizations and social learning: Journal of Environmental Management, v. 90, no. 5, p. 1692-1702. [Also available at https://doi.org/10.1016/j.jenvman.2008.12.001.]

Berkes, F., 2010a, Shifting perspectives on resource management-Resilience and reconceptualization of "natural resources" and "management": Maritime Studies, v. 9, p. 13-40. [Also available at http://www.marecentre.nl/mast/ documents/Mastvol9no1_Berkes.pdf.]

Berkes, F., 2010b, Devolution of environment and resources governance-Trends and future: Environmental Conservation, v. 37, no. 4, p. 489-500. Also available at https://doi.org/10.1017/S037689291000072X.]

Bidwell, D., Dietz, T., and Scavia, D., 2013, Fostering knowledge networks for climate adaptation: Nature Climate Change, v. 3, no. 7, p. 610-611. [Also available at https://doi.org/10.1038/nclimate1931.]

Biedenweg, K., and Gross-Camp, N.D., 2018, A brave new world - Integrating well-being and conservation: Ecology and Society, v. 23, no. 2, 32. [Also available at https://doi.org/10.5751/ES-09977-230232.] 
Bodin, Ö., and Crona, B.I., 2009, The role of social networks in natural resource governance-What relational patterns make a difference?: Global Environmental Change, v. 19 , no. 3, p. 366-374. [Also available at https://doi.org/10.1016/j.gloenvcha.2009.05.002.]

Brechin, S.R., Wilshusen, P.R., Fortwangler, C.L., and West, P.C., 2002, Beyond the square wheel-Toward a more comprehensive understanding of biodiversity conservation as social and political process: Society \& Natural Resources, v. 15, no. 1, p. 41-64. [Also available at https://doi.org/10.1080/089419202317174011.]

Bryant, M., Cheater, M., Hinds, L., and Matson, N., 2012, National wildlife refuges and sea-level rise-Lessons from the frontlines: Washington, D.C., Defenders of Wildlife, $13 \mathrm{p}$. [Also available at https://defenders.org/publications/ national-wildlife-refuges-and-sea-level-rise-lessons-frontlines.]

Burnett, P., 1976, Behavioral geography and the philosophy of mind, in Golledge, R.G., and Rushton, G., eds., Spatial choice and spatial behavior: Columbus, Ohio State University Press, p. 23-48.

Camillus, J.C., 2008, Strategy as a wicked problem: Harvard Business Review, v. 86, p. 98-101.

Canter, D.V., 1977, The psychology of place: Architectural Press, 198 p.

Cash, D., Clark, W.C., Alcock, F., Dickson, N.M., Eckley, N., and Jäger, J., 2003, Salience, credibility, legitimacy and boundaries-Linking research, assessment and decision making: John F. Kennedy School of Government, Harvard University, Faculty Research Working Papers Series, RWP02-046. [Also available at https://doi.org/10.2139/ ssrn.372280.]

Chaffin, B.C., Gosnell, H., and Cosens, B.A., 2014, A decade of adaptive governance scholarship: Ecology and Society, v. 19 , no. 3, 56. [Also available at https://doi.org/10.5751/ ES-06824-190356.]

Cheng, A.S., Kruger, L.E., and Daniels, S.E., 2003, “Place” as an integrating concept in natural resource politics-Propositions for a social science research agenda: Society \& Natural Resources, v. 16, no. 2, p. 87-104. [Also available at https://doi.org/10.1080/08941920309199.]

Cox, R., 2012, Environmental communication and the public sphere (3d ed.): Los Angeles, Sage Publications, 448 p.

Crane, T.A., 2010, Of models and meanings-Cultural resilience in social-ecological systems: Ecology and Society, v. 15 , no. 4 , 19. [Also available at https://doi.org/10.5751/ ES-03683-150419.]
Cumming, G.S., Cumming, D.H.M., and Redman, C.L., 2006, Scale mismatches in social-ecological systems-Causes, consequences, and solutions: Ecology and Society, v. 11, no. 1, 14. [Also available at https://doi.org/10.5751/ ES-01569-110114.]

Cumming, G.S., Olsson, P., Chapin, F.S., III, and Holling, C.S., 2013, Resilience, experimentation, and scale mismatches in social-ecological landscapes: Landscape Ecology, v. 28, no. 6, p. 1139-1150. [Also available at https://doi.org/10.1007/s10980-012-9725-4.]

Czech, B., Covington, S., Crimmins, T.M., Ericson, J.A., Flather, C., Gale, M., Gerst, K., Higgins, M., Kaib, M., Marino, E., Morton, J., Niemuth, N., Peckett, H., Savignano, D., Saperstein, L., Skorupa, S., Wagener, E., Wilen, B., and Wolfe, B., 2014, Planning for climate change on the National Wildlife Refuge System: Washington, D.C., U.S. Fish and Wildlife Service, National Wildlife Refuge System, 132 p. [Also available at https://www.fs.usda.gov/ treesearch/pubs/49201.]

Demeritt, D., 2002, What is the 'social construction of nature'? A typology and sympathetic critique: Progress in Human Geography, v. 26, no. 6, p. 767-790. [Also available at https://doi.org/10.1191/0309132502ph402oa.]

Dietz, T., Ostrom, E., and Stern, P.C., 2003, The struggle to govern the commons: Science, v. 302, no. 5652, p. 1907-1912. [Also available at https://doi.org/10.1126/ science.1091015.]

Engle, N.L., 2011, Adaptive capacity and its assessment: Global Environmental Change, v. 21 , no. 2, p. 647-656. [Also available at https://doi.org/10.1016/j.gloenvcha.2011.01.019.]

Faulkenberry, L., Coggeshall, J., Backman, K., and Backman, S., 2000, A culture of servitude-The impact of tourism and development on South Carolina's coast: Human Organization, v. 59, no. 1, p. 86-95. [Also available at https://doi.org/10.17730/humo.59.1.353730461t724j02.]

Folke, C., 2006, Resilience-The emergence of a perspective for social-ecological systems analyses: Global Environmental Change, v. 16, no. 3, p. 253-267. [Also available at https://doi.org/10.1016/j.gloenvcha.2006.04.002.]

Folke, C., Hahn, T., Olsson, P., and Norberg, J., 2005, Adaptive governance of social-ecological systems: Annual Review of Environment and Resources, v. 30, no. 1, p. 441-473. [Also available at https://doi.org/10.1146/ annurev.energy.30.050504.144511.] 
Game, E.T., Meijaard, E., Sheil, D., and McDonald-Madden, E., 2014, Conservation in a wicked complex world; challenges and solutions: Conservation Letters, v. 7, no. 3, p. 271-277. [Also available at https://doi.org/10.1111/ conl.12050.]

Griffith, B., Scott, J.M., Adamcik, R., Ashe, D., Czech, B., Fischman, R., Gonzalez, P., Lawler, J., McGuire, A.D., and Pidgorna, A., 2009, Climate change adaptation for the US National Wildlife Refuge System: Environmental Management, v. 44, no. 6, p. 1043-1052. [Also available at https://doi.org/10.1007/s00267-009-9323-7.]

Gunderson, L.H., and Holling, C.S., eds., 2002, PanarchyUnderstanding transformations in human and natural systems: Washington, D.C., Island Press, 507 p.

Gunderson, L.H., Holling, C.S., and Light, S.S., eds., 1995, Barriers \& bridges to the renewal of ecosystems and institutions: New York, Columbia University Press, 999 p.

Guston, D.H., 2001, Boundary organizations in environmental policy and science-An introduction: Science, Technology \& Human Values, v. 26, no. 4, p. 399-408. [Also available at https://doi.org/10.1177/016224390102600401.]

Halfacre, A.C., 2013, A delicate balance-Constructing a conservation culture in the South Carolina lowcountry: Columbia, University of South Carolina Press, 368 p. [Also available at https://doi.org/10.2307/j.ctv6wgh72.]

Hart, Z.H., Halfacre, A.C., and Burke, M.K., 2004, Community participation in preservation of lowcountry South Carolina sweetgrass (Muhlenbergia filipes [M. A. Curtis] J. Pinson and W. Batson) basketry: Economic Botany, v. 58, no. 2, p. 161-171. [Also available at https://doi.org/10.1663/0013-0001(2004)058[0161:CPIPOL ]2.0.CO;2.]

Hegger, D., and Dieperink, C., 2014, Toward successful joint knowledge production for climate change adaptation: Ecology and Society, v. 19, no. 2, 34. [Also available at https://doi.org/10.5751/ES-06453-190234.]

Holling, C.S., 2001, Understanding the complexity of economic, ecological, and social systems: Ecosystems, v. 4, no. 5, p. 390-405. [Also available at https://doi.org/10.1007/ s10021-001-0101-5.]

Holling, C.S., and Meffe, G.K., 1996, Command and control and the pathology of natural resource management: Conservation Biology, v. 10, no. 2, p. 328-337. [Also available at https://doi.org/10.1046/j.1523-1739.1996.10020328.x.]

Hopkinson, P., Huber, A., Saah, D.S., and Battles, J.J., 2017, A word to the wise-Advice for scientists engaged in collaborative adaptive management: Environmental Management, v. 59, no. 5, p. 752-761. [Also available at https://doi.org/10.1007/s00267-017-0825-4.]
Hulme, M., 2010, Problems with making and governing global kinds of knowledge: Global Environmental Change, v. 20, no. 4, p. 558-564. [Also available at https://doi.org/10.1016/j.gloenvcha.2010.07.005.]

Iguchi, J., 2011, Improving the improvement act-Climate change management in the National Wildlife Refuge System: Environs, v. 34, p. 247-269.

Jasanoff, S., ed., 2004, States of knowledge-The co-production of science and social order: London, Routledge, 336 p. [Also available at https://doi.org/10.4324/9780203413845.]

Johnson, C.Y., and Floyd, M.F., 2006, A tale of two townsBlack and white municipalities respond to urban growth in the South Carolina lowcountry: Human Ecology Review, v. 13 , p. $23-38$.

Johnson, C.Y., Halfacre, A.C., and Hurley, P.T., 2009, Resistant place identities in rural Charleston County, South Carolina - Cultural, environmental, and racial politics in the Sewee to Santee area: Human Ecology Review, v. 16, p. 1-16.

Johnson, F.A., Eaton, M.J., McMahon, G., Nilius, R., Bryant, M.R., Case, D.J., Martin, J., Wood, N.J., and Taylor, L., 2015, Global change and conservation triage on National Wildlife Refuges: Ecology and Society, v. 20, no. 4, 14. [Also available at https://doi.org/10.5751/ES-07986200414.]

Johnson, F.A., Eaton, M.J., Mikels-Carrasco, J., and Case, D.J., 2020, Building adaptive capacity in a coastal region experiencing global change: Ecology and Society, v. 25, no. 3, art. 9. [Also available at https://doi.org/10.5751/ ES-11700-250309.]

Kemmis, D., 1992, Community and the politics of place: Norman, Okla., University of Oklahoma Press, 160 p.

Klenk, N.L., Meehan, K., Pinel, S.L., Mendez, F., Lima, P.T., and Kammen, D.M., 2015, Stakeholders in climate science-Beyond lip service?: Science, v. 350, no. 6262, p. 743-744. [Also available at https://doi.org/10.1126/ science.aab1495.]

Kollmuss, A., and Agyeman, J., 2002, Mind the gap-Why do people act environmentally and what are the barriers to pro-environmental behavior?: Environmental Education Research, v. 8, no. 3, p. 239-260. [Also available at https://doi.org/10.1080/13504620220145401.]

Lee, K.N., 1993, Compass and gyroscope-Integrating science and politics for the environment: Washington, D.C., Island Press, 255 p.

Levin, S., 1999, Fragile dominion-Complexity and the commons: Cambridge, Mass., Perseus Books, 272 p. 
Ludwig, D., 2001, The era of management is over: Ecosystems (New York, N.Y.), v. 4, no. 8, p. 758-764. [Also available at https://doi.org/10.1007/s10021-001-0044-x.]

Mace, G.M., 2014, Whose conservation?: Science, v. 345 , no. 6204 , p. $1558-1560$. [Also available at https://doi.org/10.1126/science.1254704.]

Magness, D.R., Lovecraft, A.L., and Morton, J.M., 2012, Factors influencing individual management preferences for facilitating adaptation to climate change within the National Wildlife Refuge System: Wildlife Society Bulletin, v. 36, no. 3, p. 457-468. [Also available at https://doi.org/10.1002/ wsb.156.]

Martin, A., McGuire, S., and Sullivan, S., 2013, Global environmental justice and biodiversity conservation: The Geographical Journal, v. 179, no. 2, p. 122-131. [Also available at https://doi.org/10.1111/geoj.12018.]

Meadow, A.M., Ferguson, D.B., Guido, Z., Horangic, A., Owen, G., and Wall, T., 2015, Moving toward the deliberate coproduction of climate science knowledge: Weather, Climate, and Society, v. 7, no. 2, p. 179-191. [Also available at https://doi.org/10.1175/WCAS-D-14-00050.1.]

Miller, T., Baird, T., Littlefield, C., Kofinas, G., Chapin, F.S., III, and Redman, C., 2008, Epistemological pluralism-Reorganizing interdisciplinary research: Ecology and Society, v. 13, no. 2, art. 46. [Also available at https://doi.org/10.5751/ES-02671-130246.]

Mitchell, R.B., Clark, W.C., Cash, D.W., and Alcock, D., 2004, Science, scientists, and the policy process-Lessons from global environmental assessments for the northwest forest plan, chap. 6 of Forest futures-Science, politics, and policy for the next century: Rowman \& Littlefield Publishers, p. 95-111.

Ney, S., and Thompson, M., 2000, Cultural Discourses in the Global Climate Change Debate, in Jochem, E., Sathaye, J., and Bouille, D., eds., Society, Behaviour, and Climate Change Mitigation: Dordrecht, Springer Netherlands, p. 65-92.

Olsson, P., Folke, C., and Berkes, F., 2004, Adaptive comanagement for building resilience in social-ecological systems: Environmental Management, v. 34, p. 75-90. [Also available at https://doi.org/10.1007/s00267-003-0101-7.]

Pahl-Wostl, C., 2009, A conceptual framework for analysing adaptive capacity and multi-level learning processes in resource governance regimes: Global Environmental Change, v. 19 , no. 3, p. 354-365. [Also available at https://doi.org/10.1016/j.gloenvcha.2009.06.001.]
Peterson, G.D., Cumming, G.S., and Carpenter, S.R., 2003, Scenario planning - A tool for conservation in an uncertain world: Conservation Biology, v. 17, no. 2, p. 358-366. [Also available at https://doi.org/10.1046/ j.1523-1739.2003.01491.x.]

Pielke, R.A., Jr., 2007, The honest broker-Making sense of science in policy and politics: Cambridge, U.K., Cambridge University Press, 188 p. [Also available at https://doi.org/10.1017/CBO9780511818110.]

Rayner, S., and Malone, E.L., 1997, Zen and the art of climate maintenance: Nature, v. 390 , no. 6658, p. 332-334. [Also available at https://doi.org/10.1038/36975.]

Rittel, H.W.J., and Webber, M.M., 1973, Dilemmas in a general theory of planning: Policy Sciences, v. 4, no. 2, p. 155-169. [Also available at https://doi.org/10.1007/ BF01405730.]

Rounsevell, M.D.A., and Metzger, M.J., 2010, Developing qualitative scenario storylines for environmental change assessment: Wiley Interdisciplinary Reviews: Climate Change, v. 1, no. 4, p. 606-619. [Also available at https://doi.org/10.1002/wcc.63.]

Schuttenberg, H.Z., and Guth, H.K., 2015, Seeking our shared wisdom: Ecology and Society, v. 20, no. 1, 15. [Also available at https://doi.org/10.5751/ES-07038-200115.]

Shoreman-Ouimet, E., and Kopnina, H., 2015, Reconciling ecological and social justice to promote biodiversity conservation: Biological Conservation, v. 184, p. 320-326. [Also available at https://doi.org/10.1016/j.biocon.2015.01.030.]

Stanley, D., 2003, What do we know about social cohesionThe research perspective of the Federal Government's Social Cohesion Research Network: Canadian Journal of Sociology, v. 28, no. 1, p. 5-17. [Also available at https://doi.org/10.2307/3341872.]

Stedman, R.C., 2003, Is it really just a social construction?-The contribution of the physical environment to sense of place: Society \& Natural Resources, v. 16, no. 8, p. 671-685. [Also available at https://doi.org/10.1080/08941920309189.]

Swan, K., and Ice, P., 2010, The community of inquiry framework ten years later-Introduction to the special issue: The Internet and Higher Education, v. 13, nos. 1-2, p. 1-4. [Also available at https://doi.org/10.1016/j.iheduc.2009.11.003.]

U.S. Fish and Wildlife Service, 2010, Cape Romain National Wildlife Refuge Comprehensive Conservation Plan: Atlanta, Ga., U.S. Fish and Wildlife Service, 185 p. 
van Kerkhoff, L.E., and Lebel, L., 2015, Coproductive capacities: Ecology and Society, v. 20, no. 1, 14. [Also available at https://doi.org/10.5751/ES-07188-200114.]

Verweij, M., Douglas, M., Ellis, R., Engel, C., Hendriks, F., Lohmann, S., Ney, S., Rayner, S., and Thompson, M., 2006, Clumsy Solutions for a complex world-The case of climate change: Public Administration, v. 84, no. 4, p. 817-843. [Also available at https://doi.org/10.1111/j.1540-8159.2005.09566.x-i1.]

Walker, B., and Salt, D., 2006, Resilience thinkingSustaining ecosystems and people in a changing world: Washington, D.C., Island Press, 192 p.

Wall, D., 2014, The commons in history: Cambridge, Mass., MIT Press. [Also available at https://doi.org/10.7551/ mitpress/9780262027212.001.0001.]
Weaver, C.P., Mooney, S., Allen, D., Beller-Simms, N., Fish, T., Grambsch, A.E., Hohenstein, W., Jacobs, K., Kenney, M.A., Lane, M.A., Langner, L., Larson, E., McGinnis, D.L., Moss, R.H., Nichols, L.G., Nierenberg, C., Seyller, E.A., Stern, P.C., and Winthrop, R., 2014, From global change science to action with social sciences: Nature Climate Change, v. 4, no. 8, p. 656-659. [Also available at https://doi.org/10.1038/nclimate2319.]

Wiseman, J., Biggs, C., Rickards, L., and Edwards, T., 2011, Scenarios for climate adaptation-Guidebook for practitioners: Carlton, Victoria, Australia, University of Melbourne. 


\section{Glossary}

These definitions are intended to help the reader differentiate names of places, people, and concepts referenced in this document.

bridging organization or boundary organization An entity functioning in the space between science and policy to facilitate joint knowledge production through convening, communication, mediating multidirectional information flows, and translation among actors in different arenas. Such entities negotiate boundaries and provide accountability across levels while connecting and coordinating activities between actors. Members of such entities are often considered as decision brokers.

\section{Cape Romain National Wildlife}

Refuge Administered by the U.S. Fish and Wildlife Service, the refuge was designated in 1932 and consists of 26,825 hectares of coastal marsh and upland wildlife habitat. The refuge is northeast of Charleston, South Carolina.

\section{Cape Romain Partnership for Coastal} Protection A group of conservation interests, including local personnel from Federal and State agencies and nongovernmental organizations, who came together to contribute to this project. The partnership provides a forum for social learning and for exploring potential areas of conflict and cooperation in adaptation efforts.

Class 1 Wilderness A designation under the Clean Air Act (42 U.S.C. \$7401 et seq.) of air quality and visibility protection given to national wilderness areas. In 1975 , 11,735 hectares of Cape Romain National Wildlife Refuge was designated by Congress as Class 1 Wilderness.

coproduction The process of producing usable, or actionable, science through collaboration between scientists and those who use science to make policy and management decisions. commons, the Cultural and natural resources held in common, not owned privately, and accessible to all members of a society. Commons resources include natural materials such as air, water, and a habitable earth. Commons can also be understood as natural resources that groups of people including communities and user groups manage for individual and collective benefit.

engagement (in particular, community engagement) The collaborative process of working with community members and groups to address an issue that affects their lives and livelihoods (in this case, sea-level rise, population growth, and urbanization and in the South Carolina Lowcountry).

Lowcountry A geographic and cultural region along South Carolina's coastal plain, including the State's barrier islands and 10 coastal counties. Once known for its slave-based agricultural wealth in rice and indigo, the Lowcountry today is known for its historic cities and communities, natural environment, cultural heritage, and tourism industry. Occasionally appearing as "Low Country" or "low country" in some literature. The work contained in this report specifically focuses on Berkeley, Charleston, and Georgetown Counties.

modern portfolio theory An economic principle for managing risk that postulates that an "asset" should not be evaluated for investment in isolation but, instead, that a portfolio of assets be considered based on its estimated composite benefits and by how each asset in the portfolio is expected to covary with all others as market conditions fluctuate.

reserve design $A$ systematic and transparent process for planning a spatial network of land or marine parcels to accomplish conservation goals effectively. 
scenario planning, scenario analysis A technique developed by the U.S. military and the RAND Corporation to generate strategic plans based on anticipating plausible future "storylines" that combine elements of possible ecological, economic and social change. Scenario analysis allows decision makers to "test" the consequences of identified strategies under the conditions depicted by the scenarios in order that they understand the implications of a range of plausible futures.

sense of place A sociological construct used to characterize the relationship between people and spatial settings often used in relation to those characteristics that make a place special or unique, as well as to those that promote a sense of human attachment and belonging.

social-ecological environment The total environment, including social and ecological patterns and drivers and how these interact to enhance or diminish the supply of ecological goods and services desired by humans. social network Structures composed of actors who are tied to one another through socially meaningful relations. Social networks are considered to be "self organizing" when they contain sufficient diversity, connectivity, and interactions to learn and adapt with limited input from outside actors.

stakeholders Anyone with a vested interest in the social-ecological future of the Lowcountry. For the purposes of this project, the stakeholders were largely synonymous with the Cape Romain Partnership for Coastal Protection. However, this report also focuses on methods for engaging stakeholders beyond those principally interested in conservation of natural resources.

strengths, weaknesses, opportunities, and threats analysis A commonly used tool in strategic management practice for analyzing the interactions of internal and external factors important for considering future conditions and actions.

wicked problem Defined as problems that defy classification, have no definitive formulation, no stopping rule, and no test for a solution, and are unlikely to conform to a final resolution. 


\section{Appendix 1. Tracks of Tropical Storms Affecting the Lowcountry, 1910-2009}

Figures 1.1, 1.2, 1.3, 1.4, and 1.5 show hurricane and tropical storm tracks for 1910-29 and 1940-2019. No hurricanes or storms were recorded for this area for 1930-39. 


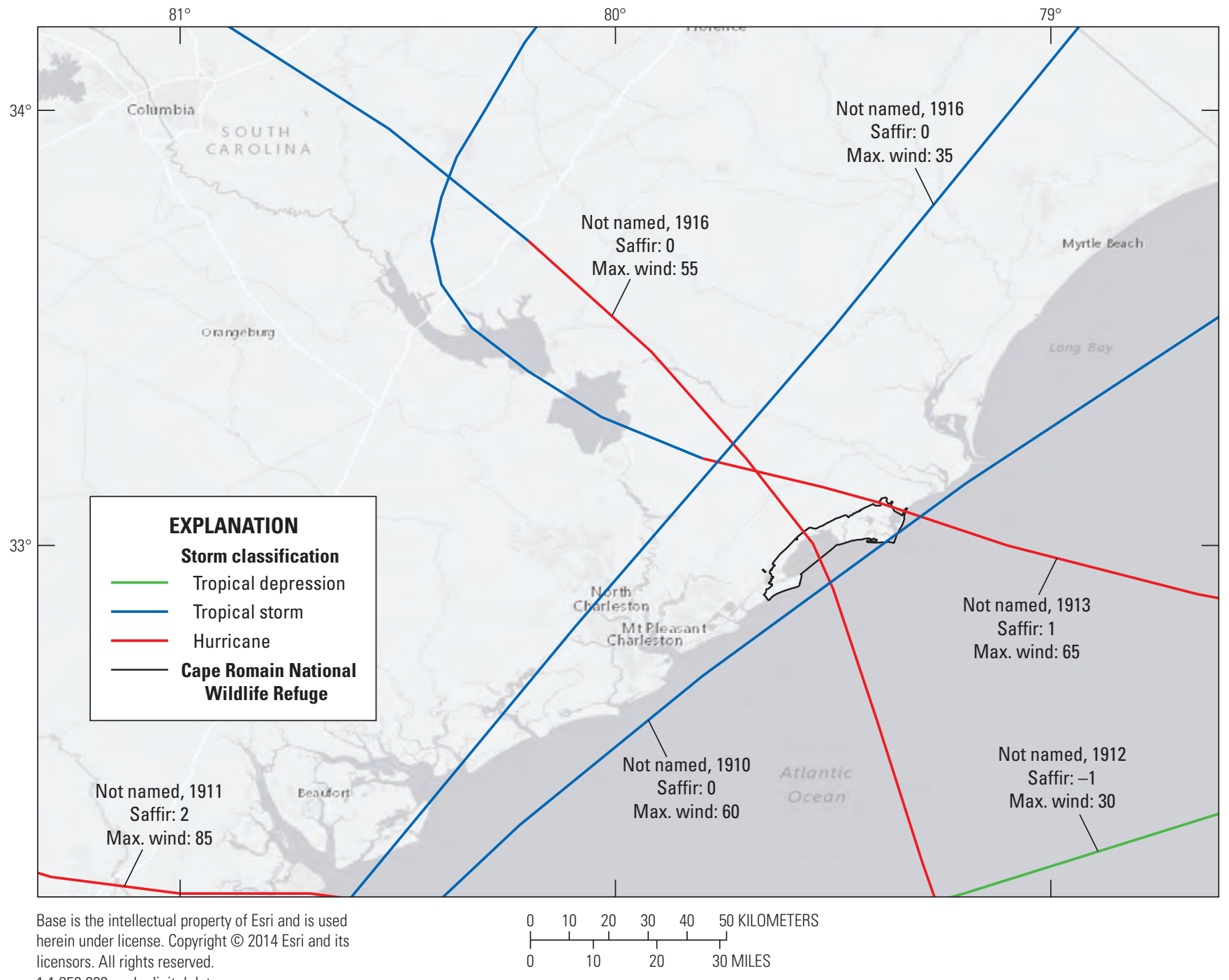

licensors. All rights reserved.

Figure 1.1. Hurricane and tropical storm tracks for 1910-19 and 1920-29. Data are from https://www.weather.gov/chs/TChistory. 


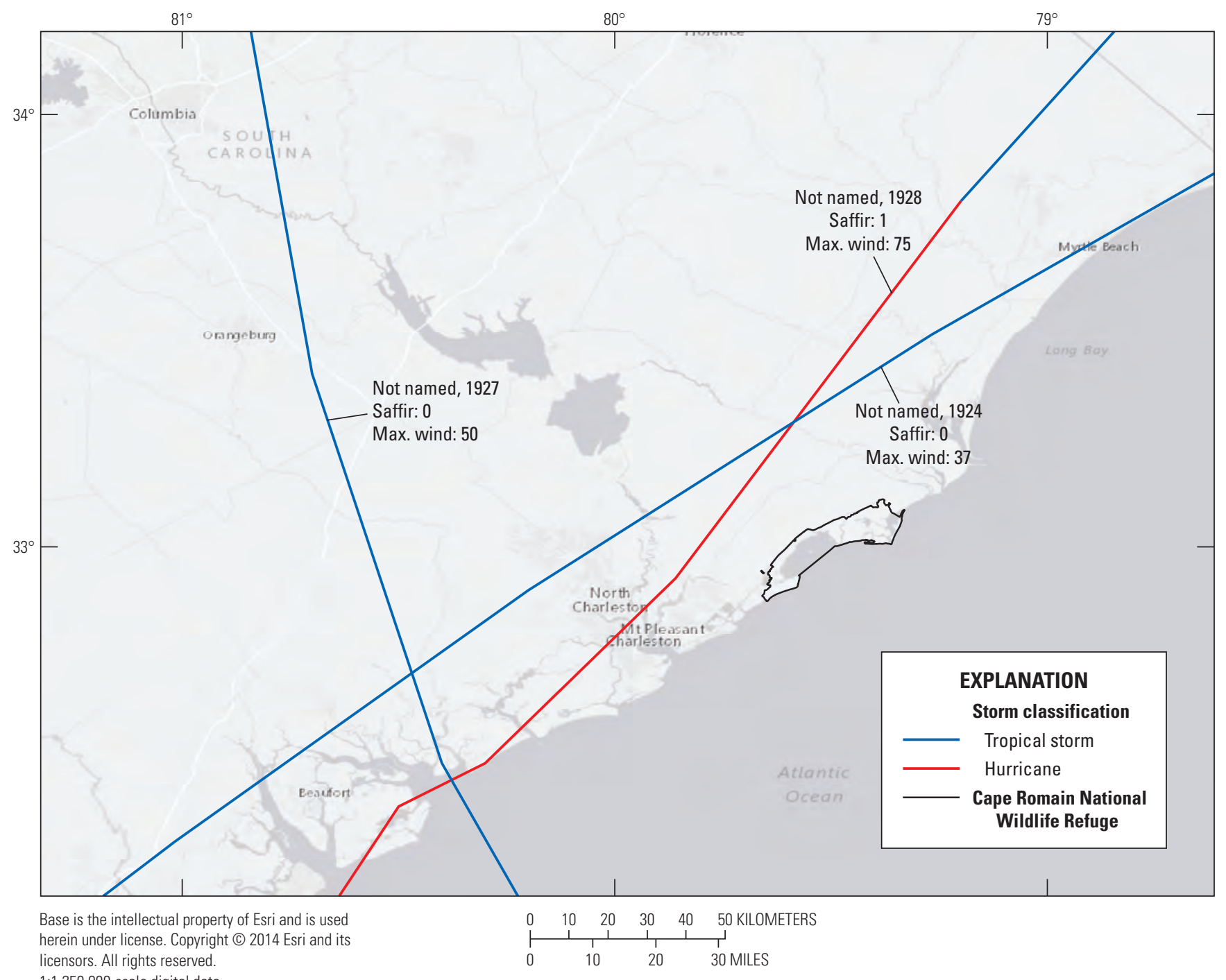

licensors. All rights reserved.

Figure 1.1.-Continued 


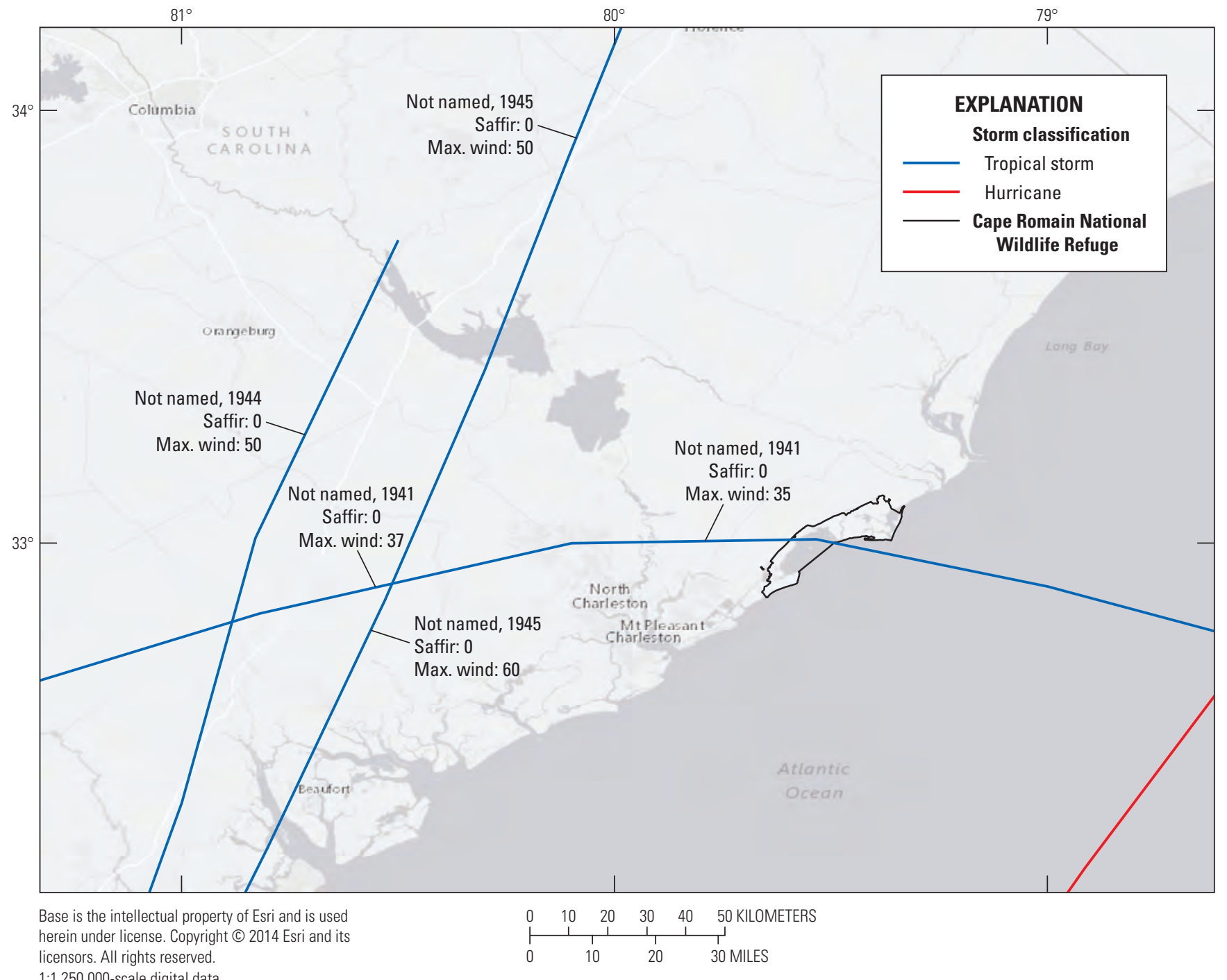

Figure 1.2. Hurricane and tropical storm tracks for 1940-49 and 1950-59. Data are from https://www.weather.gov/chs/TChistory. 


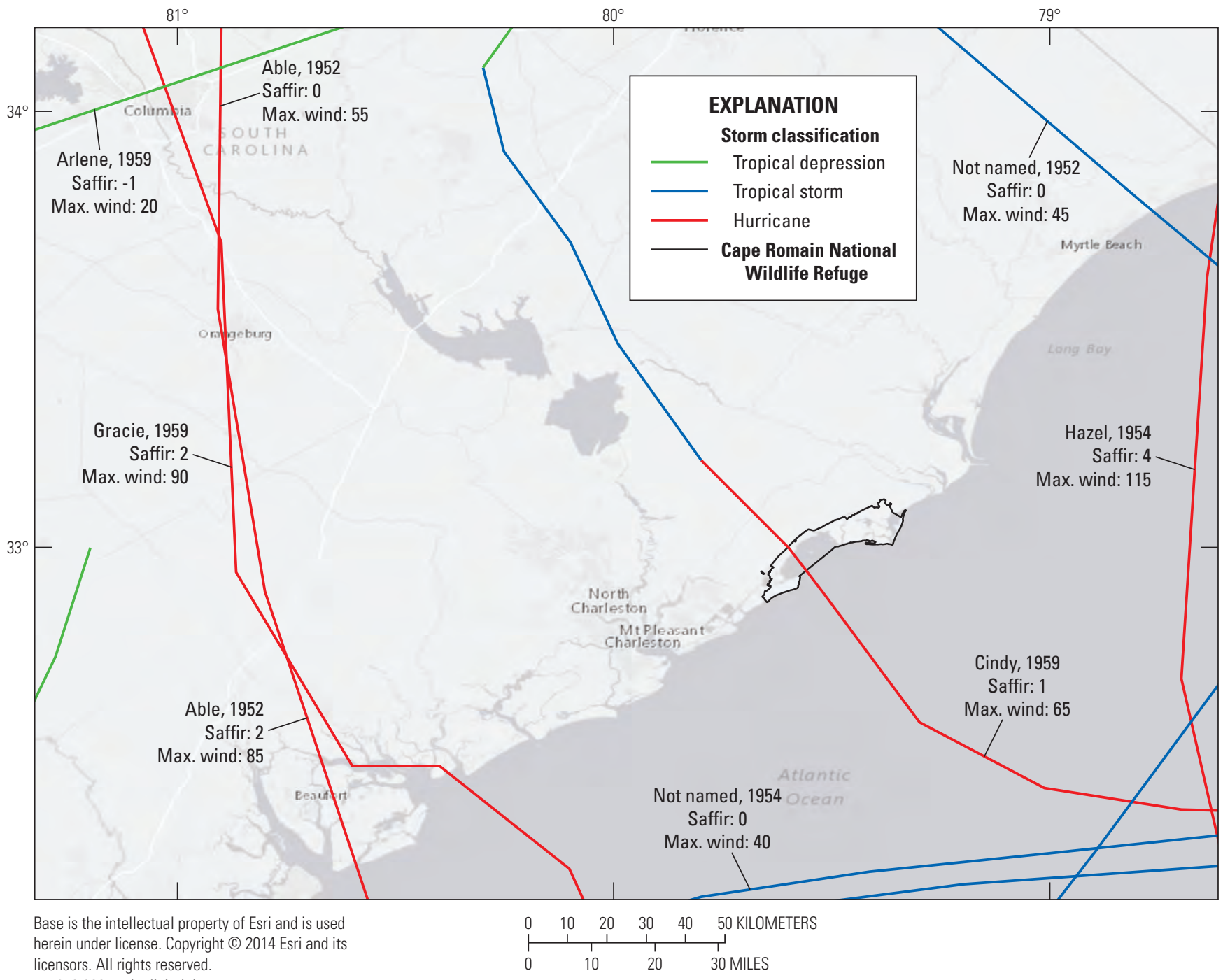

licensors. All rights reserved.

1:1,250,000-scale digital data

Figure 1.2.-Continued 


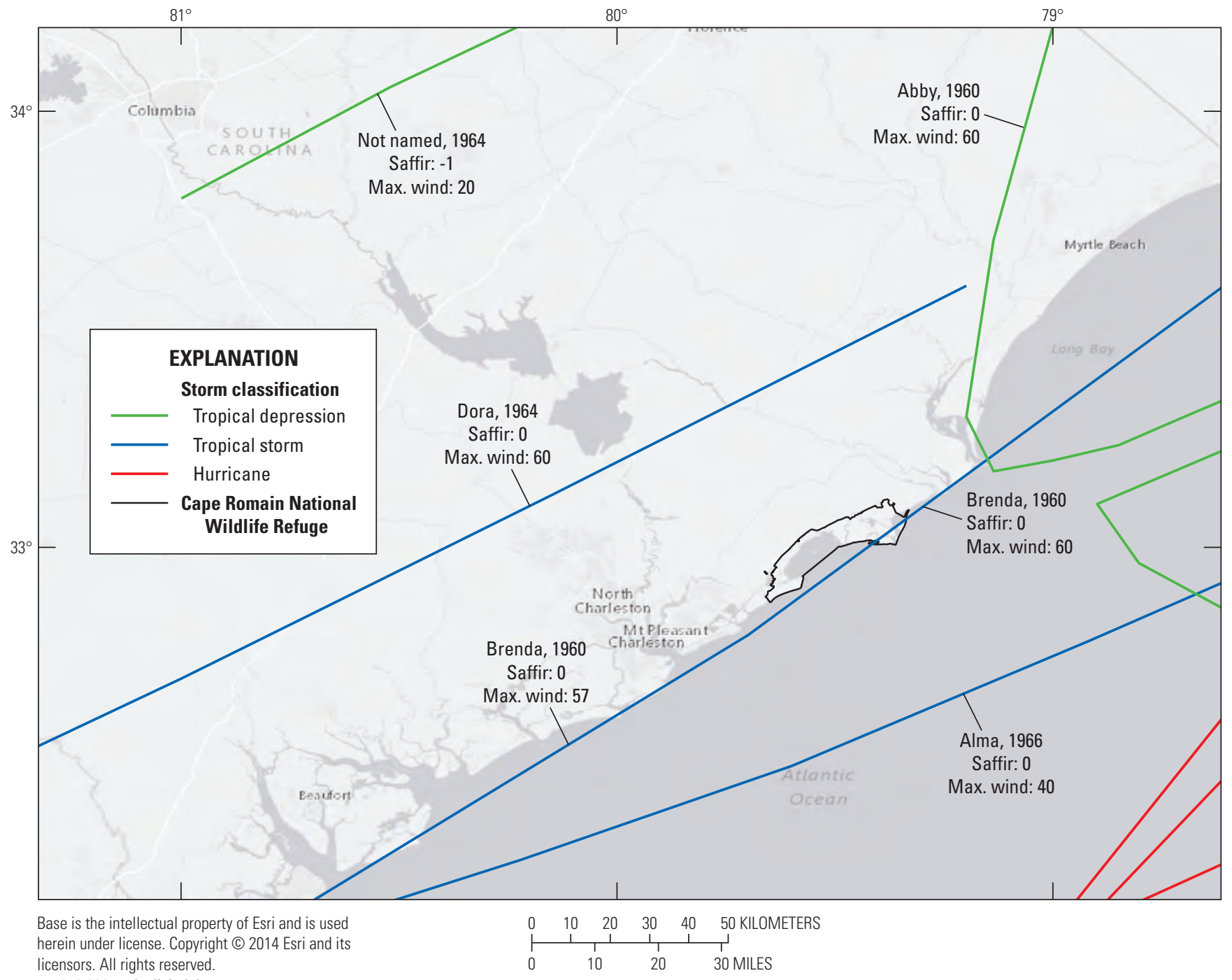

licensors. All rights reserved.

Figure 1.3. Hurricane and tropical storm tracks for 1960-69 and 1970-79. Data are from https://www.weather.gov/chs/TChistory. 


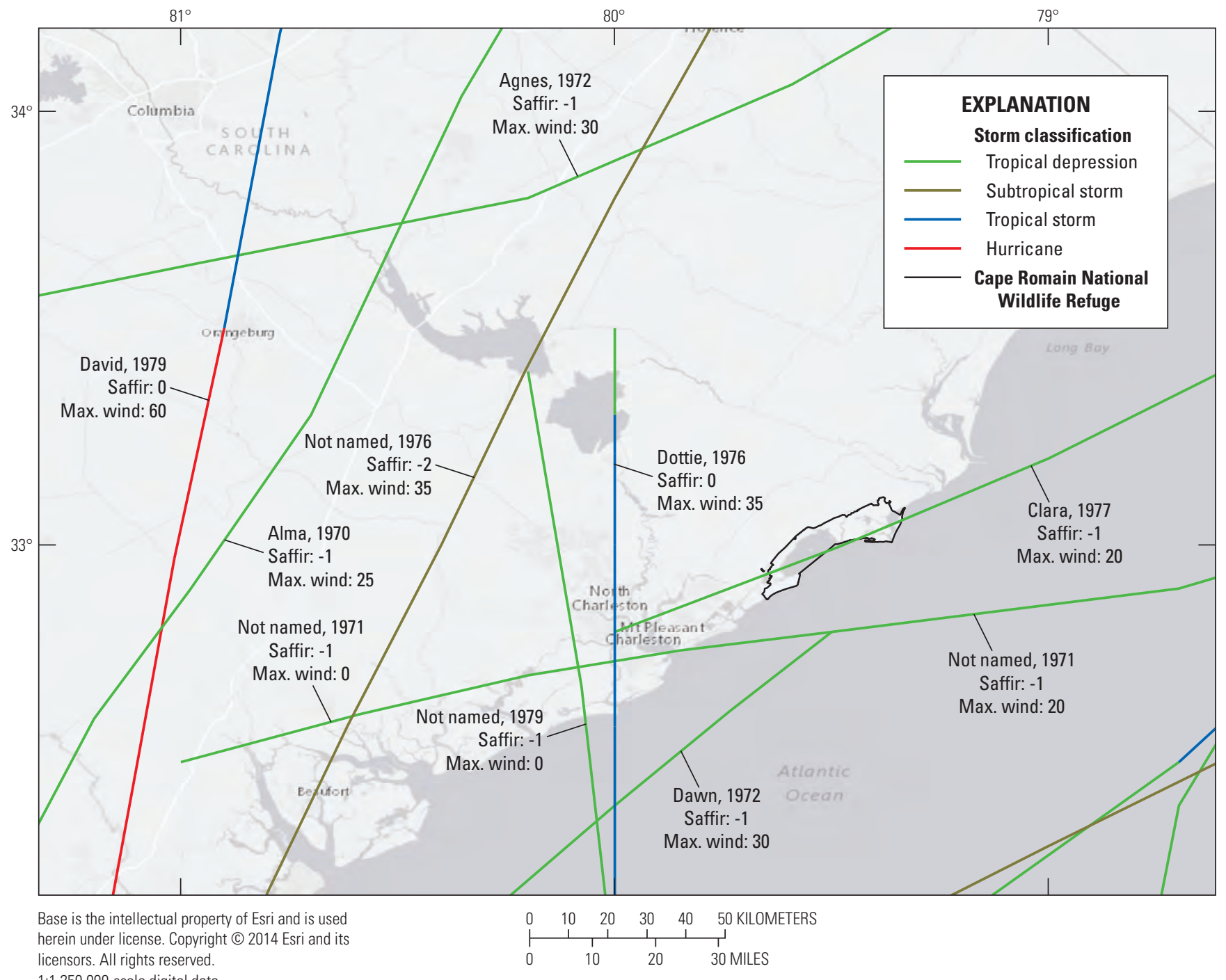

Figure 1.3.-Continued 


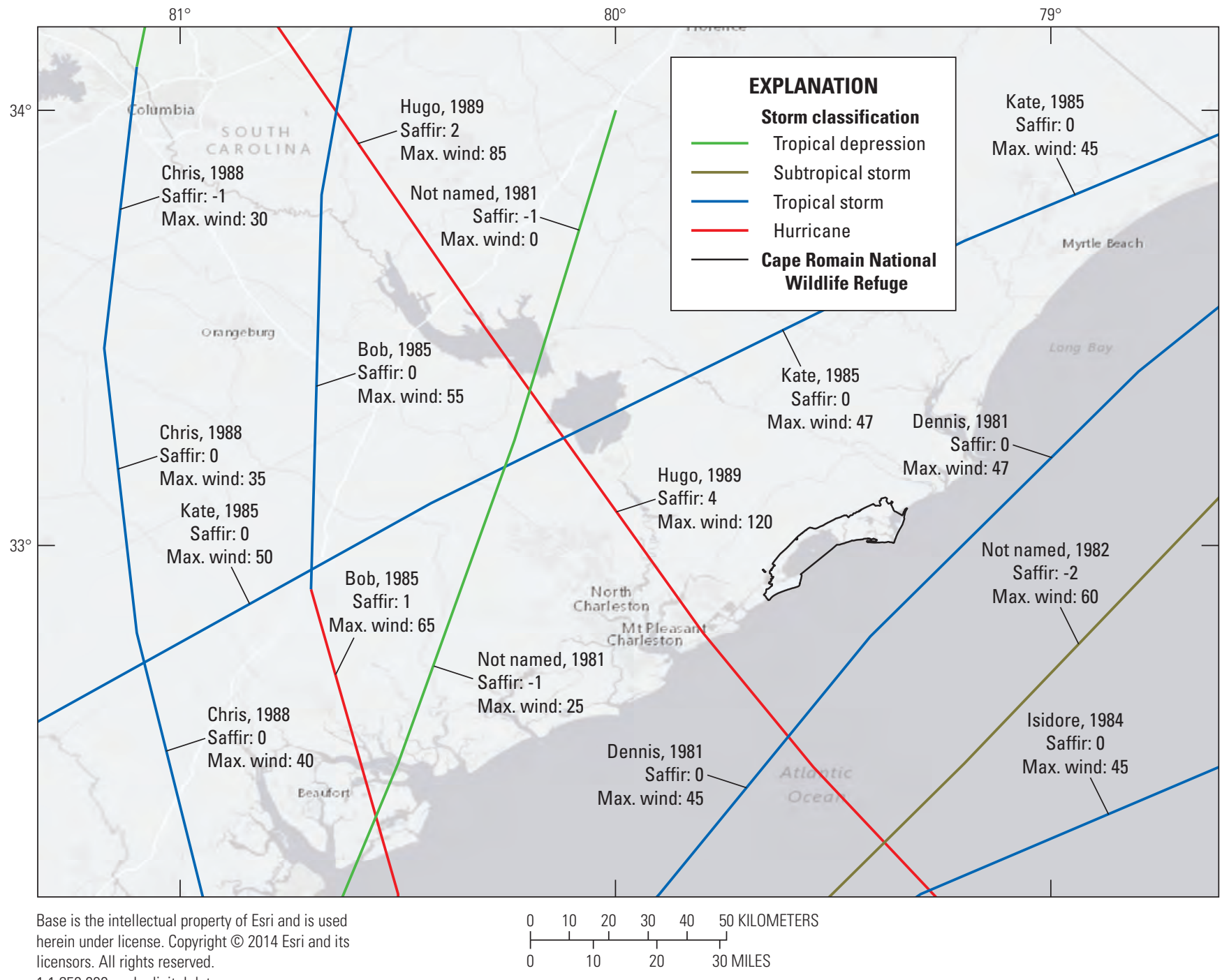

Figure 1.4. Hurricane and tropical storm tracks for 1980-89 and 1990-99. Data are from https://www.weather.gov/chs/TChistory. 


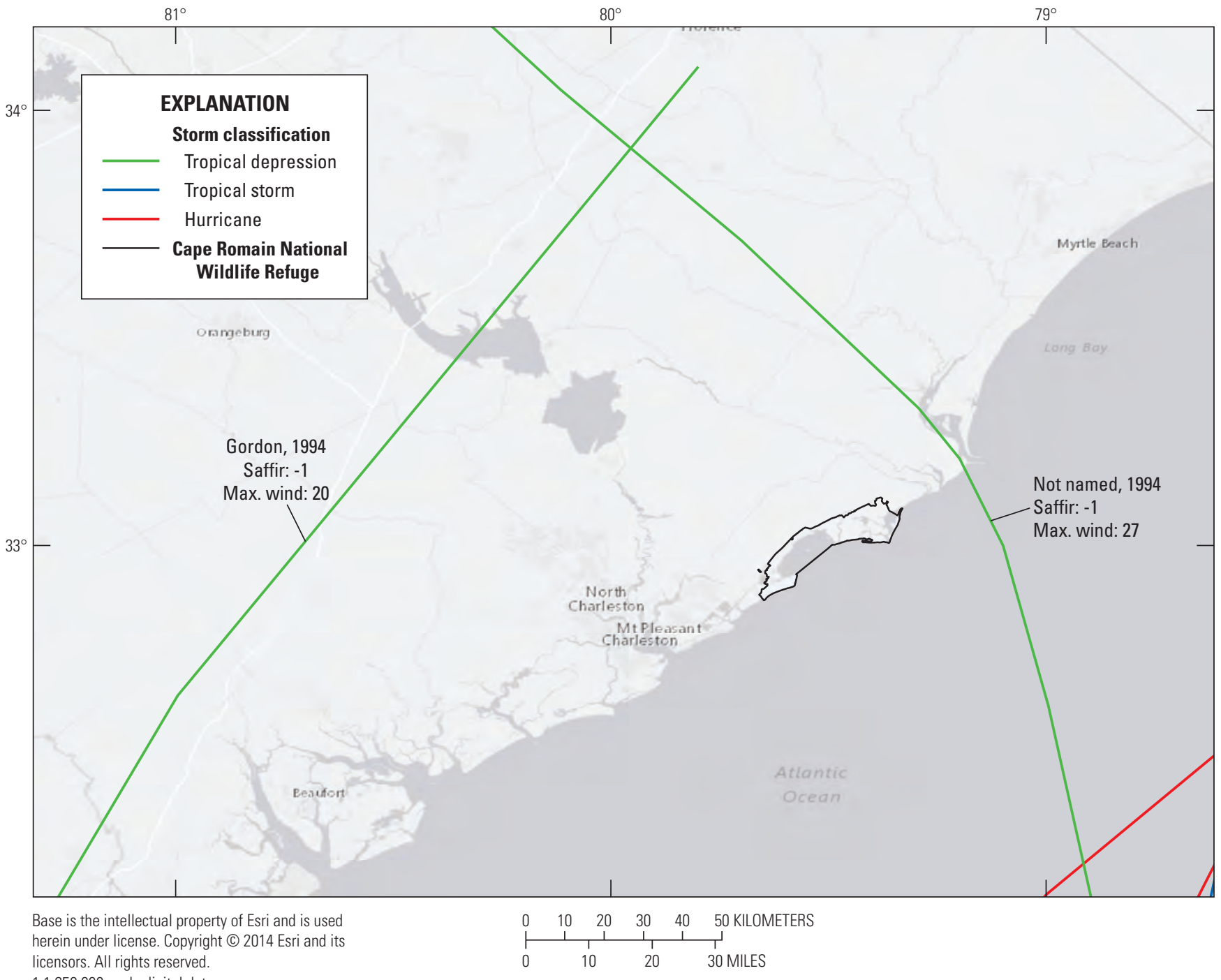

licensors. All rights reserved.

Figure 1.4.-Continued 


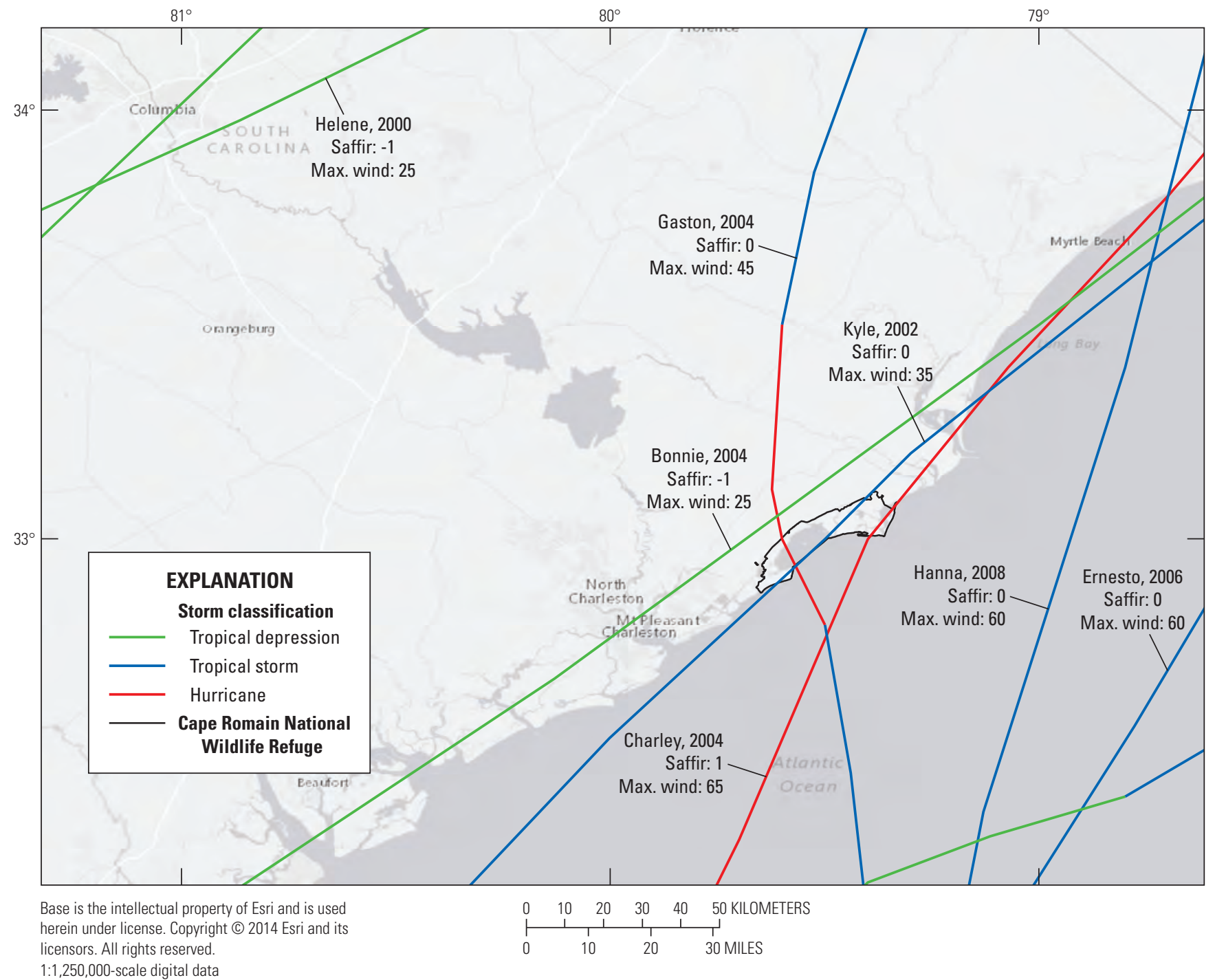

Figure 1.5. Hurricane and tropical storm tracks for 2000-9 and 2010-19. Data are from https://www.weather.gov/chs/TChistory. 


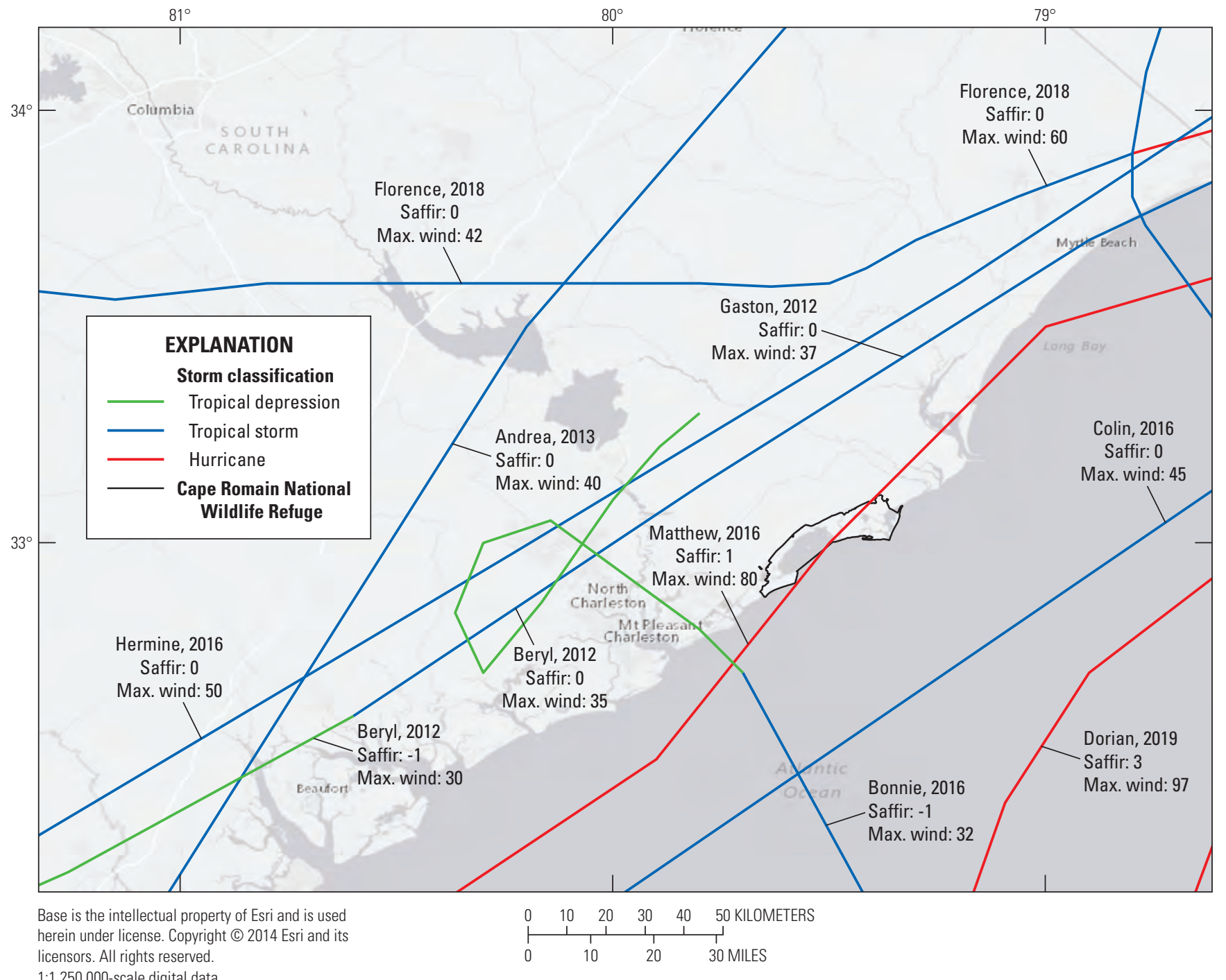

Figure 1.5.-Continued 


\section{Appendix 2. Coastal Salinity and Water Temperature Model}

Coastal ecosystems are inherently dynamic, and fluctuation of environmental conditions is a key property that determines the biological communities that they can support. The range and pattern of fluctuation of biologically important variables, such as salinity and water temperature, are sensitive to changes in land use, water management, and climate. Extremes in these conditions, exceeding historical levels, are becoming more frequent. For that reason, restoring water flow and coastal salinity regime is a current topic of interest for conservation and natural resource management. Hydrologic restoration also affects other restoration efforts, such as oyster reef, seagrass, and salt marsh, which depend on, and to some extent regulate, coastal salinity regimes. Thus, coastal salinity regime is commonly considered an important measure for gauging restoration performance at the ecosystem level (that is, broadly affecting communities) and not just a single species or habitat.

In this appendix and appendix 3, we present two methodologies for modeling and predicting the restoration performance of coastal salinity regime and oyster reef ecosystems using a combination of simple quantile distribution modeling and ecological simulation modeling. We demonstrate here an application of the coastal salinity model for filling in gaps in the data record of salinity and water temperature recorded at Skrine Creek on Cape Romain National Wildlife Refuge (NWR) from 2013 to 2018. We then use these adjusted records in simulations of oyster reef building dynamics (app. 3).

\section{Deriving Salinity from Water Flow and Temperature}

The overall approach of the coastal salinity model is to derive a time series of salinity, resolved daily, from time series of air temperature and freshwater flow, which are more readily available for longer periods of record than coastal salinity. In general, monitoring of coastal salinity is lacking in spatial and temporal coverage, possibly for the reason that maintaining gaging stations is logistically more challenging. Our approach here is to predict a daily distribution of salinity, for given antecedent conditions of air temperature and freshwater flow, representing a range that salinity is likely to fall within. As such, we do not aim to predict exact values but instead focus on narrowing the extremes and the uncertainty associated with these. This predictive approach can then be used to generate scenarios of potential future conditions under different expected patterns of change in land use, water management, and climate. We have not carried out the model as far as scenario development here but instead present a simple demonstration for filling gaps in a data record.
The application of the coastal salinity model was derived from a time series of freshwater flow data (in cubic feet per second) taken at the Santee River monitoring station (gage station 02171700; USGS, 2016a), and air temperature data (in degrees Celsius) taken from the Charleston airport (National Oceanic and Atmospheric Administration/National Weather Service Automated Surface Observing System, 32.89864, $-80.04053)$. Training data for the salinity model came from a four-year time series of coastal salinity taken at the Skrine Creek station (gage station 330428079214800; USGS, 2016b) on Cape Romain National Wildlife Refuge. This monitoring program was started by The Nature Conservancy and is currently being maintained by the South Carolina Department of Natural Resources. The site is within a tidal salt marsh creek, about 12 kilometers from the mouth of the Santee River and 4 kilometers from the Intracoastal Waterway. The Jamestown station is about 40 kilometers inshore from the Santee River mouth. The locations for these U.S. Geological Survey watermonitoring stations are shown in figure 2.1, and raw data and models are shown in figure 2.2. Figure 2.3 shows an example of quantile distributions used to derive these models.

Briefly, the model bootstraps a time series of salinity from the flow and temperature data using methods of the Coastal Salinity Index (CSI; Conrads and Darby, 2017) and the Standard Precipitation Index (SPI; McKee and others, 1993; Edwards, 1997) using quantile distributions that relate salinity training data to the long-term data. These distributions summarize the range of salinity values that are likely for a given mean air temperature or flow rate.

The CSI and SPI use a parametric gamma distribution and monthly time scale for estimating means. We refined this resolution to a daily time scale, which is the scale of the oyster model. However, this precluded use of the parametric gamma distribution, which does not accurately represent multimodal distributions, which are common at a daily scale. Instead, we took quantile distributions, which approximate the cumulative density function of salinity for a given water flow rate or air temperature. These distributions were calculated by graphing the raw salinity data against these variables and taking quantiles within a moving window along the horizontal axis. Figure 2.3 shows an example of one of these distributions.

To derive the full salinity time series, the raw salinity training data were related to the mean air temperature and water flow data over different temporal ranges of water flow. For water flow rate, means were taken over the 2, 6, and 20 days preceding each salinity data point, reasoning that the 2-day time scale represents an approximate local residence time from the Jamestown gage to Skrine Creek, the 6-day scale represents effects at the greater Santee River watershed scale, and 20 days represents seasonal patterns that can vary from year to year (for example, drought, high flow, or hot 


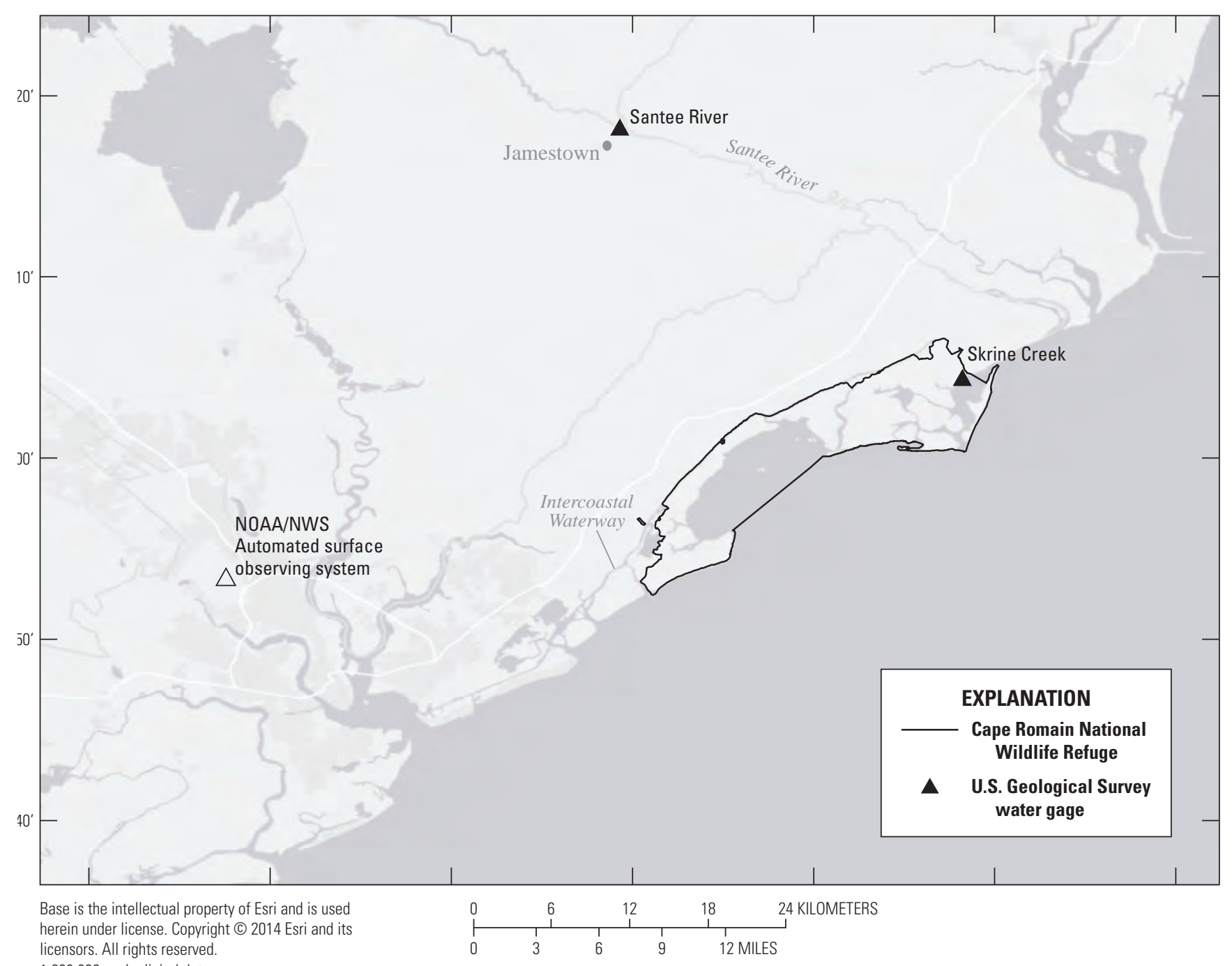

Figure 2.1. The lower Santee River and location of U.S. Geological Survey water-monitoring stations.

months). For air temperature, means were taken over 0.25 (6 hours), 2, 5, and 20 days. The 0.25 scale represents daily effects of evaporation from solar heating, which can raise and lower salinity in shallow creeks. The 2, 5, and 20 days were chosen to correspond loosely with those of flow rate, although the 5-day range had a higher correlation than 6 days, possibly because it describes atmospheric patterns and not hydrologic flow. A water temperature model was also derived using similar methods as salinity, although using only air temperature, and separate relations between air and water temperature.

Quantile distributions of salinity were determined for all these metrics and were combined to produce a daily grand salinity distribution. However, they were not all weighted equally, a few rules were adapted as a weighting scheme, and weighted averages were taken across distributions. For example, the salinity graph from Skrine Creek (raw data, fig. 2.2, middle panel) is dominated by flow rates when flows are 4,000 cubic feet per second or greater, whereas air temperature has very little, if any, effect at these high rates. Thus, a rule was set to use only the water flow distributions, and omit the temperature distributions, for days when flow rates exceeded 4,000 cubic feet per second. Additionally, under these conditions, if the first derivative of flow rate, $d F / d t$, taken over 10 days (arbitrarily chosen) was positive, (that is, flood conditions), then only the 2-day distribution was used, assuming that the Jamestown station was indicative of water flow conditions at Skrine Creek, whereas, if it was negative, (that is, ebb conditions), then all three water flow distributions were used. Other rules were included, such as assuming that evaporation is a primary factor determining salinity under low flow and hot temperature conditions. To visualize the accuracy of this coastal salinity model, the median and quantile range, 10th-90th quantile of the bootstrapped salinity time series are compared to the median of the raw salinity data in figure 2.2B. 


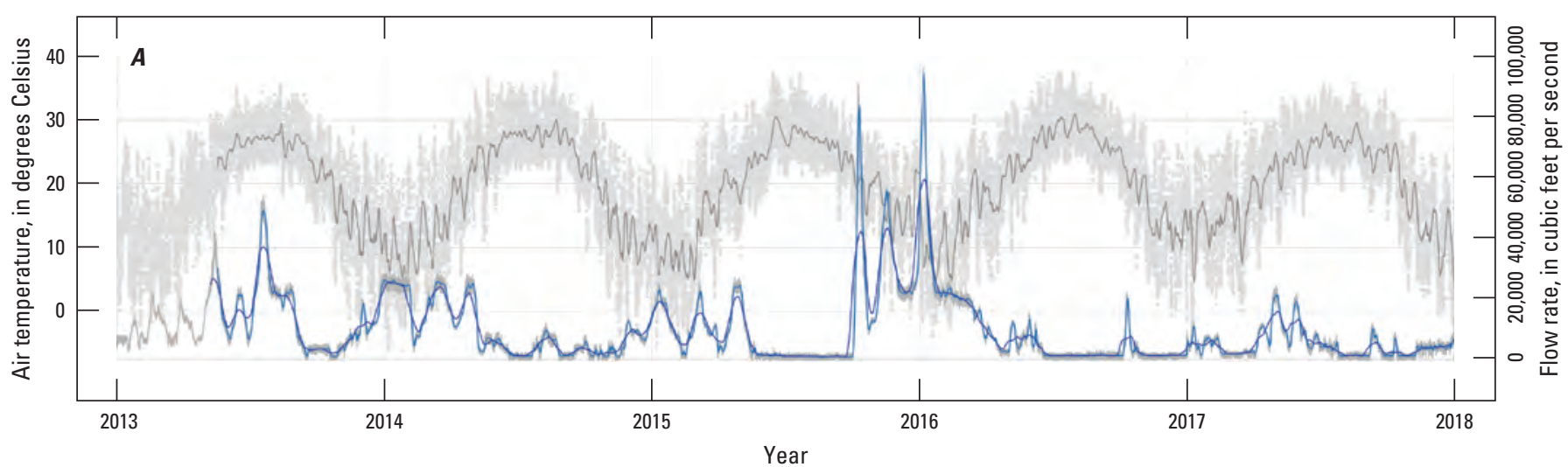

EXPLANATION

Modeled air temperature, 5-day moving average —— Flow rate, 20-day moving average Air temperature data Upstream flow rate, Santee River _ _ Flow rate, 2-day moving average

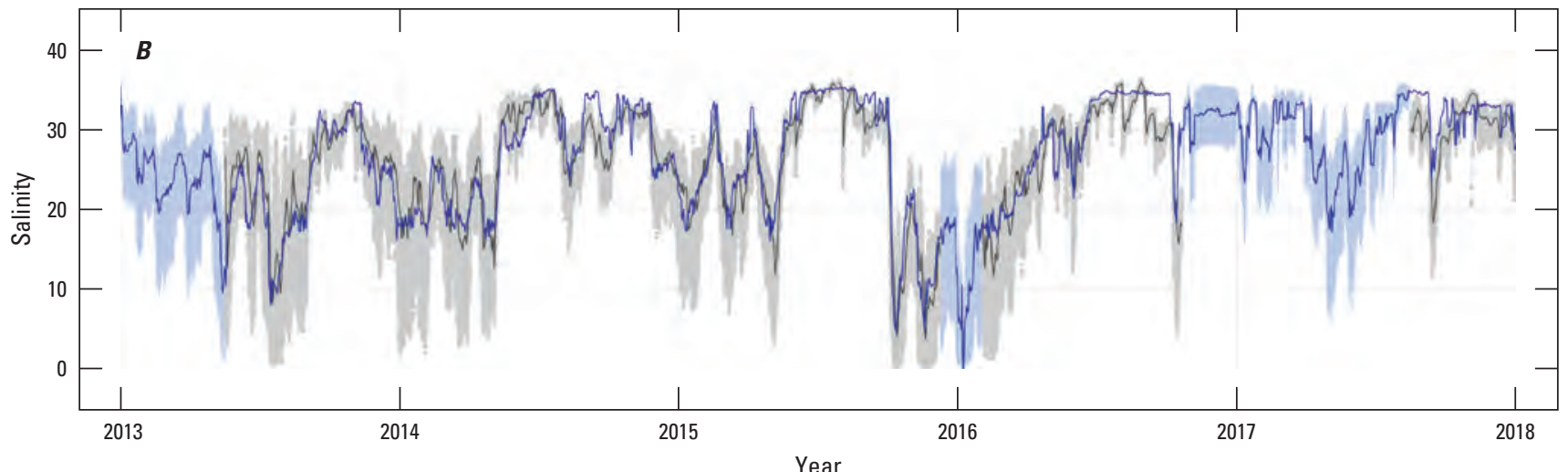

\section{EXPLANATION}

Modeled variation in salinity (data missing), quantile range $(0.1,0.9)$

Observed median daily salinity Modeled median daily salinity

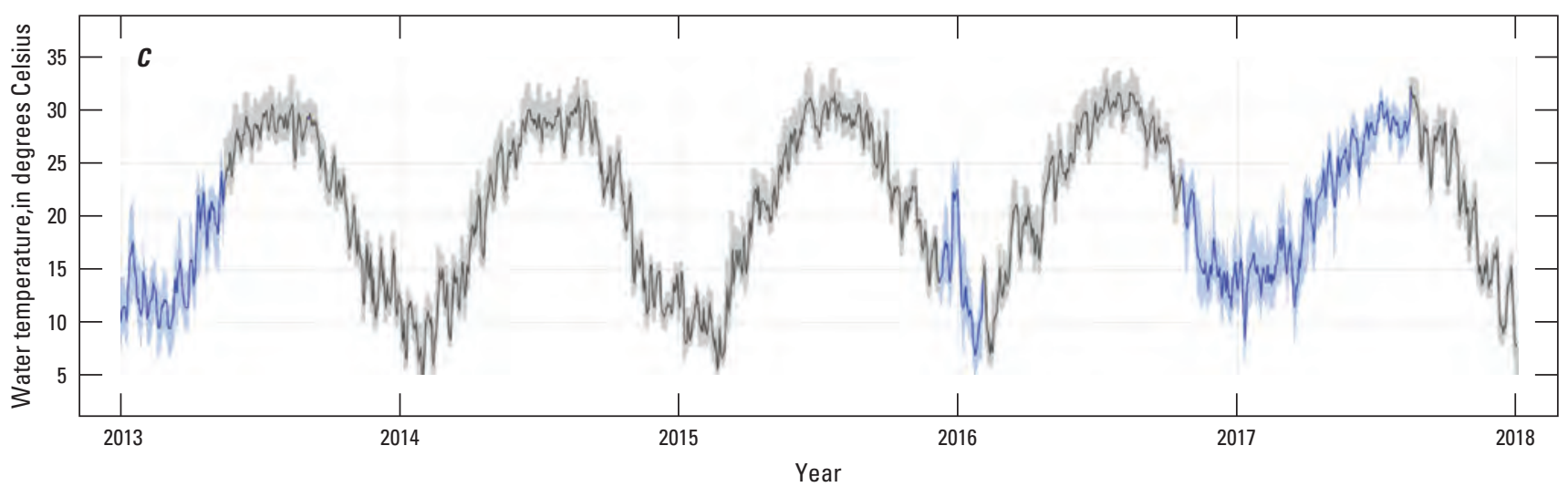

EXPLANATION

Figure 2.2. Models of $A$, upstream river flow rates recorded at the U.S. Geological Survey water-monitoring station at Jamestown, South Carolina (see fig. 2.1); $B$, coastal salinity; and $C$, water temperature derived from air temperature data collected at the Charleston, South Carolina airport. The models are shown as filling in gaps in the data record as the 10th- to 90th-quantile range of the predicted daily distributions. Daily means of the model and data are compared for salinity. 


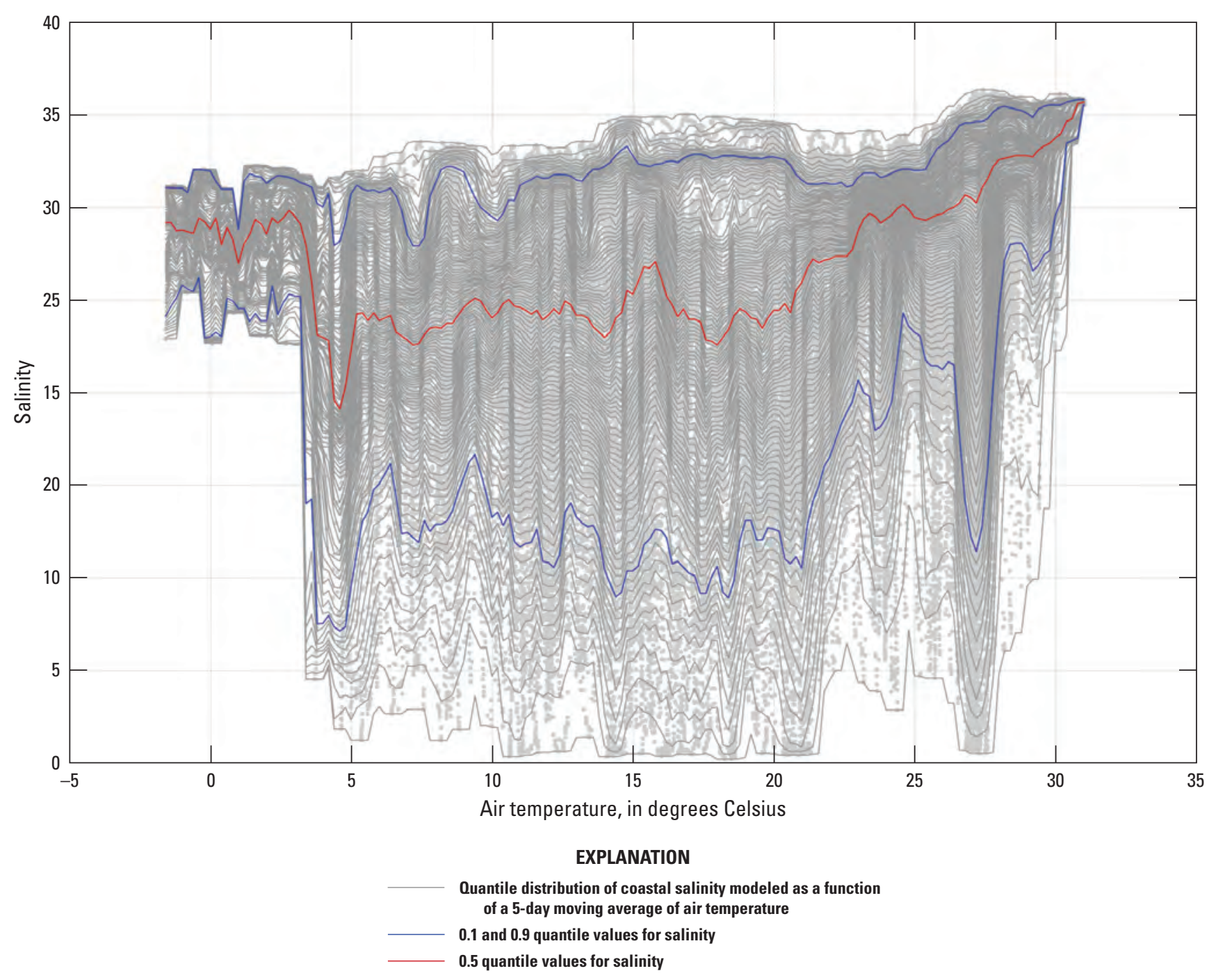

Figure 2.3. Example of quantile distributions of salinity related to the 5-day mean air temperature.

\section{Discussion}

Key questions related to restoration of coastal ecosystems in the face of global climate change include how well buffered are proposed sites to potentially large swings in environmental conditions before and after restoration? Are some sites more resilient to perturbation than others, given their landscape and bathymetric properties? In the case of oyster reef restoration, how well suited are restored reefs to sustaining their populations, when historical ranges of salinity and water temperature are likely to be exceeded at more frequent intervals in the near future? Does the reef ecosystem have regulatory properties that buffers it against this type of uncertainty?

To address these questions, we developed a model that predicts coastal salinity from nearby air temperatures and freshwater flow rates (fig. 2.2), providing links between climate modeling and management action, respectively. One main advantage of this approach is that long-term records (several decades) are available for air temperature and streamflow, whereas monitoring of coastal salinity and water temperature is not as extensive. With long-term coverage, decadal and interannual patterns of change can be identified and used as proxies for future change. For example, particularly hot or cold years can be identified and compared to the long-term average and simulated in the oyster model at different frequencies of occurrence across decades following predictions of climate models. In this way, the time scales that are relevant to oyster biology (weeks to months) can be linked to those of global climate change (decades) by finding intermediary relations between climate and ecological modeling through air temperature, freshwater flow, and salinity. We plan to continue this work to evaluate these links between ecological restoration and climatology. 
We also presented a methodology for simulating future scenarios of environmental conditions that affect oyster reef performance. These include water temperature, salinity, and terrestrial freshwater flow rates. Our approach for this was to identify ranges of fluctuation that currently occur under drought, floods, and routine water management, and to simulate variation in these patterns within predicted ranges. In this way, this coastal salinity model has the potential to be applied to develop alternative future scenarios for a given restoration site, estimating restoration performance across these scenarios, such as was done with the reserve design project.

\section{References Cited}

Conrads, P.A., and Darby, L.S., 2017, Development of a coastal drought index using salinity data: Bulletin of the American Meteorological Society, v. 98, no. 4, p. 753-766. [Also available at https://doi.org/10.1175/BAMS-D-1500171.1.]

Edwards, D.C., 1997, Characteristics of 20th century drought in the United States at multiple time scales: WrightPatterson Air Force Base, Ohio, Department of the Air Force, Air Force Institute of Technology, 97-051, Colorado State University, M.S. thesis, 174 p. [Also available at ht tps://apps.dtic.mil/dtic/tr/fulltext/u2/a325595.pdf.]
McKee, T.B., Doesken, N.J., and Kleist, J., 1993, The relationship of drought frequency and duration to time scales, in Proceedings of the 8th Conference on Applied Climatology, Anaheim, Calif., January 17-22, 1993: Fort Collins, Colo., Colorado State University, 6 p.

U.S. Geological Survey [USGS], 2016a, USGS 02171700 Santee River NR Jamestown, SC, in USGS water data for the Nation: U.S. Geological Survey National Water Information System database, accessed December 16, 2016, at https://doi.org/https://doi.org/10.5066/ F7P55KJN. [Site information directly accessible at https://waterdata.usgs.gov/nwis/inventory/?site_no= 02171700\&agency_cd=USGS\&amp.]

U.S. Geological Survey [USGS], 2016b, USGS 330428079214800 Skrine Creek near McClellenville, SC, in USGS water data for the Nation: U.S. Geological Survey National Water Information System database, accessed December 16, 2016, at https://doi.org/https://doi.org/ 10.5066/F7P55KJN. [Site information directly accessible at https://waterdata.usgs.gov/nwis/inventory/?site_no $=330$ 428079214800\&agency_cd=USGS\&amp.] 


\section{Appendix 3. Predicting Long-Term Performance and Risk of Oyster Reef Restorations Under Deep Uncertainty in Climate and Management Policy}

\section{Introduction}

Changes in oceanographic patterns (for example, sealevel rise, tropical storms, low amplitude nuisance flooding) along the U.S. Atlantic and Gulf of Mexico coast over the past few decades have led to increased public awareness and examination of the multiple protective services that coastal ecosystems can provide. Coastal habitats are now being valued for their natural resilience properties, which may be effective tools for buffering against damage caused by major storms, and for stabilizing shorelines (Costanza and others, 2008; Cheong and others, 2013); for these reasons, coastal habitats are becoming increasingly attractive for application to coastal zone management (Allen and Web, 2011; Arkema and others, 2013; Temmerman and others, 2013; Sutton-Grier and others, 2015). At the same time, human coastal communities rely heavily on estuaries and coastal wetlands for supporting local fisheries economies through recreational and commercial harvest of finfish and shellish and through additional revenues related to tourism. These economies are intrinsically linked with the productivity of the ecosystems, where collapse of a fishery can be devastating (Camp and others, 2015; Pine and others, 2015).

Because of this multiple utility value, tradeoffs are possible between managing coastal ecosystems for fisheries harvest and for coastal protection. Harvest necessarily removes biomass from the ecosystem, which can disrupt natural resilience properties. At the same time, oysters are highly plastic in their abilities to acclimate and adapt to environmental conditions, and grow and reproduce rapidly. Harvest could complement these properties if applied within naturally evolved ranges of predation. However, identifying thresholds of overfishing and detecting when it is occurring are often very difficult (Camp and others, 2015). In reality, we are somewhere in between; catastrophic collapses of oyster fisheries continue to occur, and recent changes in hydrology, climate, land use, and harvest economics over the past few decades continue to impose additional pressures, although the importance of conservation is recognized.

To better understand the ecological responses of oyster reef restoration to possible future climate and harvest pressures, we developed two new simulation models of oyster reefs (presented here) and coastal salinity (presented in appendix 2). These models were developed to be applied in conjunction because reef restoration and regulation of freshwater flows are two of the primary agents for restoring and managing coastal ecosystems in the Gulf of Mexico and Atlantic coasts. The oyster model was developed to predict restoration performance under different scenarios of hydrologic flow, climate, and harvest pressure; performance was measured as the production of ecosystem services of the reef for fisheries harvest and coastal protection (that is, regulating hydrology and wave energy). We have completed preliminary testing of the model and are now developing applications to real problems identified by fisheries and land managers who are interested in reef restoration and wish to examine effects of different types of uncertainty in environmental conditions and harvest policy.

This model was developed to address five primary areas of research: (1) understand the underlying reef structure that supports oyster populations, (2) learn about the establishment period and long-term viability of reefs after restoration, (3) understand the dynamics of coastal salinity and oyster reefs, which interact to affect reef performance, (4) set predictions that can be tested through monitoring, and (5) determine the feasibility of and appropriate timing for opening restored reefs to fishing. These points represent potential future applications of the model, which can be developed through partnerships with State and local agencies and organizations. In this appendix, we demonstrate a simple, preliminary application that estimates oyster reef responses to the salinity and temperature conditions modeled in the previous section.

\section{Oyster Reef Simulation Model}

Oyster reefs are self-organizing ecosystems, meaning that they create, modify, and maintain habitat and conditions that benefit the oysters and the reef ecological community (Wilberg and others, 2013, Yurek and others, 2021). The structure of the reef is dynamic, interacts with the physical environment, and is a function of shell production from live oysters, persistence of deposited dead shell, and exogenous factors of hydrodynamics and estuarine chemistry that break down and scatter the shell (Bahr and Lanier, 1981). We developed a simulation model of the oyster reef building process that tracks reef dynamics across levels of the individual, population, and physical reef structure so that ecological effects that scale across these three levels can be tracked.

We used existing models of oyster bioenergetics, shell longevity, and budget, and population dynamics to build a new three-dimensional model of the reef system. The model tracks the dynamics and interactions of individual oysters, oyster shell substrate, and recruits, applying a complex dynamic energy budget (DEB, Lavaud and others, 2017) to regulate allocation of energy to growth and maintenance of tissue, shell, and gonad for individual organisms over their lifecycle. 
Live oysters and reef shell were tracked explicitly, and reproduction was modeled as a combined process of gamete production, larval survival, and spat settlement.

Our oyster simulation model was developed to assist in planning for oyster reef restorations and to accommodate limitations in the availability and spatial and temporal coverage of monitoring programs. To do this, we combined previous modeling efforts developed over the past 25 years that include models of oyster DEB (Lavaud and others, 2017), shell persistence on the reef (Powell and others, 2006; Powell and Klinck, 2007; Harding and others, 2010; Southworth and others, 2010; Kuykendall and others, 2015), management of shell budgets (Soniat and others, 2012), oyster population dynamics (Pine and others, 2015), and relationships of growth and mortality to environmental factors (Hofmann and others, 1992, 1994; Powell and others, 1992; Soniat and others, 1998; Wang and others, 2008, 2017; La Peyre and others, 2016; Lowe and others, 2017).

Two important features of reef ecosystems are that live adult oysters, shell, and recruits all occupy space on the reef, and as the reef accretes in biomass, its overall area and height approach a limit determined by the balance between accretion rate and intertidal hydrodynamics (Bahr and Lanier, 1981). Thus, some reduction in one or more of these groups is necessary to make room for the others, both during the process of accretion and at maximum height, so that the reef can steadily accumulate and maintain shell biomass to balance what is lost to degradation (Powell and others, 2006; Powell and Klinck, 2007). Key feedbacks occur in the simulation model as the oysters, shell, and recruits interact with environmental conditions during the reef accretion process and when the reef approaches capacity. One critical variable affecting reef accretion is the turnover rate of shell boxes, which are intact shell valves made available after adult mortality, that also degrade through exposure to the physical environment (Powell and others, 2006). Changes in this variable affect the total available surface area for spat settlement, which in turn affects the reef accretion rate and the size structure of the oyster population through time.

Reefs occur in many states of accretion, and at different water depths, in the intertidal and subtidal zones and generally have an upper limit to their accretion height because of a combination of constraining factors at the reef crest, such as temperature and light exposure, and increased hydraulic force (Lenihan, 1999). This model represents these dynamics in three modules that describe (1) oyster population biology, (2) a three-dimensional structure of the reef, and (3) regulation of wave energy by this structure (fig. 3.1). Module 1 describes the biological and ecological processes of oyster population dynamics, and module 2 describes the relation between population dynamics and reef volumetric structure. These two are fully coupled (arrows in fig. 3.1); the reef volume and surface area impose constraints on oyster growth and reproduction, and living oysters supply biomass to fill out the reef. Module 3, the effect of wave energy on oyster population dynamics, is still in development and currently represents the ecosystem service of wave attenuation as a model output. However, in the future, this module can be further developed to represent a feedback on oyster biology (growth and reproduction).

The model presented here tracks individual live oysters in units of energy (joules) allocated to growth and maintenance (Lavaud and others, 2017) and reef shell in units of wet biomass (grams). Previous models of oyster growth used oyster size classes and tracked abundance within these classes (Hofmann and others, 1992; Powell and others, 1992; Pine and others, 2015), whereas the shell models used either densities on a reef (Powell and others, 2006; Powell and Klinck, 2007; Kuykendall and others, 2015) or harvestable sack units (Soniat and others, 2012). We sought to standardize units across these studies by modeling a complete organism at the individual level and tracking how the dynamics of the three reef components, live oysters, boxes, and crushed shell, scale up to define the population and reef structure. However, because previous studies tended to examine tissue and shell separately, data on a whole organism are generally not widely available across the southeast region, except for a few targeted studies. We acknowledge that these studies span populations that may vary greatly in metabolic rates and population dynamics and that it is important to know the specific dynamics of the populations being managed whenever possible because the success and persistence of reef restorations are likely to be sensitive to these variables. This model is therefore intended to be used to set baseline predictions for understanding reef dynamics and can be updated as new data become available.

The basic components of the oyster biological model (live oysters, shell substrate, and recruits) are as follows. Live oysters represent all ages post-settlement (juvenile and adults) and are tracked explicitly as individuals (called "adult" here for simplicity).These are modeled as a whole organism composed of tissue, gonad, and shell (measured in joules), and allocations of food intake to these groups, mediated by a storage buffer, are regulated by complex energy flux equations (Lavaud and others, 2017). Shell substrate is all shell deposited postmortality and is tracked explicitly as individual boxes that retain concave structure and also implicitly as a crushed shell pool. These two variables are described by equations representing shell degradation rates. Reproduction is modeled as the combined process of gonad growth, gamete production, a larval pool, and spat that settle on the reef as individuals. Spat settlement dynamics are a function of the available shell area of live oysters, boxes, and crushed shell, which are calculated as physical morphometrics of the reef.

Exogenous factors affecting oyster metabolism and population dynamics are salinity, temperature, food availability, inorganic suspended solids, and predators (Powell and others, 1994; Pine and others, 2015; La Peyre and others, 2016). The first three environmental variables all affect oyster metabolism and are modeled as time series that could potentially have varying patterns under different future scenarios of climate 


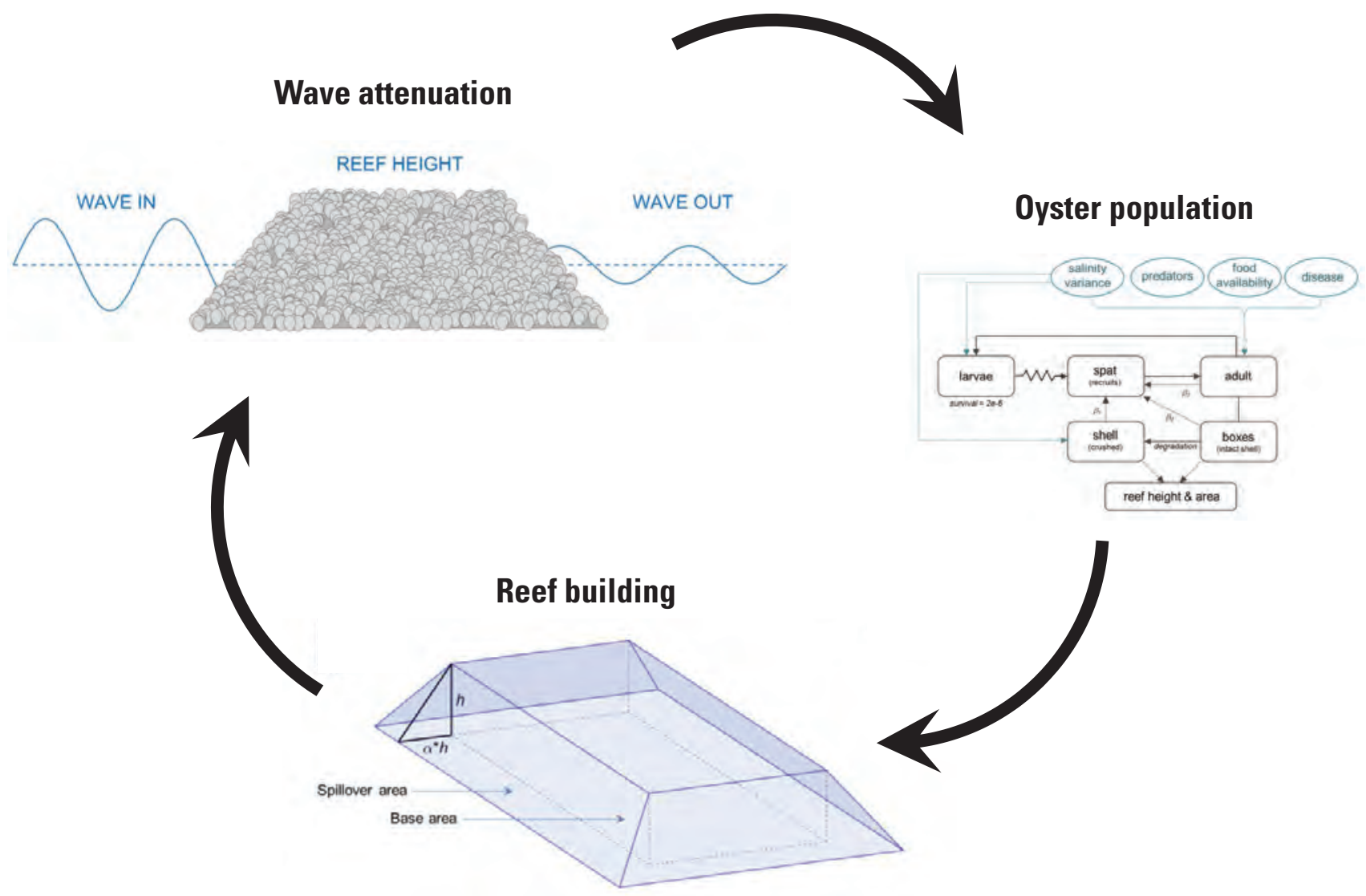

Figure 3.1. Overview of oyster reef simulation model composed of three modules: oyster population, reef building, and wave attenuation. Arrows indicate hypothesized feedbacks between modules. The wave attenuation model and figure were adapted from Allen and Webb (2011), and the feedback on oyster biology is currently inactive.

change and variability. Sources of mortality currently included in the model are predation, burial, natural mortality, and terminal age, each described by separate equations in the model. Disease and harvest policy, modeled similar to predation, are also included but for our purposes here are turned off because they represent special, complex problems and will be treated in future modeling studies.

\section{Preliminary Results}

We summarize the functionality of this model by presenting results of two sets of simulations: one that models a 100-year time series with recruitment dynamics included and another that has recruitment turned off and tracks an initial population through to its extinction (about 20 years). The first set (long run) demonstrates oyster population and reef dynamics through time, and the second set (extinction) allows for easier examination of individual dynamics. Both sets of simulations use time steps of 1 day.
For both the long run and extinction sets, restorations were simulated on the first time step of the model runs by stocking an initial oyster population at a density of 400 square meters over a base reef area of 200 by 1,000 centimeters. The oysters were assumed to be the size of spat (energy reserve was $3.698 \times 10^{-5}$ joule; volume was $8 \times 10^{-9}$ cubic centimeter), and reef height was assumed to begin at zero centimeters. Oysters were not assumed to be particularly vulnerable at this low reef height, for our purposes here, although this is recognized to be a factor (Colden and others, 2017). After these initial conditions, no other external sources of oysters, larvae, or shell were applied to the reefs throughout the remainder of the simulations; and for the long-run scenario, reefs were assumed to be self-recruiting.

Environmental conditions were applied by looping a selected 1-year subset of the data record successively over the several years of the simulation run. The purpose of this was to remove interannual and lagged effects that could carry across years, for simplicity here, and to examine potential variations in population dynamics for different patterns of salinity and temperature. The modeled salinity and water 
temperature distributions described in the previous section were used. These were derived from data recorded at the U.S. Geological Survey station at Skrine Creek on Cape Romain National Wildlife Refuge, South Carolina, (gage station 330428079214800; USGS, 2016). For the extinction scenarios, each of the 5 years, 2013 to 2017, was applied in separate simulations. The chlorophyll $a$ time series used in the model was taken from a long-term monitoring station in a nearby watershed, at North Inlet in Winyah Bay, S.C. (station code NIWOLWQ), part of the National Oceanic and Atmospheric Administration's National Estuarine Research Reserve System. We recognize that these data may not be accurate for Skrine Creek, although nutrients are not necessarily limiting in South Carolina (chlorophyll $a$ values are high relative to other areas).

Results of the long-run simulations are presented in figure 3.2. The top two panels show the dynamics of the reef volumetric structure and surface area available for spat settlement, respectively. The bottom two panels show oyster population dynamics as biomass and individual density summarized by size classes, respectively. For the latter, size bins were taken from previous modeling studies (for example, Soniat and others, 2012), for purposes of comparing to those, although the model is individual based. The general trend in this simulation is that the reef slowly accretes in biomass up to about year 85, where it reaches maximum height (chosen by the user). For the remainder of the simulation (years 85 to 100), reef height and shell biomass remain stable (top panel), although the available settlement area (second panel) and oyster population demographics (bottom panel) go into significant oscillations. Interestingly, the periods of oscillation of settlement area (1 year) and demographics (5-7 years) occur at different time scales. In other simulations with different parameters (not shown), the reefs demonstrated varying dynamics, including one simulation where the reef accreted very quickly (perhaps unrealistically) and then went into unstable oscillations (rapid increase and loss of biomass) and another that never reached maximum height.

The oyster model also tracks mortality through time, as shown in figure 3.3. This helps to visually check that the dynamics are behaving reasonably. For example, natural mortality and predation are complex functions that are related to individual density and size (not described here). However, their levels are fairly consistent through time, suggesting that these sources support stable reef dynamics through time. Interestingly, large oscillations in burials for this scenario are possible (years $60-70$ and $80-90$ ) without greatly affecting the stability of the reef.

Results of the simulations with recruitment turned off (extinction scenario) are shown in figures 3.4, 3.5 and 3.6. These simulations have a population initiated at time step 1 , stocked at a density of 400 individuals per square meter and declining to zero, representing the dynamics of a single cohort under low total population density. Figure 3.4 shows the simulation that loops one year of environmental conditions for 2013. This population grows in total biomass in the first 6 years (fig. 3.4A) and rapidly loses individuals in the first 3 years, primarily spat and juveniles (fig. 3.4B). Note spat densities are not shown but begin at 400 and decline to about 170 individuals per square meter at around 0.5 year, at which point they grow into the juvenile class. This population then slowly declines until extinction at about year 22 (fig. 3.4B). Boxes that degrade to become crushed shell are also shown (fig. 3.4B).

The dynamics of oyster shell biomass and surface area of the reef for the 2013 simulation are shown in figure 3.5. Biomass is summed across live individuals and across dead boxes, with reef height shown for comparison (fig. 3.5A). Shell surface areas are calculated as the total geometric area summed across individuals (solid lines), and as the total area available for settlement (dotted lines; fig. 3.5B). Total and available area differ because a part of the total area is assumed to never be settled, and an additional part becomes unavailable when occupied by other oysters (only in the long-run example; fig. $3.5 \mathrm{~B}$ ). The grand total of available settlement area summed across all shell types, is shown in the bottom panel (fig. 3.5C). Note that the reef height is driven largely by the dynamics of the shell boxes (top panel), which break down and contribute to the crushed shell pool that comprises reef volume. Also, the surface area of shell boxes (middle panel, red lines, left axis) is greater than that of live oysters (middle panel, blue lines, right axis) because both sides of each valve (four total) are counted for boxes, whereas only two sides of a live oyster are considered exposed.

Population biomass is compared across the five simulations that respectively loop years 2013 to 2017 separately (fig. 3.6). The overall pattern of population growth and decline is similar among these; however, they have different extinction dates. The 2013 population persisted for about 22 years (fig. 3.6A), whereas the 2017 population went extinct at about year 19 (fig. 3.6E). The 2017 population produced the most total biomass (about $2.3 \times 10^{5}$ kilograms) and the 2013 population the least (about $2.3 \times 10^{5}$ kilograms). Water temperatures for 2013 were generally the lowest of the 5 years and 2017 the highest (fig. 3.1); however, 2017 had a large amount of filled data compared to others, and water temperatures may have been artificially raised for winter months.

Finally, individual densities are compared across the year simulations in figure 3.7, for selected size classes, with years distinguished by colored lines. The top panel shows the period when the population grows into the adult size class (50-75 millimeters), at approximately 0.75 to 1.5 years, and similarly into the marketable sack class (greater than 75 millimeters), around year 1.5. Year 2017 is the first to reach marketable size, followed by 2016, with 2013 last. After the initial transition into this size class, all years maintain their marketable densities at roughly the same relative rate (not shown) before going extinct. This similarity could be because the sources of mortality included in the model (presented here) are not particularly sensitive to variations in salinity and temperature, which can be adjusted for future modeling. The general pattern of increase and decrease in box density through time 

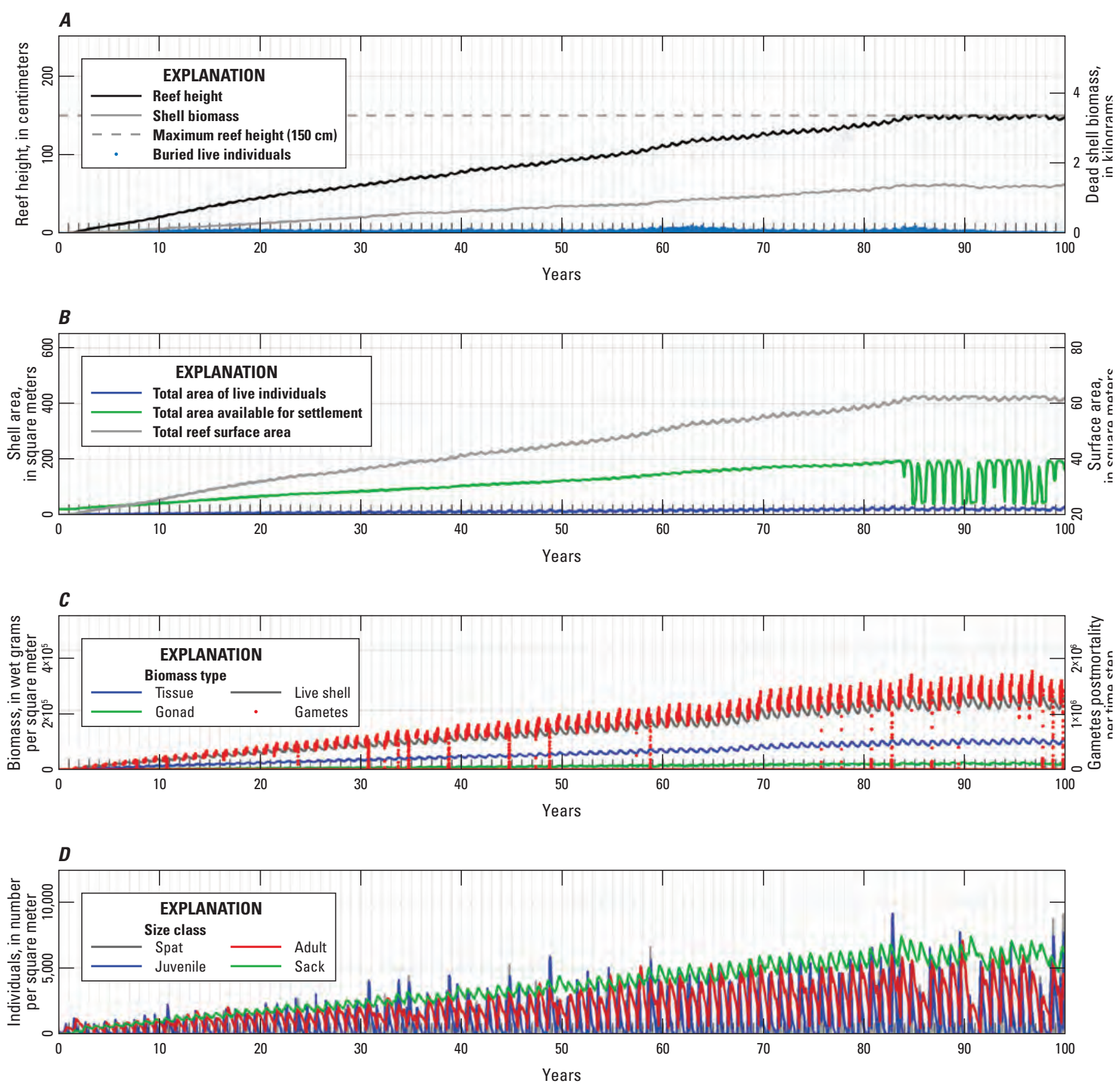

Figure 3.2. Oyster reef and population dynamics simulated through time over 100 years.

(bottom panel) of the five simulations is generally similar; however, 2017 has consistently the highest number of boxes and 2013 the lowest. Interestingly, 2016 has a rapid increase in box density from years 1 to 3 , compared to the others, followed by intermediate levels. This result could be because the environmental conditions are much more dynamic that year (high amount of salinity variance because of upstream flooding), which affects the degradation rate of boxes. 

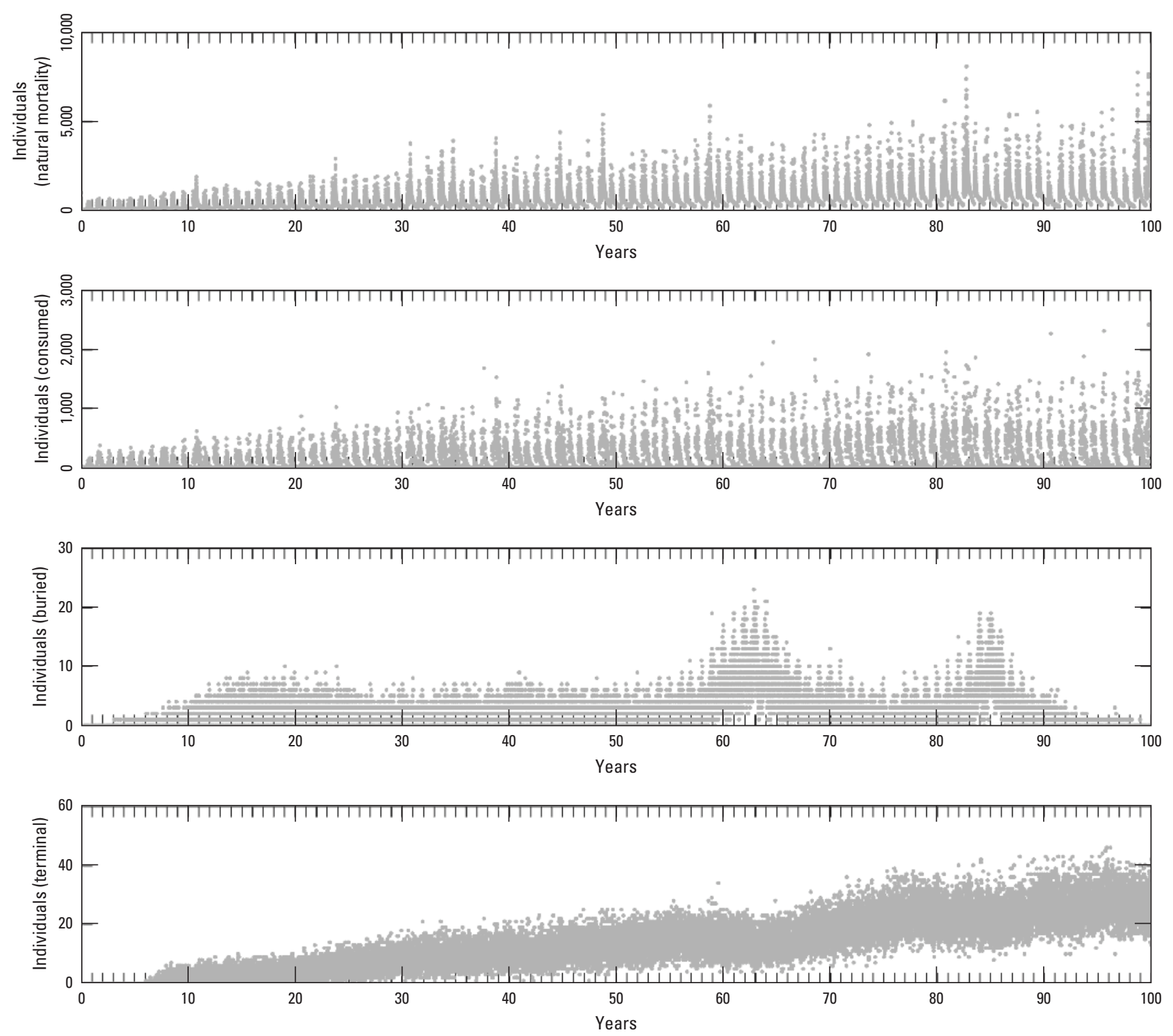

Figure 3.3. Results of oyster mortality through time for a 100 -year simulation. Dots indicate number of individual oysters killed at each time step. Around year 60, an increase in reef height coincides with increased burial mortality, and these seem to feedback on each other.

\section{Discussion}

Oyster reefs are valuable for the fisheries economy, are resilient to environmental fluctuation, and are believed to contribute to stabilizing shorelines in tandem with salt marsh. Unfortunately, these systems have experienced catastrophic collapse throughout most of the historical range (La Peyre and others, 2014). Currently, restoration of historically productive and potentially ecologically stabilizing oyster reefs is a major concern. To support these projects, we developed a new simulation model of an oyster reef building system that simultaneously tracks the population dynamics of oysters, regulatory ecosystem services of wave attenuation, a resilience property, and provisioning services of available harvest biomass, an economic property.

Restorations of oyster reefs are often implemented in areas to that do not have intensive monitoring data (La Peyre and others, 2014). We designed a flexible model that can be broadly applicable to any area of the coast, regardless of monitoring status. To accomplish this, we drew from over 30 years of research and modeling, combining information on first principles of oyster physiology, metabolism, population dynamics, and physical structural properties of reefs. The model was parameterized using a combination of empirical information and expert judgement. Ultimately, all the model 

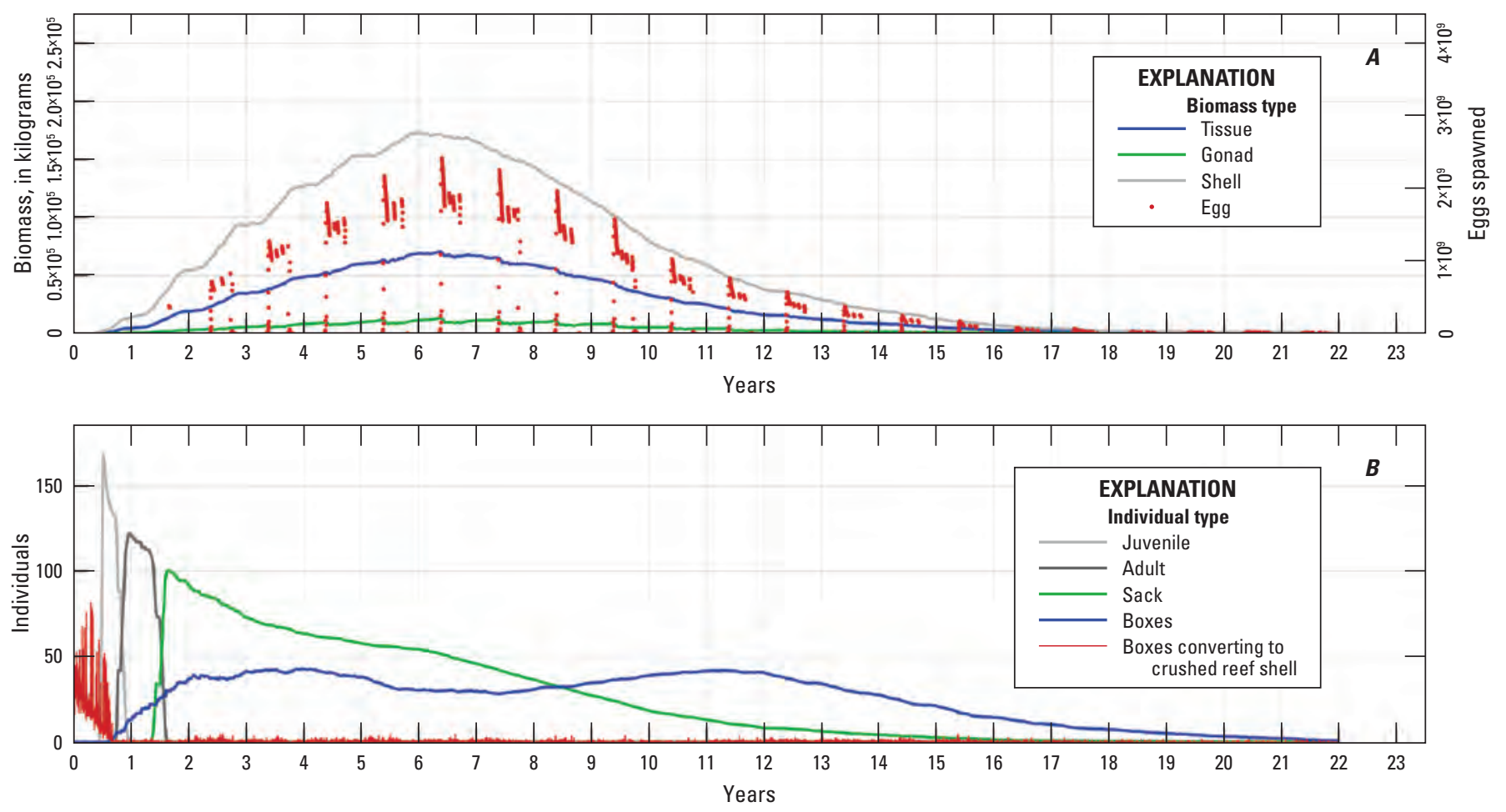

Figure 3.4. Simulated time series of oyster biomass and individual density for the extinction scenario using year 2013 data. $A$, biomass. $B$, individuals.

parameters should be obtainable from monitoring data. The baseline predictions for restoration performance can be set and updated throughout the restoration process as more information becomes available.

Human population density is increasing along many coastal areas, including in the United States (McGranahan and others, 2007). At the same time, pressure is mounting on human development, livelihood, and economics as important resources such as fisheries decline and as climate factors, such as sea-level rise, flooding, and erosion, threaten to undermine the long-term stability of coastal infrastructure. Critically, this exposure to multiple converging pressures imposes on coastal managers difficult choices between managing for objectives of coastal protection or for extractive use of reefs for recreational or commercial harvest. An important first step to tackling this decision problem is to develop a framework for predicting ecosystem response to changes in climate and fishery management policy. Research often approaches these as separate subjects, examining either ecosystem properties or management of fishery yields. This approach is also evident in restoration practice, where projects tend to be viewed as either creation of protected reefs that exclude all fishing or as enhancement of a resource to be extracted to the full extent possible, including mariculture. The current trend is to maintain these under separate authorities, managed either by State natural resource agencies or by independent conservation organizations, to meet distinct, often exclusive objectives. Under this paradigm, harvest policy (that is, regulations) tends to produce limited amounts of ecosystem services for coastal protection, and conservation practices (that is, setting no take reserves) offer limited economic value for shellfisheries in comparison to harvest. We addressed this limitation by developing a simulation model where decisions can be made to vary the level of fishing pressure on oyster reef restorations, both in units of catch rates and as temporal openings and closures, also viewing the effects that these policies have on the regulating services of wave attenuation. In this way, the tradeoff space of decision making can be viewed, and outcomes from restorations and harvest policies can be identified within it, whereas in real systems, this is very difficult to do experimentally. 

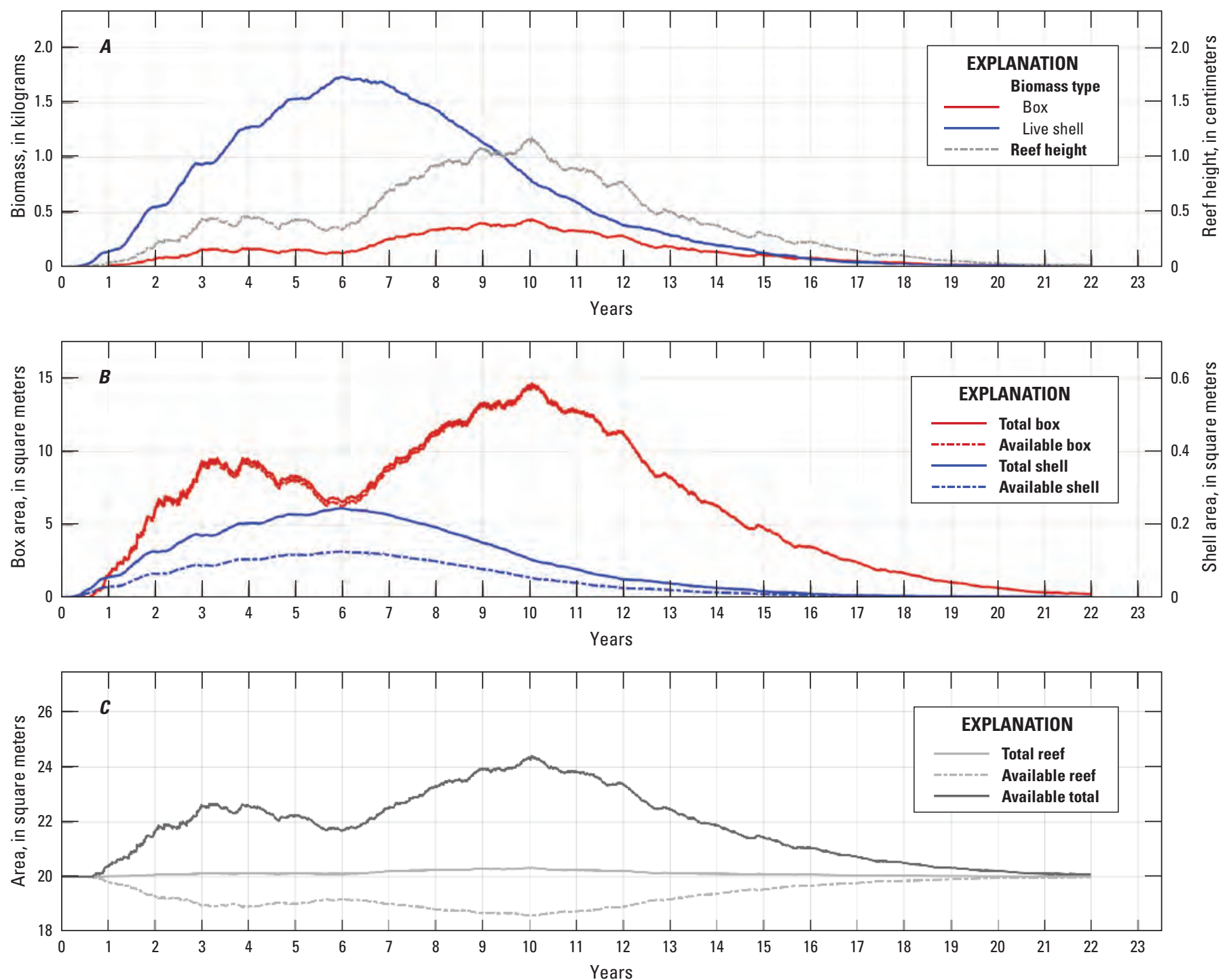

Figure 3.5. Oyster reef dynamics for extinction scenario. Here 1 year of data from 2013 was looped over successive simulation years. 

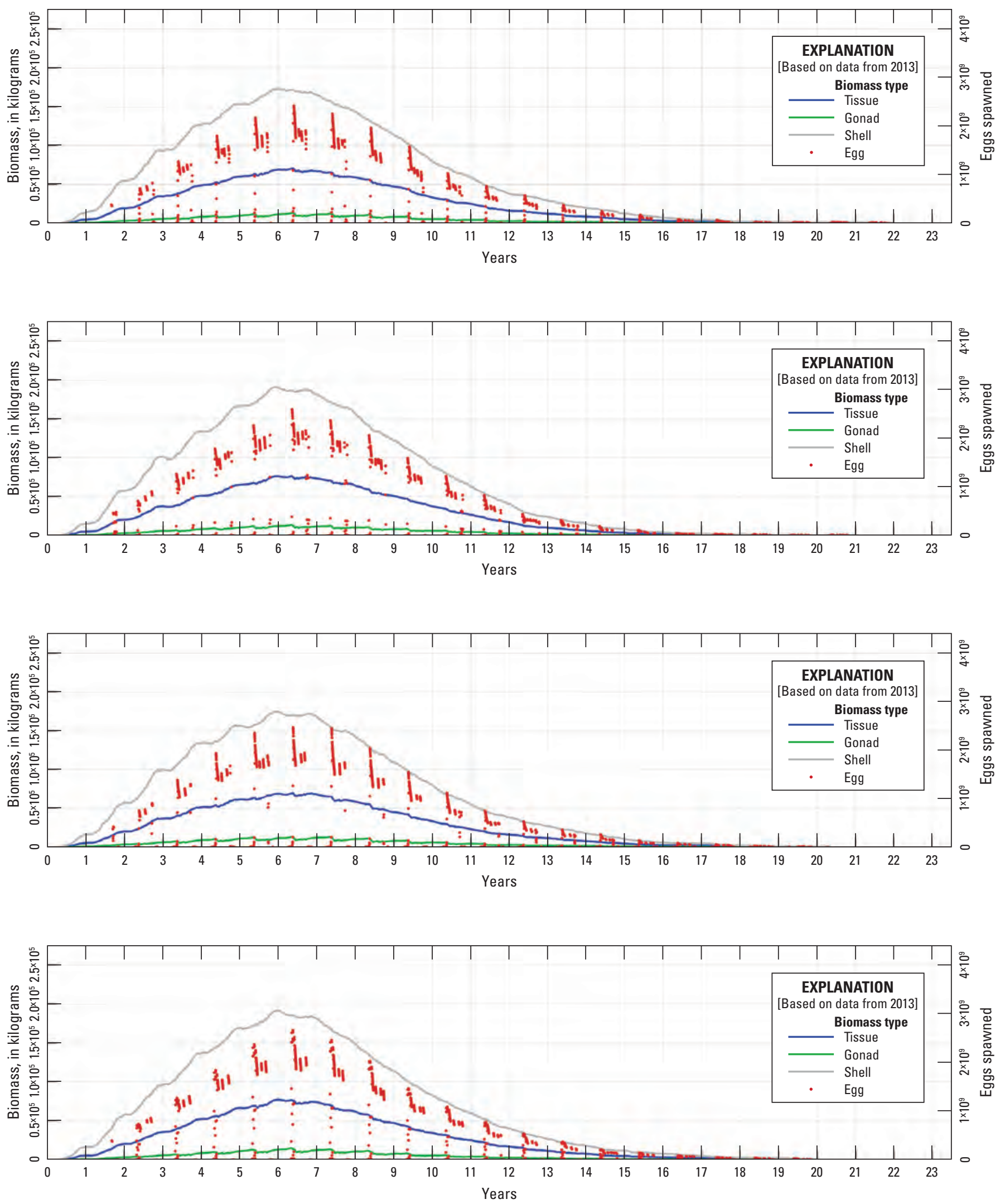

Figure 3.6. Across year comparison of oyster biomass dynamics for 2013 to 2017. 


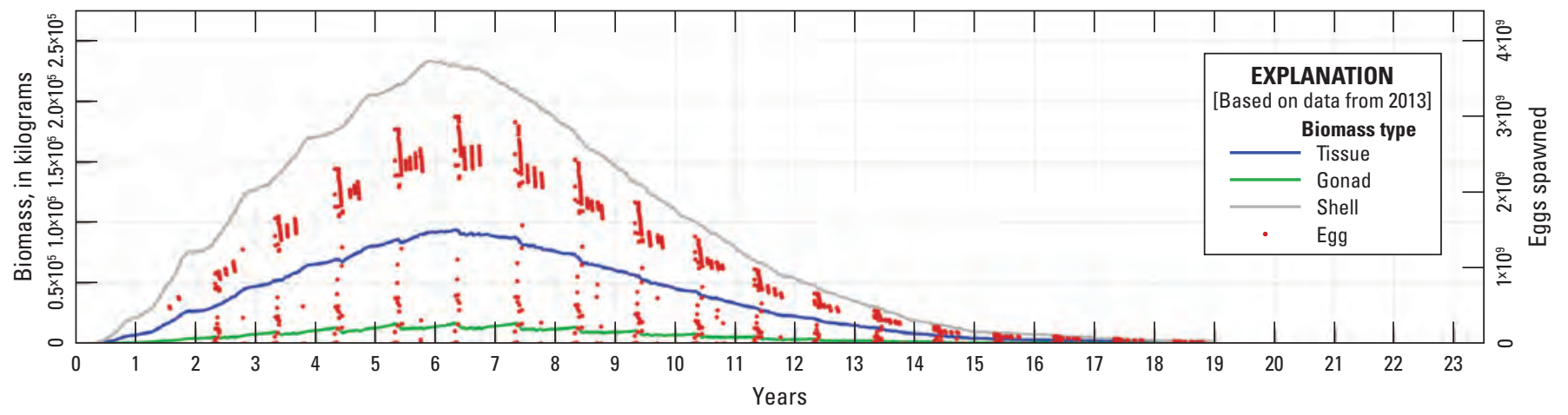

Figure 3.6.-Continued
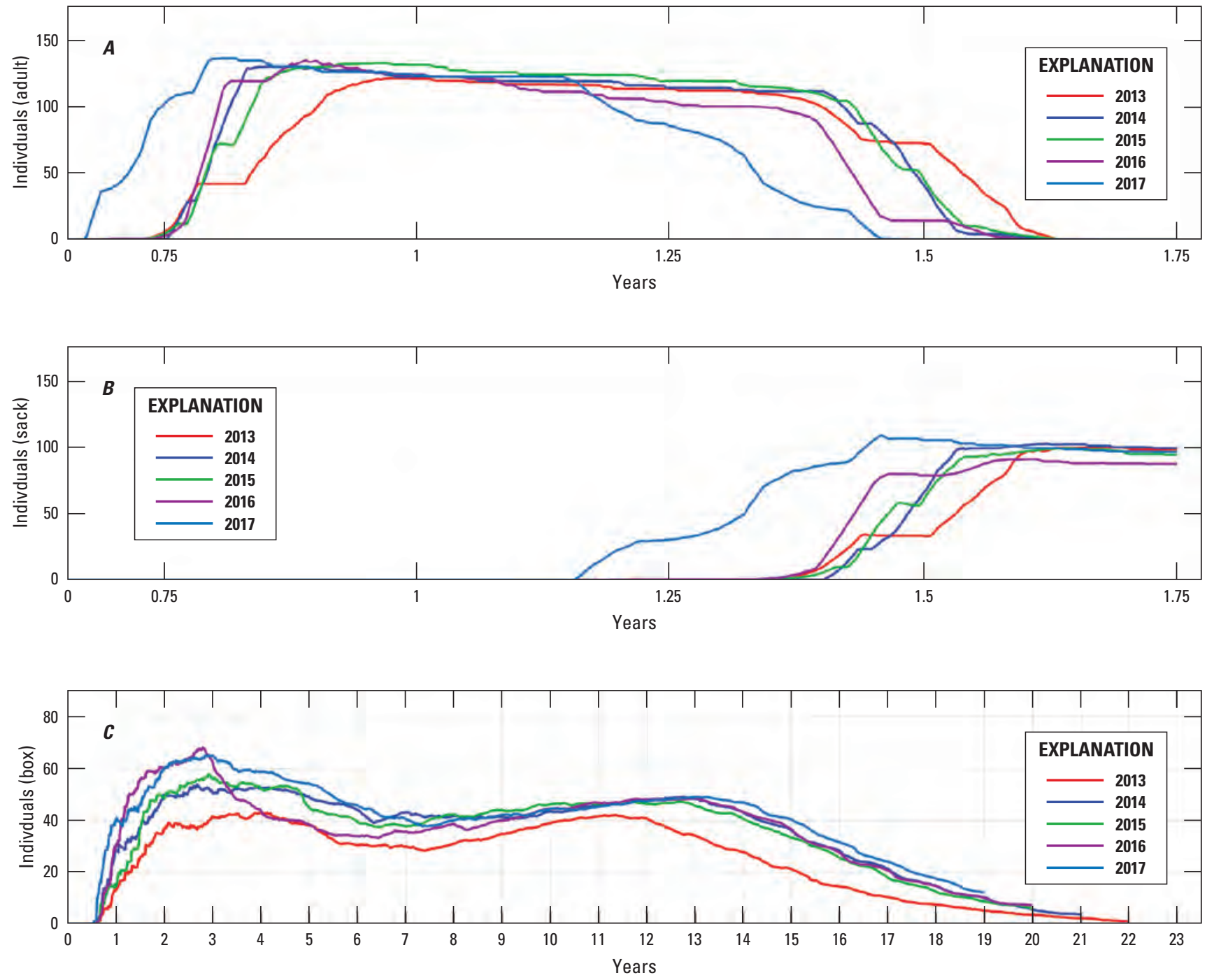

Figure 3.7. Across year comparison of oyster density through time, separated by demographic groupings. 


\section{References Cited}

Allen, R.J., and Webb, B.M., 2011, Determination of wave transmission coefficients for oyster shell bag breakwaters, in Magoon, O.T., Noble, R.M., Treadwell, D.D., and Kim, Y.C., Proceedings of the Conference on Coastal Engineering Practice, San Diego, Calif., August 21-24, 2011, p. 684-697.

Arkema, K.K., Guannel, G., Verutes, G., Wood, S.A., Guerry, A., Ruckelshaus, M., Kareiva, P., Lacayo, M., and Silver, J.M., 2013, Coastal habitats shield people and property from sea-level rise and storms: Nature Climate Change, v. 3, no. 10, p. 913-918. [Also available at https://doi.org/ 10.1038/nclimate1944.]

Bahr, L.M., and Lanier, W.P., 1981, The ecology of intertidal oyster reefs of the South Atlantic coast-A community profile: U.S. Fish and Wildlife Service, FWS/OBS 81/15, 105 p.

Camp, E.V., Pine, W.E., III, Havens, K., Kane, A.S., Walters, C.J., Irani, T., Lindsey, A.B., and Morris, J.G., Jr., 2015, Collapse of a historic oyster fishery-Diagnosing causes and identifying paths toward increased resilience: Ecology and Society, v. 20, no. 3, art. 45. [Also available at https://doi.org/10.5751/ES-07821-200345.]

Cheong, S.M., Silliman, B., Wong, P.P., Van Wesenbeeck, B., Kim, C.K., and Guannel, G., 2013, Coastal adaptation with ecological engineering: Nature Climate Change, v. 3, no. 9, p. 787-791. [Also available at https://doi.org/10.1038/ nclimate1854.]

Colden, A.M., Latour, R.J., and Lipcius, R.N., 2017, Reef height drives threshold dynamics of restored oyster reefs: Marine Ecology Progress Series, v. 582, p. 1-13. [Also available at https://doi.org/10.3354/meps12362.]

Costanza, R., Pérez-Maqueo, O., Martinez, M.L., Sutton, P., Anderson, S.J., and Mulder, K., 2008, The value of coastal wetlands for hurricane protection: Ambio, v. 37, no. 4, p. 241-248. [Also available at https://doi.org/https://doi.org/ 10.1579/0044-7447(2008)37[241:TVOCWF]2.0.CO;2.]

Harding, J.M., Mann, R., Southworth, M.J., and Wesson, J.A., 2010, Management of the Piankatank River, Virginia, in support of oyster (Crassostrea virginica, Gmelin 1791) fishery repletion: Journal of Shellfish Research, v. 29, no. 4, p. 867-888. [Also available at https://doi.org/10.2983/ 035.029.0421.]

Hofmann, E.E., Klinck, J.M., Powell, E.N., Boyles, S., and Ellis, M., 1994, Modeling oyster populations II. Adult size and reproductive effort: Journal of Shellfish Research, v. 13, no. 1, p. 165-182.
Hofmann, E.E., Powell, E.N., Klinck, J.M., and Wilson, E.A., 1992, Modeling oyster populations III. Critical feeding periods, growth: Journal of Shellfish Research, v. 11, no. 2, p. 399-416.

Kuykendall, K.M., Moreno, P., Powell, E.N., Soniat, T.M., Colley, S., Mann, R., and Munroe, D.M., 2015, The exposed surface area to volume ratio-Is shell more efficient than limestone in promoting oyster recruitment?: Journal of Shellfish Research, v. 34, no. 2, p. 217-225. [Also available at https://doi.org/10.2983/035.034.0203.]

La Peyre, M.K., Furlong, J., Brown, L.A., Piazza, B.P., and Brown, K., 2014, Oyster reef restoration in the northern Gulf of Mexico-Extent, methods and outcomes: Ocean and Coastal Management, v. 89, p. 20-28. [Also available at https://doi.org/10.1016/j.ocecoaman.2013.12.002.]

La Peyre, M.K., Geaghan, J., Decossas, G., and Peyre, J.F.L., 2016, Analysis of environmental factors influencing salinity patterns, oyster growth, and mortality in Lower Breton Sound Estuary, Louisiana, using 20 years of data: Journal of Coastal Research, v. 32, no. 3, p. 519-530. [Also available at https://doi.org/10.2112/JCOASTRES-D-15-00146.1.]

Lavaud, R., La Peyre, M.K., Casas, S.M., Bacher, C., and La Peyre, J.F., 2017, Integrating the effects of salinity on the physiology of the eastern oyster, Crassostrea virginica, in the northern Gulf of Mexico through a dynamic energy budget model: Ecological Modelling, v. 363, p. 221-233. [Also available at https://doi.org/10.1016/j.ecolmodel.2 017.09.003.]

Lenihan, H.S., 1999, Physical-biological coupling on oyster reefs-How habitat structure influences individual performance: Ecological Monographs, v. 69, no. 3, p. 251-275.

Lowe, M.R., Sehlinger, T., Soniat, T.M., and Peyre, M.K.L., 2017, Interactive Effects of Water Temperature and salinity on growth and mortality of eastern oysters, Crassostrea virginica-A meta-analysis using 40 years of monitoring data: Journal of Shellfish Research, v. 36, no. 3, p. 683-697. [Also available at https://doi.org/10.2983/035.036.0318.]

McGranahan, G., Balk, D., and Anderson, B., 2007, The rising tide-Assessing the risks of climate change and human settlements in low elevation coastal zones: Environment and Urbanization, v. 19, no. 1, p. 17-37. [Also available at https://doi.org/10.1177/0956247807076960.]

Pine, W.E., III, Walters, C.J., Camp, E.V., Bouchillon, R., Ahrens, R., Sturmer, L., and Berrigan, M.E., 2015, The curious case of eastern oyster Crassostrea virginica stock status in Apalachicola Bay, Florida: Ecology and Society, v. 20, no. 3, 46. [Also available at https://doi.org/10.5751/ ES-07827-200346.] 
Powell, E.N., Hofmann, E.E., Klinck, J.M., and Ray, S.M., 1992, Modeling oyster populations-I. A commentary on filtration rate. Is faster always better?: Journal of Shellfish Research, v. 11, no. 2, p. 387-398.

Powell, E.N., and Klinck, J.M., 2007, Is oyster shell a sustainable estuarine resource?: Journal of Shellfish Research, v. 26, no. 1, p. 181-194. [Also available at https://doi.org/ 10.2983/0730-8000(2007)26[181:IOSASE]2.0.CO;2.]

Powell, E.N., Klinck, J.M., Hofmann, E.E., and Ray, S.M., 1994, Modeling oyster populations. IV. Rates of mortality, population crashes, and management: Fish Bulletin, v. 92, no. 2, p. 347-373.

Powell, E.N., Kraeuter, J.N., and Ashton-Alcox, K.A., 2006, How long does oyster shell last on an oyster reef?: Estuarine, Coastal and Shelf Science, v. 69, no. 3-4, p. 531-542. [Also available at https://doi.org/10.1016/ j.ecss.2006.05.014.]

Soniat, T.M., Klinck, J.M., Powell, E.N., Cooper, N., Abdelguerfi, M., Hofmann, E.E., Dahal, J., Tu, S., Finigan, J., Eberline, B.S., Peyre, J.F.L., Peyre, M.K.L., and Qaddoura, F., 2012, A shell-neutral modeling approach yields sustainable oyster harvest estimates - A retrospective analysis of the Louisiana state primary seed grounds: Journal of Shellfish Research, v. 31, no. 4, p. 1103-1112. [Also available at https://doi.org/10.2983/035.031.0421.]

Soniat, T.M., Powell, E.N., Hofmann, E.E., and Klinck, J.M., 1998, Understanding the success and failure of oyster populations - The importance of sampled variables and sample timing: Journal of Shellfish Research, v. 17, no. 4, p. 1149-1165.

Southworth, M., Harding, J.M., Wesson, J.A., and Mann, R., 2010, Oyster (Crassostrea virginica, Gmelin 1791) population dynamics on public reefs in the Great Wicomico River, Virginia, USA: Journal of Shellfish Research, v. 29, no. 2, p. 271-290. [Also available at https://doi.org/10.2983/ 035.029.0202.]

Sutton-Grier, A.E., Wowk, K., and Bamford, H., 2015, Future of our coasts-The potential for natural and hybrid infrastructure to enhance the resilience of our coastal communities, economies and ecosystems: Environmental Science \& Policy, v. 51, p. 137-148. [Also available at https://doi.org/ 10.1016/j.envsci.2015.04.006.]
Temmerman, S., Meire, P., Bouma, T.J., Herman, P.M., Ysebaert, T., and De Vriend, H.J., 2013, Ecosystem-based coastal defence in the face of global change: Nature, v. 504, no. 7478, p. 79-83. [Also available at https://doi.org/ 10.1038/nature12859.]

U.S. Geological Survey [USGS], 2016, USGS 330428079214800 Skrine Creek near McClellenville, SC, in USGS water data for the Nation: U.S. Geological Survey National Water Information System database, accessed December 16, 2016, at https://doi.org/https://doi.org/ 10.5066/F7P55KJN. [Site information directly accessible at https://waterdata.usgs.gov/nwis/inventory/?site_no=330 428079214800\&agency_cd=USGS\&amp.]

Wang, H., Chen, Q., La Peyre, M.K., Hu, K., and La Peyre, J.F., 2017, Predicting the impacts of Mississippi River diversions and sea-level rise on spatial patterns of eastern oyster growth rate and production: Ecological Modelling, v. 352, p. 40-53. [Also available at https://doi.org/10.1016/ j.ecolmodel.2017.02.028.]

Wang, H., Huang, W., Harwell, M.A., Edmiston, L., Johnson, E., Hsieh, P., Milla, K., Christensen, J., Stewart, J., and Liu, X., 2008, Modeling oyster growth rate by coupling oyster population and hydrodynamic models for Apalachicola Bay, Florida, USA: Ecological Modelling, v. 211, nos. 1-2, p. 77-89. [Also available at https://doi.org/10.1016/j.e colmodel.2007.08.018.]

Wilberg, M.J., Wiedenmann, J.R., and Robinson, J.M., 2013, Sustainable exploitation and management of autogenic ecosystem engineers-Application to oysters in Chesapeake Bay: Ecological Applications, v. 23, no. 4, p. 766-776. [Also available at https://doi.org/10.1890/12-0563.1.]

Yurek, S., Eaton, M.J., Lavaud, R., Laney, R.W., DeAngelis, D.L., Pine III, W.E., La Peyre, M., Martin, J., Frederick, P., Wang, H. and Lowe, M.R., 2021. Modeling structural mechanics of oyster reef self-organization including environmental constraints and community interactions. Ecological Modelling, 440, p.109389. 


\section{Appendix 4. Integrating Econometric Land-Use Models with Ecological Modeling of Ecosystem Services to Guide Coastal Management and Planning- Methods and Provisional Results}

\section{Introduction}

In the natural resources and environmental sciences, there are few examples of research analyzing the dynamic implications of land-use policy on land development and conservation. Many of the analyses evaluating growth management policies options come from the urban economics literature, and they tend to focus on the management of urban sprawl. The growing body of literature on the economics of urban sprawl is surveyed in Glaeser and Kahn (2004) and Nechyba and Walsh (2004). Moreover, few of these studies have developed methods to connect policy effects on land-use decisions and the resulting change in ecosystem services provision. Irwin (2010) and Duke and Wu (2014) provide a comprehensive review of the land-use modeling literature and its current deficiencies. With this project, we will contribute to a growing area of research in the land-use and environmental economics literature by evaluating the cost effectiveness of alternative land-use policies that target the conservation of coastal land with high ecological value for local flood prevention (for example, areas largely covered by wetlands) while accounting for future effects of climate change and urbanization. Here, we present our methodological framework and offer some preliminary findings, but note that this research is ongoing and that results are provisional (see Villegas, 2019).

In this project, we are developing an iterative procedure to specify a spatially explicit econometric model of land-use change that directly incorporates ecosystem services and feedback mechanisms between land use, ecosystem services and land values in a dynamic framework. More specifically, using landscape simulations, we intend to study how climate change, spatial patterns of urbanization, and alternative coastal development policies affect land-use decisions, and how these decisions affect the conservation of critical wetland habitat and the landscape's capacity to mitigate risks from future flooding. We focus our study on three fast-growing coastal counties of South Carolina that encompass the Charleston metropolitan area: a region subject to rapid urbanization and rising threats from current and future flooding. Figure 4.1 shows the study area, including county boundaries.

Coastal flooding is an imminent climatic and economic threat in the United States. Some 39 percent of U.S. households are in coastal areas along the country's 12,000 miles of coastline (National Oceanic and Atmospheric Administration [NOAA], 2018). Climate scientists warn that sea-level rise and changes in storm frequency will make coastal systems more vulnerable to the dynamic forces of wind, waves, tides, currents, and storms. In the United States, biophysical changes have already been shown to impair the capacity of municipal storm water drainage systems to empty into the ocean, and because flooding events began to be recorded in the 1960s, the number of inland floods increased between 300 and 925 percent along coastal areas. In some places, like Norfolk, Virginia, Charleston, South Carolina, and Miami, Florida, minor floods now occur as frequently as high tides (Dahl and Stedman, 2013).

Floods can cause substantial natural, human and economic damage. Between 1980 and 2016, flooding has caused on average $\$ 7.96$ billion in damages and 82 fatalities per year. In 2016, the monetary cost of floods was more than twice the 26 -year annual average, adding to $\$ 16.5$ billion and causing 49 deaths. Moreover, that year, disaster floods alone (that is, without considering hurricanes) constituted almost 25 percent of all weather and climate disasters in the United States that cost over $\$ 1$ billion each (totaled of $\$ 67$ billion; NOAA, 2018, 2020). Figures 4.2 and 4.3 show trends and location of floods in the study area since 1996.

Flooding risks are exacerbated by rapid urbanization trends and the subsequent loss of natural barriers (for example, coastal wetlands). Land development creates areas that are impermeable to precipitation, which leads to increased runoff and makes coastal areas more prone to flooding. Additionally, high-density growth increases the magnitude of economic damages and human costs as more people move towards vulnerable areas and become exposed to climatic threats. In 2010, shoreline coastal counties were home to about 39 percent of the Nation's households, or more than 123.3 million people (a 6.5-percent increase since the previous 2000 Census), and a number that is projected to increase by 8 percent by 2020 . Finally, land development destroys, displaces, or inhibits the formation of naturally occurring wetland habitats that promote infiltration or absorption, reduce runoff, and decrease the landscape's vulnerability to floods. Land development and new impervious surfaces prevent water, sediments, organic matter ,and nutrients from percolating into the soil and therefore inhibit the formation of wetlands. Additionally, the construction of physical structures like bulkheads, sea walls, jetties, and sandbags pose a physical impediment for wetlands and marshes to migrate inland, which is their natural response to sea-level rise, and further impair the landscape's capacity to prevent flooding. Figure 4.4 shows a map of housing unit growth from 1990 to 2016 by census track in the three counties in the study area. It shows the number of structures built after 1990 recorded in the 2016 American Community Survey (U.S. Census Bureau, 2017). 


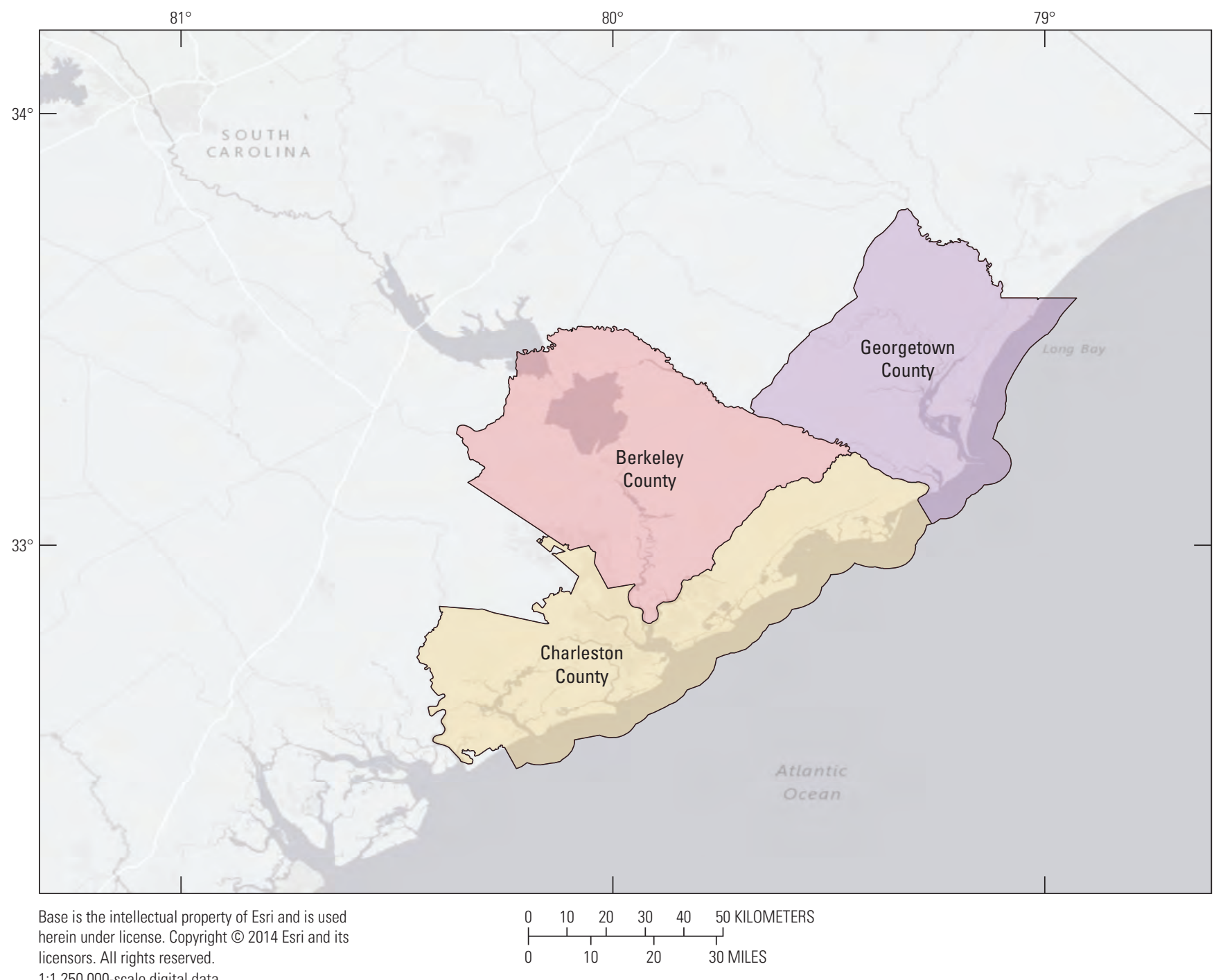

Figure 4.1. The study area showing three counties in South Carolina used to develop the econometric model of land-use change.

As shown by figure 4.4, new development is concentrated around urban centers and near the coast. An examination of the most recent national land cover data indicates that new development in the study area is dominated by high- and medium-density development and is generally more suburban in nature.

NOAA predicts that flood trends in the United States will continue to accelerate. In combination with current projections of sea-level rise, storm frequency and urban growth along the coast, this prognosis makes flooding the costliest and fastest-growing climatic threat in the Nation. Thus, general policy concern over the rising effects of floods is of increasing relevance and civic requests for public planning and intervention are increasingly justifiable.

Urban planners have traditionally dealt with flooding using engineering solutions (for example, by building eater storage and infiltration structures like dams, pumps, and spillways). To a lesser extent, they have also used prescriptive regulation on land use to limit the damages to private properties from flooding events. For instance, in South Carolina, the Beachfront Management Act of 1988 (Coastal Tidelands and Wetlands Act, as amended, §48-39-250 et seq.) establishes a zone adjacent to the shoreline and wetlands within which structure cannot be built or reconstructed. Alternatively, policy makers could consider enacting land-use policies that affect the level, intensity, and distribution of development, as well as a desired composition of the natural landscape (for example, by promoting the conservation of coastal wetlands that provide beneficial flood protection services). In this study, we will consider three types of potential land-use policies that have been used by local jurisdictions across the country in various forms:

1. a flat-rate development impact fee (that is, a uniform fee that applies to each parcel that is being developed); 


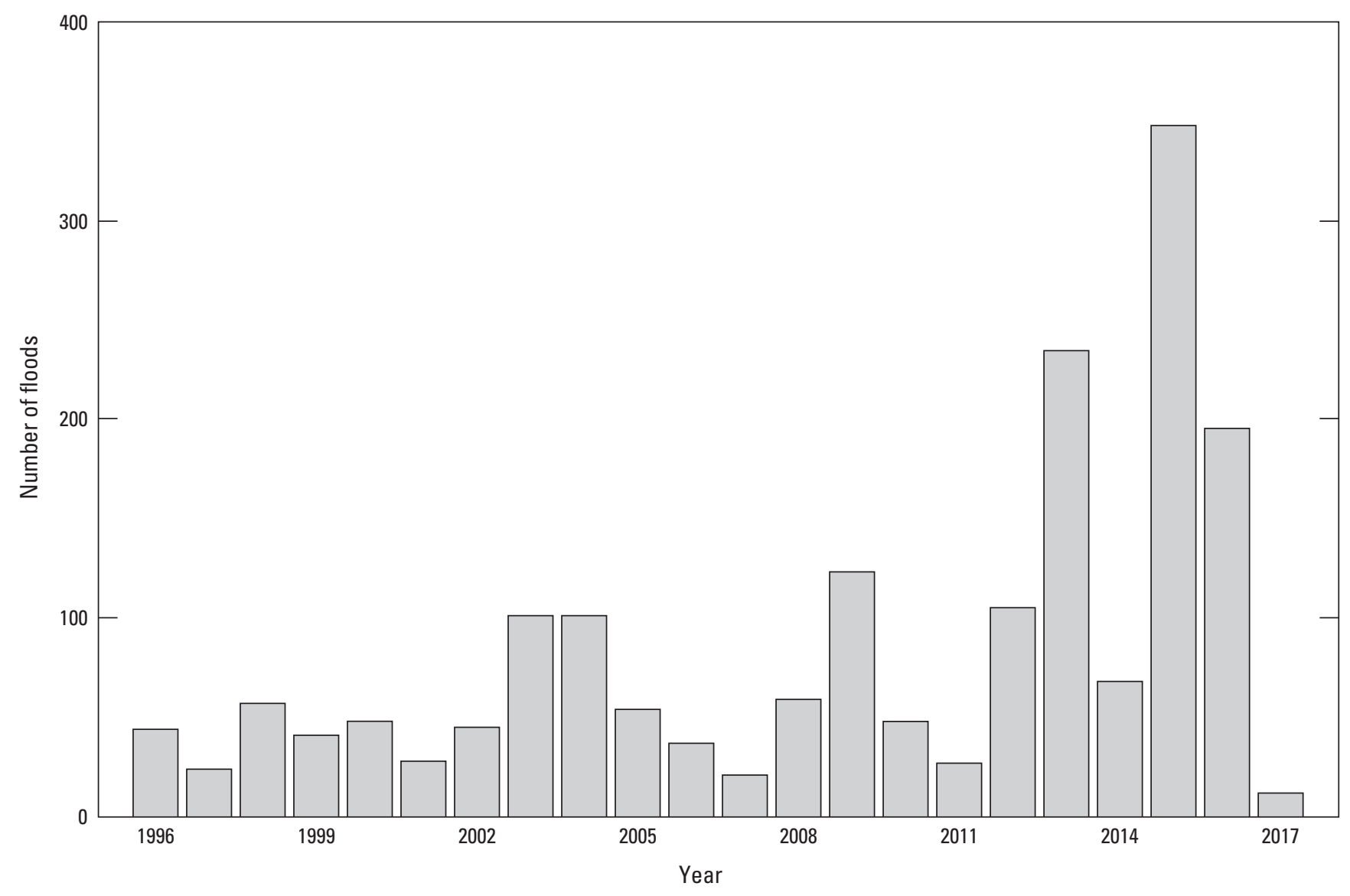

Figure 4.2. History of floods in the study area (1996-2017).

2. a development impact fee that is related to spatial features of each parcel that is critical for flood prevention, such as the extent of impervious surface cover after development; and

3. a prescriptive policy limiting the amount of a parcel that is covered by impervious surface after development.

The policies above can be refined as the research progresses. For example, maximum impervious surface limits (policy 3) or variable development impact fees (policy 2) could vary with features of a parcel. For instance, parcels that are closer to water bodies or wetlands could have lower impervious surface allowances or pay higher development fees. Each of the policies described above can be assessed by comparing their associated costs (reduced development value) and benefits (increased flood protection and reduced damages from flooding events).

When complete, this project intends to (1) develop a model of land-use change that is coupled with flood risks that change over time because of sea-level rise and change in land use, (2) show the geographic areas that are effected and their associated damages from flooding in the future given current growth trends in the South Carolina Lowcountry region, and (3) show how alternative land-use policies can reduce flooding risks and resulting economic damages.

\section{Overview of Methodology}

An iterative simulation procedure that combines a spatially explicit statistical model of land-use change at the parcel level with an ecological model of flood prevention services is used. Future landscape scenarios are generated and used to evaluate the effects of various urban growth policies. The exogenous forces in this conceptual model are climatic trends (that is, sea-level rise and changes in storm frequency) and urbanization trends (for example, population growth).

The iterative procedure begins with an initial landscape in the current period. The current physical landscape has particular spatial features that relate to its current value and its future value in development and give the land some capacity to mitigate flood risks. A probabilistic model is developed to predict the probability that each currently undeveloped parcel in the landscape will develop in the next period. Parcels are either converted to developed uses or stay undeveloped according to 


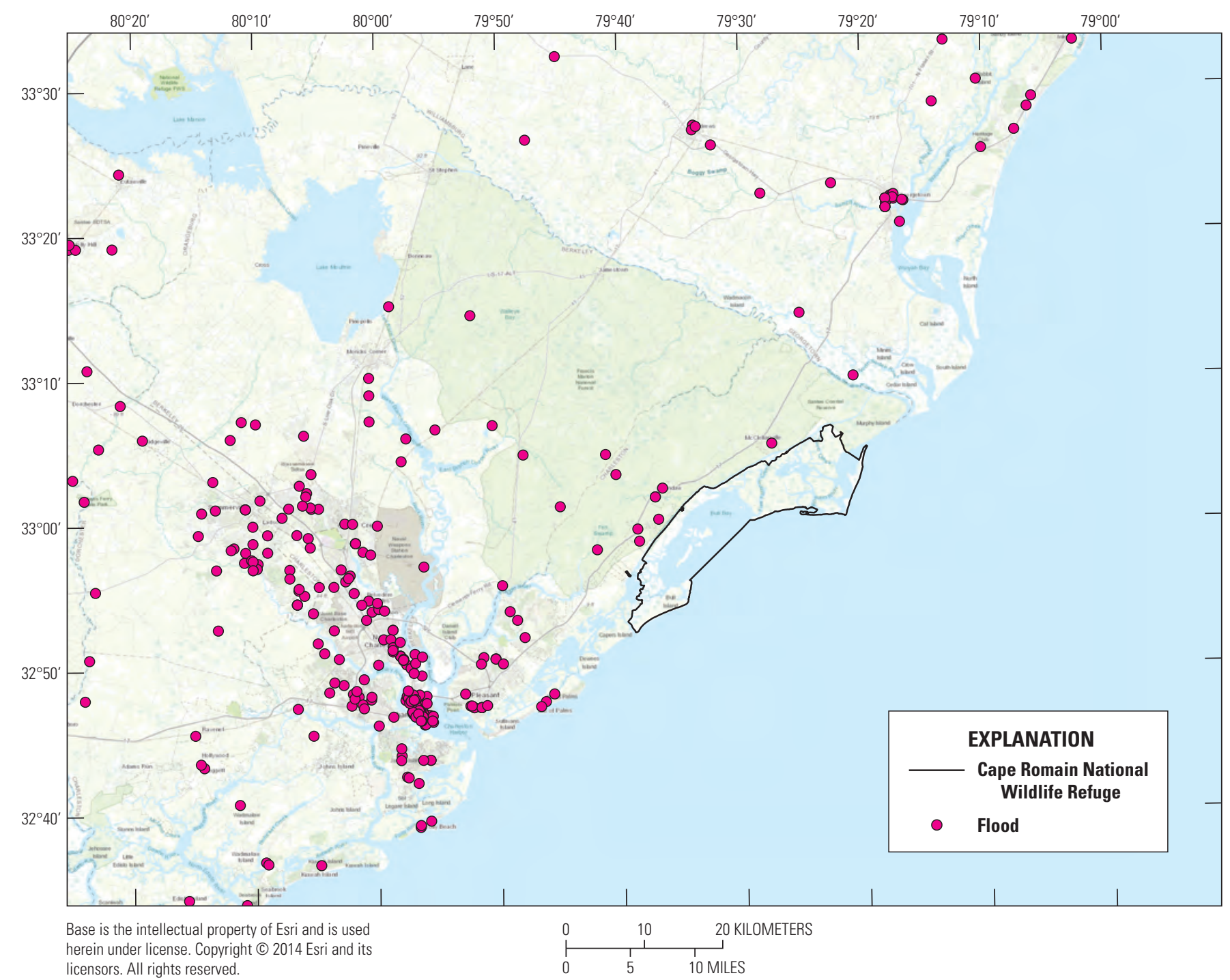

reserved.

1:625,000-scale digital data

Figure 4.3. Location of flooding incidents in relation to privately owned land parcels considered in this study (1996-2016).

a conversion rule that assigns a higher probability of development to land with higher value in development as compared to its current use.

In the next period, the physical landscape will exhibit different spatial features and different ability to mitigate flooding hazards because of development. These different spatial features affect land values in undeveloped and developed uses. For example, if land around a given undeveloped parcel is converted to development, the value of the undeveloped parcel is likely to change similar to the value it would attain if it were to be developed. Over many iterations, the landscape may also be altered by climatic forces. Thus, in future periods, the landscape may have more water coverage (because of sea-level rise), more coverage of impervious surfaces (because of new development), and less coverage of wetland habitats (because of a combination of sea-level rise and new development). A simulated business-as-usual future landscape that allows the development process to iterate over time without any policy intervention can be compared to future landscapes whose development patterns are altered by one of the three policies described earlier. Under alternative land-use regulations or policies, future landscapes may exhibit different spatial features and therefore have different inherent capacities to prevent floods. The business-as-usual development patterns and the policy-altered development patterns can be compared on their effectiveness in lowering expected damages from flooding and assessed on how expected damages are distributed spatially.

There are two main components for implementing the conceptual framework just described: (1) a land-use change model and (2) a simulation procedure. The land-use change model is the centerpiece of the analysis because it provides the behavioral explanation for changes in the landscape that reflect the decision-making process of individual landowners. 


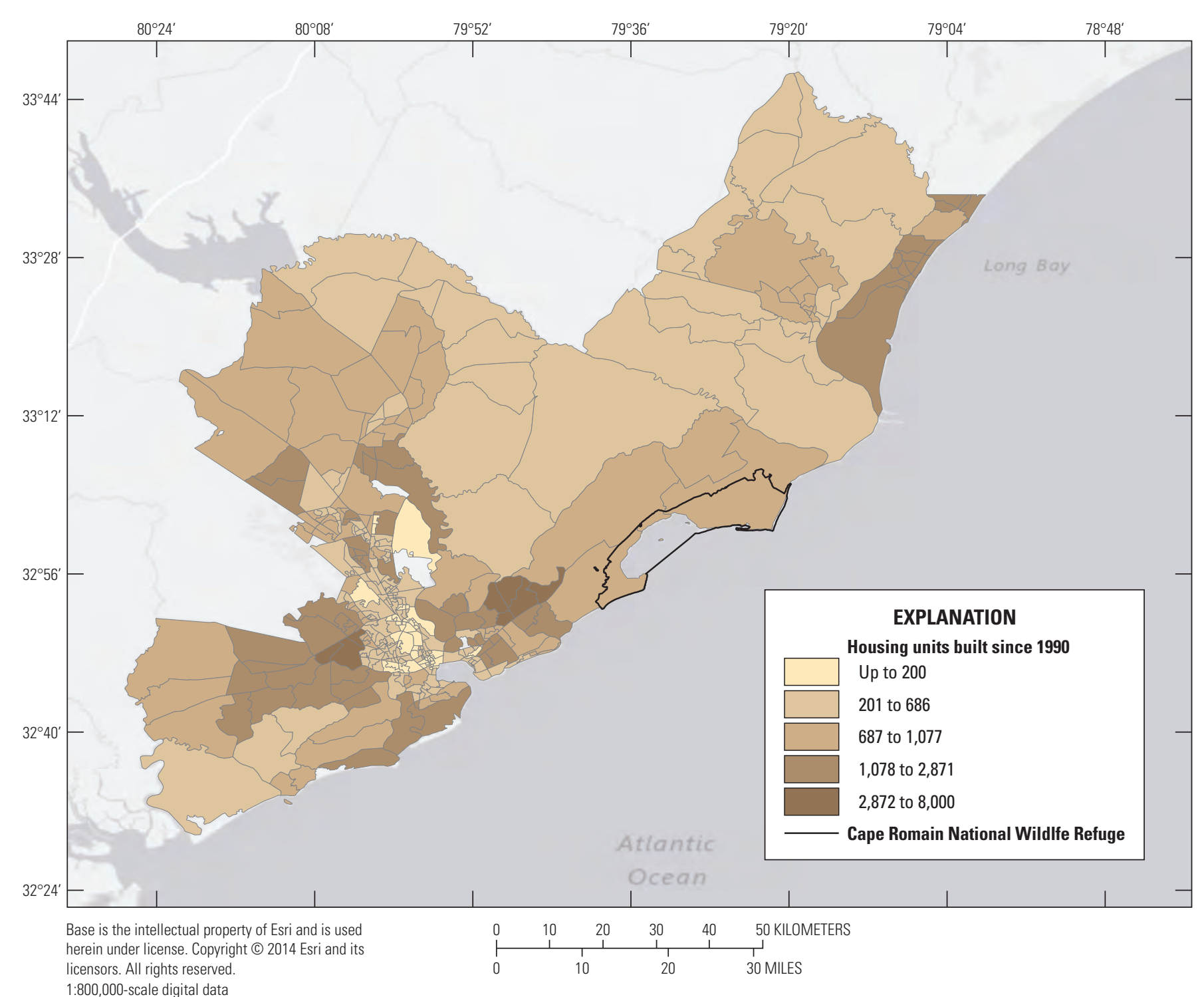

Figure 4.4. New housing stock in the study area (1990-2016).

In other words, the land-use change model is developed to estimate land-use transition probabilities for each parcel in the landscape. The inputs for the land-use change model are derived from a first stage estimation and prediction analysis using hedonic models of land value. Hedonic modeling uses revealed preference tools to estimate property value by considering the contribution to this value of particular characteristics (Rosen, 1974). In turn, the outputs of the model (that is, the probabilistic transition rules) are used to simulate future landscapes that are consistent with the underlying forces of the model. It is through the simulations procedure that the moving components of the general framework (that is, the land-use change model, the ecological production function of flood prevention services, the first-stage hedonics analysis, and the different policy rules) affect one another in a dynamic way. Figure 4.5 illustrates the iterative procedure described above.

\section{Data}

To estimate the land-use change models that are a core component of this research, we use the predictions of land values generated in a first stage analysis as explanatory variables in a second-stage probabilistic model of land development. The value of undeveloped land in development is estimated using statistical property-value models that incorporate information on parcel characteristics such as its physical and geographical characteristics. A full list of the sources of data used in the analysis is presented in the table 4.1. Characteristics of land available for analysis include housing market data (for example, sales prices and value of buildings on a parcel), physical and spatial characteristics of the land (for example, soil type, elevation, and tree cover, or proximity to water or 


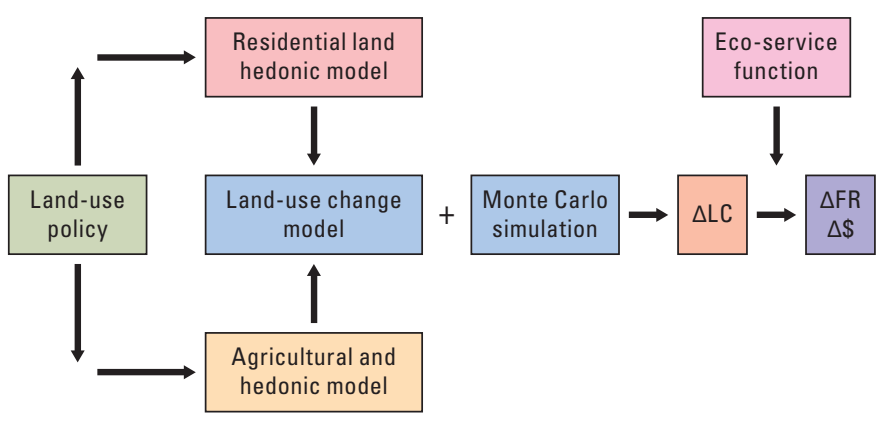

Figure 4.5. The iterative landscape simulation procedure beginning with a current landscape and flood prevention services of the landscape that affect land-use decisions and result in altered landscapes in the next period. Future landscapes may exhibit changes in land cover composition $(\Delta \mathrm{LC})$, which in turn affect land values, flood risk indicators $(\Delta \mathrm{FR})$ and economic damages from flood events $(\Delta \$)$. Changes in flood risk indicators are determined using an ecological function that takes $\Delta \mathrm{LC}$ as inputs. Land-use decisions by landowners are affected by land-use policies through their effect on land values.

employment centers) and social-economic characteristics of the area (for example, average income and racial composition of households nearby).

There are three primary types of data used to complete this project: (1) land market data, (2) geophysical and landscape data, and (3) National Weather Service data on historical floods. The land market data for the land-use change analysis were obtained from county tax assessor databases. These databases contain information for every parcel, including lot size, zoning designation and characteristics of the physical structures on the lot, like square footage and number of rooms. Tax assessor databases also contain historical transaction data on property sales, which are key for predicting the land values that are used in the land-use change model.

For the empirical analysis, we use only a subset of all the properties listed in the tax assessor databases. The sampled properties meet certain selection criteria that were set to minimize potential errors in the prediction analysis. Overall, there are 210,721 parcels available for analysis: 105,756 from Charleston County, 68,513 from Berkeley County, and 36,452 from Georgetown County. Of those, 153,009 are currently considered residential properties, and the remaining 57,712 are considered undeveloped. The starting point of the landuse models predicts the probability that each one of those 57,712 parcels is developed within the next 5 years.

Parcel characteristics included in the tax assessor databases have been augmented with other geospatial features obtained from public sources including flood hazard maps and raster data of land cover types, elevation, streams and rivers, and soil quality classes. In addition, spatial variables such as proximity to employment centers, water bodies, main roads, and access points to public beaches were created using geographic information system parcel layers obtained from county geographic information system offices.

A second central interest of this project is to examine the effect of changes in land use on flood risk. Therefore, National Weather Service data on historical floods are currently being used in conjunction with land cover data from the National Land Cover Database to develop a measure of flood risk, which is a key input for the comparative analysis component of this project.

\section{Outcomes}

Currently, preliminary versions of the land-use model have been estimated, and we are in the process of refining the models before initiating the simulation component of this project. As we work towards refining the predictive models, we are developing a flood risk index that will be used in the simulation and comparative pieces of this project.

Upon completion, we will have alternative coupled land use change and flood risk models that can be used to analyze the implications of development patterns as related to potential flood risks and their associated property damages. We will also have spatially explicit maps that show expected development patterns in the future under current growth trends and under scenarios with alternative policy rules. Finally, we will have estimates of monetary damages that can be avoided when alternative land use management policies are directed at reducing flood risks. 
Table 4.1. Econometrics model data sources.

[GIS, geographic information system]

\begin{tabular}{|c|c|c|}
\hline Layer & Source & Website \\
\hline \multicolumn{3}{|r|}{ Primary sources } \\
\hline Land cover data & $\begin{array}{l}\text { National Land Cover } \\
\text { Database }\end{array}$ & http://www.mrlc.gov/finddata.php \\
\hline Soil data & $\begin{array}{l}\text { National Resources } \\
\text { Conservation Service }\end{array}$ & http://www.nrcs.usda.gov/wps/portal/nrcs \\
\hline Geographic names & U.S. Geological Survey & https://gdg.sc.egov.usda.gov/ \\
\hline $\begin{array}{l}2015 \text { primary and secondary } \\
\text { roads }\end{array}$ & U.S. Geological Survey & https://gdg.sc.egov.usda.gov/ \\
\hline National Elevation dataset & U.S. Geological Survey & https://gdg.sc.egov.usda.gov/ \\
\hline $\begin{array}{l}\text { South Carolina public access } \\
\text { to beaches }\end{array}$ & $\begin{array}{l}\text { South Carolina Department } \\
\text { of Health and } \\
\text { Environmental Control }\end{array}$ & https://scdhec.gov/ \\
\hline Housing price index & Federal Reserve Bank & https://fred.stlouisfed.org/series/USSTHPI \\
\hline Tax assessor data Charleston & Tax assessor office & https://www.charlestoncounty.org/ \\
\hline Tax assessor data Berkeley & Tax assessor office & https://berkeleycountysc.gov/ \\
\hline $\begin{array}{l}\text { Tax assessor data } \\
\text { Georgetown }\end{array}$ & Tax assessor office & http://www.georgetowncountysc.org/ \\
\hline Charleston County GIS office & GIS office & https://www.charlestoncounty.org/ \\
\hline Berkeley County GIS office & GIS office & https://gis.berkeleycountysc.gov/ \\
\hline $\begin{array}{l}\text { Georgetown County GIS } \\
\text { office }\end{array}$ & GIS office & http://www.georgetowncountysc.org/ \\
\hline
\end{tabular}

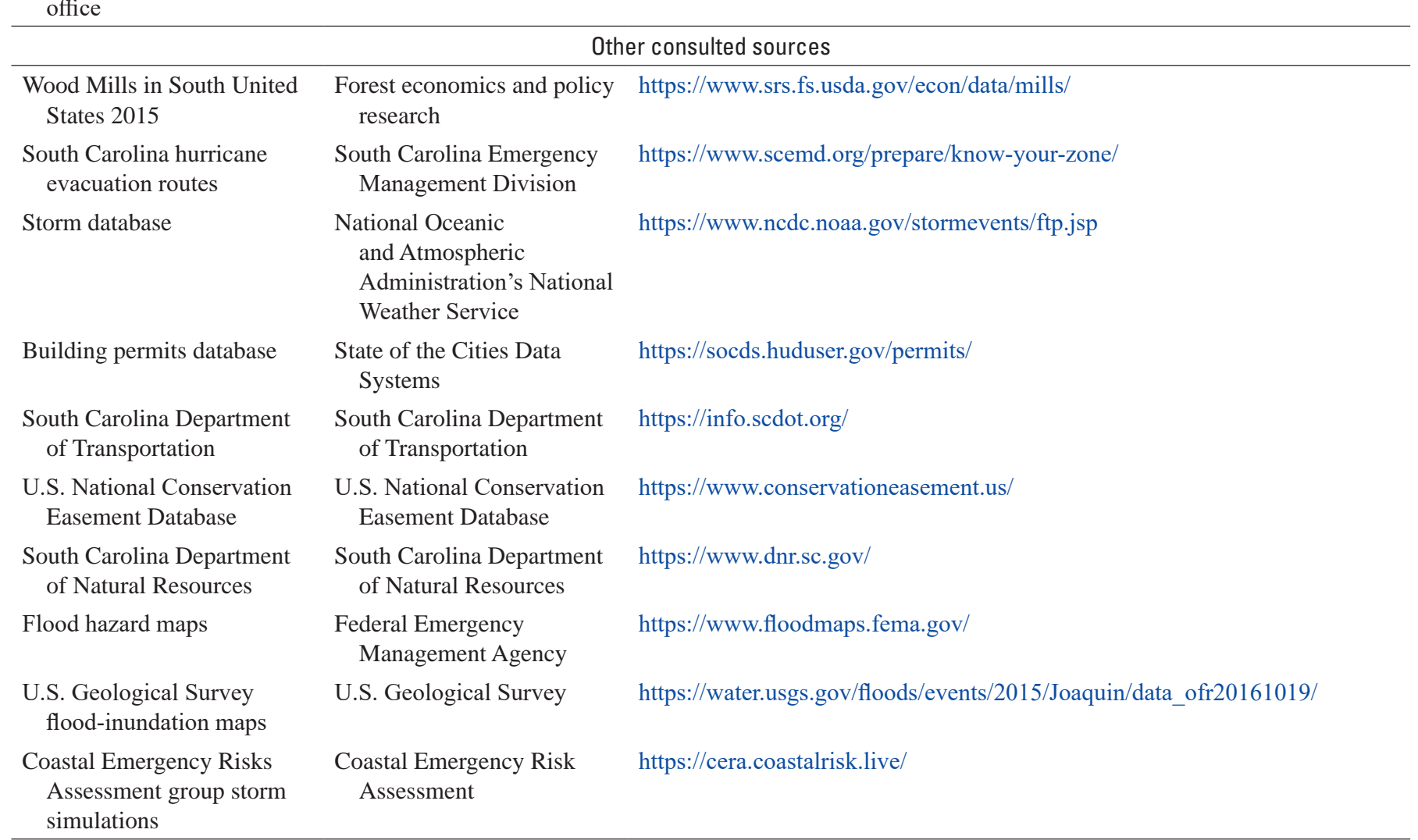




\section{References Cited}

Duke, J.M., and Wu, J., eds., 2014, The Oxford handbook of land economics. Oxford University Press, 746 p. [Also available at https://doi.org/10.1093/oxfordhb/978019976374 0.001.0001.]

Glaeser, E.L., and Kahn, M.E., 2004, Sprawl and urban growth, chap. 56 of Henderson, J.V., and Thisse, J., Handbook of regional and urban economics: Elsevier, v. 4, p. 2481-2527.

Irwin, E.G., 2010, New directions for urban economic models of land use change-Incorporating spatial dynamics and heterogeneity: Journal of Regional Science, v. 50, no. 1 , p. 65-91. [Also available at https://doi.org/10.1111/j.14679787.2009.00655.x.]

Nechyba, T.J., and Walsh, R.P., 2004, Urban sprawl: The Journal of Economic Perspectives, v. 18, no. 4, p. 177-200. [Also available at https://doi.org/10.1257/ 0895330042632681.]

National Oceanic and Atmospheric Administration [NOAA], 2018, What percentage of the American population lives near the coast?: National Oceanic and Atmospheric Administration, National Ocean Service web page, accessed February 9, 2018, at https://oceanservice.noaa.gov/facts/ population.html.
National Oceanic and Atmospheric Administration [NOAA], 2020, U.S. billion-dollar weather and climate disasters: National Oceanic and Atmospheric Administration, National Centers for Environmental Information, accessed July 2020 at https://www.ncdc.noaa.gov/billions/.

Dahl, T.E., and Stedman, S.M., 2013, Status and trends of wetlands in the coastal watersheds of the conterminous United States 2004 to 2009: U.S. Fish and Wildlife Service and National Oceanic and Atmospheric Administration, 46 p. [Also available at https://www.fws.gov/wetlands/ Documents/Status-and-Trends-of-Wetlands-In-the-CoastalWatersheds-of-the-Conterminous-US-2004-to-2009.pdf.]

Rosen, S., 1974, Hedonic prices and implicit marketsProduct differentiation in pure competition: Journal of Political Economy, v. 82, no. 1, p. 34-55. [Also available at https://doi.org/10.1086/260169.]

U.S. Census Bureau, 2017, American community survey: U.S. Department of Commerce, accessed April 2018 at https://www.census.gov/programs-surveys/acs/technicaldocumentation.html.

Villegas, L., 2019, Integrating econometric models of land use change with models of ecosystem services and landscape simulations to guide coastal management and planning for flood control: EfD Discussion Paper Series DP 19-13. [Also available at https://efdinitiative.org/publications/integratingeconometric-models-land-use-change-models-ecosystemservices-and-landscape.] 



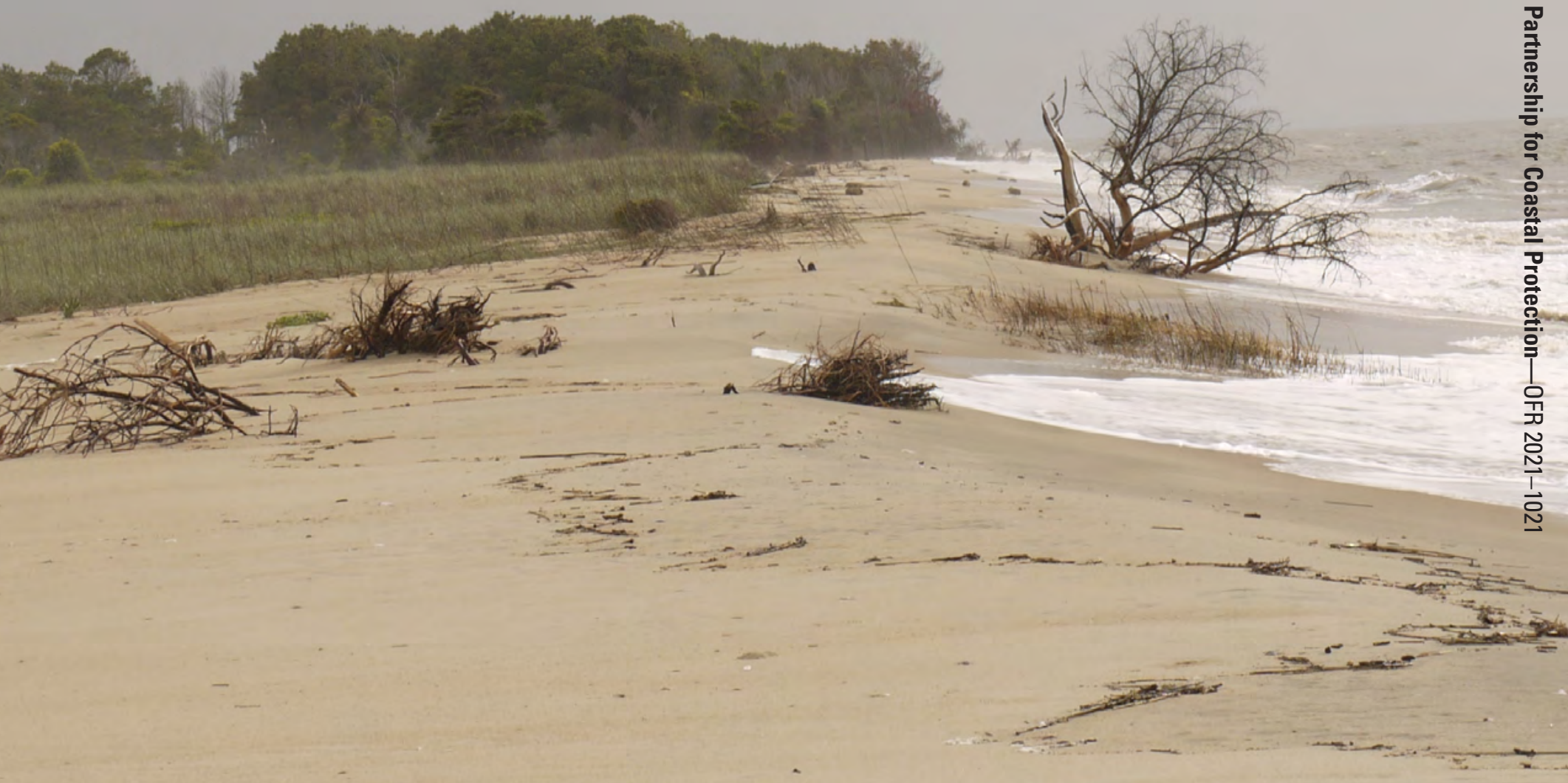

